A STUDY OF HYDRAULIC AND NUCLEAR STABILITY OF BOILING WATER PARALLEL FLOW CHANNEL REACTOR SYSTEMS

J. R. WORDEN, D. S. ROWE AND P. 1. DIONNE

FEBRUARY 1968

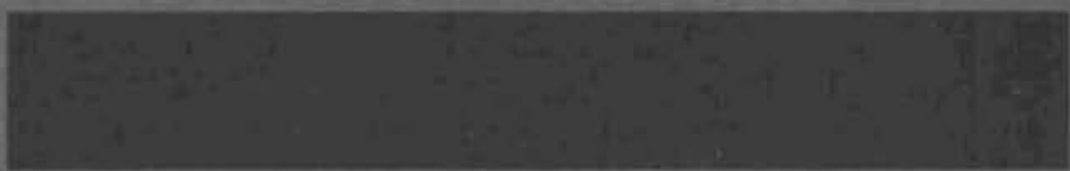

AEC RESEARCH \& DEVELOPMENT REPORT

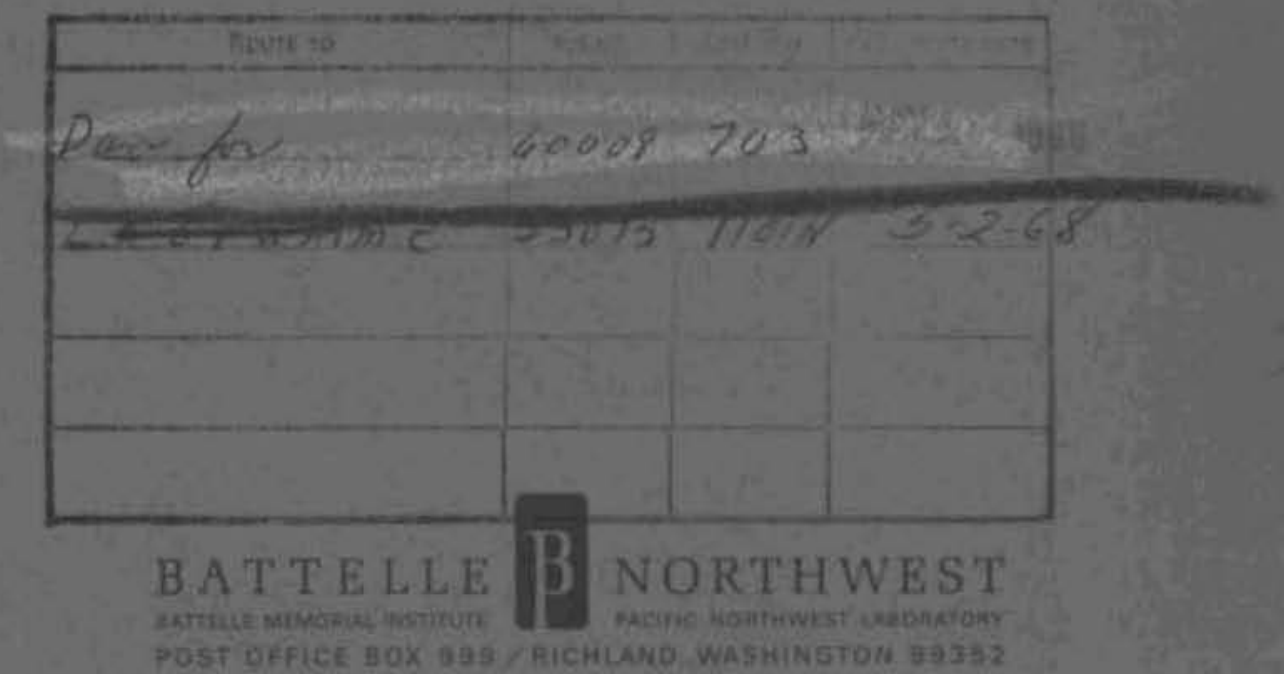




\section{LEGAL NOTICE}

This report was prepared as an account of Government spomored work. Neithes the United Stoter, nor the Commission, nor any person acting on behalf of the Commistion:

A. Makes any wartanty or representation, expressed or implied, with itspect to the accuracy, com. pleteness, or usefulness of the information contained in this report, or that the use of sny information. apparatus, method, or procoss disclased in this report may not infringe privately owned rights; of

8. Astumes any llabilities with tespect to the vie of, of far damages resuffing from the use of any information, opparatos, method; or process disclosed in thix repart.

As used in the above, "persan acting on beholf of the Commisslon" includes any enployee or contractor of the Commission or employee of Nuch cantractor, to the extent that such entiployee or con. troctar of the Commission, of employes of such contractor proparas, disseminates, ar provides acces to. ony information puruvant to bly employmant or contract with the Commission, ar his ermployment with weh controstor.

\section{PACIFIC NORTHIWEST LABORATORY \\ RICHEAND, WASHINGION}

aperated by

BATTELE MEMORIAL INSTITUTE

for the

UNITED STATES ATOMIC ENERGY COMMISSION UNDER CONTRACT AT(45.1H-1830 
BNWL -574

UC- 80 , Reactor

Technology

A STUOY OF HYDRAULIC AND NUCLEAR STABILITY

OF BOILING WATER PARALLEL

FLOW CHANNEL REACTOR SYSTEMS

\author{
By \\ J. R. Worden and D. S. Rowe \\ Engineering Development Department \\ and \\ P. J. Dionne \\ Applied Physics and Ëlectronics Department
}

February 1968

PACIFIC NORTHWEST LABORATORY

RI CHLAND, WASHINGTON

This document is furnished pursuant to the Memorandum of Understanding of June 7, 1960, between U.S. and Canadian Governments, establishing a cooperative program on the development of heavy water moderated power reactors. 


\section{Printed in the United States of America} Available from

Clearinghouse for Federal Scientific and Technical Information Nationa1 Bureau of Standards, U.S. Department of Commerce Springfield, Virginia 22151

Price: Printed Copy $\$ 3.00$, Microfiche $\$ 0.65$ 


\title{
A STUDY OF HYDRAULIC AND NUCLEAR STABILITY \\ OF BOILING WATER PARALLEL \\ FLOW CHANNEL REACTOR SYSTEMS
}

\begin{abstract}
$\underline{\text { ABSTRACT }}$
Stability of a boiling, light water cooled, heavy watermoderated reactor has been studied by simulation on an analog computer. The model consists of a two-region reactor with coupling between the nuclear kinetics and hydrodynamics. Those parts of the reactor system external to the recirculating loop, such as turbines and feedwater pumps, were approximated by appropriate control functions. The simulation provides valid results over a range in power level from about $2 / 3$ nominal up to the threshold of parallel channel instability.

The reactor has an overall positive power coefficient of reactivity and requires automatic control. It is concluded from the study that the system is stable under a large variety of operating conditions, confirming results of design studies by AECL personnel。
\end{abstract}



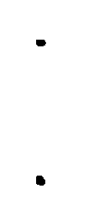


\section{TABLE OF CONTENTS}

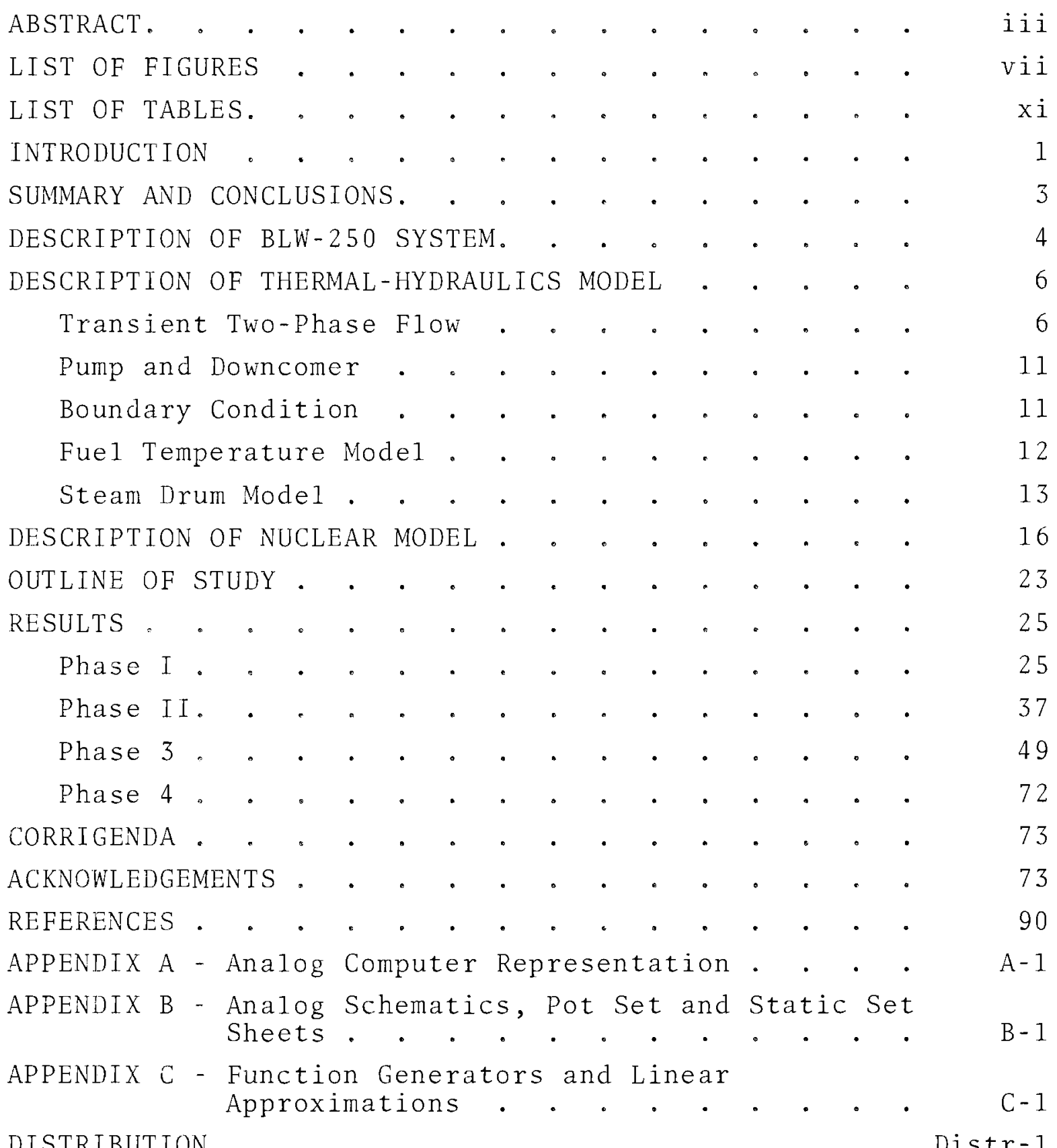




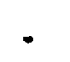

$\bullet$

,

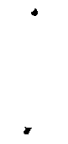

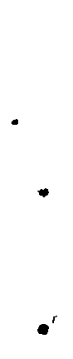

$\bullet$ 


\section{LIST OF FIGURES}

2 Two-Phase Siip-Flow Functions for Erthalpy and Momentum Transport

3 Steam Drum

4 BLW-250 System Stability (In-Out Mode1--UO2 Fuel-Nominal Conditions Power Runup-Instability Threshold)

BLW-250 System Stability (In-Out Mode1--UO2 Fue1--Nominal Conditions $0.5 \mathrm{mk}$ Step in Center Region)

6 BLW-250 System Stability (In-Out Mode1--UO2 Fue 1-Nominal Conditions $0.5 \mathrm{mk}$ Step In Outer Region)

7 BLW-250 System Stability (In-Out Mode1--UO 2 Fue1--Nominal Conditions $1.1 \mathrm{mk}$ Stem in Outer Region

8 BLW-250 System Stability (In-Out Mode1--UO2 Fuel--Nominal Conditions $0.85 \mathrm{mk}$ in Center Region)

9 BLW-250 System Stability (In-Out Mode1--UO 2 Fue1--Nominal Conditions $0.75 \mathrm{mk}$ in Center Region)

10 BLW-250 System Stability (In-Out Mode1--UO2 Fuel--Nominal Conditions 4\% Step Increase in Steam Demand)

11 BLW-250 System Stability (In-Out Mode1--UO 2 Fue 1-Nominal Conditions $10 \%$ Step Increase in Power Set Point)

12 BLW-250 System Stability (In-Out Mode1--UO 2 Fuel--Nominal Conditions $10 \%$ Step Decrease in Feedwater Enthalpy)

13 BLW-250 System Stability (In-Out Mode1--UO 2 Fue1--Coolant Density Reactivity Coefficient Increased $25 \% 0.55 \mathrm{mk}$ Step in Center Region)

14 BLW-250 System Stability (In-Out Mode1--UO2 Fuel--Coolant Density Reactivity Coefficient Reduced $10 \% 1.0 \mathrm{mk}$ Step in Center Region)

15 BLW-250 System Stability (In-Out Mode1--UO 2 Fue1--Flow in Core Reduced $10 \% 0.45 \mathrm{mk}$ Step in Center Region) 
16 BLW-250 System Stability (In-Out Mode1--UO 2 Fue1--5\% Increase in Steam Drum Pressure $0.7 \mathrm{mk}$ Step in Center Region)

17 BLW-250 System Stability (In-Out Mode1--UO2 Fue1--5\% Decrease in Steam Drum Pressure $0.7 \mathrm{mk}$ Step in Center Region)

18 BLW-250 System Stability (In-Out Mode1--UO 2 Fue1--Steam Drum 1/2 Size $0.75 \mathrm{mk}$ Step in Center Region)

19 BLW-250 System Stability (In-Out Mode1--UO2 Fue1--A11 Subcooled Water in Steam Drum $0.75 \mathrm{mk}$ Step in Center Region)

20 BLW-250 System Stability (In-Out Mode1--UO Fue1--A11 Saturated Water in Steam Drum $0.75 \mathrm{mk}$ Step in Center Region)

21 BLW-250 Stability Study (In-Out Mode1--U3Si Fue1--0.5 mk Step in Center Region)

22 BLW-250 System Stability (In-Out Mode1--U3Si Fue1--0.5 mk in Outer Region)

23 BLW-250 System Stability (In-Out Mode1--U3Si Fue1--0.9 mk Step in Center Region)

24 BLW-250 System Stability (In-Out Mode1--U3Si Fue1--4\% Step Increase in Steam Demand)

25 BLW-250 System Stability (In-Out Model--U3Si Fue1--F1ow in Core Reduced $10 \% 0.5 \mathrm{mk}$ Step in Center Region)

26 BLW-250 System Stability (In-Out Mode1--Uranium Metal Fuel 0.5 mk Step in Center Region)

27 BLW-250 System Stability (In-Out Model--Uranium Metal Fuel $0.5 \mathrm{mk}$ Step in Outer Region)

28 BLW-250 System Stability (In-Out Mode1--Uranium Metal Fue1 1.0 mk Step in Center Region)

29 BLW-250 System Stability (In-Out Mode1--Uranium Metal Fue1 4\% Step Increase in Steam Demand)

30 BLW-250 System Stability (In-Out Mode1--Uranium Metal Fuel Flow in Core Reduced $10 \% 0.5 \mathrm{mk}$ Step in Center Region)

31 BLW-250 System Stability (Side-by-Side Mode1-$\mathrm{UO}_{2}$ Fue1 - $0.5 \mathrm{mk}$ Step in One Region) 
A-1 System Block Diagram A-2

A-2 Function for Enthalpy Transport Equation (Code average)

A- 6

A-3 Function for Enthalpy Transport Equation A-7

A-4 Two-Phase Density Function for Core Exit and Outlet Riser

A -9

A-5 Two-Phase Density Function for Core Average Density

A -10

A-6 Function for Rate of Density Change with Enthalpy

A -12

A-7 Local Axial Power Distribution and Integrated Axial Power Distribution

A -14

A-8 Function for Sine-Square-Weighted Density A-15

A-9 Function for Sine-Square-Weighted Density A-16

A-10 Armand Two-Phase Pressure Drop Friction Multiplier

A -19

A-11 Steam Drum A-23

B-1 CANDU-BLW-250 Boiling Stability Study Kinetics B-2

B-2 CANDU-BLW-250 Boiling Stability Study Temperature Circuit-Fue1 Mode1 B-3

B-3 CANDU-BLW-250 Boiling Stability Study Reactivity Coefficients and Enthalpy

B-4 CANDU-BLW-250 Boiling Stability Study Inlet

Risers

B- 5

B-5 CANDU-BLW-250 Boiling Stability Study Subcooled Core

B-6 Two-Phase Core Flow Channel $1 \quad B-7$

B-7 Two-Phase Core Flow Channel $2 \quad$ B-8

B-8 CANDU-BLW-250 Boiling Stability Study outlet Riser-Flow Channel 1 B-9

B-9 CANDU-BLW-250 Boiling Stability Study outlet Riser-Flow Channe1 2

$B-10$

B-10 CANDU-BLW-250 Boiling Stability Study steam Drum

$B-11$

B-11 CANDU-BLW-250 Boiling Stability Study Control1ers 
C-1 Schematic of Digital Computer Function Generator C-2

C-2 Steam Density versus Enthalpy above Saturation (Modified Armand Correlation)

C-3 Function Generator Curve. Core Two-Phase Regions, Outlet Risers (Modified Armand Correlation)

C-4 Core Average Value of $R$ at Approximately 800 psia

C-5 Function Generator Curve. Core Two-Phase Regions, Average Value of $\mathrm{R}$ C - 6

C-6 Riser, Value of $\mathrm{R}$ at Approximately 800 psia C-7

C-7 Function Generator Curve, Outlet Risers (Average Value of R)

C -8

C-8 Two-Phase Friction Multiplier (Armand Correlation)

C-9 Steam Drum Water Level as Function of Diameter $\mathrm{C}-12$

C-10 F1ashing Functions $\mathrm{C}-15$

C-11 Flashing Functions $C-16$ 


\section{LIST OF TABLES}

I Coupling Coefficients for In-Out Model 20

I Coupling Coefficients for Side-to-Side Model 20

II Strip Chart Symbol Nomenclature 28

A-I Parameters Used for Computing Nominal Hydraulic Constants

A-I I Nominal Hydraulics Constants A-26

A-III Fuel Parameters $\quad$ A-27

A-IV Computer Constants for Fuel Simulation A-28

A-V Original 6-Group and Reduced 3-Group Delay Parameters 


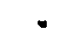

$\bullet$

.

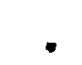

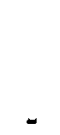

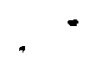

. 


\section{A STUDY OF HYDRAULIC AND NUCLEAR STABILITY \\ OF BOILING WATER PARALLEL \\ FLOW CHANNEL REACTOR SYSTEMS \\ J. R. Worden, D, S, Rowe, and P. J. Dionne}

\section{INTRODUCTION}

Nuclear kinetics, flow system thermal and hydraulic characteristics, and their interactions in a boiling water-cooled reactor can produce instabilities in the form of flow oscillations leading to "burnout" or "dryout" of the fuel clad surface, or reactor power oscillations with attendant control difficulties of unacceptable magnitude. The stability of boiling water-cooled and moderated reactors has been extensively investigated and the systems currently in use have been found to be stable.

Heavy water-moderated reactors cooled by boiling (light) water differ significantly in nuclear and hydraulic characteristics from boiling water reactors. Most heavy watermoderated designs of interest would have a positive reactivity coefficient with voiding of the coolant channels, rather than the negative coefficient typical of boiling water reactors. This fact, coupled with the larger size of the heavy watermoderated reactor core, presents the possibility that the power distribution in the reactor could be unstable.

When this project was initiated in July, 1965, analog computer studies of a boiling, light water-cooled, heavy water-

moderated reactor $(B L W-250)^{(1)}$ had been made by AECL personnel (2) to study nuclear stability of the reactor. They used a linearized single-flow channel analytical model embodying the basic assumptions of a point reactor, no coolant inertia, and no coolant transport times. The results of their study yielded useful information concerning stability of the reactor. However, it was considered desirable to obtain additional information regarding parallel channel stability as influenced by the feedback between nuclear and hydrodynamic phenomena. 
This report presents a description and results of a study performed at the Pacific Northwest Laboratory under the AEC-AECL cooperative program for development of heavy water reactors. Use of an analytical model in the study improved upon the limiting assumptions of the early AECL study. It included a two-region reactor, two paralel flow channels, coolant transport and inertia effects, and regional coupling between neutron kinetics and hydrodynamics. The analog computer used in this study was of much larger capacity than that used in the AECL study。

The purpose of this study was to investigate the bounds of reactor stability during normal operation. of particular interest was paralle1 channel stability when the neutron kinetics and hydrodynamics were coupled. No accident analysis was included in the scope of the study.

The present model represents a first step in development of a detailed analog simulation of the kinetic behavior, including spatial effects, of an entire reactor system. The extent of the present model was dictated by the available analog equipment. Since the model was developed, a digital computer (PDP-7) has been added to the analog facility at Battelle-Northwest. Such a hybrid facility, along with straight-forward extensions of the methods used for this study, would have enhanced the usefulness of the program considerably. For example, all nonlinear functions could be generated by use of the digital machine instead of function generators and their limited range of validity. The model could then be used to study startup control requirements. Also, the number of regions in the core could be increased, and a discrete, detailed representation of a reactor flow channel could be added. The present model is regarded, in any event, as an excellent basis for future development of an analog computer simulation capable of reliably determining the operating characteristics of a given reactor plant, including the increasingly important spatial kinetic problems. 
The body of this report describes the reactor system, the models and attendant equations used, and results of the study. Complete details of the analog simulation are included in the appendices.

\section{SUMMARY AND CONCLUSIONS}

Stability of a boiling, light water-cooled, heavy watermoderated reactor has been studied with the primary purpose of investigating system stability as influenced by interaction of nuclear kinetics and hydrodynamics.

An analog simulation was made of a BLW-250 reference design, including the major components of the main recircu lating coolant loop. Those parts of the reactor system external to the recirculating loop, such as turbines and feedwater pumps, were approximated by appropriate control functions. The major segments in the simulation include a downcomer, a steam arum, and two parallel flow paths through the reactor.

The simulation provided valid results over a power level ranging from about $2 / 3$ nominal (assumed $760 \mathrm{MWt}$ ) up to the threshold of parallel channel instability. Parallel channel instability was observed at $1480 \mathrm{NWt}$, or a factor of about 2 above the nominal operating power level.

It is concluded from the study that the BLW-250 is stable against induced oscillations despite a large positive reactivity feedback associated with decreases in coolant density. No cases of parallel channel instability were detected over a large variety of operating conditions during transient studies. Loss of control was observed during certain transients involving large changes in coolant density exceeding the reactivity rate capabilities of the regulating system assumed for the study. However, such transients in the real system would be terminated by protective devices lacking in the simulation. 
The BLW-250 was additionally concluded to be stable with either uranium silicide $\left(\mathrm{U}_{3} \mathrm{Si}\right)$ or uranium metal fuel. The destabilizing effect of the shorter fuel time constant associated with the silicide and metal fuels was compensated for by the smaller coolant reactivity coefficients of typical $\mathrm{U}_{3} \mathrm{Si}$ or metal fueled cores.

The present simulation has proven useful for stability studies of parallel channel systems. The model is concluded capable of exhibiting parallel channel instability and, equally significant from the standpoint of reactor control, the tworegion core model demonstrates, at least in some measure, importance of spatial effects on reactor control and stability.

\section{DESCRIPTION OF BLW-250 SYSTEM}

A general description of the BLW-250 has been published (1) and details will not be repeated here. Briefly, this model is a $\mathrm{D}_{2} \mathrm{O}$ moderated, boiling $\mathrm{H}_{2} \mathrm{O}$ cooled, pressure tube reactor. The fuel consists of 18 -rod clusters of natural $\mathrm{UO}_{2}$ arranged in a square lattice of 11.0 in. pitch. There are 308 coolant channels surrounded by a 31.1 in. radial reflector $\left(D_{2} O\right)$. No axial reflector is provided. It was assumed for the present study that the reactor would operate nominally at 760 MWt, a power level raised slightly by later designs.

The equivalent reactor system for this study, shown in Figure 1, includes only the major components of the main recirculating coolant loop. Those parts of the reactor system external to the recirculating loop, such as turbines and feedwater pumps, were approximated by appropriate control functions. The system segmentation was based on the analog computer capacity at PNL. The major segments include a downcomer, a steam drum, and two parallel flow paths through the reactor. Each reactor flow path consists of three segments-- inlet piping-and core non-boiling region, core boiling region, and outlet piping. 


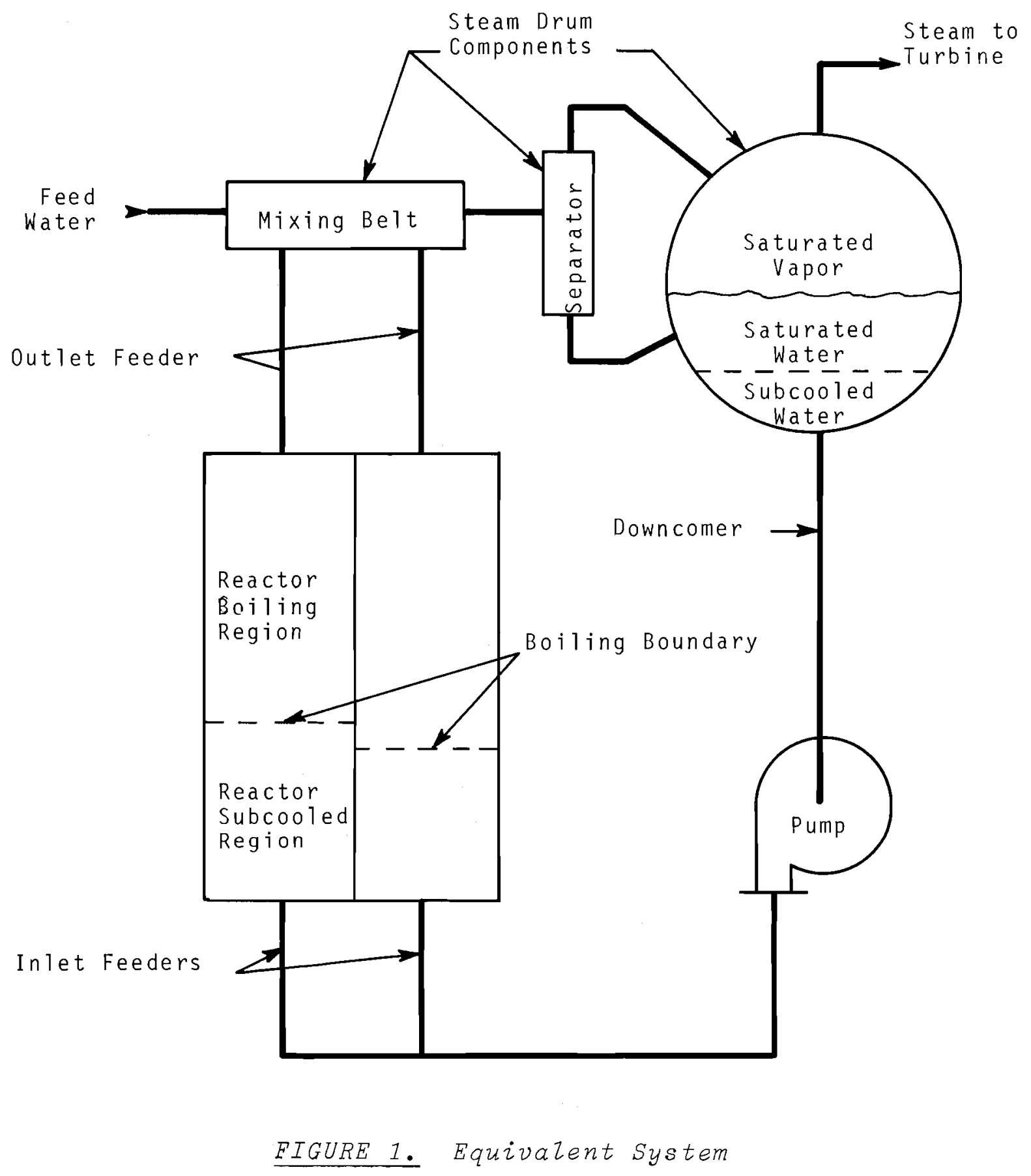




\section{DESCRIPTION OF THERMAL-HYDRAULICS MODEL}

\section{TRANSIENT TWO-PHASE FLOW}

The most general flow channel in the system is one with heat addition and two-phase flow. The equations of continuity, momentum, and energy were derived assuming one-dimensional, two-phase separated slip flow. The derivations are quite similar to those of others $(3,4)$ and result in the following equations:

$$
\begin{gathered}
\frac{\partial G}{\partial x}+\frac{\partial f}{\partial t}=0 \\
\frac{\partial G}{\partial t}+\frac{\partial}{\partial x}\left[\Phi_{2} G^{2} / \rho\right]=-g_{c}\left[\frac{\partial P}{\partial x}+K \psi G^{2}+\rho \cos \theta\right] \\
\frac{\partial}{\partial t}\left[\rho \Phi_{1}\right]+\frac{\partial(G h)}{\partial x}=\frac{q^{\prime}}{A}
\end{gathered}
$$

where the terms are defined as:
A Cross-sectional area
D Hydraulic diameter
$f$ Friction factor based on al1-1iquid flow
$\mathrm{G}$ Mass velocity, $\left[\alpha_{\gamma \rho_{g}}+(1-\alpha) \rho_{f}\right] u_{f}$
$g_{C}$ Gravitational constant
h Enthalpy, $X h_{g}+(1-X) h_{f}$
$J$ Conversion factor
K Two-phase friction multiplier
$\mathrm{P}$ Pressure
$q^{\prime}$ Heat addition per unit length
$t$ Time
X Quality, $\dot{\mathrm{m}}_{\mathrm{g}} /\left(\dot{\mathrm{m}}_{\mathrm{f}}+\dot{\mathrm{m}}_{\mathrm{g}}\right)$
$\dot{m}_{g}$ Mass flow rate of vapor
$\dot{\mathrm{m}}_{\mathrm{f}}$ Mass flow rate of. Iiquid
$\mathrm{x}$ Space variable 


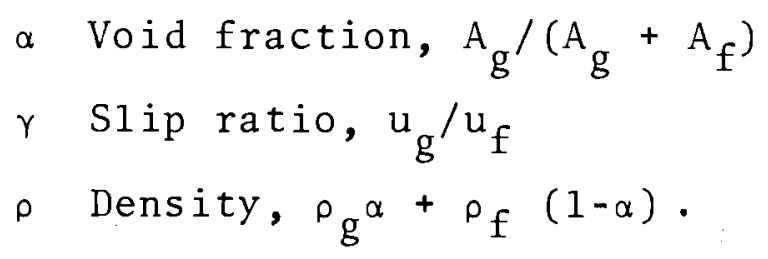

The subscripts $f$ and $g$ refer to saturated liquid and vapor, respectively.

The primary difference between Equations (2) and (3) and those derived by Meyer ${ }^{(4)}$ is in the use of the functions $\Phi_{1}$ and $\Phi_{2}$. These are functions which correct the enthalpy and momentum transport during slip flow. The terms containing these functions are analogous to Meyer's terms containing $\mathrm{H}^{-}$(flow weighted enthalpy) and $v^{\prime}$ (effective specific volume for momentum transport). Derivation of Equations (2) and (3) gives the functions $\Phi_{1}$ and $\Phi_{2}$ as

$$
\begin{aligned}
& \Phi_{1}=\frac{\rho_{g} \alpha h_{g}+\rho_{f}(1-\alpha) h_{f}}{h p} \\
& \Phi_{2}=\frac{\rho u_{f}^{2}}{G^{2}}\left[\rho_{g} \alpha \gamma^{2}+\rho_{f}(1-\alpha)\right]
\end{aligned}
$$

Both of these functions can be evaluated as functions of enthalpy and pressure using a void fraction correlation. The Armand correlations, as modified by Massena ${ }^{(5)}$, are written:

$$
\alpha=\frac{(0.833+0.167 X) X v_{g}}{X v_{g}+(1-X) v_{f}}
$$

For the range of pressure considered in this study, the functions $\Phi_{1}$ and $\Phi_{2}$ are primarily functions of the enthalpy above saturation, and are on $1 y$ a weak function of pressure for the range of pressures expected (Figure 2). This is also true for the density $(\rho)$. These functions may then be written as : 


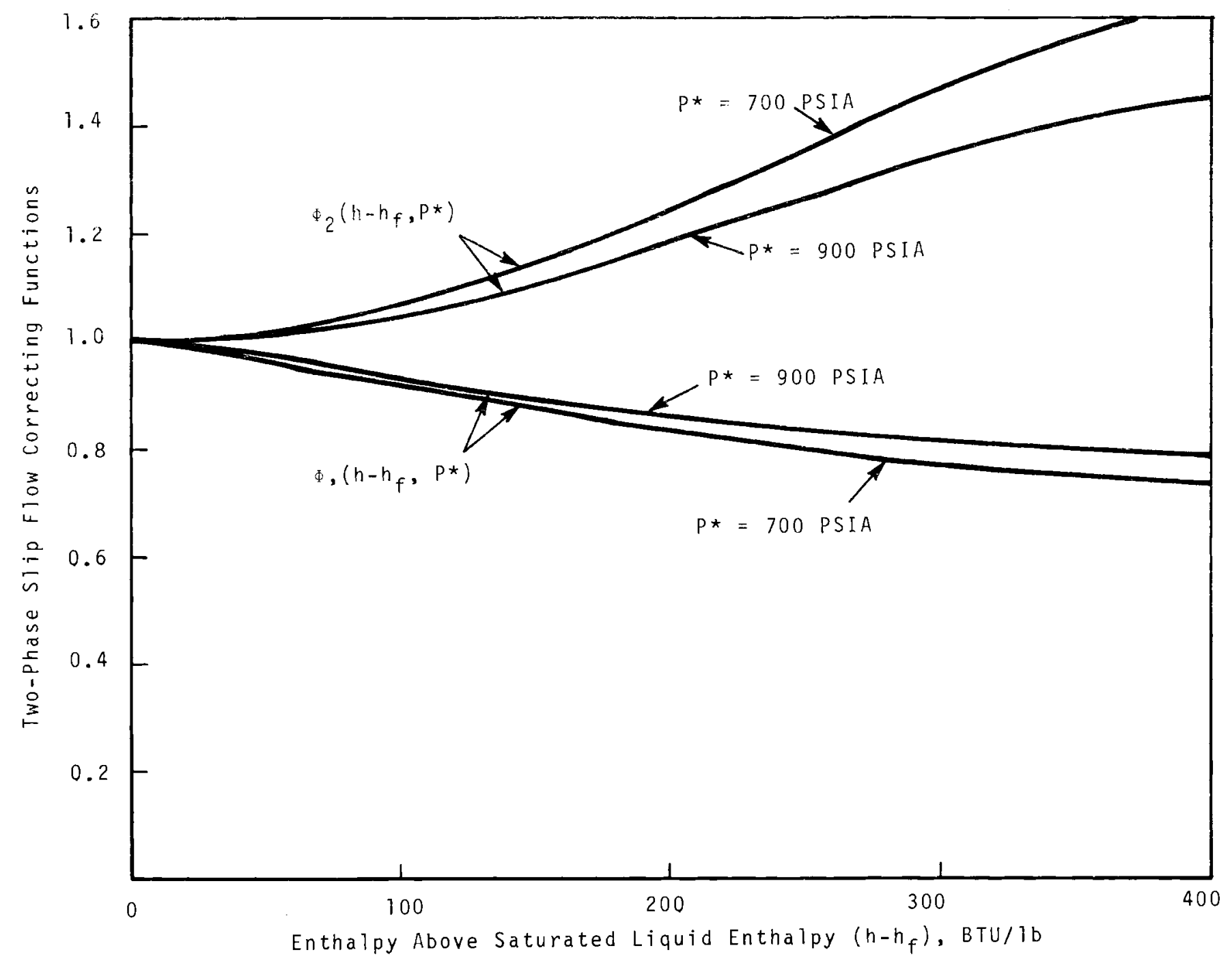

FIGURE 2. Two-Phase Slip-Flow Functions for Enthalpy and Momentum Transport 


$$
\begin{aligned}
\Phi_{1} & =\Phi_{1}\left(h-h_{f}, P^{*}\right) \\
\Phi_{2} & =\Phi_{2}\left(h-h_{f}, P^{*}\right) \\
\rho & =\rho\left(h-h_{f}, P^{*}\right)
\end{aligned}
$$

where $P^{*}$ is a reference pressure.

By using Equation (1), Equation (3) can be written as:

$$
\left.\frac{\partial(\rho h \Phi}{\partial t} 1\right)-h \frac{\partial \rho}{\partial t}+G \frac{\partial h}{\partial x}=\frac{q^{\prime}}{A}
$$

or expanding the first term gives

$$
\rho h \frac{\partial \Phi}{\partial t}+\rho \Phi_{1} \frac{\partial h}{\partial t}+h_{1} \frac{\partial \rho}{\partial t}-h \frac{\partial \rho}{\partial t}+G \frac{\partial h}{\partial x}=\frac{q^{\prime}}{A}
$$

From Equation (7) and (9) the partial derivatives in time can be reduced to time derivatives of enthalpy only, or

$$
\left[\rho h \frac{\partial \Phi 1}{\partial\left(h-h_{f}\right)}+\rho \Phi_{1}+h\left(\Phi_{1}-1\right) \frac{\partial \rho}{\partial\left(h-h_{f}\right)}\right] \frac{\partial h}{\partial t}+G \frac{\partial h}{\partial x}=\frac{q^{\prime}}{A}
$$

It should be noted that the term in brackets on the left side of Equation (11) is a function of enthalpy and pressure as

$$
f\left(h-h_{f}, P^{*}\right)=\rho h \frac{\partial \Phi 1}{\partial\left(h-h_{f}\right)}+\rho \Phi_{1}+h\left(\Phi_{1}-1\right) \frac{\partial \rho}{\partial\left(h-h_{f}\right)}
$$

where

$$
f\left(h-h_{f}, P^{*}\right) \frac{\partial h}{\partial t}+G \frac{\partial h}{\partial x}=\frac{q^{\prime}}{A}
$$

The Equations (1), (2) and (3) represent the basic set of hydrodynamic equations used for this study. These equations 
are solved with a finite difference approximation to obtain a system of first order equations. For a segment of channel starting at point 1 and ending at point 2 , these equations are:

Continuity

$$
\frac{\mathrm{d}_{\mathrm{\rho}}^{-}}{\mathrm{d} \mathrm{t}}=-\left(\frac{\mathrm{G}_{2}-\mathrm{G}_{1}}{\Delta \mathrm{x}}\right)
$$

Momentum

$$
\begin{gathered}
\frac{d \bar{G}}{d t}=-g_{C}\left[\frac{P_{2-} P_{1}}{\Delta x}+K \bar{\psi} \bar{G}^{2}+\bar{\rho} \cos \theta\right] \\
-\frac{\left(\Phi_{2} G^{2} / \rho\right)_{2}-\left(\Phi_{2} G^{2} / \rho\right) 1}{\Delta x}
\end{gathered}
$$

$\underline{\text { Energy }}$

$$
\frac{d \bar{h}}{d \bar{t}}=\frac{\frac{q^{\prime}}{\bar{A}}-\bar{G}\left(\frac{h_{2}-h_{1}}{\Delta x}\right)}{\bar{f}\left(h-h_{f}, p^{*}\right)}
$$

The bars (-) in the foregoing equations indicate the average value between points 1 and 2 . Evaluations of the density, $\bar{p}$, and function, $\bar{f}\left(h-h_{f}, p^{*}\right)$ are averages over the channel section of interest, assuming steady state distributions of enthalpy. These averages are defined as

$$
\bar{\rho}=\frac{1}{\mathrm{~L}_{2}-\mathrm{L}_{1}} \int_{\mathrm{L}_{1}}^{\mathrm{L}_{2}} \rho(\mathrm{x}) \mathrm{dx}
$$


and

$$
\frac{1}{\bar{f}\left(h-h_{f}, P^{*}\right)}=\frac{1}{L_{2}-L_{1}} \int_{L_{1}}^{L} 2 \frac{d x}{f\left(h-h_{f}, P^{*}\right)}
$$

Details of evaluating these averages for the particular sections of flow channel are given in Appendix A.

PUMP AND DOWNCOMER

Modeling of the downcomers and pumps is required to complete the loop between the steam drum and reactor inlet. For the downcomers, hydrodynamic equations for single-phase flow are used with a first order time delay to simulate enthalpy transport. Pump modeling is accomplished by an equivalent single pump, with the characteristics given by

$$
\Delta \mathrm{P}_{\mathrm{p}}=\Delta \mathrm{P}_{\mathrm{o}}-\mathrm{K} \dot{\mathrm{M}}^{2}
$$

where

$$
\begin{aligned}
\Delta \mathrm{P}_{\mathrm{p}} & =\text { pump pressure rise } \\
\Delta \mathrm{P}_{\mathrm{O}} & =\text { pump pressure rise at zero flow } \\
\mathrm{K} & =\text { internal pump loss constant } \\
\dot{\mathrm{M}} & =\text { flow rate. }
\end{aligned}
$$

BOUNDARY CONDITION

In solving the system of hydrodynamic equation, the boundary condition of the sum of all pressure drops around a closed loop is made equal to zero.

This boundary condition gives us the sum of all flow rates integrated in time. Specific values of the flow rate leaving a section of flow channel because of fluid expansion is given 
by a combination of Equations (9) and (14), and is

$$
\mathrm{G}_{2}=\mathrm{G}_{1}+\Delta \mathrm{x} \frac{\partial \bar{\rho}}{\partial\left(\mathrm{h}-\mathrm{h}_{\mathrm{f}}\right)} \frac{\mathrm{d} \overline{\mathrm{h}}}{\mathrm{dt}}
$$

Detailed methods of this computation as applied to the system can be found in Appendix A.

\section{FUEL TEMPERATURE MODEL}

A multinode fuel temperature model was used, since the oxide fuel element surface heat flux is weakly dependent upon the coolant temperature. If a one-node approximation is made, the heat flux would be too strongly influenced by the coolant temperature. The following sketch is a representation of the present fuel temperature model.

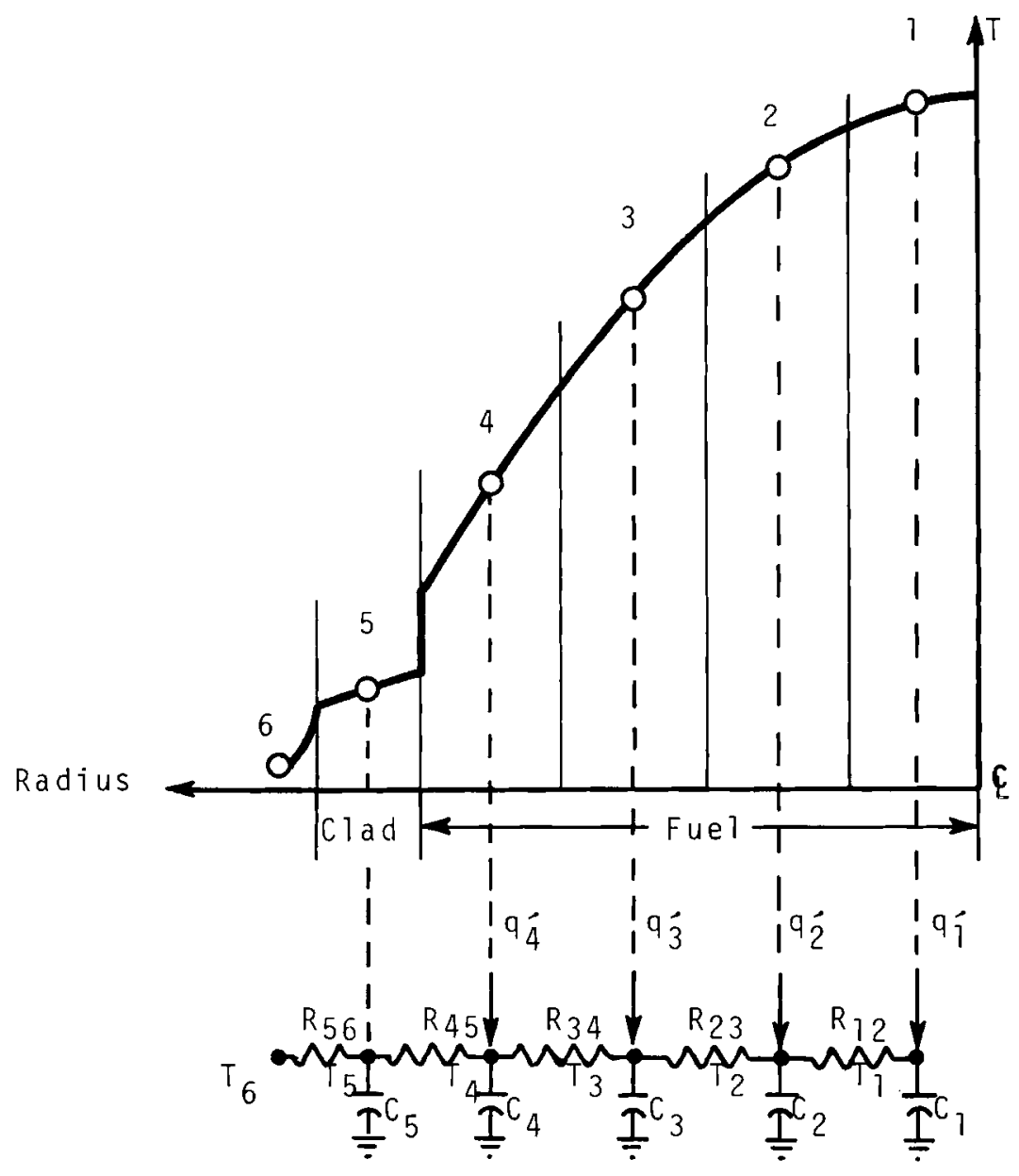


Resistances and capacitances were computed for the equivalent electrical circuit and were found to be suitable for a "breadboard" layout. Since the averaging of all temperatures would have required excessive computer amplifiers, $\mathrm{T}_{3}$ was used for the average fuel temperature. The fuel temperature model was initially set up for an oxide fuel. However, by appropriate changes in the thermal resistances and capacitances, the effects of silicide and metallic fuel were investigated. Specific values of fuel properties and circuit parameters are given in Appendix A, Tables A-III and A-IV.

STEAM DRUM MODEL

The steam drum (Figure 3) used for this study is assumed to consist of three regions identified as (1) a mixing region for the feedwater and reactor two-phase flow, (2) a steam separator, and (3) a central drum region. Equations describing the first two regions are based on steady state energy and mass balances. The third region uses Brown's (6) method of transient thermodynamics to describe the pressure transient.
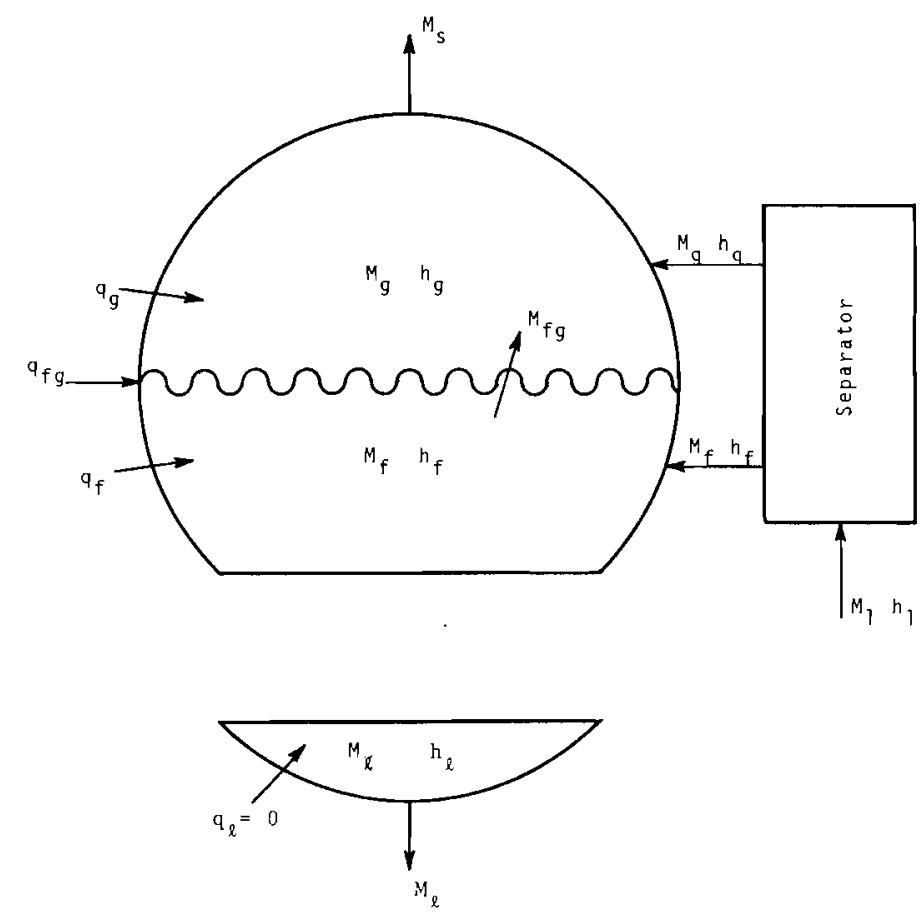

FIGURE 3. Steam Drum 
Pressure changes within the drum are very complex and depend upon how much of the vapor condenses during a pressure increase and upon how much water flashes during a pressure decrease. To include these effects rigorously is extremely difficult; therefore, a simple approximation is used. During a pressure increase, it is assumed that some constant fraction (Z) of the total drum water is heated to saturation by condensing vapor. During a pressure decrease, this same fraction is allowed to flash. However, if the pressure decreases sufficiently to reach the saturation pressure of subcooled water at the bottom of the drum, all the drum water is available to flash. This method of calculation provides a reasonable method for determining whether the condensation of vapor in the drum is a parameter significantly affecting the stability of the system.

The general equation for the rate of pressure change (6) in the steam drum is given by

$$
\frac{d P}{d t}=\left[\left(\dot{M}_{g}-\dot{M}_{s}\right) v_{g}+\left(\dot{M}_{f}-\dot{M}_{\ell}\right) v_{f}\right] f(Z, P)
$$

where

$$
\begin{aligned}
& \dot{\mathrm{M}}_{\mathrm{g}}=\text { Saturated vapor flow rate into drum } \\
& \dot{\mathrm{M}}_{\mathrm{S}}=\text { Steam flow rate to turbine } \\
& \dot{\mathrm{M}}_{\mathrm{f}}=\text { Saturated liquid flow rate into drum } \\
& \dot{\mathrm{M}}_{\ell}=\text { Liquid flow rate from drum to downcomer. }
\end{aligned}
$$

The function $f(z, P)$ has two cases to account for the behavior discussed above

Case 1

$$
\left(\frac{d P}{d t}<0 \text { and only if } h_{\ell}=h_{f}\right)
$$




$$
f(1, P)=\left[\frac{v_{g}-v_{f}}{h_{g}{ }^{-h_{f}}}\left(\dot{M}_{g} \frac{d h_{g}}{d P}-\dot{M}_{f} \frac{d h_{f}}{d P}-\frac{V}{J}\right)-\left(\dot{M}_{g} \frac{d v_{g}}{d P}+M_{f} \frac{d v_{f}}{d P}\right)\right]^{-1}
$$

\section{Case 2}

$$
\begin{aligned}
\left(\frac{d P}{d t}\right. & \left.>0 ; \frac{d P}{d t}<0 \text { if } h_{f}>h_{\ell}\right) \\
f(Z, P) & =\left[\frac{v_{g}-v_{f}}{h_{g}-h_{f}}\left(\dot{M}_{g} \frac{d h_{g}}{d P}+z \dot{M}_{f} \frac{d h_{f}}{d P}-\frac{\dot{M}_{g} v_{g}+Z \dot{M}_{f} v_{f}}{J}\right)\right. \\
& \left.-\left(\dot{M}_{g} \frac{d v_{g}}{d P}+z \dot{M}_{f} \frac{d v_{f}}{d P}\right)\right]^{-1}
\end{aligned}
$$

The liquid enthalpy $h_{\ell}$ changes these conditions and is determined by

$$
\frac{\mathrm{dh}}{\mathrm{dt}}=\frac{\dot{\mathrm{M}}_{\ell}}{(1-Z) \mathrm{M}_{\mathrm{f}}}\left(\mathrm{h}_{\mathrm{f}}-\mathrm{h}_{\ell}\right)
$$

for $h_{f}>h_{\ell}$ only; otherwise $h_{\ell}=h_{f}$.

The function $f(Z, P)$ assumes the masses of vapor and liquid to remain constant. Parameter $Z$, the fraction of saturated drum liquid, although retained as a parameter, was assumed constant for a given calculation. The function $f(z, P)$ was evaluated at several pressures with $Z$ arbitrary, and with the general form

$$
f(Z, P)=[A(p)+Z B(P)]^{-1}
$$

Since the function does not change rapidly with pressure, the functions for $A$ and $B$ in Equation (23) were assumed linear to give 
$f(Z, P)=[(6.23-0.0041 P)+Z(17.0-0.0168 P)]^{-1}$.

The procedure used to fit this function and the steam drum equation on the analog computer are given in Appendix A.

\section{DESCRIPTION OF NUCLEAR MODEL}

The nuclear kinetics model used in the study is based on coupled reactor theory. (7) The kinetics equations for a tworegion reactor can be written in the form:

$$
\begin{aligned}
\frac{d P_{1}}{d t}= & \frac{\left[k_{11}(1-\beta)-1\right]}{\ell} P_{1}+\frac{k_{12}(1-\beta)}{\ell} P_{2}+k_{11} \sum_{i} \lambda_{i} C_{1 i} \\
& +k_{12} \sum_{i} \lambda_{i} C_{2 i} \\
\frac{d P_{2}}{d t}= & \left.\frac{\left[k_{22}(1-\beta)-1\right.}{\ell}\right]_{P_{2}}+\frac{k_{21}(1-\beta)}{\ell} P_{1}+k_{21} \sum_{i} \lambda_{i} C_{1 i} \\
& +\frac{k_{22}}{i} \sum_{i} C_{2 i} \\
& \frac{d C_{1 i}}{d t}=\frac{\beta_{i}}{\ell} P_{1}-\lambda_{i} C_{1 i} \\
& \frac{d C_{2 i}}{d t}=\frac{\beta_{i}}{\ell} P_{2}-\lambda_{i} C_{2 i}
\end{aligned}
$$

where

$$
\begin{aligned}
& \mathrm{P}_{\mathrm{n}}=\text { total power in } \mathrm{nth} \text { region, } \\
& \beta_{i}=\text { neutron fraction in the ith delay group, }
\end{aligned}
$$




$$
\begin{aligned}
\beta= & \sum \beta_{i}, \\
\lambda_{i}= & \text { decay constant for the ith delay group, } \\
\ell= & \text { prompt neutron lifetime, } \\
\text { and } k_{m n}= & \text { time-dependent coupling coefficients for determining } \\
& \text { probability of a neutron born in the nth region to } \\
& \text { produce a fission event in the mth region. }
\end{aligned}
$$

A rigorous derivation of the kinetics equations would include a time delay for neutrons diffusing from one region to the other. The prompt neutron lifetime would be subscripted, and the power level appearing in the second term on the right side of both Equations (24) and (25) would contain a retarded argument; thus,

$$
P(t) \rightarrow P(t-\tau)
$$

where the parameter, $\tau$, represents the delay time for neutrons diffusing from one region to the other. This time, of the same order of magnitude as the neutron lifetime, or about $10^{-3} \mathrm{sec}$, is much shorter than are those of the present study in which transients of several seconds duration are characteristic. Consequently, neglect of this time delay factor should not introduce significant errors in the results.

The coupling coefficients, $\mathrm{k}_{\mathrm{mn}}$, although time-dependent quantities, are determined from calculations of static power distributions over the core. For the steady state, it can be shown from Equations (24) through (27) that

$$
\frac{P_{1}}{P_{2}}=\frac{k_{12}}{1-k_{11}}=\frac{1-k_{22}}{k_{21}}
$$


Thus, if the relative power split between the two regions is known, and if $k_{11}$ and $k_{22}$ are calculated independently, the cross coupling terms $k_{12}$ and $k_{21}$ can be calculated from Equation (28). This method asures neutron balance in the steady state so that an artificial source term, as commonly used in point kinetics studies, is not necessary.

The generalized form of Equation (28) in event the reactor is other than "just critical", is

$$
\frac{P_{1}}{P_{2}}=\frac{k_{12}}{k-k_{11}}=\frac{k-k_{22}}{k_{21}}
$$

where the parameter, $k$, is the system eigenvalue or effective neutron multiplication factor of the entire core. Equation (29) allows determination of the change in the coupling coefficients associated with a change in local properties of the core from a calculation of static flux shapes.

Calculation of the parameters, $k_{m m}$ requires a determination of the fission source in the mth region due to neutrons born in that region. The ratio of this partial source to the total source in the $\mathrm{mth}$ region in just $\mathrm{k}_{\mathrm{mm}}$.

The calculations required to determine the coupling coefficients were derived from a one-dimensional, diffusion theory code, HFN. (8) The spatial power distribution was calculated assuming two energy groups with cross-sections supplied by AECL personnel. (9) A calculation over the entire core gives the relative power split, $\mathrm{P}_{1} / \mathrm{P}_{2}$, as well as the fission source at each space point across the core. This fission source is then used in subsequent calculations as an external source of unit magnitude in the fast group to determine the partial sources from which the $k_{m n}$ can be calculated. Fission events are treated as removal events 
for these latter cases, and the HFN calculation is stopped after a single iteration. The partial sources are inputed to region 1 and region 2 , in turn, to give the required power distributions from which $k_{11}$ and $k_{22}$, respectively, can be determined as just described. As stated previously, the coupling coefficients, $\mathrm{k}_{12}$ and $\mathrm{k}_{21}$, are determined from Equation (28).*

In order to determine the change in the coupling coefficients associated with a change in system reactivity, the thermal fission cross-section was increased by $1 \%$ in each region in turn. The entire procedure was repeated to determine a new set of coefficients, $k_{m n}$, this time using Equation (29).

This entire procedure thus gives the initial values of the coupling coefficients, $\mathrm{k}_{\mathrm{mn}}$, as well as the changes in the coefficients associated with a change, $\Delta \mathrm{k}_{\mathrm{m}}$, in system eigenvalue due to a perturbation occurring in the mth region.

A set of calculations was made for two geometrical divisions of the core. For the first, called the "in-out model," the core was divided radially into annular regions with a center region radius of $117 \mathrm{~cm}$. The calculated coupling coefficients for this arrangement are shown in Table I.

The system eigenvalue from the calculation using $H F N$

is 0.99925 , indicating the reactor is indeed "just critical." Otherwise, Equation (29) would be used to determine $k_{12}$ and $k_{21}$. 
TABLE I. Coupling Coefficients for In-Out Model

$$
\begin{array}{lll}
\mathrm{k}_{11}=0.841 & \Delta \mathrm{k}_{11} / \Delta \mathrm{k}_{1}=4.76 & \Delta \mathrm{k}_{11} / \Delta \mathrm{k}_{2}=-0.80 \\
\mathrm{k}_{12}=0.047 & \Delta \mathrm{k}_{12} / \Delta \mathrm{k}_{1}=0.41 & \Delta \mathrm{k}_{12} / \Delta \mathrm{k}_{2}=-0.11 \\
\mathrm{k}_{21}=0.074 & \Delta \mathrm{k}_{21} / \Delta \mathrm{k}_{1}=0.34 & \Delta \mathrm{k}_{21} / \Delta \mathrm{k}_{2}=0 \\
\mathrm{k}_{22}=0.978 & \Delta \mathrm{k}_{22} / \Delta \mathrm{k}_{1}=0.07 & \Delta \mathrm{k}_{22} / \Delta \mathrm{k}_{2}=1.28
\end{array}
$$

The second geometrical division, designated as the "sideto-side model" consisted of dividing the reactor into halves, each with equal properties. It was not possible to calculate the partial sources for a semi-circular cylinder using a one-dimensional diffusion code. Consequently, a rectangular parallelepiped model equal in height and volume to the BLW-250 was used. While admittedly not exact, the approximation should be adequate to determine whether significantly different results are obtained from those using the in-out model. The coupling coefficients for this model are given in Table II.

TABLE II. Coupling Coefficients for Side-to-Side Model

$$
\begin{aligned}
& k_{11}=k_{22}=0.925 \Delta k_{11} / \Delta k_{1}=\Delta k_{22} / \Delta k_{2}=2.0 \\
& k_{12}=k_{21}=0.975 \Delta k_{12} / \Delta k_{1}=\Delta k_{21} / \Delta k_{1}=\Delta k_{22} / \Delta k_{1}=0 \\
& \Delta k_{11} / \Delta k_{2}=\Delta k_{12} / \Delta k_{2}=\Delta k_{21} / \Delta k_{2}=0
\end{aligned}
$$

The values of the coupling coefficients at any time, $t$, are given by

$$
k_{m n}(t)=k_{m n}(t=0)+\Delta k_{m n}
$$

and the change in value, $\Delta \mathrm{k}_{\mathrm{mn}}$, is related to changes in system eigenvalue, $\Delta \mathrm{k}_{\mathrm{m}}$, through the relationship

$$
\Delta \mathrm{k}_{m n}=\frac{\Delta \mathrm{k}_{m n}}{\Delta \mathrm{k}_{\mathrm{m}}} \Delta \mathrm{k}_{\mathrm{m}}+\frac{\Delta \mathrm{k}_{\mathrm{mn}}}{\Delta \mathrm{k}_{\mathrm{n}}} \Delta \mathrm{k}_{\mathrm{n}}
$$


where, as stated previously, the quantity, $\Delta \mathrm{k}_{m}$, is the change in eigenvalue of the entire reactor due to a perturbation in the mth region. Finally, the changes in system eigenvalue corresponding to changes in physical properties of the core were determined from*

$$
\Delta \mathrm{k}_{\mathrm{m}}=\alpha \bar{\rho}_{\mathrm{C}}\left(\Delta \bar{\rho}_{\mathrm{C}}\right)_{\mathrm{m}}+\alpha_{\mathrm{T} f}\left(\Delta \overline{\mathrm{T}}_{\mathrm{F}}\right)_{\mathrm{m}}+\alpha_{\mathrm{TC}}\left(\Delta \mathrm{T}_{\mathrm{C}}\right)_{\mathrm{m}}+\left(\Delta \mathrm{k}_{\mathrm{C}}\right)_{\mathrm{m}}
$$

where the symbol, $\Delta$, denotes a change in average value (over the mth region) of the coolant density, $\bar{\rho}_{c}$, fuel temperature, $\overline{\mathrm{T}}_{f}$, and coolant temperature, $\mathrm{T}_{\mathrm{C}}$. The last term, $\left(\Delta \mathrm{k}_{\mathrm{C}}\right)_{\mathrm{m}}$, is the reactivity due to control rods in the $m$ th region, a discussion of which follows. The reactivity coefficients, $\alpha$, associated with each of the physical properties were determined from detailed core calculations and for the present study, design values for the BLW-250 were supplied by AECL personnel.

Because of the large variation in coolant density along a channel, the average density, $\vec{p}_{C}$, in Equation (32) was calculated from flux-squared weighting, thus approximately accounting for the variation in worth of neutrons along a channel in sustaining the chain reaction in the core. Assuming the neutron flux to vary sinusoidally, the average coolant density is calculated from

$$
\bar{\rho}_{C}=\frac{\int_{0}^{J_{j}} \rho(x) \sin ^{2} \frac{\pi x}{L} d x}{\int_{0}^{L} \sin ^{2} \frac{\pi x}{L} d x}
$$

where $L$ is the length of a coolant channel in the core.

* See Corrigenda 
Because of the overall positive power coefficient of reactivity, the $B L W-250$ requires automatic control. It was assumed for the present study that control rods are distributed uniformly over the reactor core and that the reactivity controller operates all of these rods simultaneously as required to control the reactor. The symmetry of the side-to-side model enabled the reactivity associated with rod movement to be split equally between the two regions. For the in-out model, the total reactivity worth of the control rods was split between the central and outer regions in accordance with the relative importance of neutrons absorbed in the two regions. Flux-squared weighting was used to approximate the relative rod worth, with the resulting split in reactivity found to be $79 \%$ in the center region and $21 \%$ in the outer.

In the actual BLW-250 reactor, 7 mechanical absorbers are inserted from the upper end. Six are located at a radius of approximately $110 \mathrm{~cm}$, and the other is on the axis. Because an accurate description of this situation was not possible in the mathematical model, the simplifying assumptions described above were necessary.

The controller equations for the reactivity are

$$
\frac{\mathrm{d}\left(\Delta \mathrm{k}_{\mathrm{c}}\right)}{\mathrm{dt}}=\mathrm{G}_{\mathrm{p}}\left(\mathrm{P}_{\mathrm{s}}-\mathrm{P}\right)
$$

and

$$
\Delta k_{c}=\int_{0}^{t} \frac{d\left(\Delta k_{c}\right)}{d t} d t
$$


where

$P_{S}=$ power level setpoint

$\mathrm{P}=$ calculated power at any time, $t$

and $G_{p}=$ constant.

For the side-to-side model, the calculated power, $\mathrm{P}$, was the total reactor power, $\mathrm{P}_{1}+\mathrm{P}_{2}$. For the in out model, the neutron flux detectors were assumed to be located in the outer region only. Therefore, the calculated power in Equation (34) for this case was the power in the outer region, $\mathrm{P}_{2}$. The power setpoint, $\mathrm{P}_{\mathrm{S}}$, was total reactor power (760 MWt) and power in the outer region (585 MWt) for the side-to-side and in out models, respectively。

In summary, when the in-out model was used, reactivity from the controller depended on variations in power level in the outer region only. This reactivity was then split between the center region (79\%), and the outer region (21\%). When the side-towside model was used, complete symmetry was maintained with equal reactivity going to both regions.

\section{OUTLINE OF STUDY}

The study of nuclear and hydraulic stability of the BLW-250 was conducted in four phases. In the first phase, the model was operated with parameters representing the reactor under normal operating conditions。 It was further assumed that the core contained an equilibrium fuel loading, that exit steam quality was $16 \%$, that the steam drum contained half steam and half water, and that the reactor was controlled to a fixed power level (base load operation). The core was divided into two regions (in-out model) on the basis of hydraulic properties. In the first or central region, the pressure tubes were unorificed at the inlet to the core. This central region has a flat spatial power distribution. In the second or outer region, the pressure tubes were orificed to give equal exit quality for all channels. The 
radius dividing the two regions was $117 \mathrm{~cm}$. Approximate1y 23\% of the total reactor power ( $760 \mathrm{MWt})$ was generated in the central region. Average nuclear and thermal-hydraulic parameters were calculated for each region. Phase I of the study then consisted of studying the dynamic response of the reactor system to various input disturbances. These disturbances, al1 introduced as step functions, include changes in mass flow rate of steam from the steam drum to the turbine, reactivity of the core, power set point of the reactivity controller, and enthalpy of the feedwater into the steam drum.

The second phase of the study consisted of determining the effect of various modifications to $B L W-250$ design or of operating properties on dynamic response to a step reactivity input to the central region. Changes were made to reactivity coefficients, total flow through the core, steam drum pressure, drum size, percent steam in the drum, downcomer transport delay, and gain on the reactivity controller. The changes were made one at a time and the given quantity was returned to its nominal value after the transient was run. The third phase examined the effect of $\mathrm{U}_{3} \mathrm{Si}$ and uranium-metal fuel on reactor stability. Although fuel time constants and the reactivity coefficients were changed, all other parameters were kept the same as for the $\mathrm{UO}_{2}$ study.

A different geometrical core division was used for the fourth phase of the study. The reactor was divided into halves (side-to-side) with equal power levels and mass flow rates for each half. Although the average thermal-hydraulic properties were the same in both regions, the nuclear coupling between regions was considered to be smaller, thus suggesting modes of oscillation differing from those of the earlier mode1. 


\section{RESULTS}

\section{PHASE I}

The primary purpose of this phase was to examine stability of the BLW-250 under normal operating conditions. The simulation was designed for studies over a range in power levels from about $2 / 3$ nominal up to the threshold of parallel channe 1 instability occurring at about twice the nominal power. With the nominal power level at $750 \mathrm{MW}_{t}$, results of the simulation will be valid only between about 500 and $1500 \mathrm{MW}_{t}{ }^{\circ}$ This limitation is imposed by the limited valid range of the sunction generators used in the simulation.

Wherever possible, the simulation was checked to assure that reasonable results were being obtained. An important example of this approach was a calculation to check the transient response of the hydraulics model as compared with calculations made by AECL personnel using a digital computer program, HYDNA. The calculations were performed for a BLW-250 central channel by using friction constants for areas and lengths of the central channel reference design affected by pressure drops. Constants and values for these parameters were assigned as follows:

Average Mass Velocity

Average Heat F1ux

Inlet Enthalpy

Steam Drum Pressure

Average Exit Quality

Pressure Drop:

Inlet Header to Fuel

Fuel to Outlet Riser

Outlet Riser to Steam Drum
$3.41 \times 10^{6} 1 \mathrm{~b} / \mathrm{hr}-\mathrm{ft} \mathrm{t}^{2}$

$0.174 \times 10^{6} \mathrm{Btu} / \mathrm{hr}-\mathrm{ft}^{2}$

$504 \mathrm{Btu} / 1 \mathrm{~b}$

765 psia

$16 \%$

$$
\begin{array}{r}
45.2 \mathrm{psi} \\
103.9 \mathrm{psi} \\
29.4 \mathrm{psi}
\end{array}
$$


Analog calculations were made to determine the response of the channel flow rate to small step increases in channel heat flux (Figure $3 \mathrm{a}$ ). A comparison of the results from the analog and digital computations shows reasonable agreement between the two calculations. Oscillations appeared only when the inlet flow rate approached very close to the unstable point and with a period of $0.3 \mathrm{sec}$. The digital calculations indicated some flow oscillations to have occurred farther from the unstable point and with a period of about $0.6 \mathrm{sec}$.

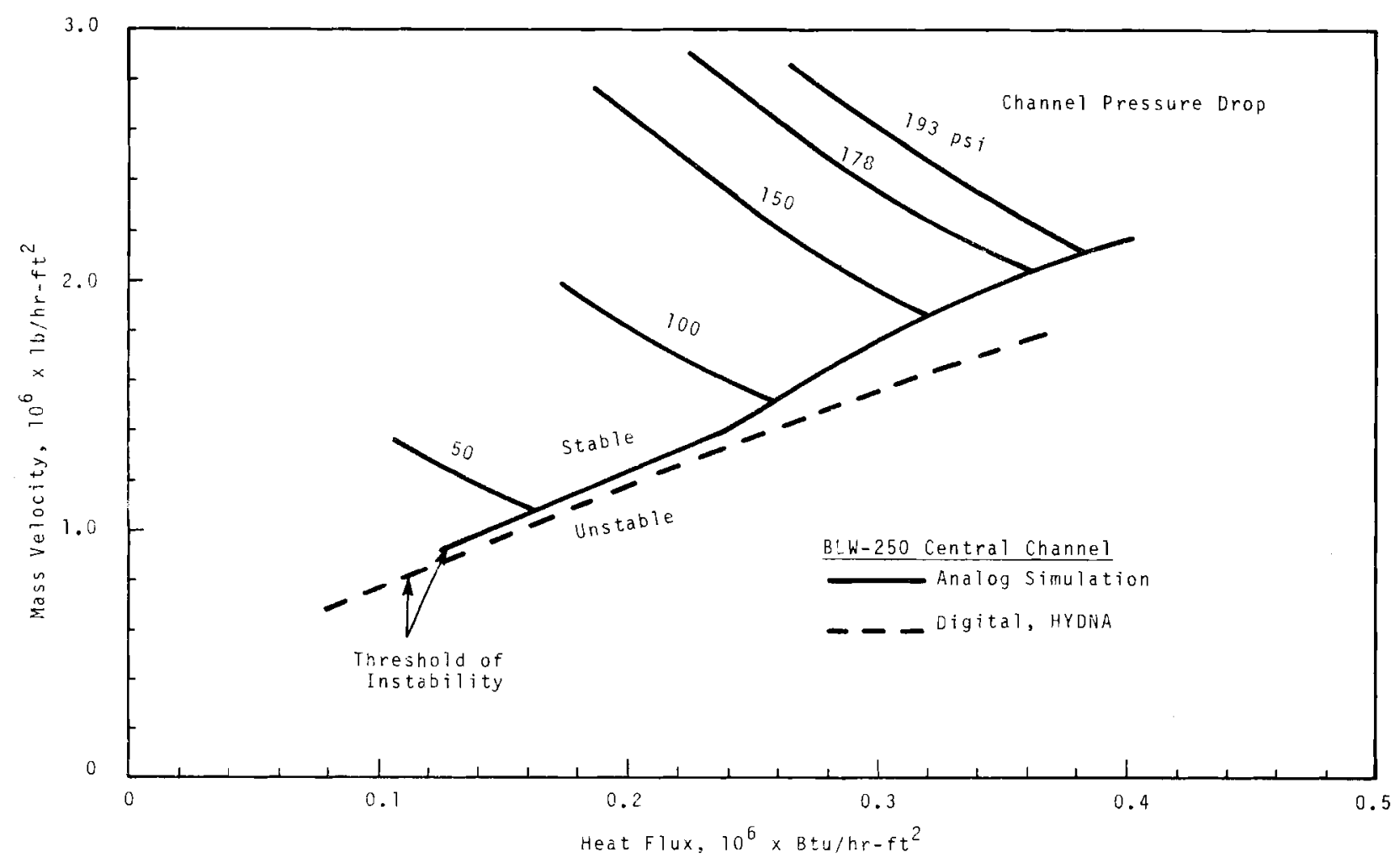

FIGURE 3a. Threshold of Instability Comparison Using Analog Computer Model and Digital Computer Program, HYDNA

The differences found in the period of oscillations can probably be attributed to the size of the channel segments used in the difference equations. The period of oscillation 
is a function of the transit time through the two-phase piping. The effective transit time, with only two nodes of two-phase flow, is faster than with a large number of segments, and thus could result in a shorter period of oscillation.

When the thermal-hydraulic model was coupled to the nuclear model and the entire BLW-250 system was simulated, the instability threshold was observed at $1480 \mathrm{MW}$, or just about twice the nominal power as expected (Figure 4 and Table III). The fact that no oscillations were observed just prior to the onset of parallel channel instability could possibly be due to the coupling of the center and outer regions. These oscillations also could have been obscured by the inherent noise in the simulation. The presence of this background noise level, present in all the runs, was due to the use of non-linear equipment (multipliers and dividers) and will be discussed in more detail later in the report.

Table III defines symbols appearing on the following strip chart exhibits (Figures 4 thru 31) and the measurement units denoted by each. Heavy vertical 1 ines atop the left side strip chart on each page indicate time in seconds. Event markers, also shown by heavy vertical 1 ines, precede introduction of transients by one second.

Parallel channel instability was also observed by holding the reactor power constant and reducing the coolant flow rate. When the total flow rate in the core was reduced to about $1 / 3$ the nominal value, coolant in the center region was boiling over nearly the entire length of a channel and the system became unstable.

A check of the entire simulation was made by inserting a $0.5 \mathrm{mk}$ step increase in reactivity into each region in turn. Results obtained from a point kinetics model indicated that the total reactor power would increase about $60 \mathrm{MW}_{\mathrm{t}}$ and 
TABLE III. Strip Chart Symbol Nomenclature

$\underline{\text { Symbo1 }}$ Definition

Units

$\mathrm{PL}_{1}$

Total neutron power in central region

$\mathrm{MW}_{\mathrm{t}}$

$\mathrm{PL}_{2}$

Total neutron power in outer region

$M W_{t}$

$\mathrm{P}_{\mathrm{D}} \quad$ Pressure in steam drum

psi

$\dot{\mathrm{M}}_{\mathrm{S}}$

Mass flow rate of steam from drum to turbine

$1 \mathrm{~b} / \mathrm{sec}$

${ }^{\mathrm{M}} \mathrm{FW}$

Mass flow rate of feedwater into drum

$1 \mathrm{~b} / \mathrm{sec}$

$\mathrm{L}_{\mathrm{D}}$

Level of water in drum

ft

$\overline{\mathrm{T}}_{\mathrm{f} 1}$

Average fuel temperature in the central region

${ }^{\circ} \mathrm{F}$

$\overline{\mathrm{T}}_{f 2}$

Average fuel temperature in the outer region

${ }^{\circ} \mathrm{F}$

i 11

Mass flow rate in inlet risers and subcooled portion of core-center region

$1 \mathrm{~b} / \mathrm{sec}$

$M_{21} \quad$ Mass flow rate in two-phase portion of corecenter region

$1 \mathrm{~b} / \mathrm{sec}$

$\dot{M}_{12}$ Mass flow rate in inlet risers and sub-

cooled portion of core-outer region

$1 \mathrm{~b} / \mathrm{sec}$

$\dot{\mathrm{M}}_{22}$

Mass flow rate in two-phase portion of core-outer region

$1 \mathrm{~b} / \mathrm{sec}$

$\mathrm{h}_{21}$-h $_{11}$ Enthalpy change across core-center region

$\mathrm{Btu} / 1 \mathrm{~b}$

${ }^{\mathrm{n}} 22^{-\mathrm{h}} 12$

Enthalpy change across core-outer region

Btu/1b

$\mathrm{L}_{\mathrm{B} 1}$

Boiling length - center region

$\mathrm{ft}$

$\mathrm{L}_{\mathrm{B} 2}$

Boiling length - outer region

ft 
the transient (in reactor power) would last about 4 sec. However, adding the $0.5 \mathrm{mk}$ step increase to the center region in the present model raised total reactor power approximately $75 \mathrm{MW}_{t}$ for a transient period of about $5 \mathrm{sec}$ (Figure 5 ). Furthermore, a $5 \mathrm{lb}$ rise in steam drum pressure, twice the expected amount, was noted. On the other hand, introducing the same transient in the outer region raised reactor power about $55 \mathrm{MW}_{\mathrm{t}}$ for only about $3 \mathrm{sec}$, with a concurrent rise in drum pressure of $2 \mathrm{lb}$ (Figure 6). The transient response of the system for this latter case was of slightly less magnitude than predicted by the point model.

These results indicate that the simulation does account for spatial effects. Furthermore, the transient response of the system to a perturbation, determined from a point kinetics model, represented an average behavior obtained by perturbing first in one region of the present two-region model and then in the other. The results were just what one would expect.

Since the system response was obviously quite sensitive to spatial effects in the present model, it was decided to determine the controllable maximum reactivity by step additions to each region.* It was found that a $1.1 \mathrm{mk}$ step increase in reactivity in the outer region could be controlled** (Figure 7). The lack of precision characterizing this result, reproducible to within only about $0.05 \mathrm{mk}$, was due in large part to noise in the simulation. It was determined by visual read-out that the total reactivity in the simulation varied peak-topeak, by approximately $0.1 \mathrm{mk}$. Consequently, at any given instant, $\pm 0.05 \mathrm{mk}$ of reactivity in the simulation could be attributable to noise alone.

\footnotetext{
* See Corrigenda

** In the actual system, the reactor would trip out at a power level $10 \%$ above nominal.
} 

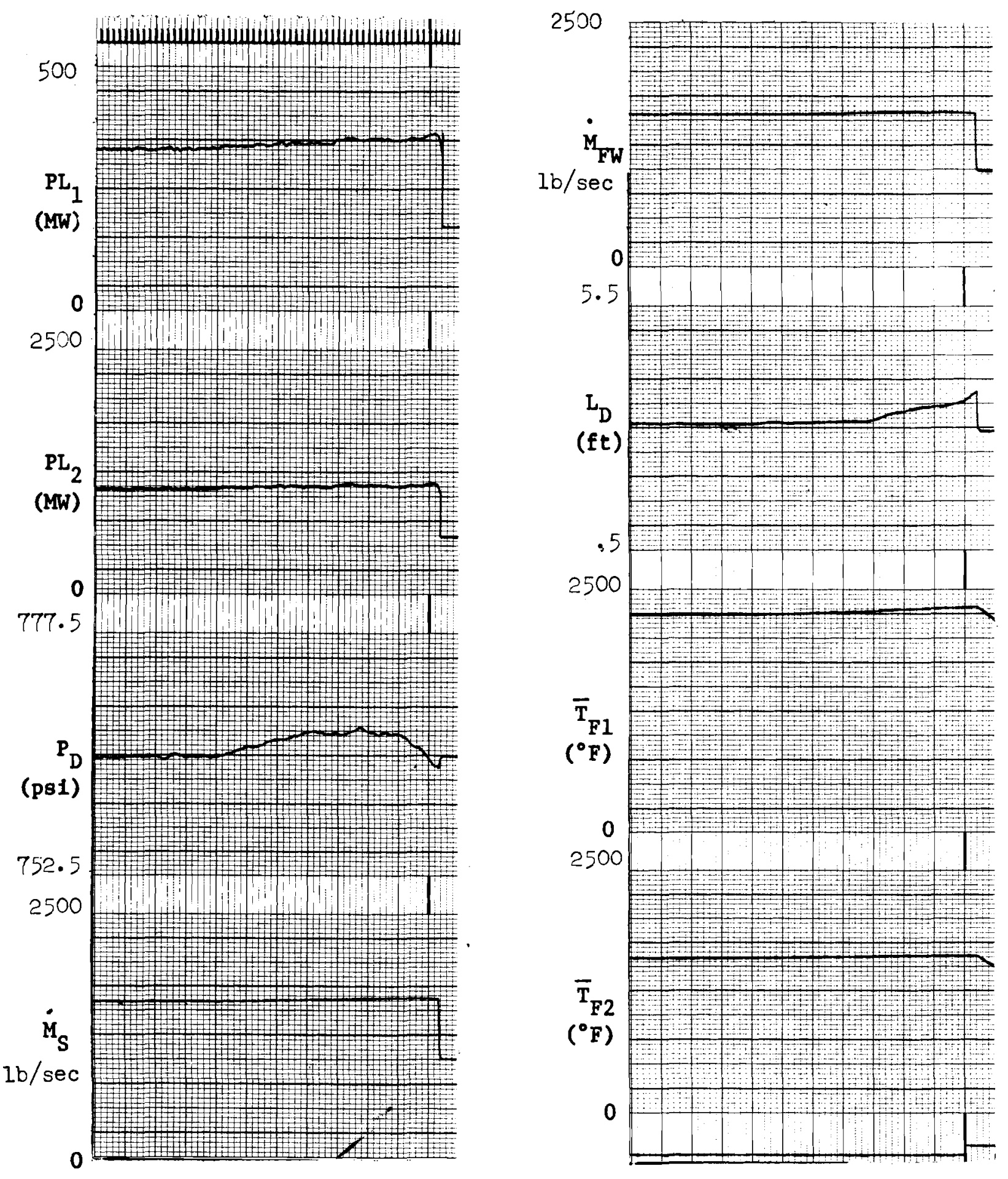

FIGURE 4. BLW-250 System Stabizity (In-Out Modez--UO2 Fuez-Nominat Conditions Power Runup--Instability Threshold) 

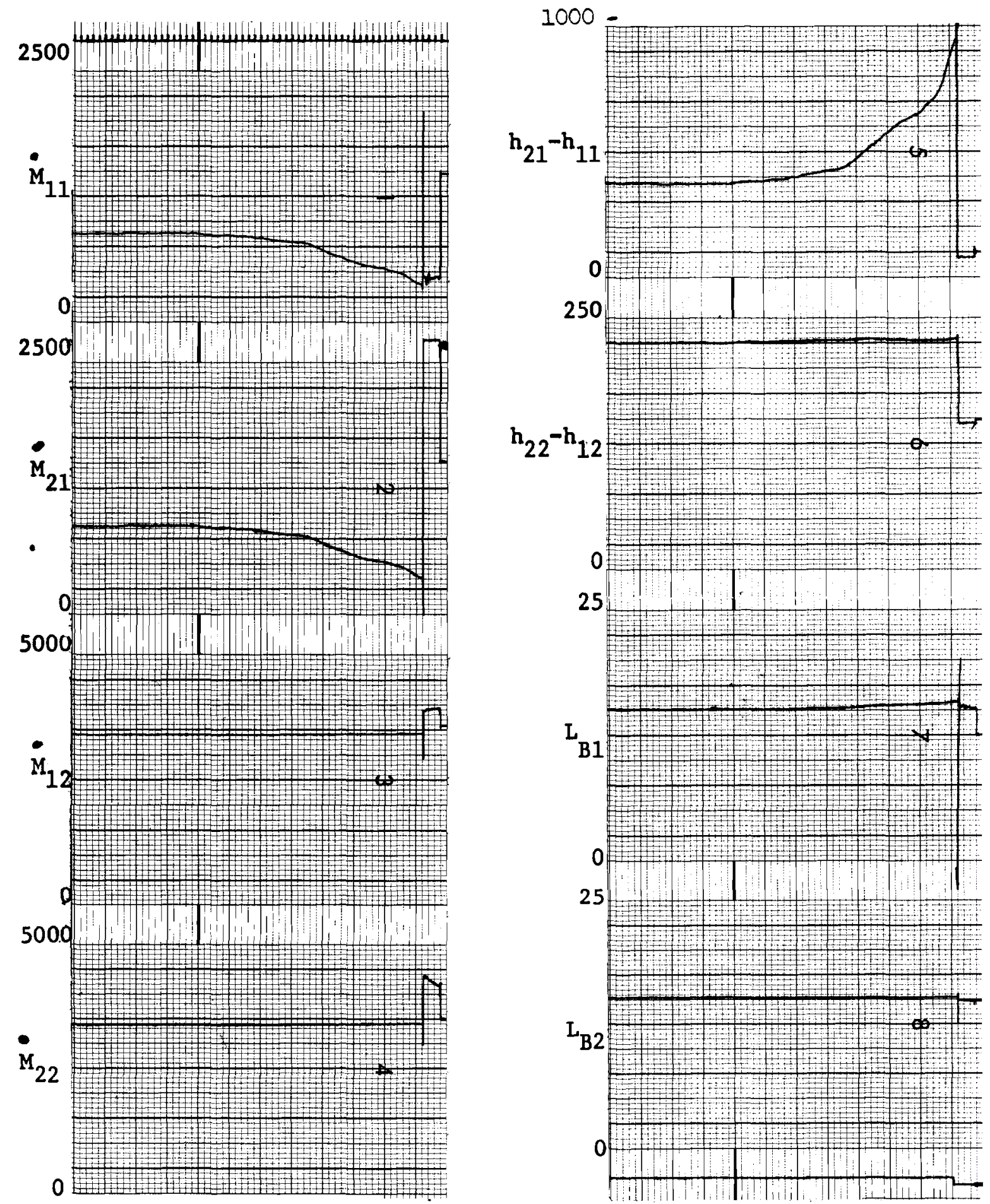

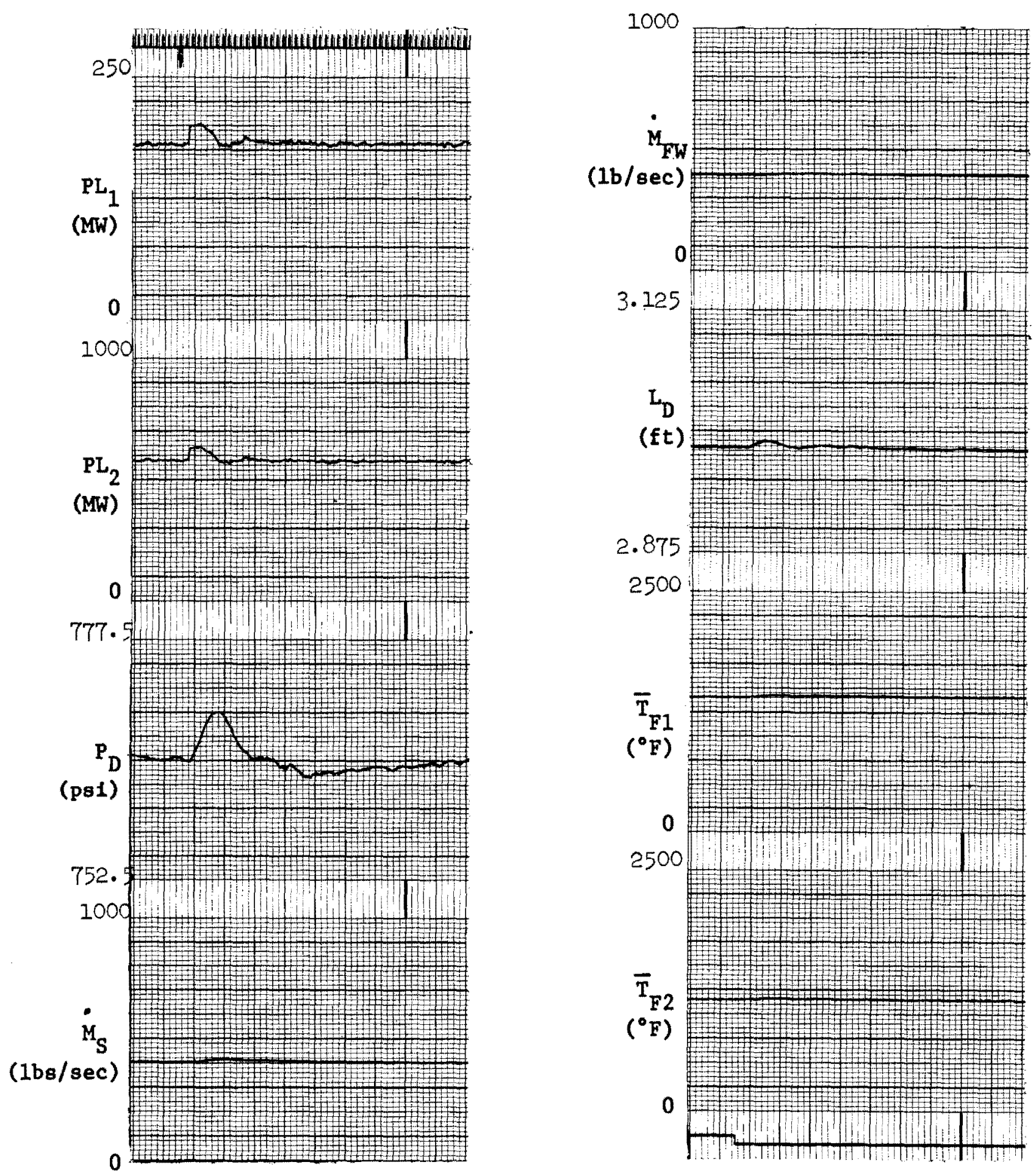

FIGURE 5. BLW-250 System Stabizity (In-Out Model--UO2 Fuel-Nominal Conditions $0.5 \mathrm{mk}$ Step In Center Region) 

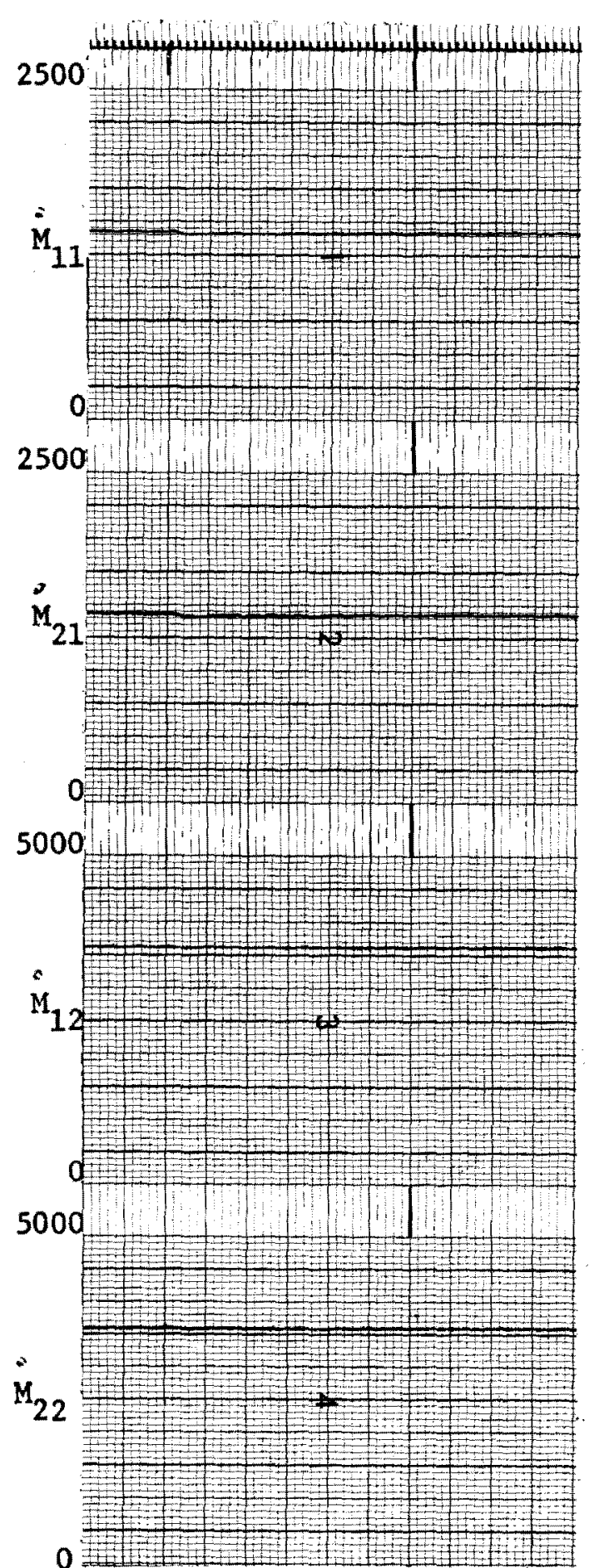

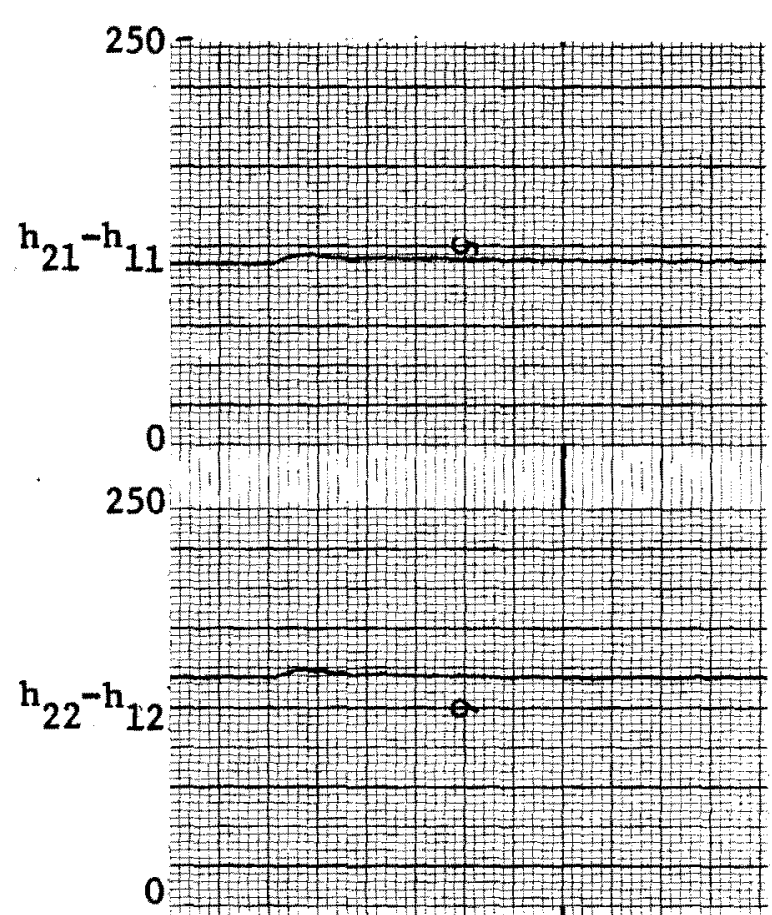

25
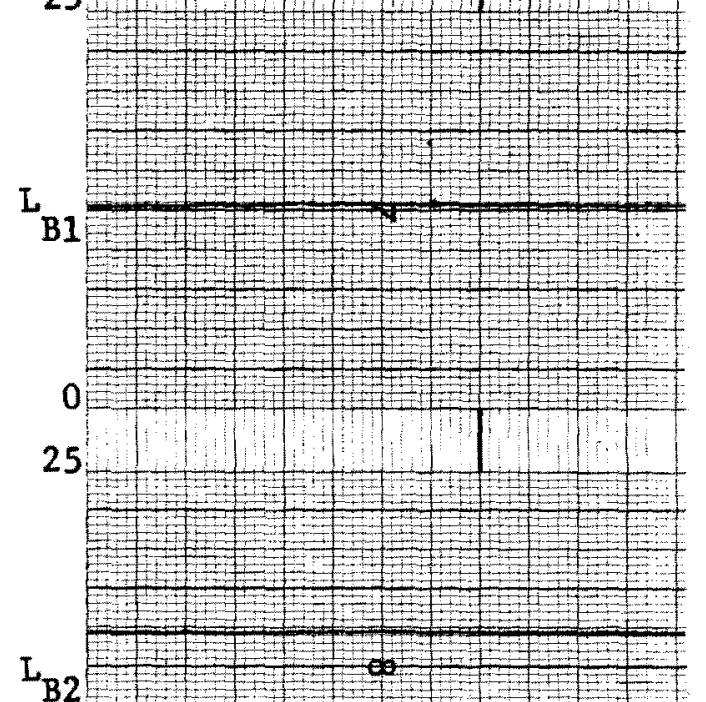

B2

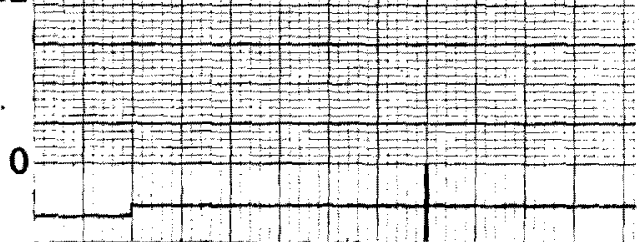



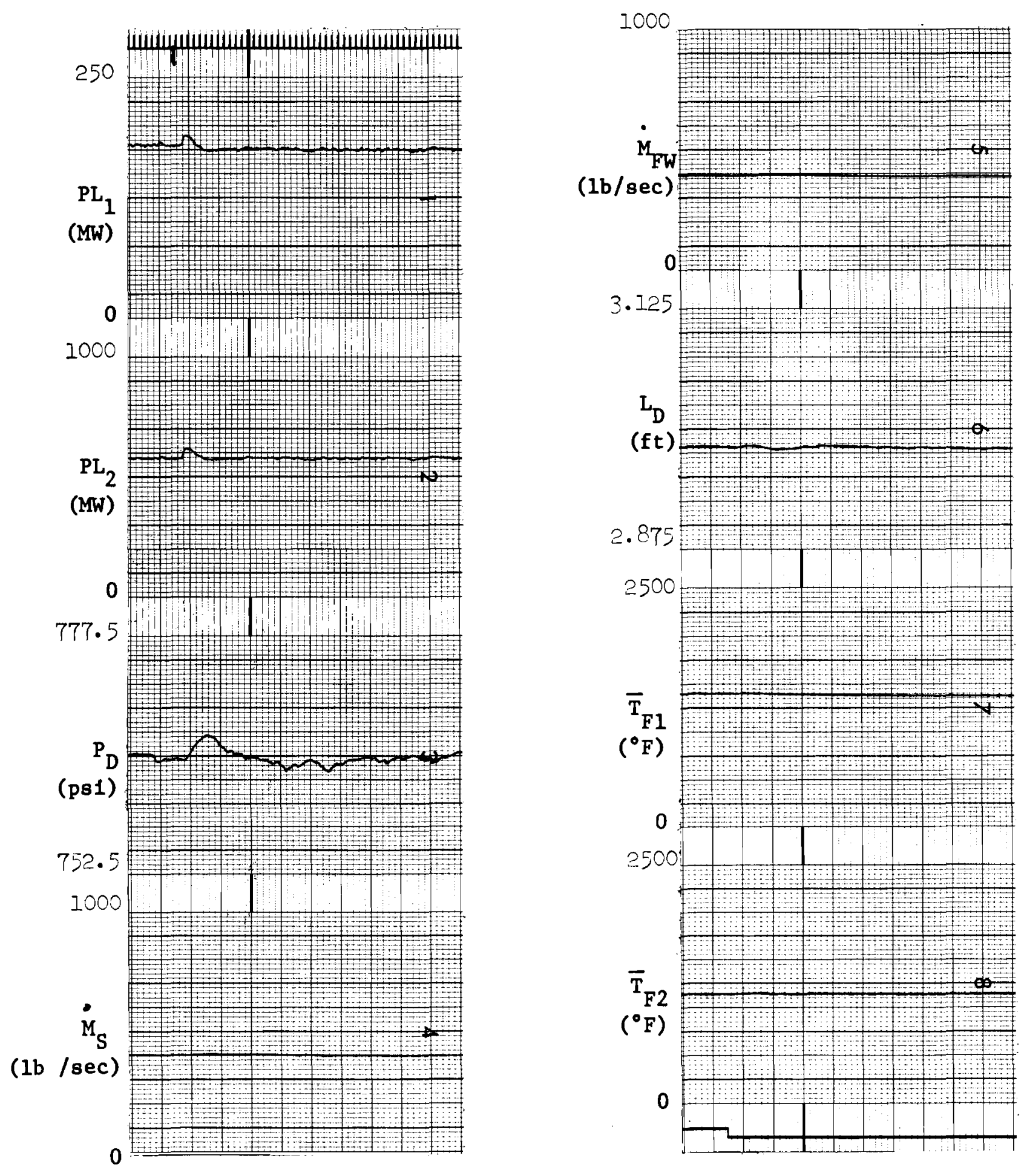

FIGURE 6. BLW-250 System Stabizity (In-Out Modez--U02 Fuez-Nominal Conditions $0.5 \mathrm{mk}$ Step In Outer Region) 

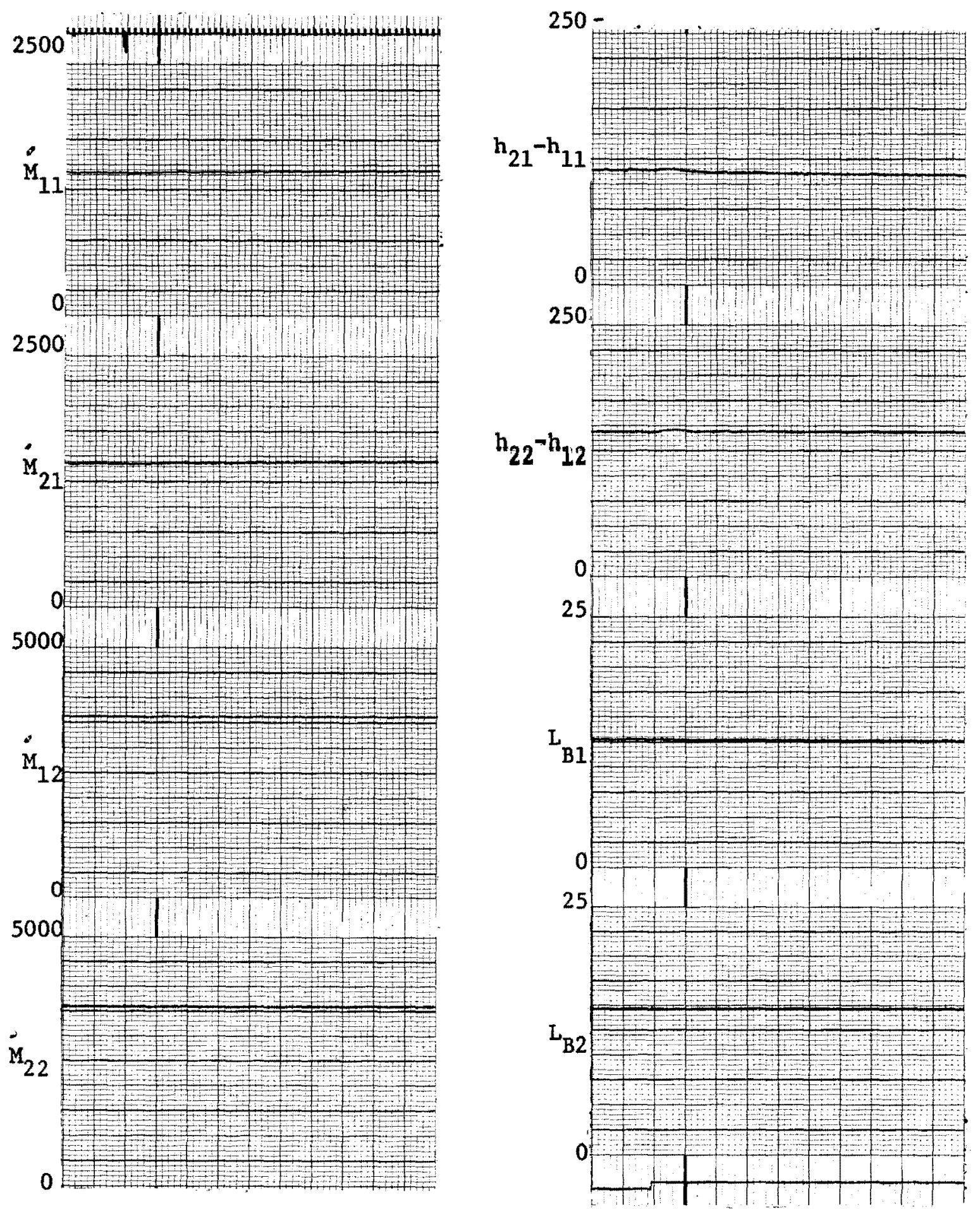

FIGURE 6. (Contd) 
An interesting sidelight observed during this and subsequent runs (Figure 7 ) was the effect of the rod movement on power distribution. Note that the power level in the center region was depressed about 5\% after the controller had compensated for a reactivity addition in the outer region. By recalling that nearly $80 \%$ of the reactivity removal due to control rods (reactivity controller) occurs in the center region, it is seen that control rods were inserted in the center region, in effect, to compensate for a perturbation that was made in the outer region.

When the same $1.1 \mathrm{mk}$ step was added in the center region, an uncontrolled power excursion resulted. A $0.85 \mathrm{mk}$ step, added in the center region (Figure 8 ), nearly produced a power level reversal in the controller before an uncontrolled excursion occurred. This response was caused by the time delay associated with heat conduction from fuel to coolant, and the following excursion by reactivity addition due to decreasing coolant density as heat was conducted out of the fuel.

The maximum controllable reactivity step in the center region was $0.75 \mathrm{mk}$ (Figure 9). As before, this was reproducible to about $\pm 0.05 \mathrm{mk}$. Thus, it is seen that a difference of more than $1 / 4 \mathrm{mk}$ in maximum controllable step reactivity exists between the center and outer regions of the present model.

A $4 \%$ step increase in steam demand to the turbine showed an expected drop in steam drum pressure and rise in reactor power (Figure 10). Very 1ittle effect was observed in coolant flow rate. A similar result, in reverse, was obtained when the steam demand was decreased $4 \%$.

Increasing the power set point by a $10 \%$ step resulted in about a 5\% overshoot in reactor power and a rather large swing in drum pressure (Figure 11). 
The effect of sudden1y injecting cold water into the steam drum was determined by introducing a $10 \%$ step decrease in feedwater enthalpy (Figure 12). The immediate effect was a decrease in drum pressure and consequent reduction in flow rate through the core. Reactivity feedback through the coolant density coefficient increased reactor power and thus tended to increase pressure in the drum. Thus, interestingly enough, the system proved self-stabilizing against changes in feedwater temperature through the influence of changes in drum pressure.

\section{PHASE I I}

The second part of the study consisted essentially of an attempt to assess the importance of variations in design parameters on BLW-250 operating characteristics.

Of the various transients observed during Phase $I$, the step reactivity addition in the center region was selected as a standard. As perturbations were made to design parameters, the maximum controllable reactivity step that could be added to the center region was re-established. It is important to recall that an uncertainty of approximately $\pm 0.05 \mathrm{mk}$ exists in any given run. Consequently, unless the maximum controllable reactivity was observed to differ by more than $0.1 \mathrm{mk}$ from the unperturbed result, the perturbation effect was assumed to be negligible.

For example, the fuel temperature coefficient provides an inherent stabilizing effect on BLW-250 system dynamics. However, this coefficient was set to zero and the maximum controllable reactivity in the center region $(0.7 \mathrm{mk})$ did not differ significantly from the unperturbed result (0.75 mk). Similarly, the model proved insensitive to expected changes in coolant temperature coefficient, since large coolant temperature changes do not occur over the range of the model. 

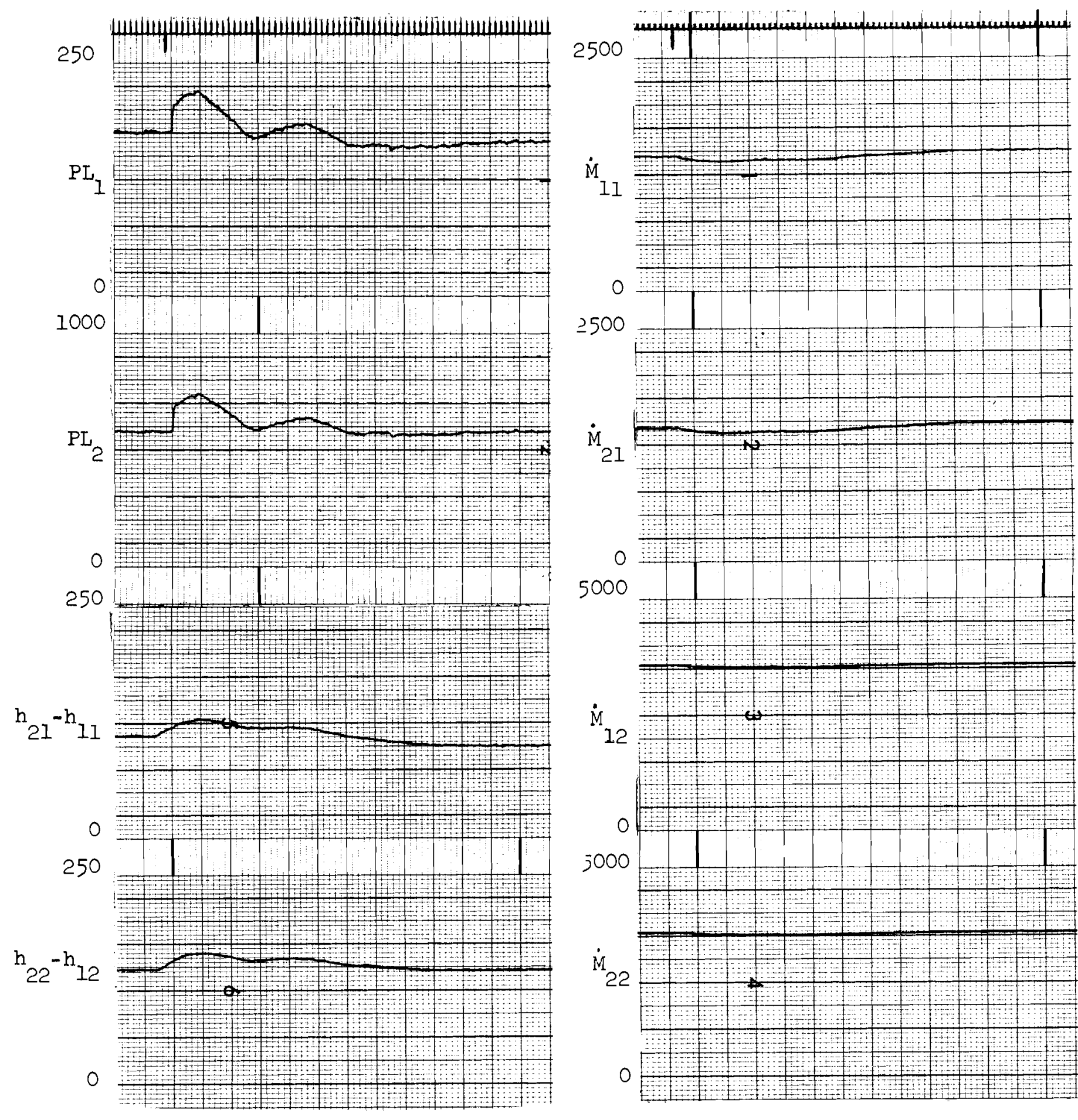

FIGURE 7. BLW-250 System Stabizity (In-Out Model--UO Fuel-Nominal Conditions $1.1 \mathrm{mk}$ Step in outer Region) 

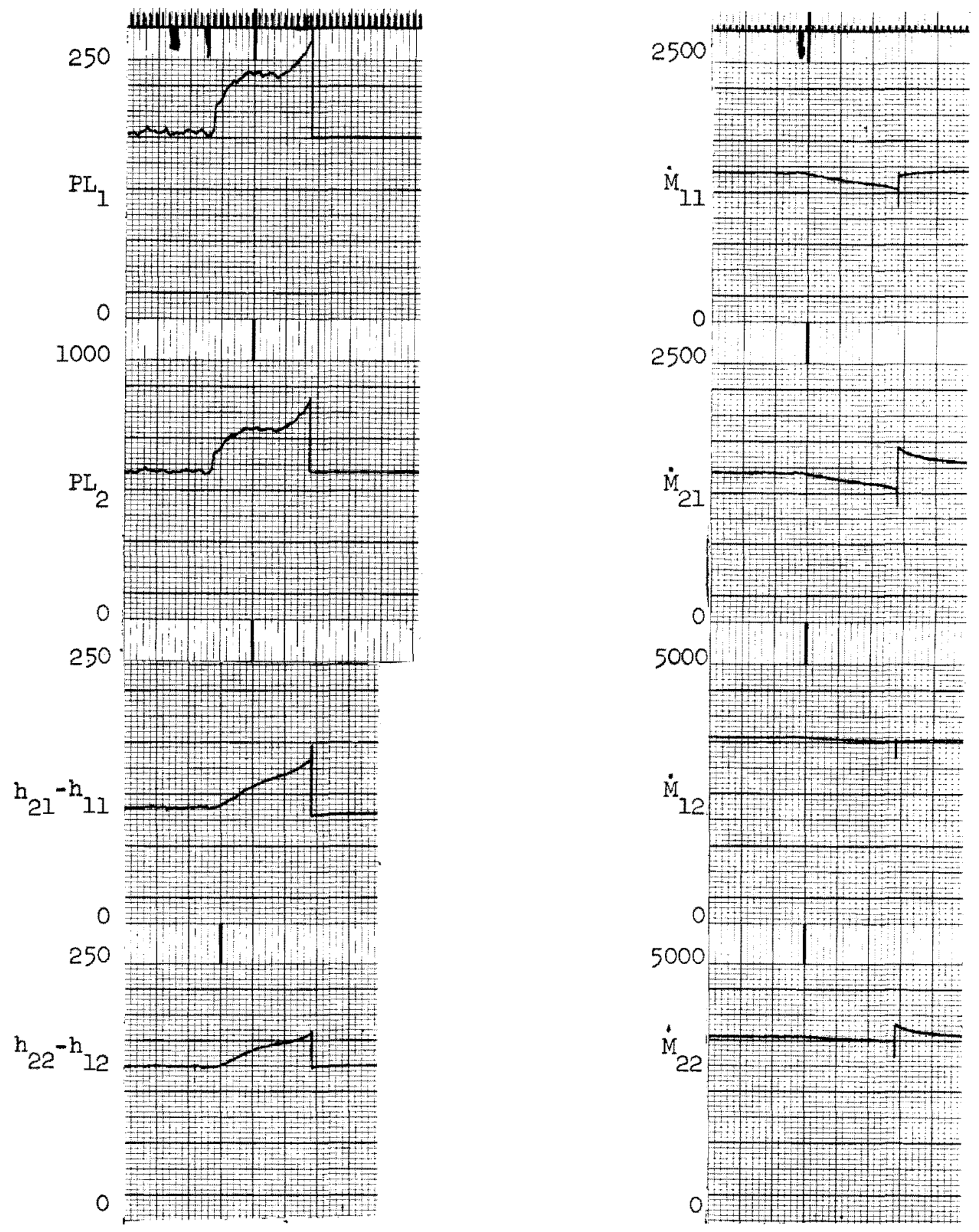

FIGURE 8. BLW-250 System Stability (In-out Model--UO2 Fuel-Nominal Conditions $0.85 \mathrm{mk}$ in Center Region) 

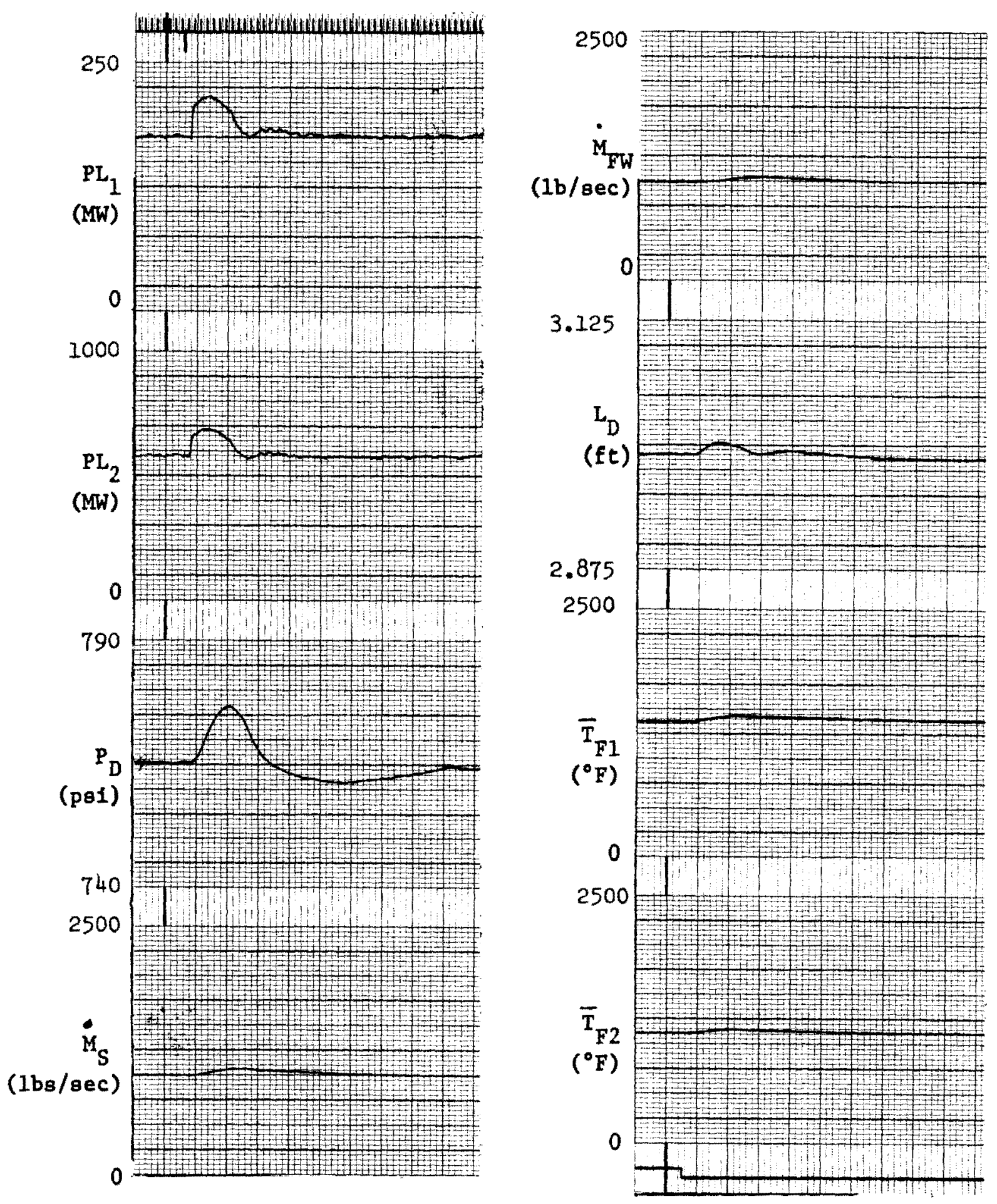

FIGURE 9. BLW-250 System Stabizity (In-Out. Model--Uo, Fuel-Nominal Conditions $0.75 \mathrm{mk}$ in Center Region) 

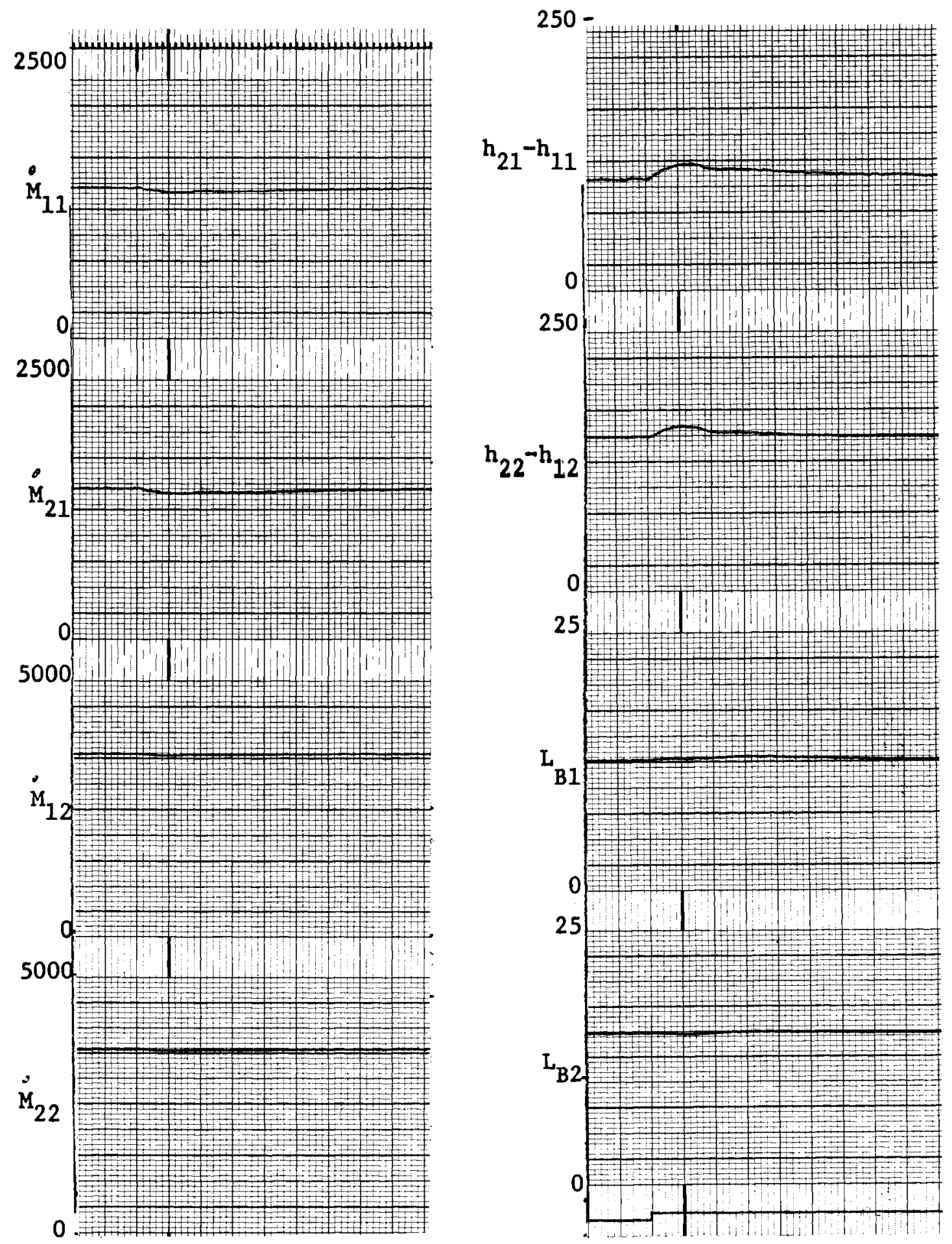

FIGURE 9. (Conta) 

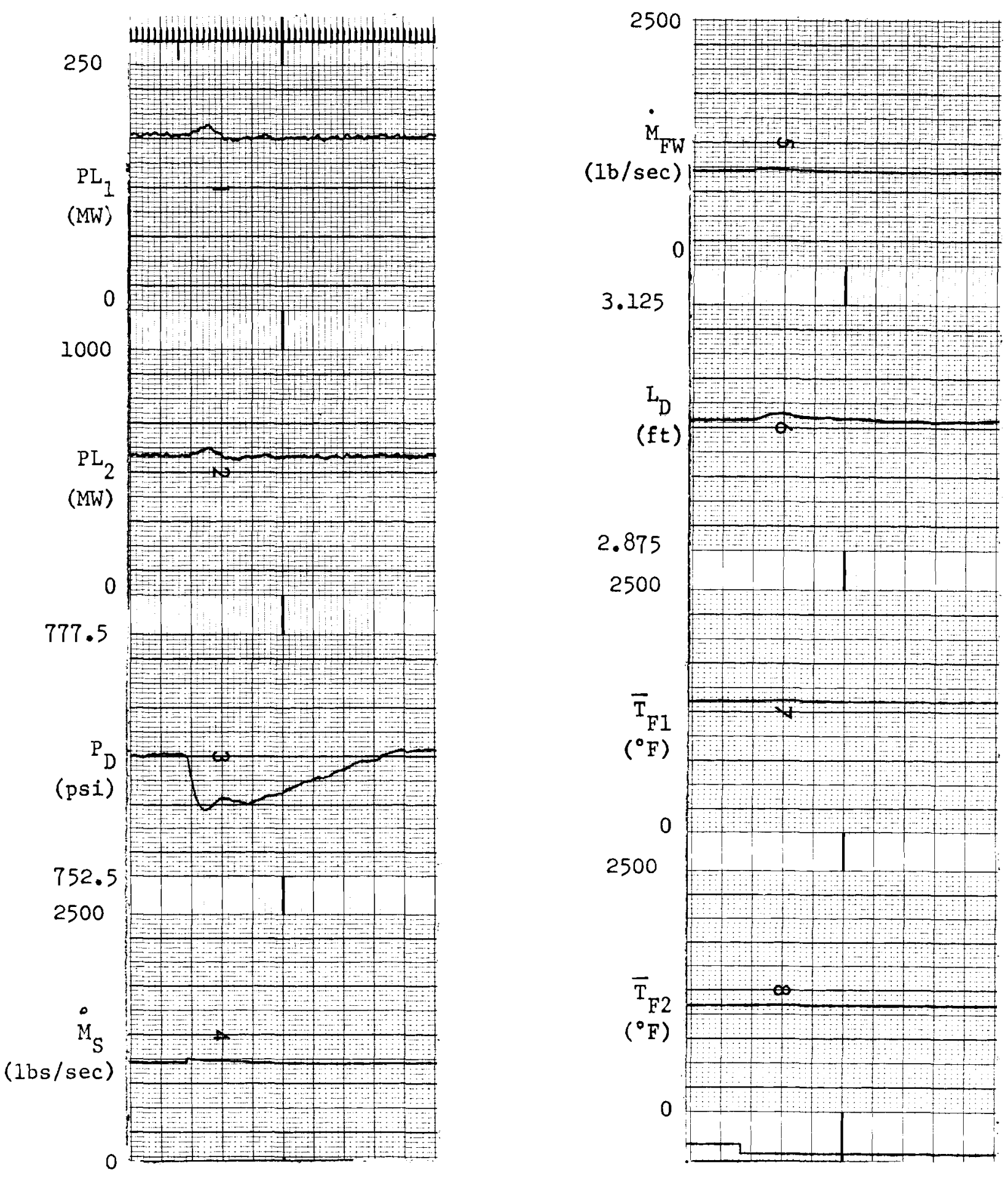

FIGURE 10. BLW-250 System Stability (In-Out Model--UO2 Fuel-Nominal Conditions $4 \%$ Step Increase in Steam Demand) 

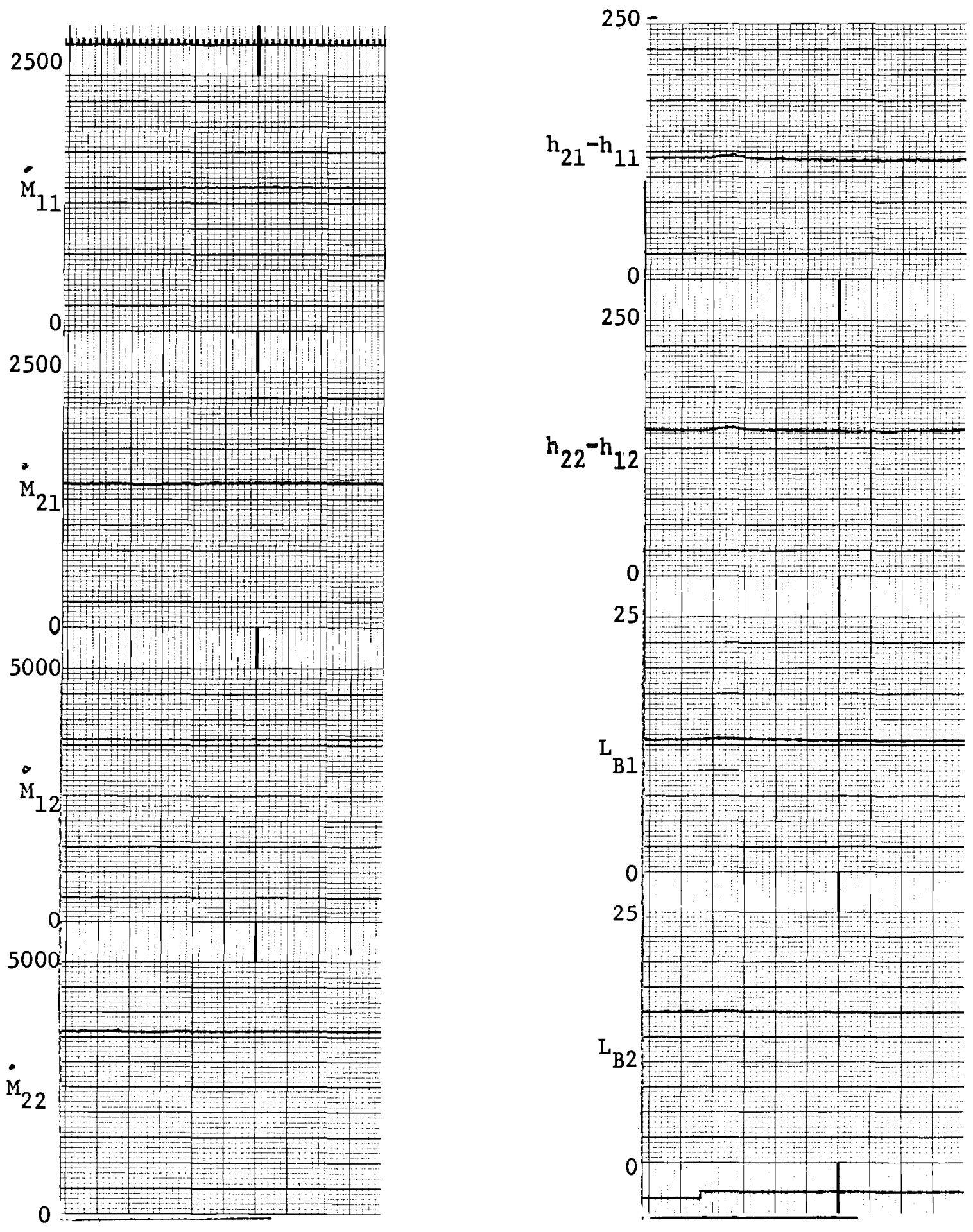

FIGURE 10. (Contd) 

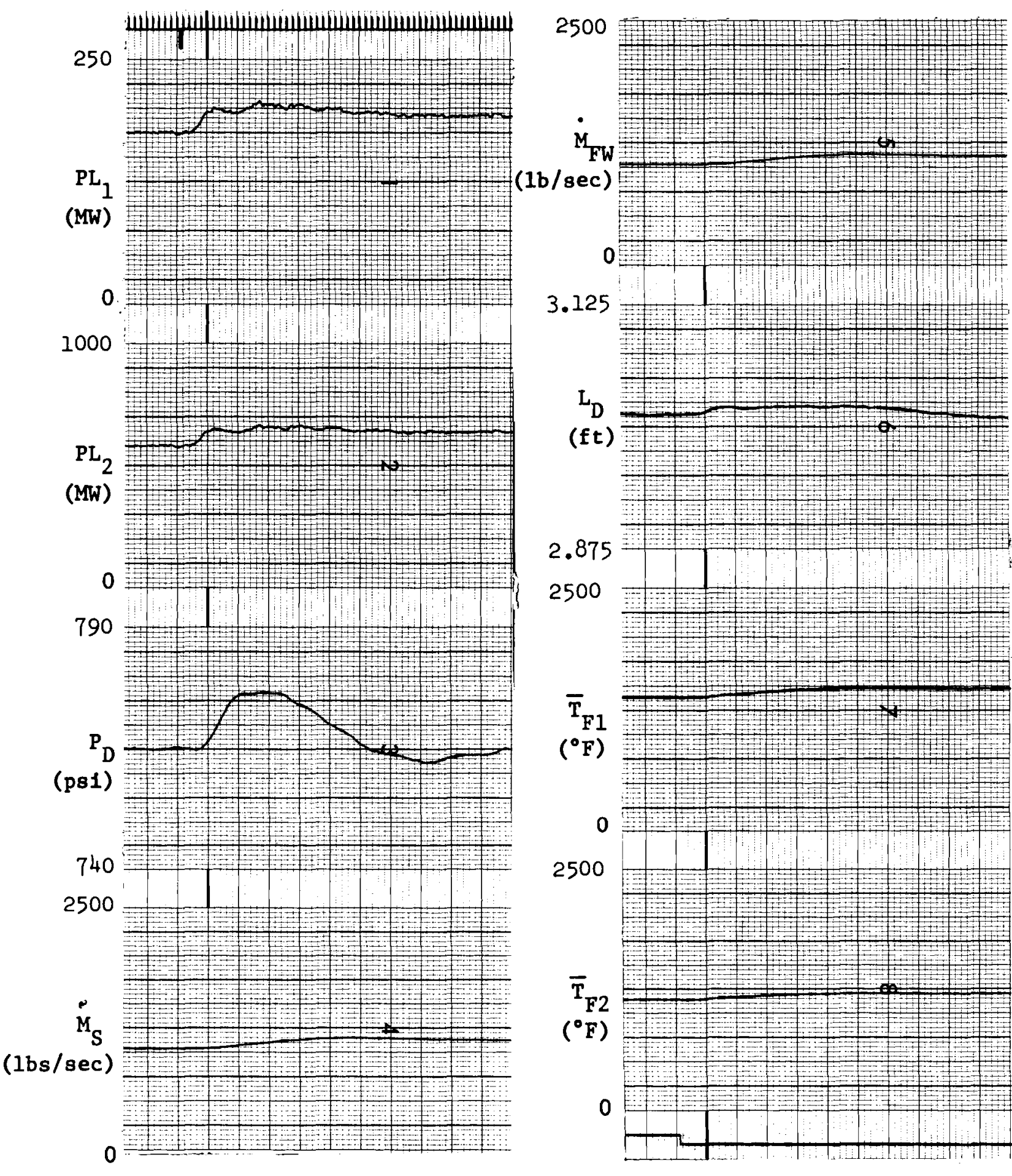

$(1 \mathrm{~b} / \mathrm{sec})$

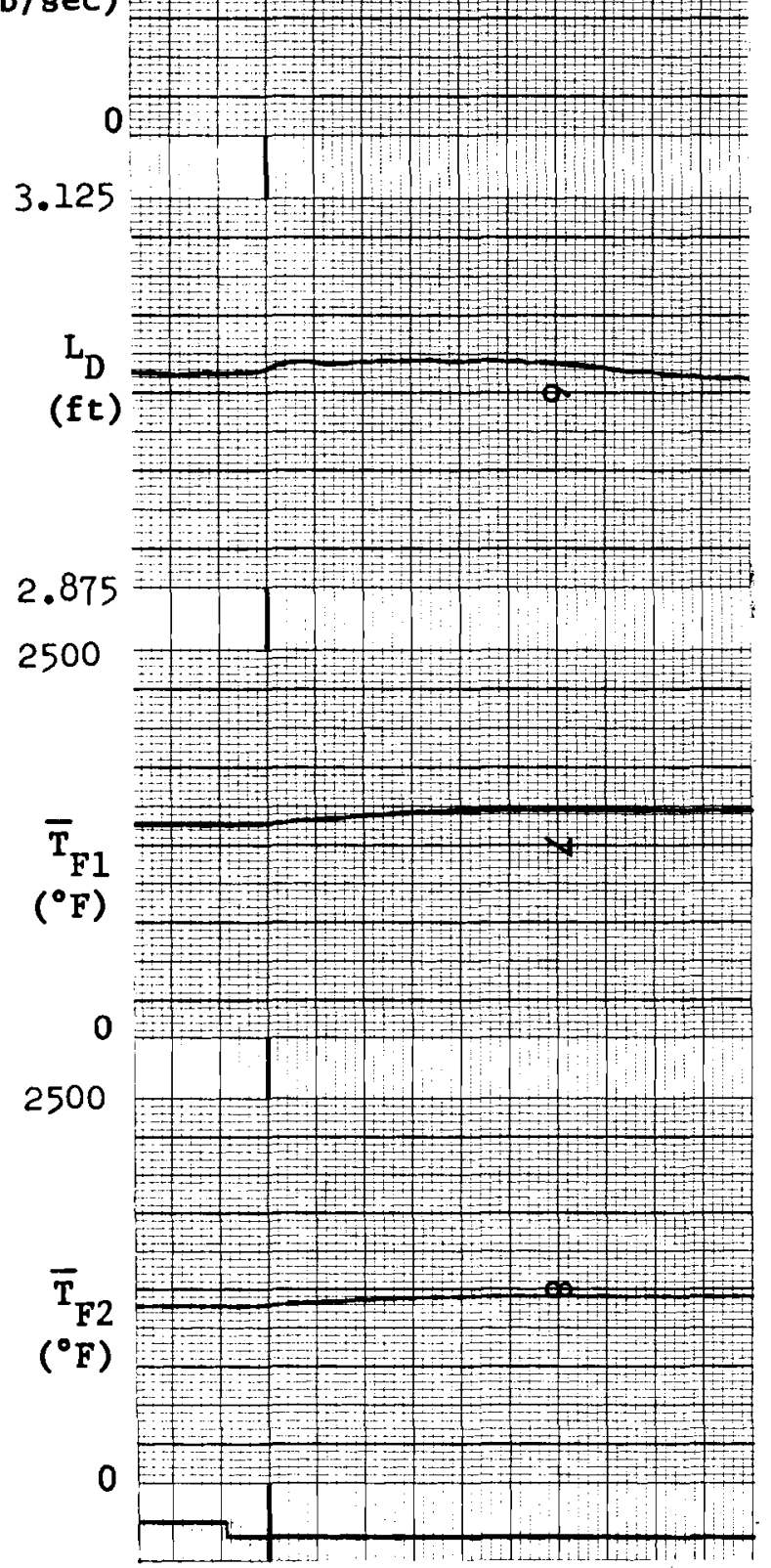

FIGURE 11. BLW-250 System Stability (In-out Model--UO2 Fuel-Nominal Conditions $10 \%$ Step Increase in Power Set Point) 

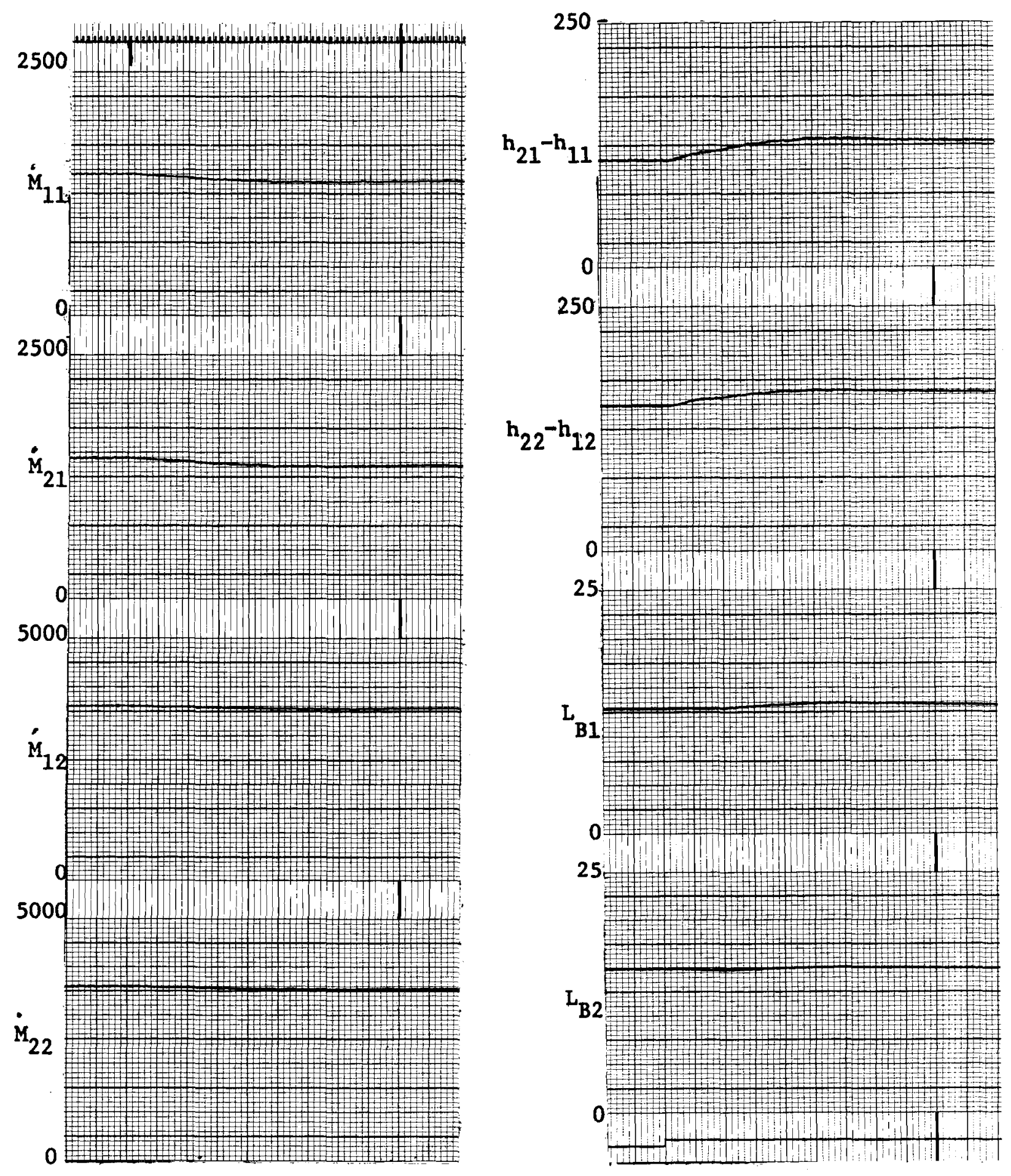

FIGURE 11. (Contd) 


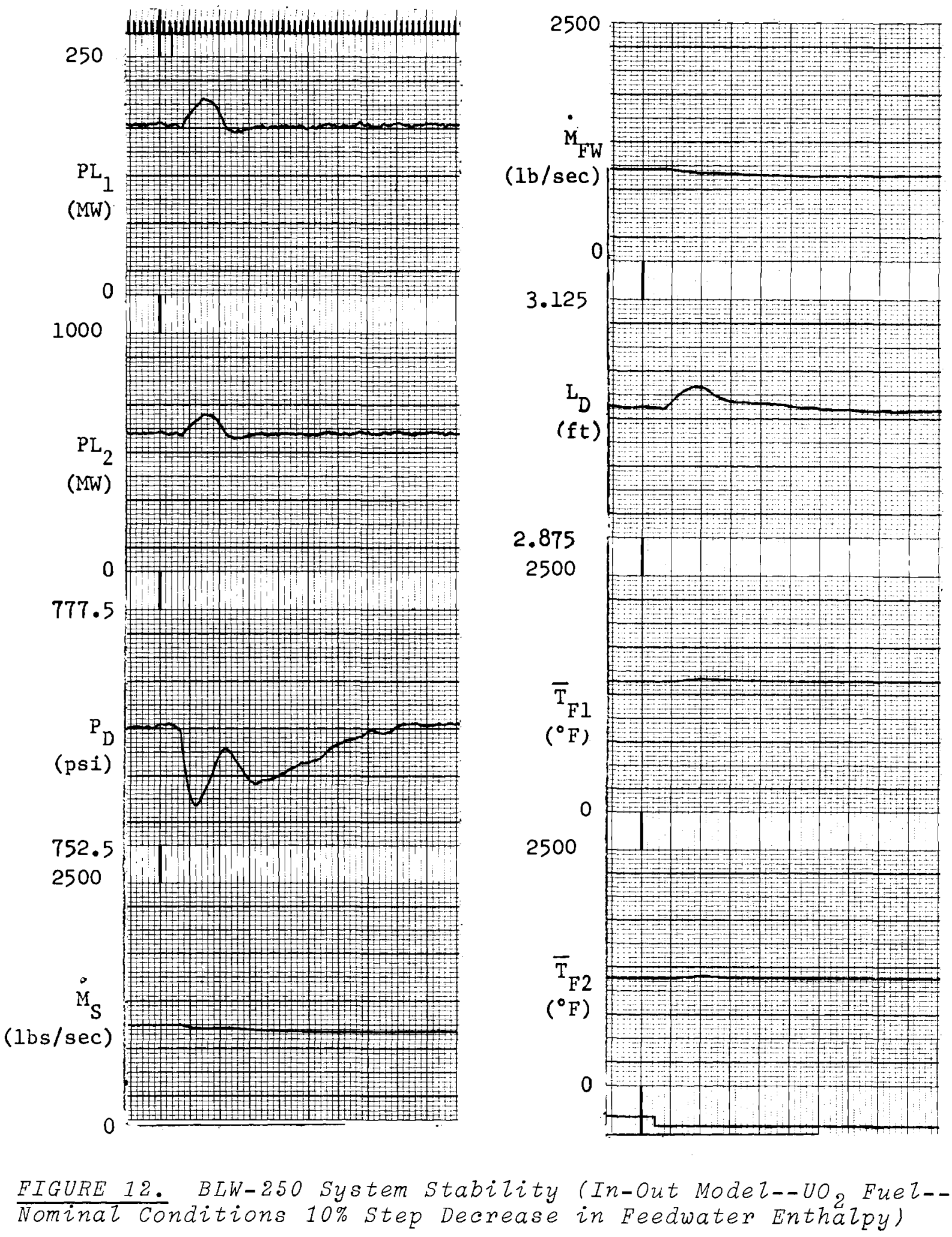



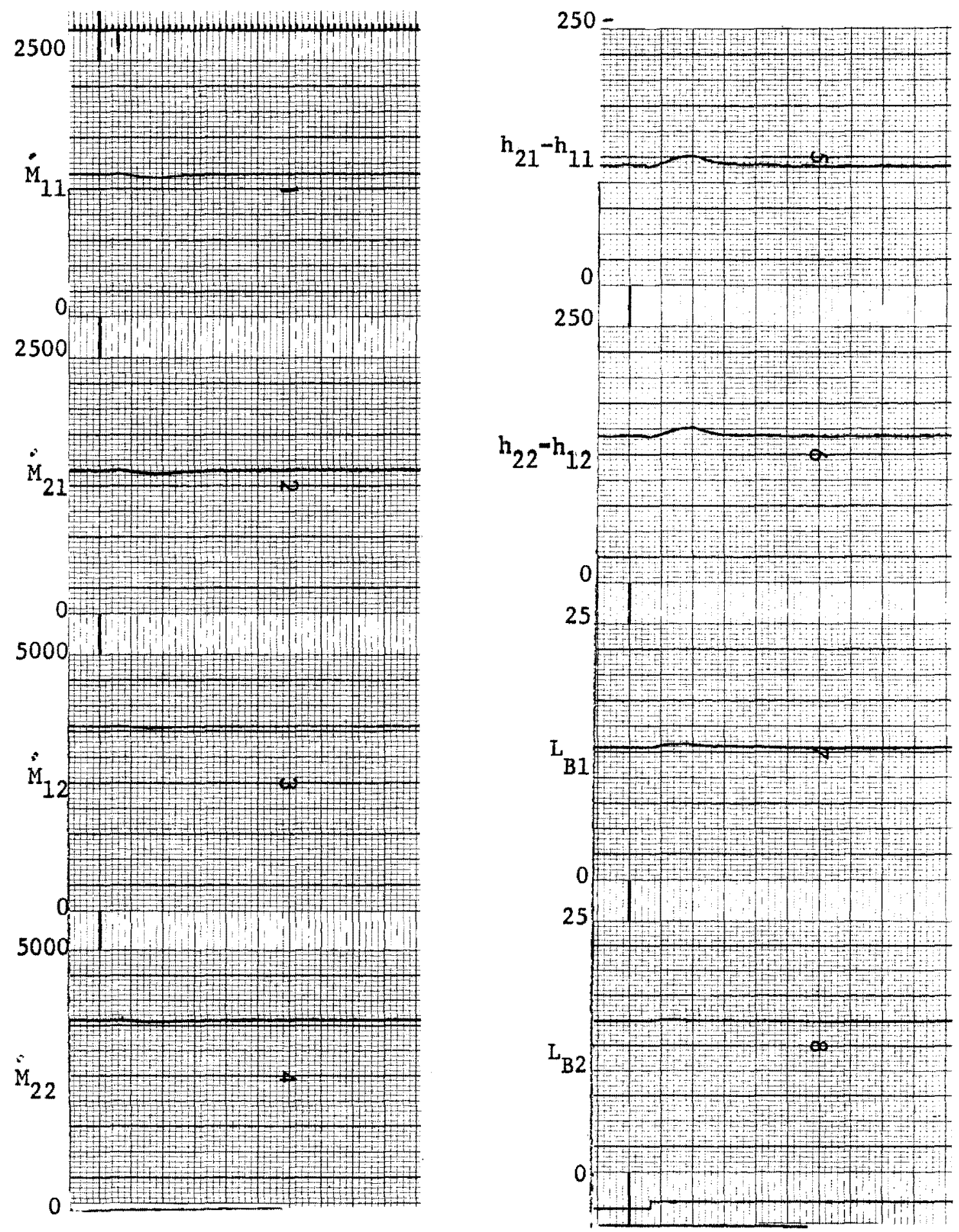

EIGURE 12. (contd) 
The main reactivity feedback during a transient came from the change in coolant density. When coolant density coefficient was increased by $25 \%$, the maximum controllable reactivity in the center region was only $0.55 \mathrm{mk}$ (Figure 13 ). On the other hand, with the coefficient decreased $50 \%, 1.6 \mathrm{mk}$ was controllable. The previously mentioned delay effect associated with coolant density was evidenced by the sharpness with which the controller terminated a 1 mk transient when the coefficient was at half-value (Figure 14).

The sensitivity of the system to coolant density changes, as would be expected, was even greater at reduced flow rates. With the flow reduced $10 \%$, a reactivity-induced excursion followed a step of only $0.45 \mathrm{mk}$ in the center (Figure 15). The controller handled $0.4 \mathrm{mk}$ under the same conditions.

The steam drum representation was altered in several ways to assess the importance of drum design on system dynamic behavior. Drum pressure was increased by 5\% (Figure 16) and decreased by $5 \%$ (Figure 17) and, in each case, a $0.7 \mathrm{mk}$ step was added in the center region. At the lower pressure, the system showed some overshoot when returning to the nominal power whereas, at the higher drum pressure, the transient was sharply controlled. Interaction between drum pressure and coolant density was found to play a significant role in determining dynamic response of the BLW-250 system.

Decreasing the steam drum to half-size (Figure 18) was of negligible effect on system dynamics (compare to Figure 9). It has been pointed out (12) that, for this case, an insensitive test was used to measure the effect of changing drum size. A step change in steam flow rather than reactivity would have provided a better measure of the importance of steam drum size. 
The effect between all subcooled (Figure 19) and all saturated water in the drum (Figure 20) was negligible and consistent with findings for the two different-sized drums.

Changing the transport time of coolant from the steam drum to the core had no effect. Nominally, an 8-sec delay was used in the simulation. Although a faster system response could be expected by reducing this delay, no discernible differences were observed over the 6 to 20 -sec range.

PHASE 3

If the BLW-250 were fueled with a short time constant fuel such as $U_{3} \mathrm{Si}$ or uranium metal, reactor stability would be expected to suffer because of the shorter fuel-to-coolant heat conduction time.

The changing of fuel time constant to simulate $\mathrm{U}_{3} \mathrm{Si}$ fuel produced a system instability of such magnitude that merely the noise in the simulation caused an uncontrollable power excursion. The reactivity coefficients in this instance, however, were typical of an oxide-fueled core. It was found that the destabilizing effect of the fuel short time constant was compensated for by changing to coefficients representative of a typical $\mathrm{U}_{3} \mathrm{Si}$ core design.

The negligible difference in transient response observed by adding a $0.5 \mathrm{mk}$ step in the center region (Figure 21) or the outer region (Figure 22) as opposed to the situation with the oxide-fueled core was a consequence of the much smaller coolant density coefficient. The steam drum pressure transient varied about $50 \%$ more than did the same transient incident in the oxide-fueled core. On the other hand, the maximum controllable reactivity step in the center region $(0.9 \mathrm{mk}$, Figure 23) was slightly higher than for the oxide case. 


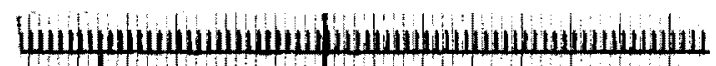

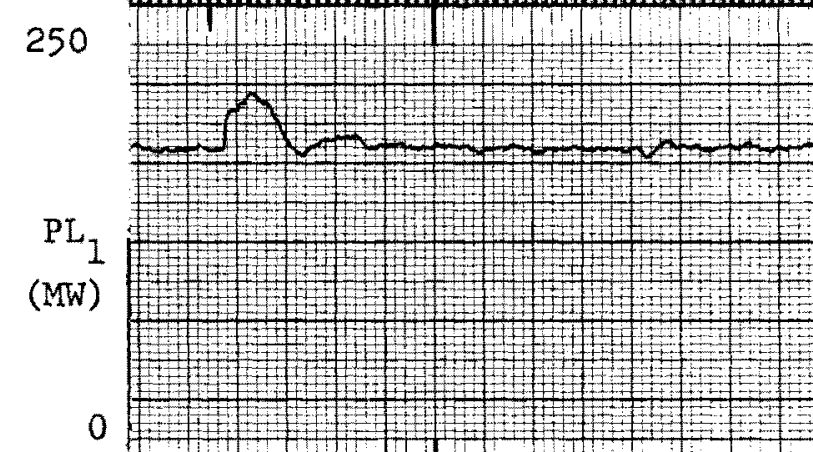

$$
1000
$$

${ }^{P}$

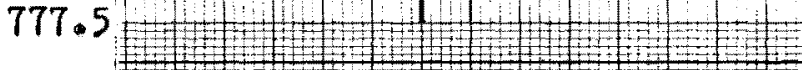

$\mathrm{PL}_{2}$
$(\mathrm{MW})$

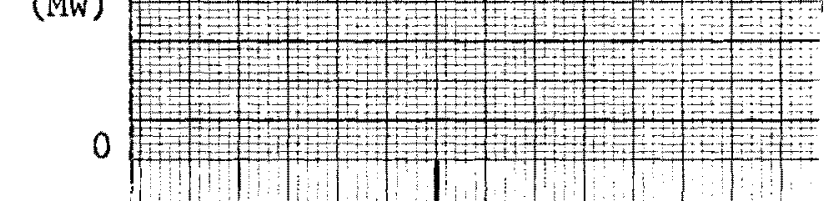

777.

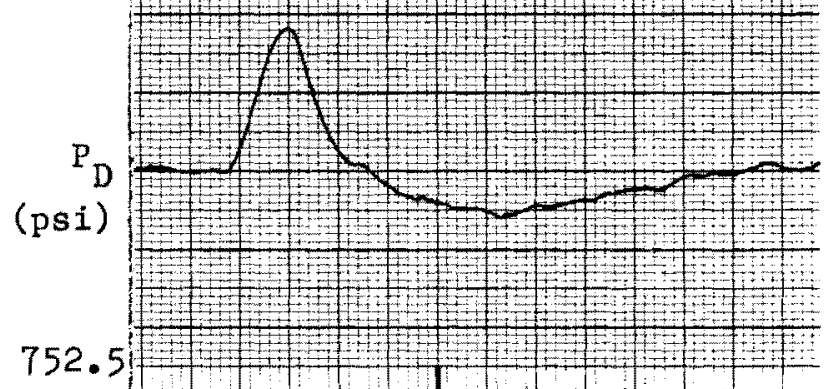

2500

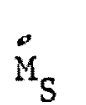

$(1 \mathrm{bs} / \mathrm{sec})$
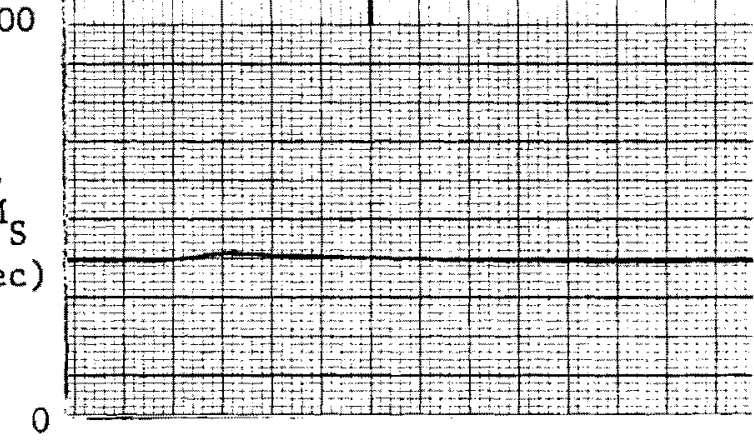

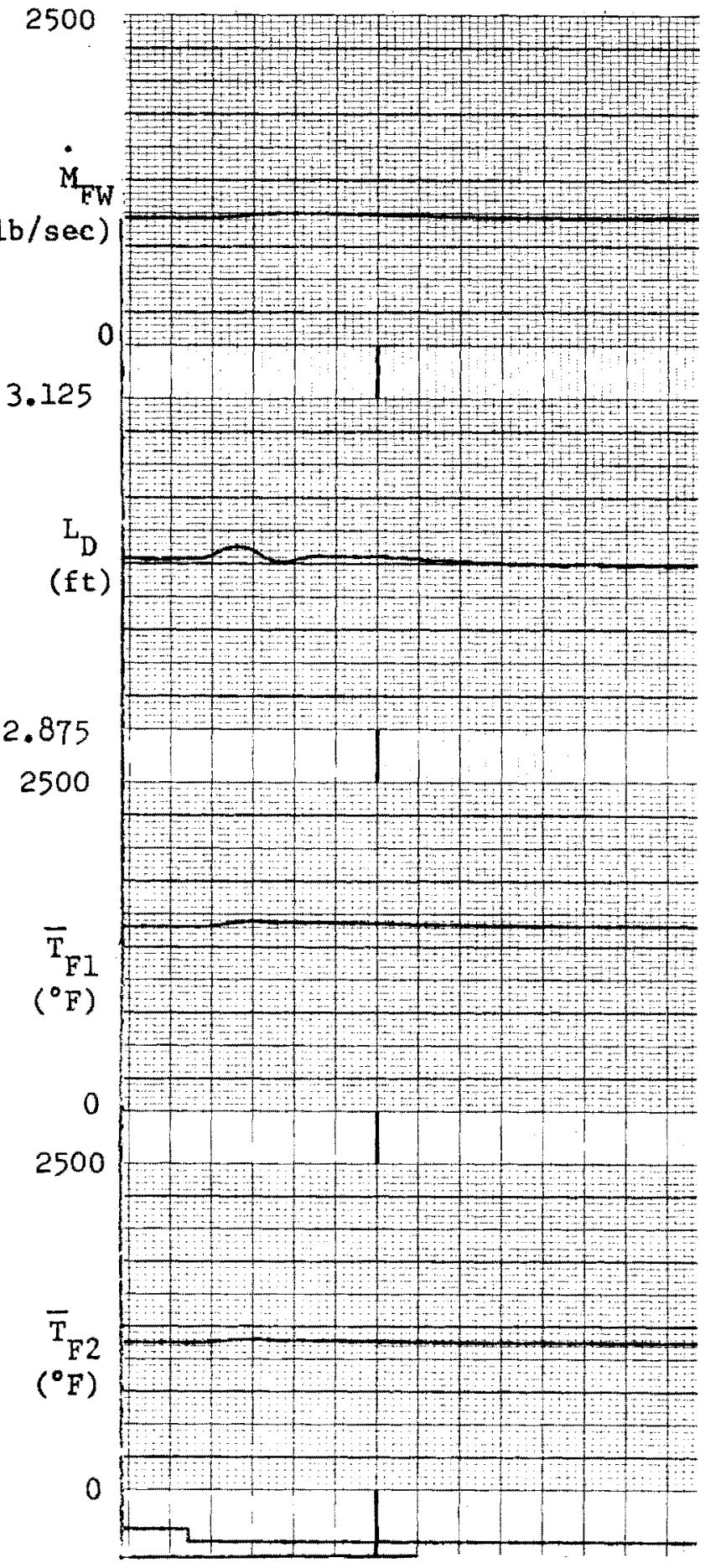

FIGURE 13. BLW-250 System Stability (In-Out Modez--UO, Fuel-Coolant Density Reactivity Coefficient Increased $25 \% 0.55 \mathrm{mk}$ Step in Center Region) 


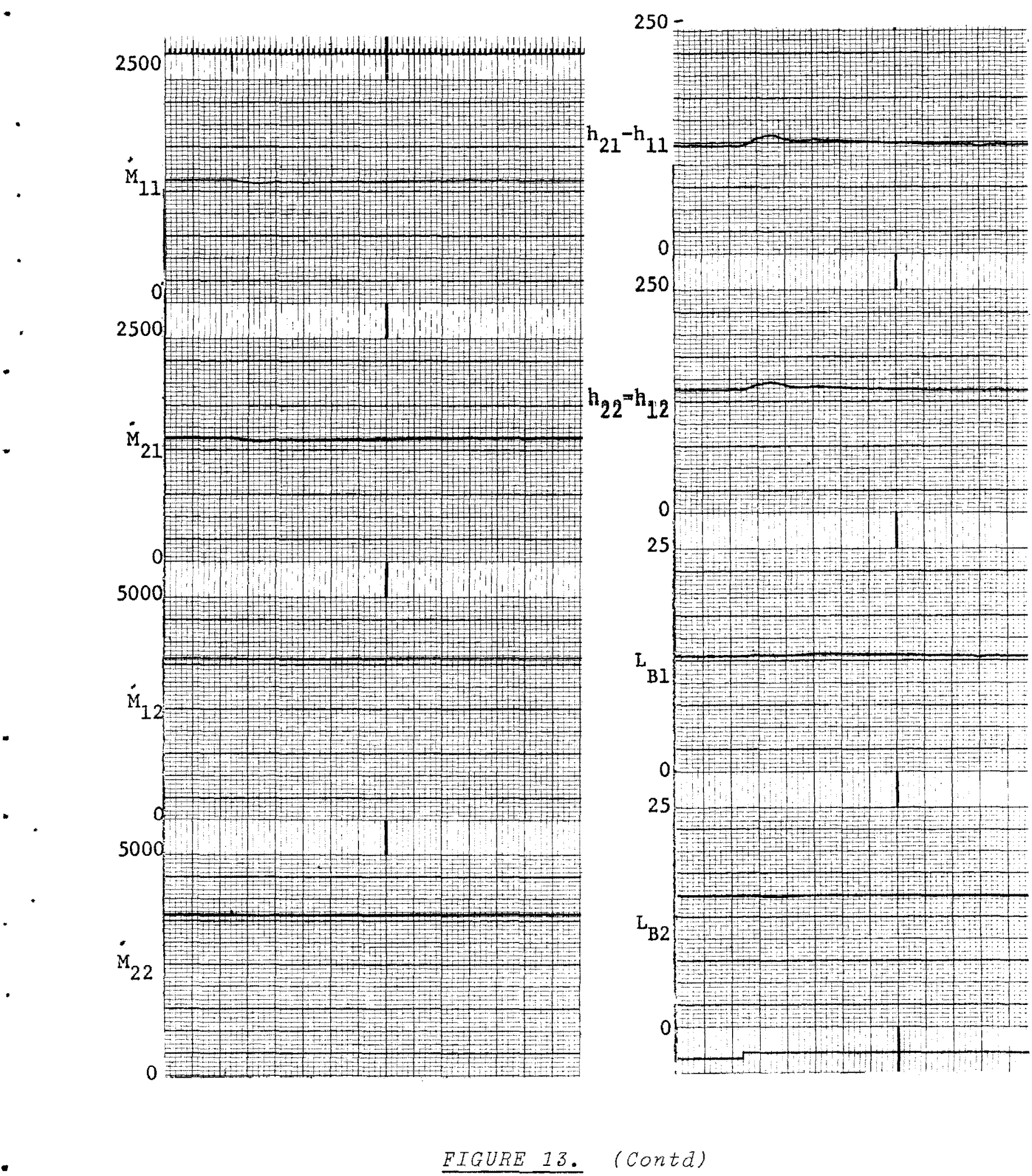



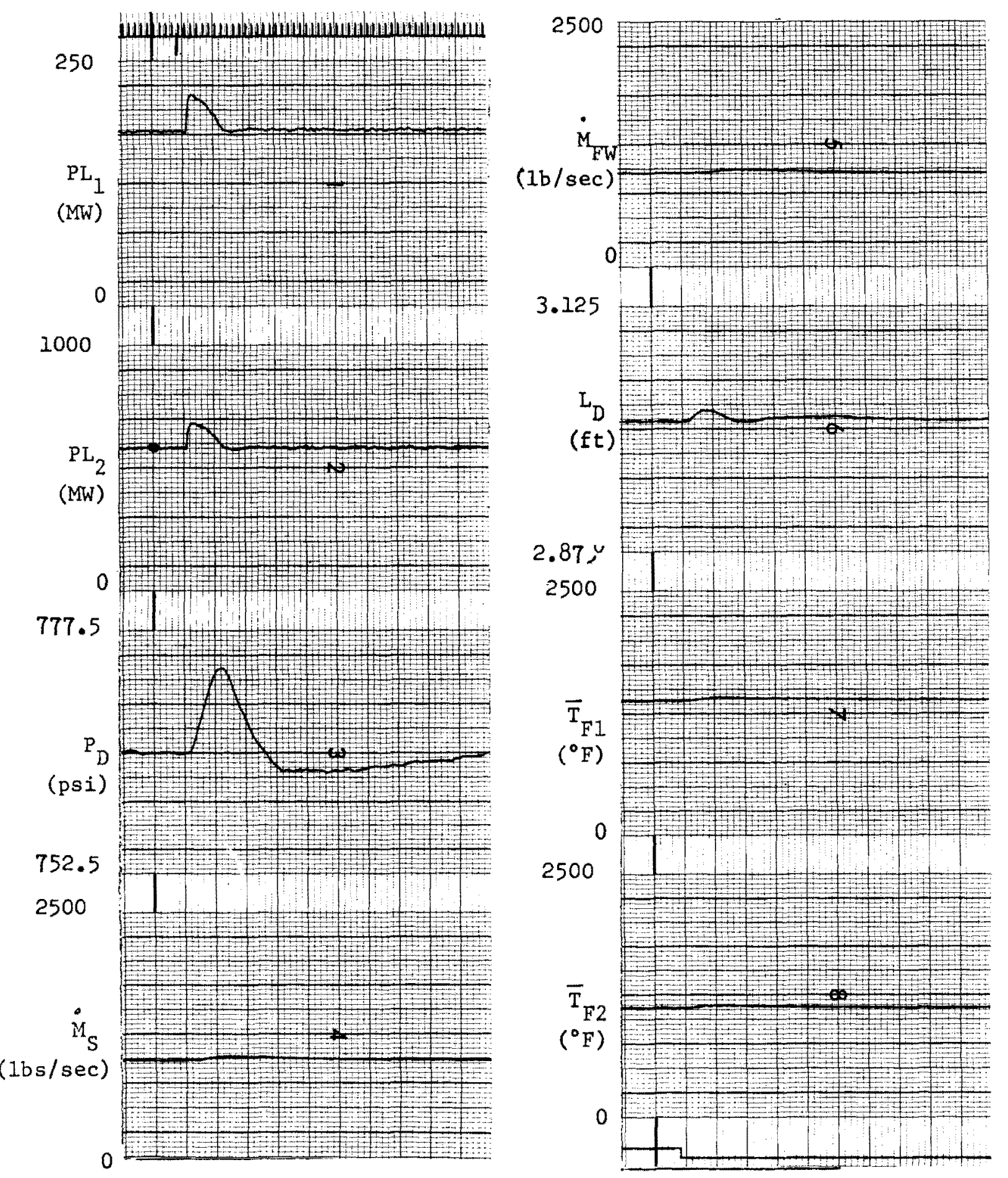

FIGURE 14. BLW-250 System Stability (In-Out Modez--UO Fuel-Coolant Density Reactivity Coefficient Reduced 10\% $1.0 \% \mathrm{mk}$ Step in Center Region) 

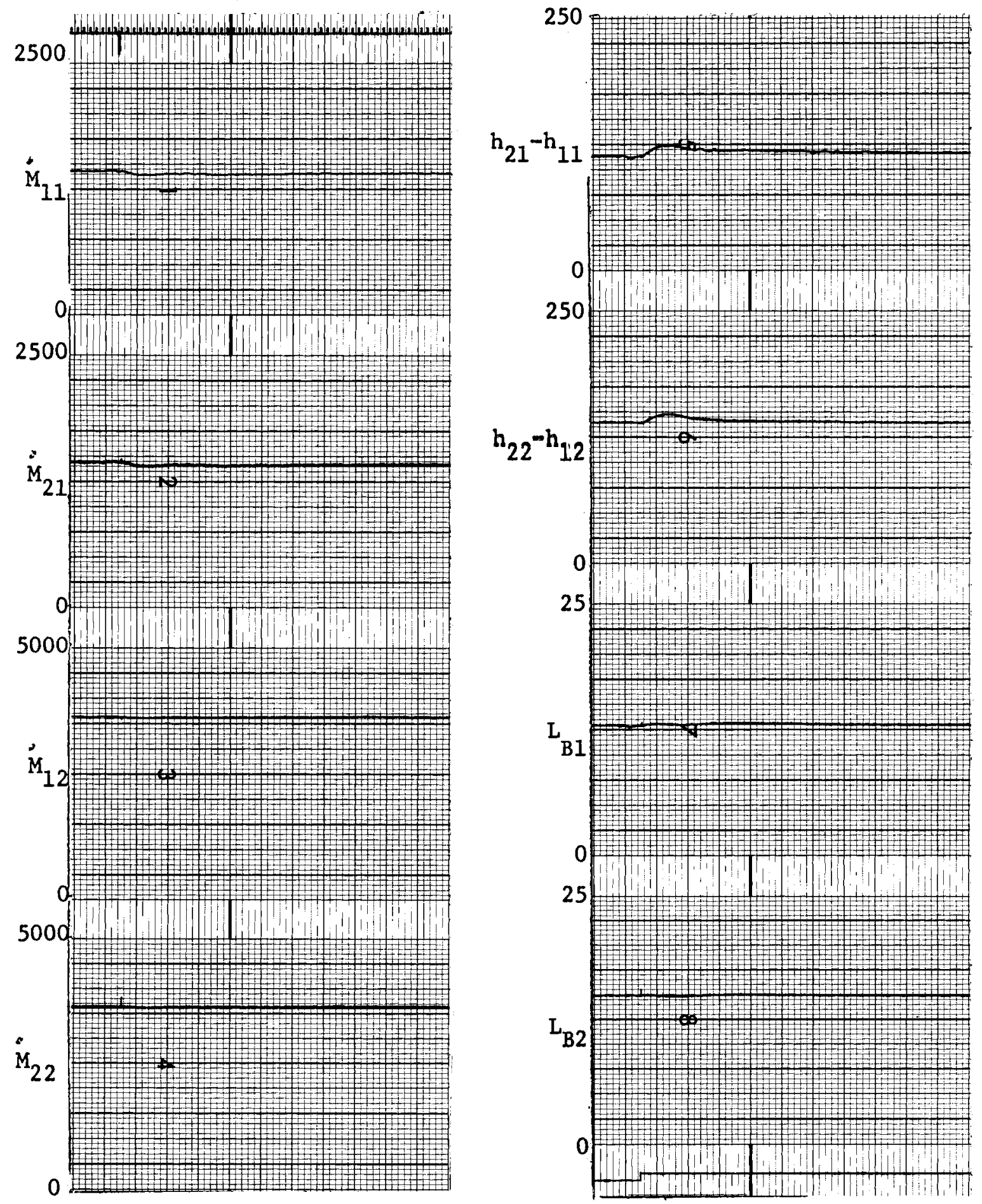

FIGURE 14. (Contd) 

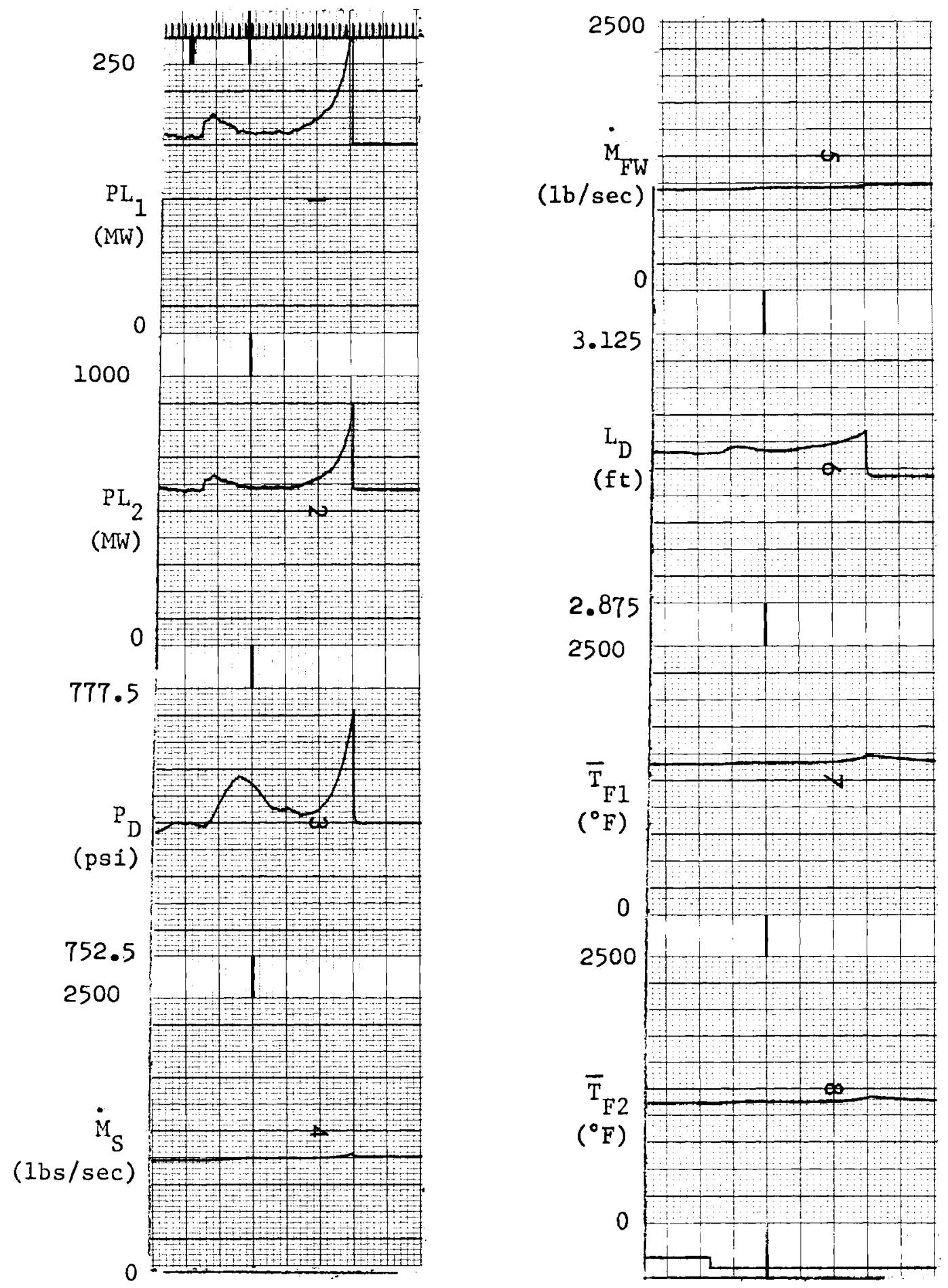

FIGURE 15. BLW-250 System Stabizity (In-Out Model--Uo Fuel-Flow in Core Reduced 10\% $0.45 \mathrm{mk}$ Step in Center Region' 

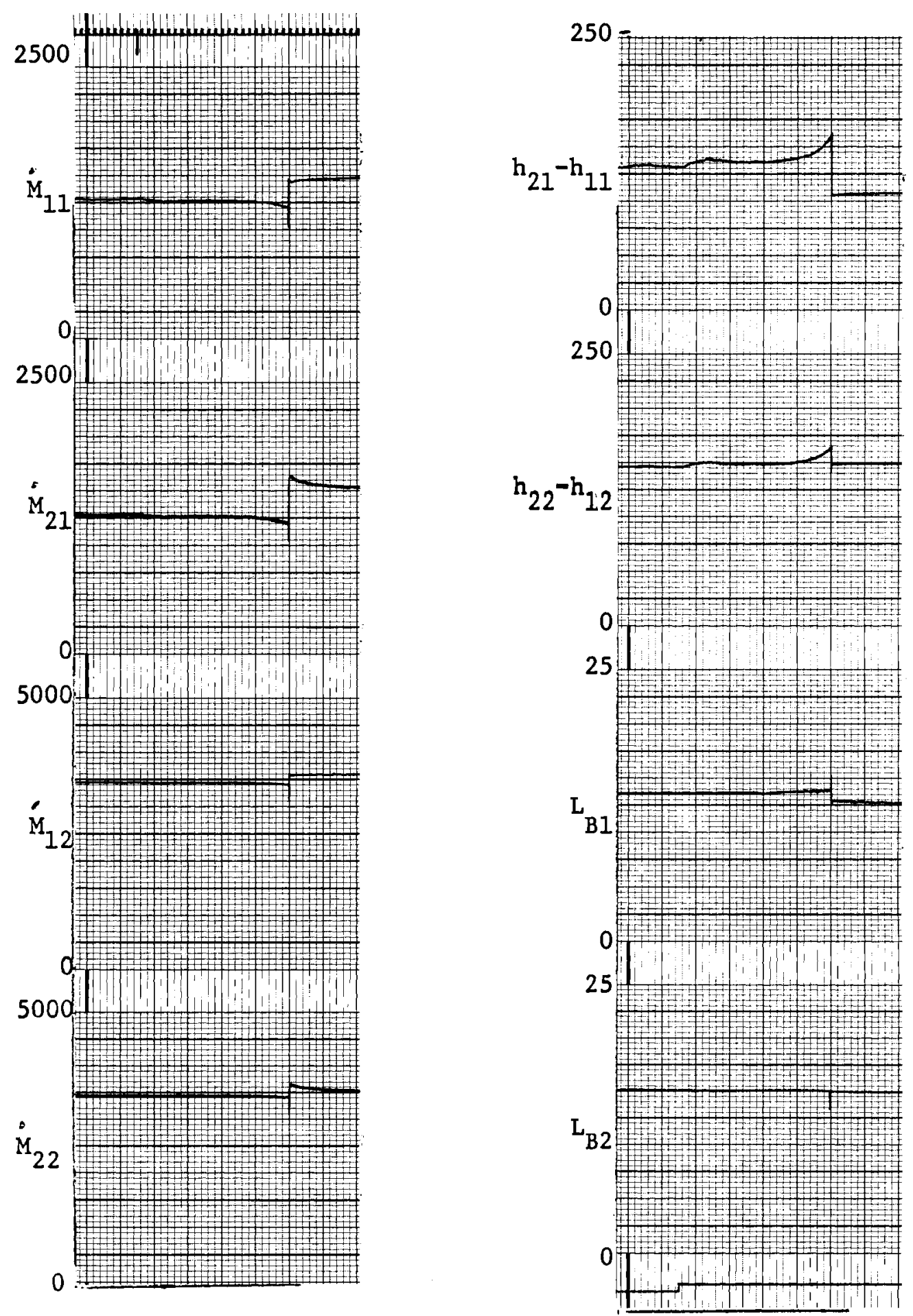

FIGURE 15. (Contd) 

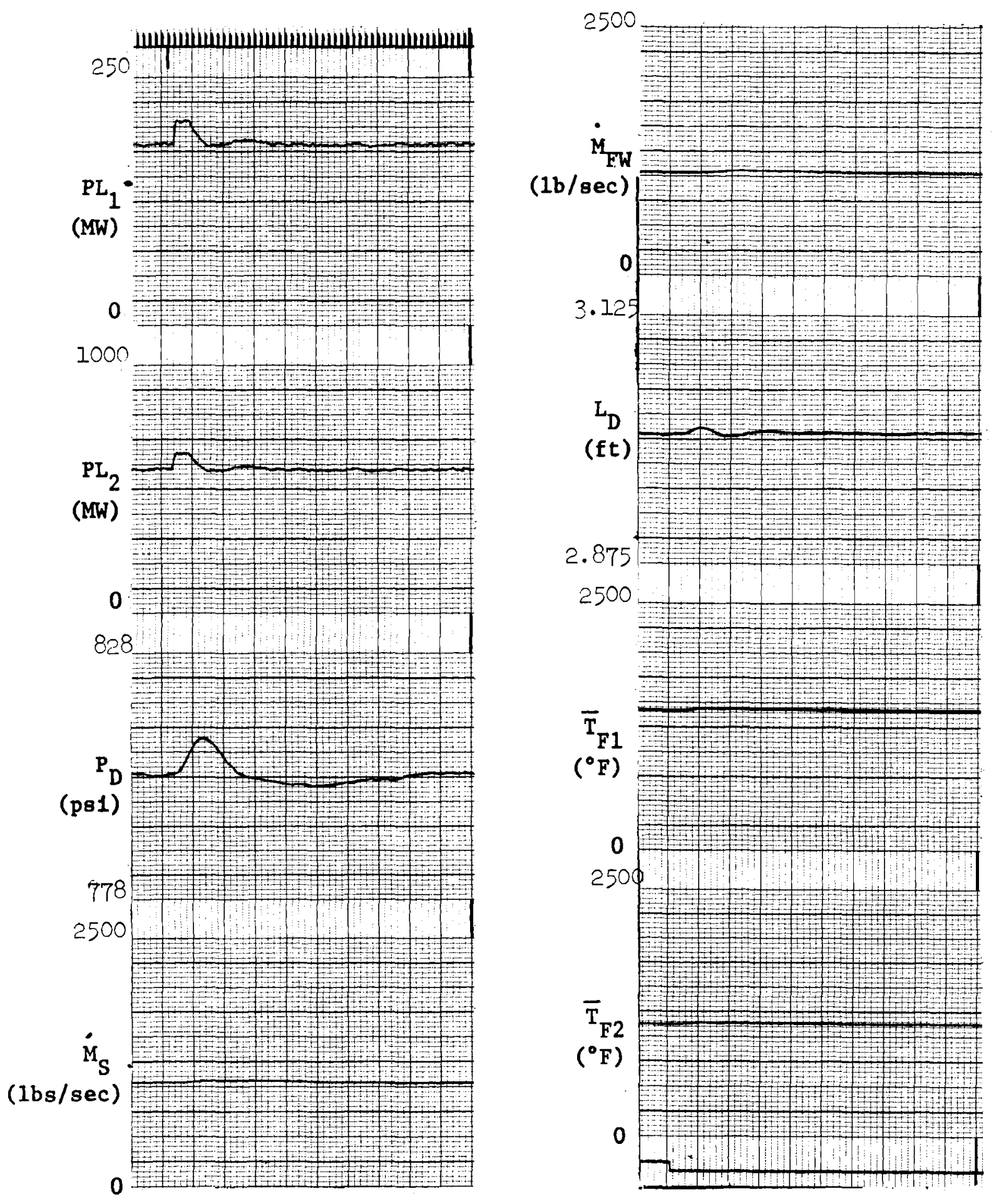

FIGURE 16. BLW-250 System Stabizity (In-Out Model--Uo Fuel--

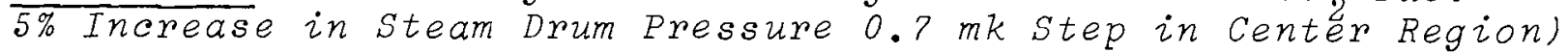



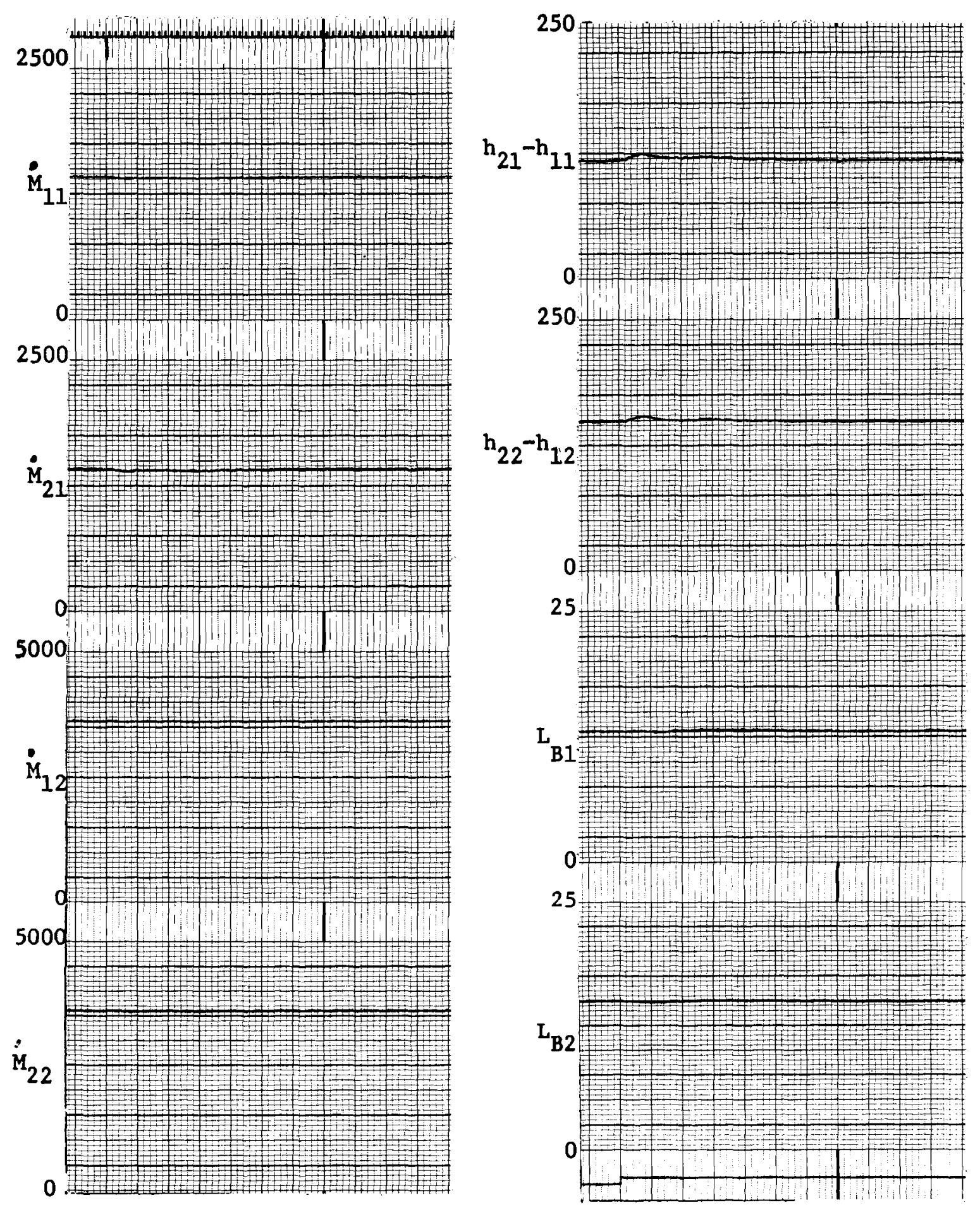

FIGURE 16. (Contd) 


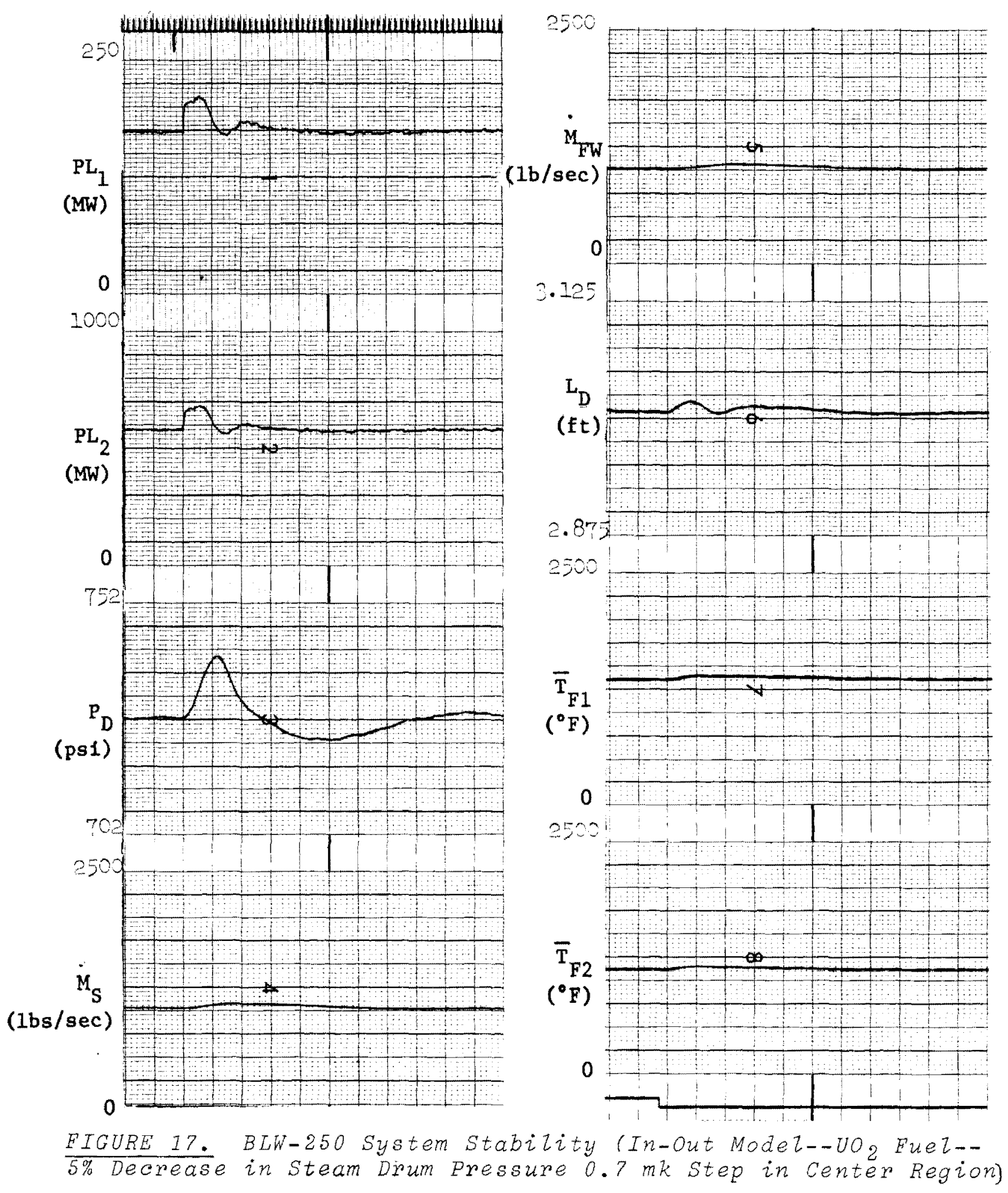



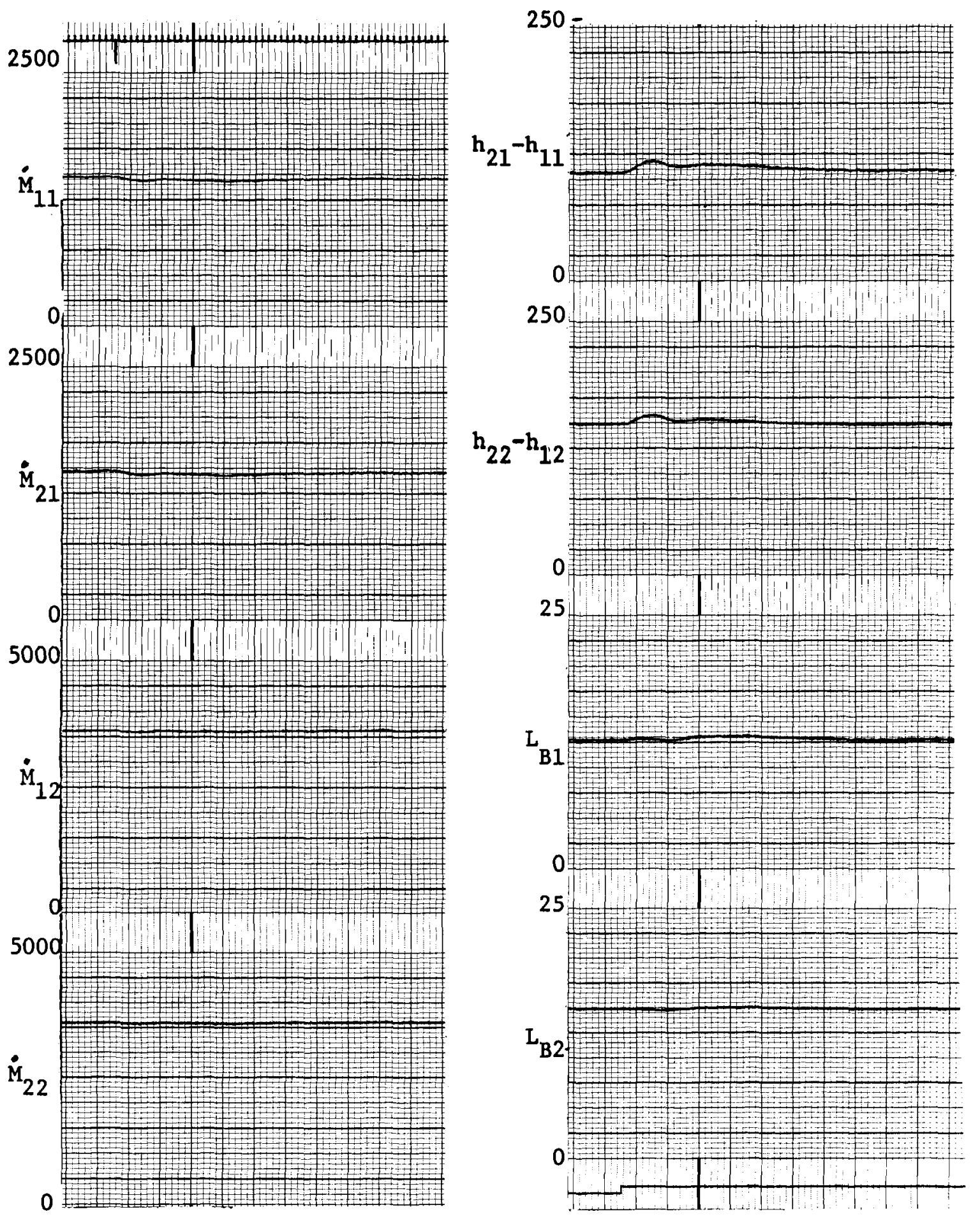

FIGURE 17. (Contd) 

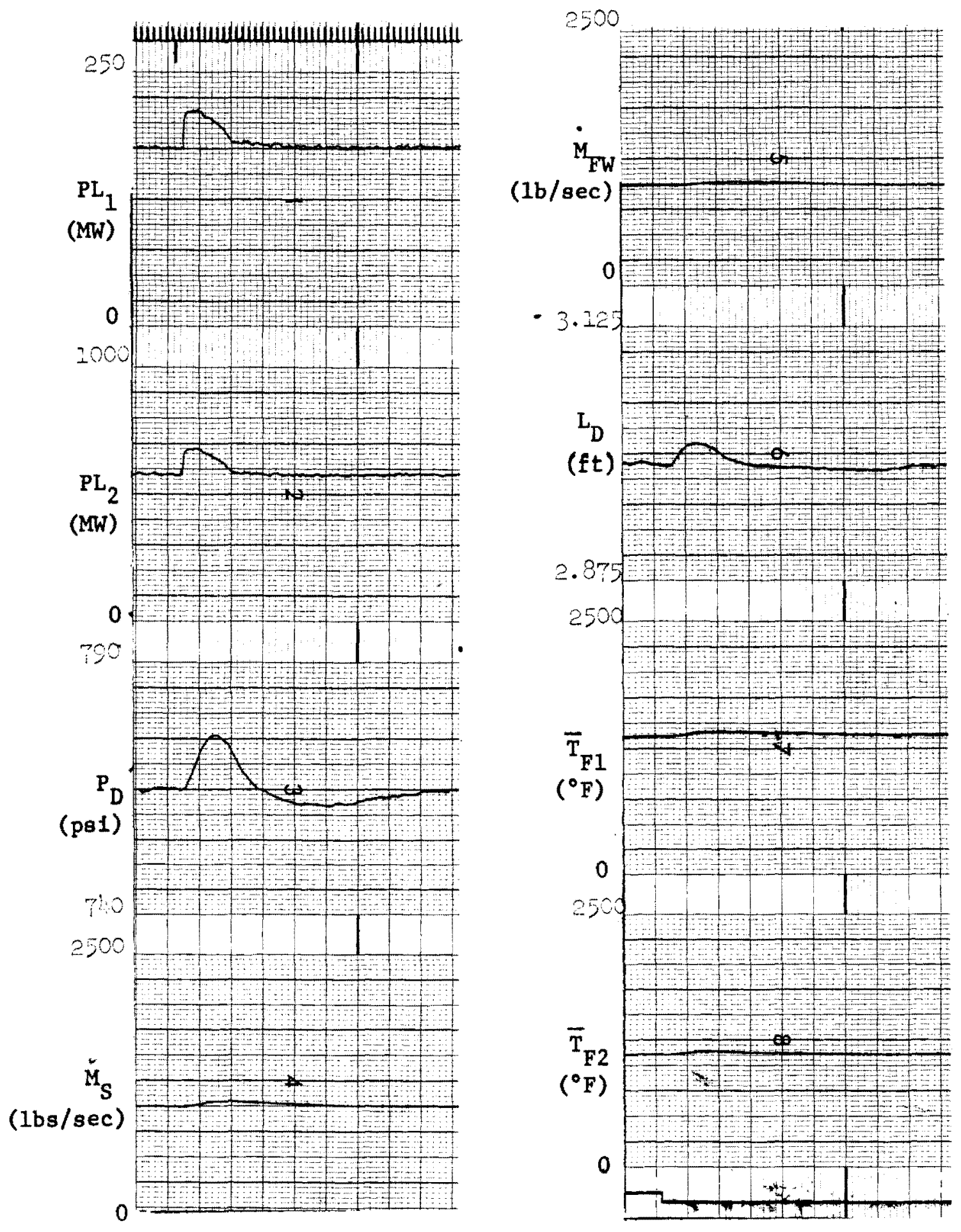

FIGURE 18. BLW-250 System Stabizity (In-Out Model--UO2 Fuel-Steam Lirum $1 / 2$ Size $0.75 \mathrm{mk}$ Step in Center Region) 

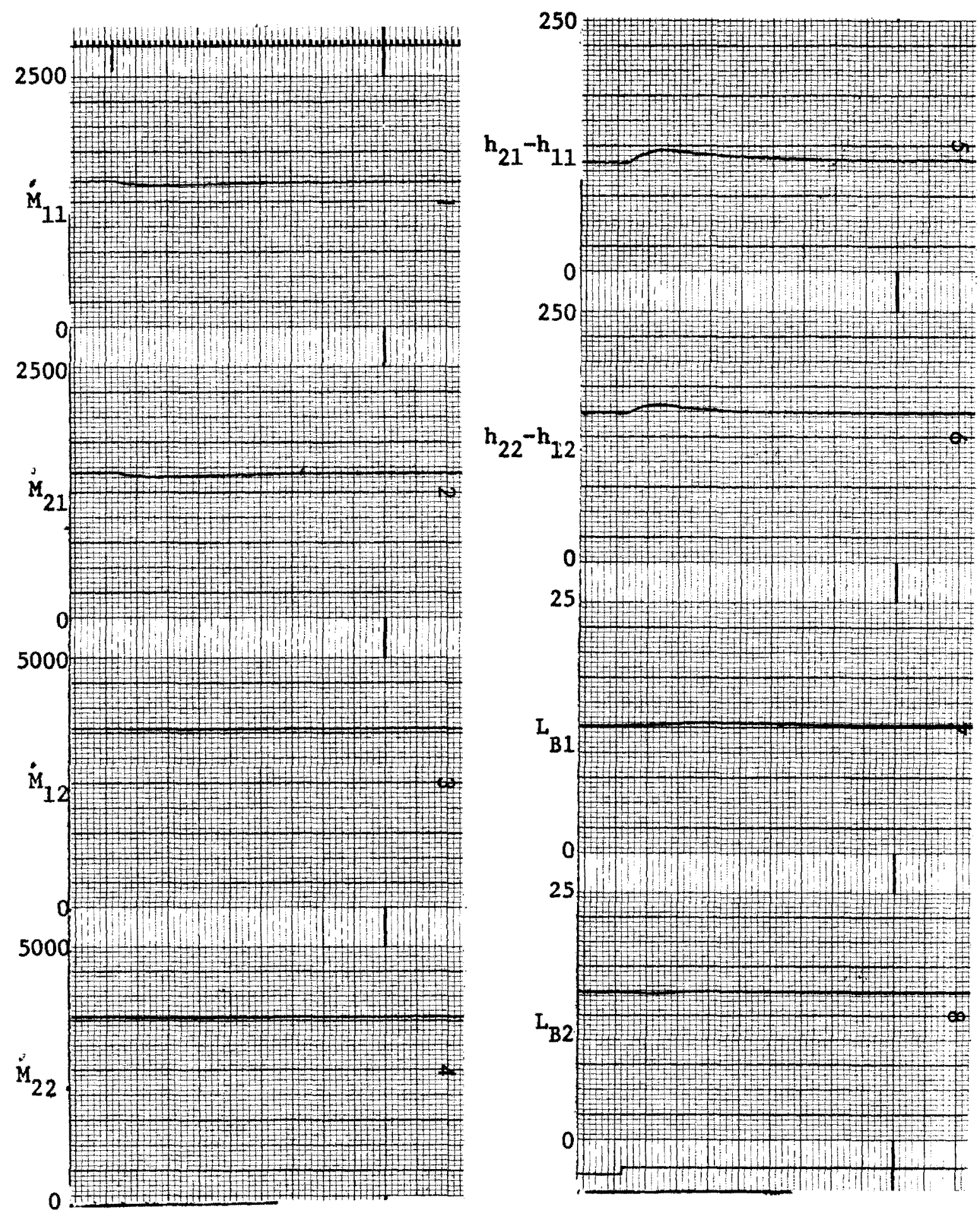

$$
\text { FIGURE 18. (Conta) }
$$



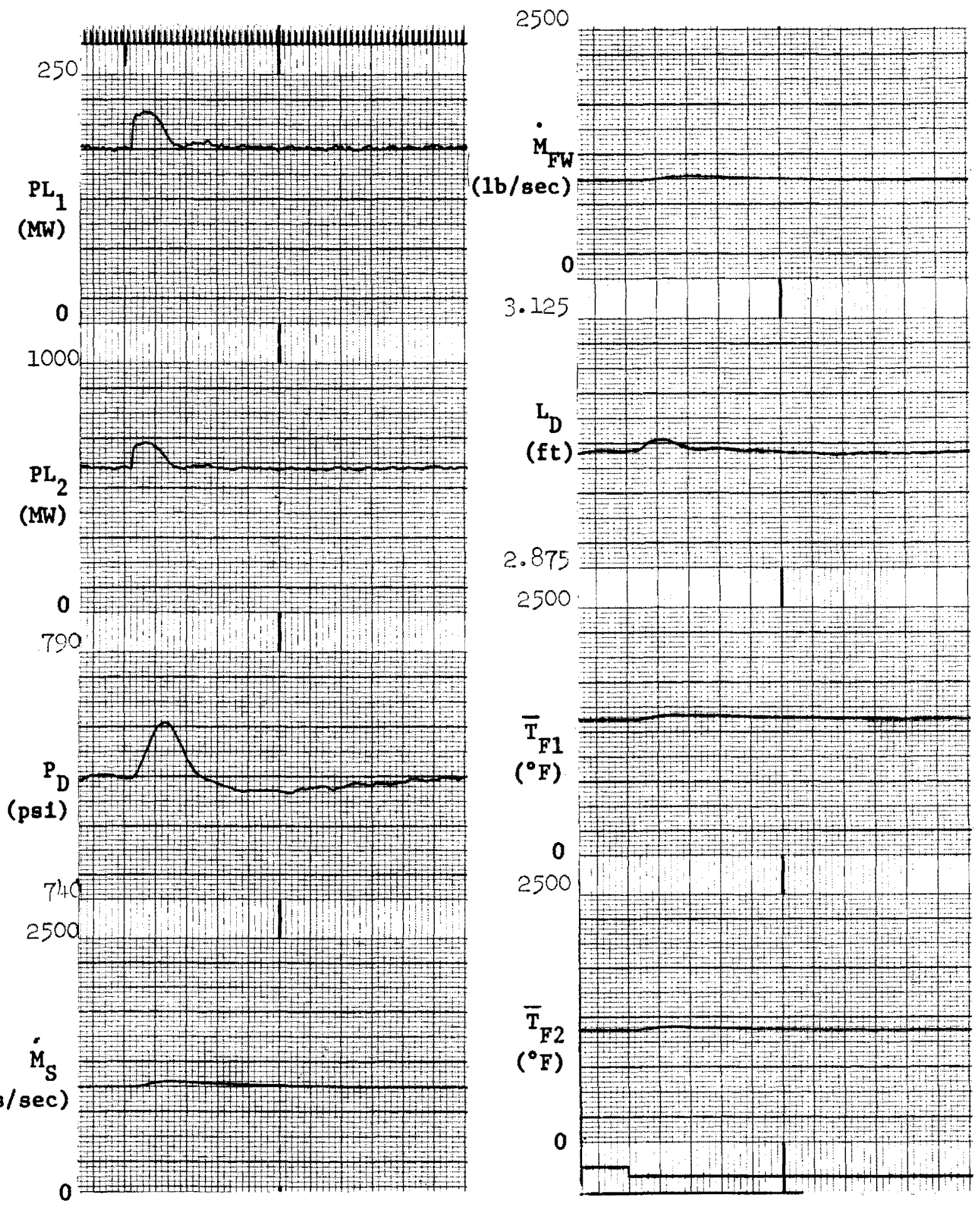

EIGURE 19. BLW-250 System Stability (In-Out Model--UO2 Fuel-All Subcooled Water In Steam Drum $0.75 \mathrm{mk}$ Step in Center Region) 

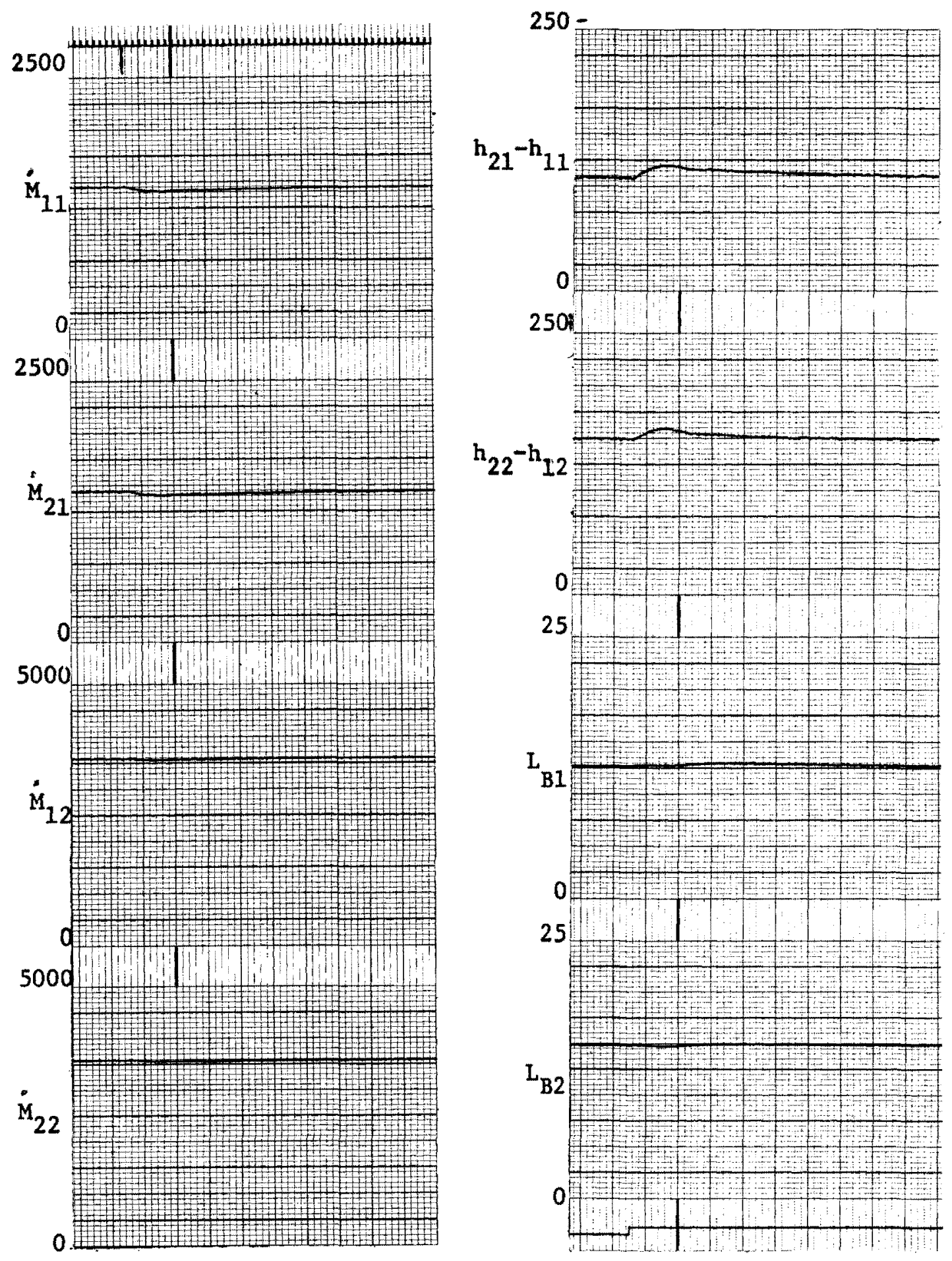

EIGURE 19. (Contd) 

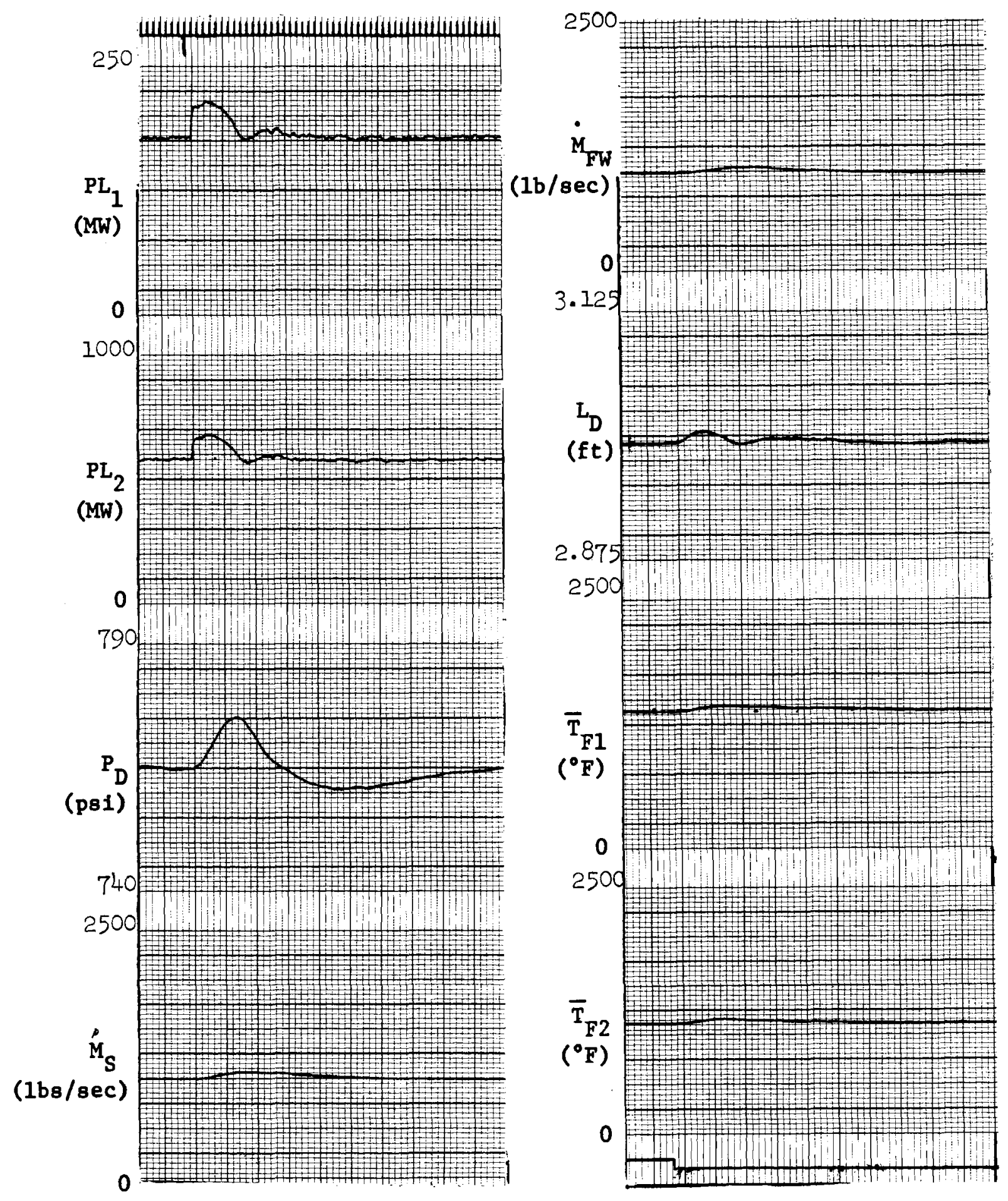

FIGURE 20. BLW-250 System Stability (In-Out Model--Uo Fuel-All Saturated Water In Steam Drum $0.75 \mathrm{mk}$ Step in Center Region) 

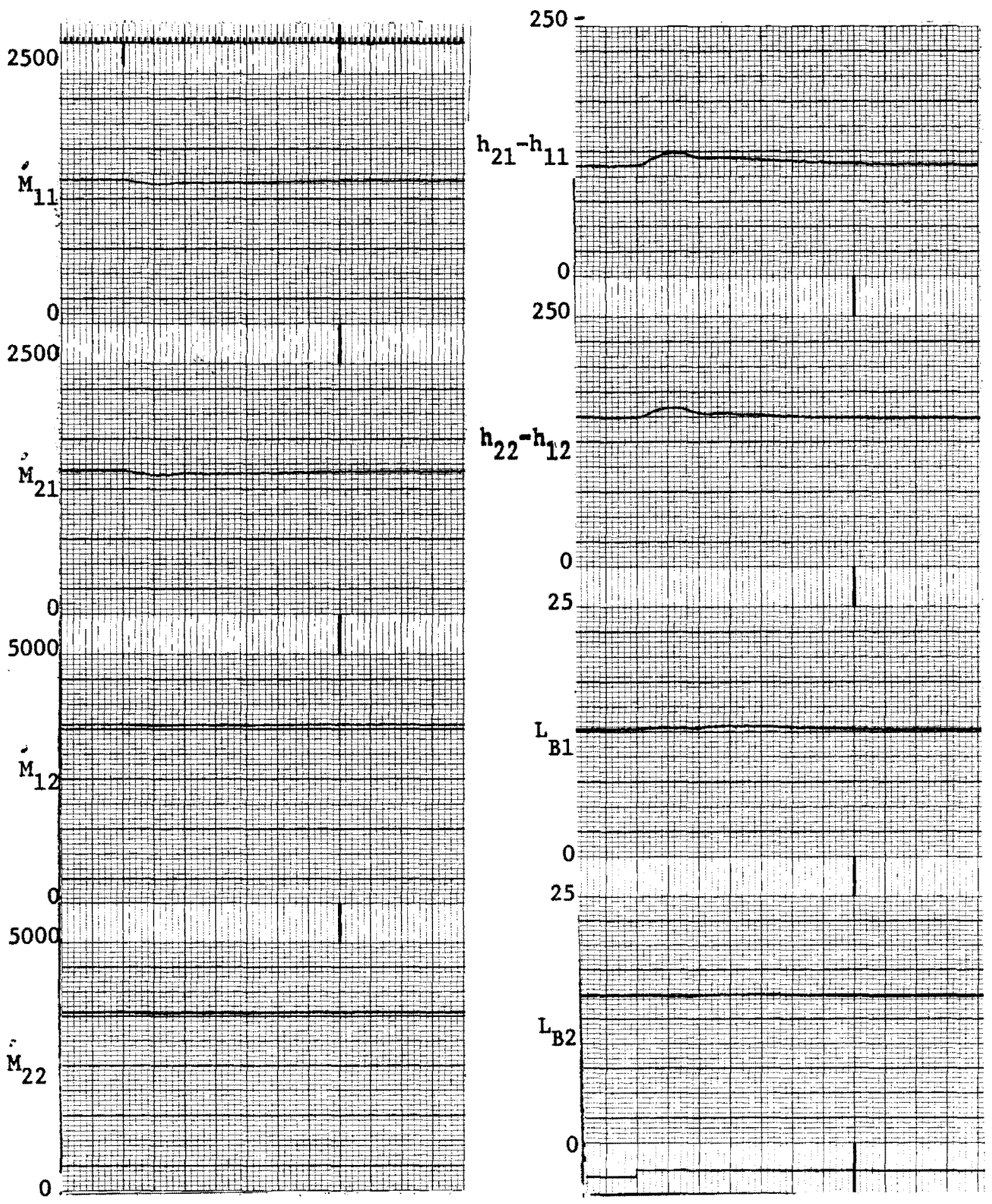

FIGURE 20. (Contd) 

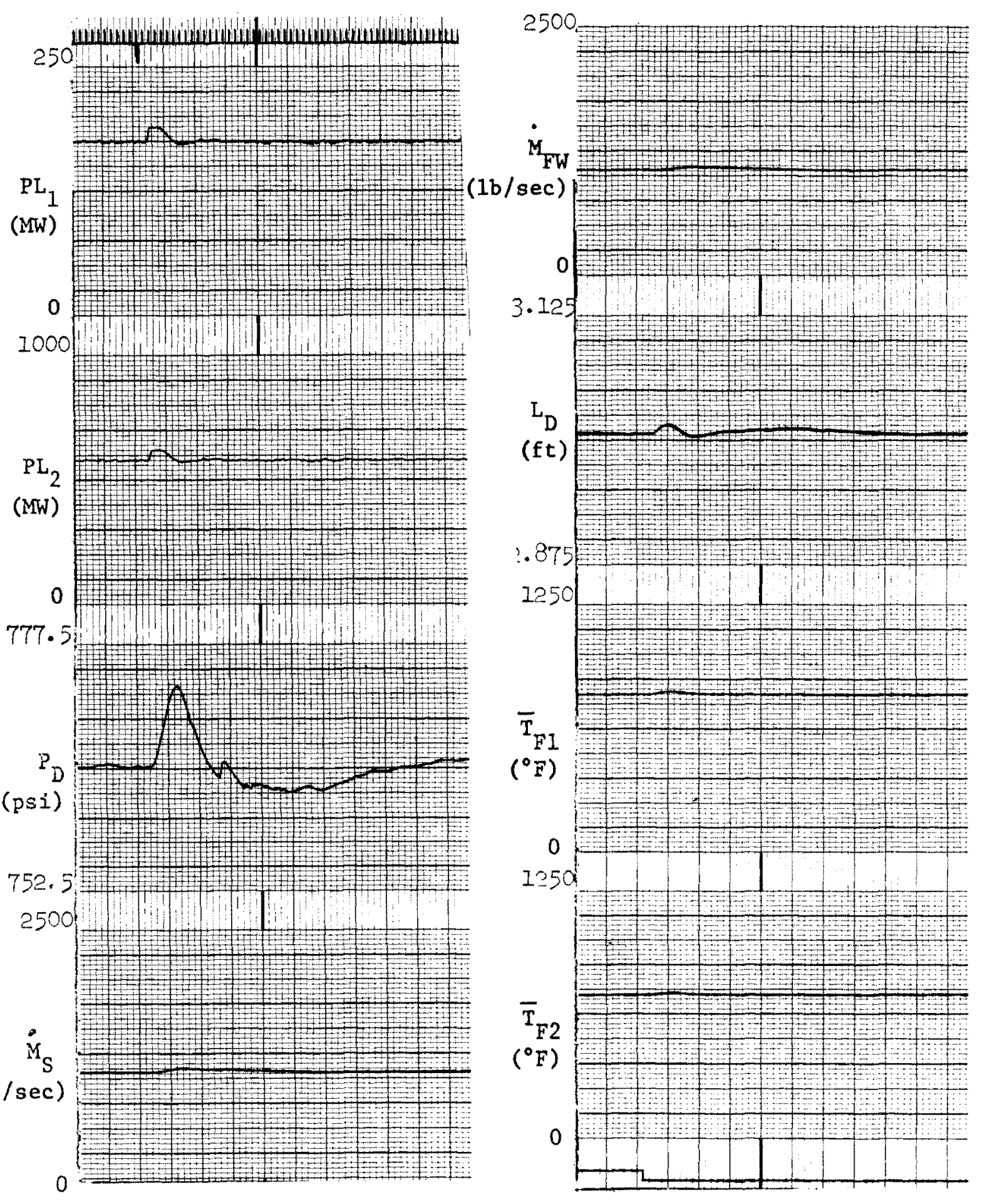

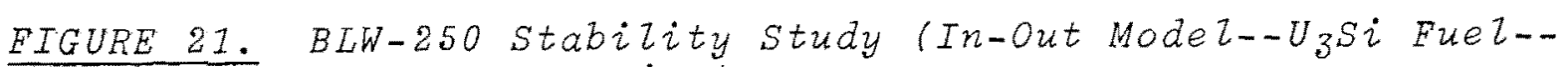
0.5 mk Step In Center Region) 

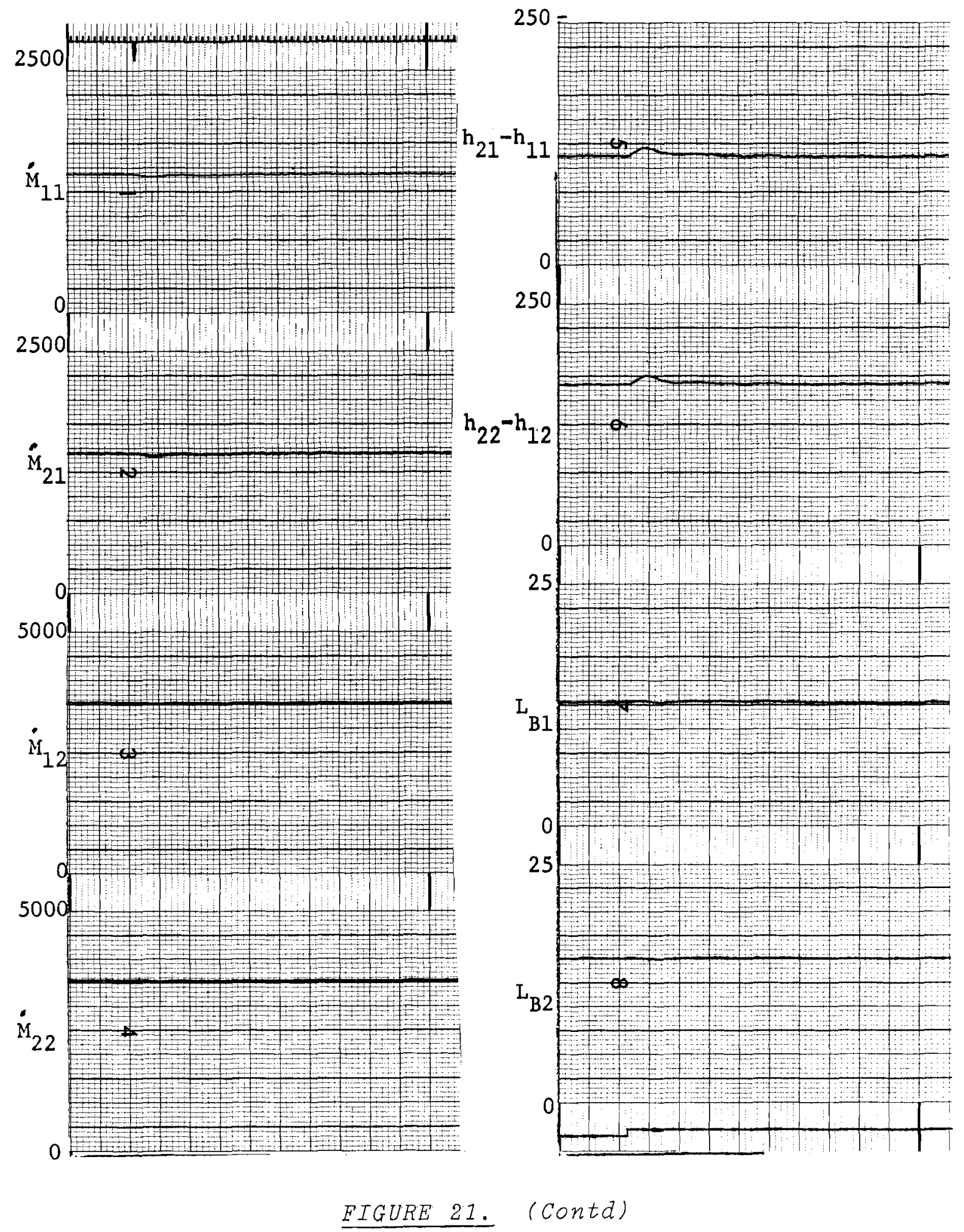

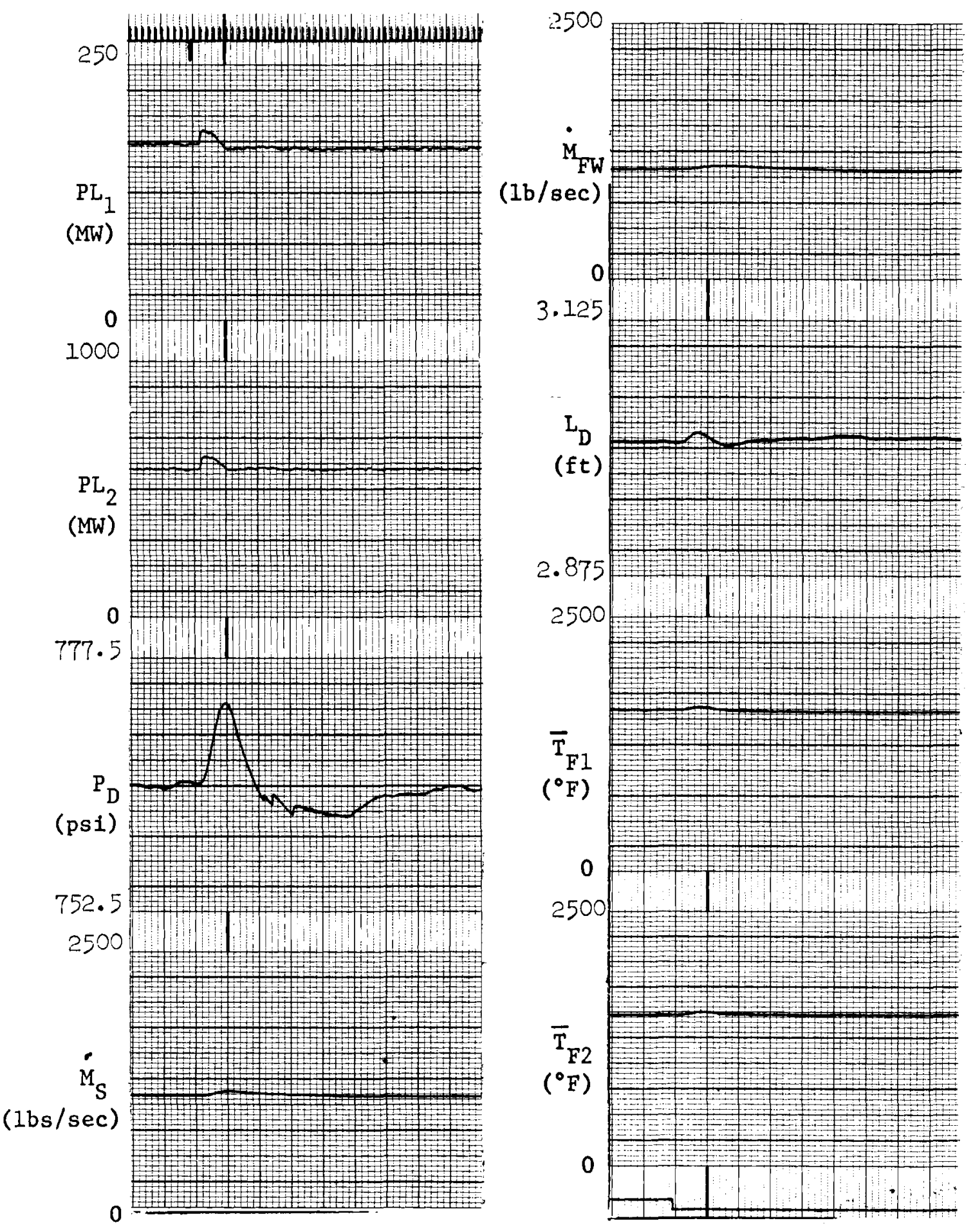

FIGURE 22. BLW-250 System Stabizity (In-Out Moder--U ${ }_{3}$ Si Fuez-$0.5 \mathrm{mk}$ In Outer Region) 

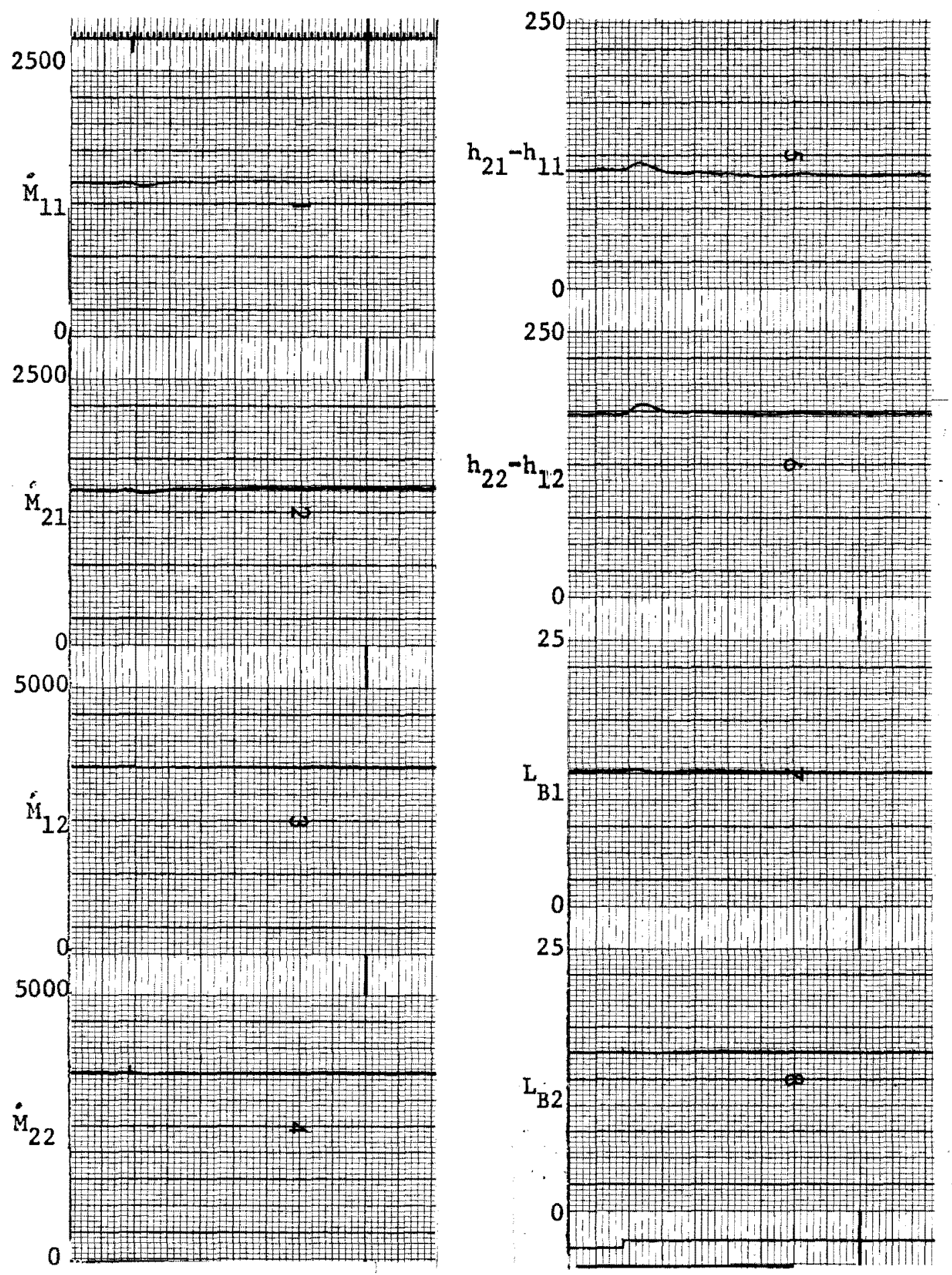

FIGURE 22. (Contd) 


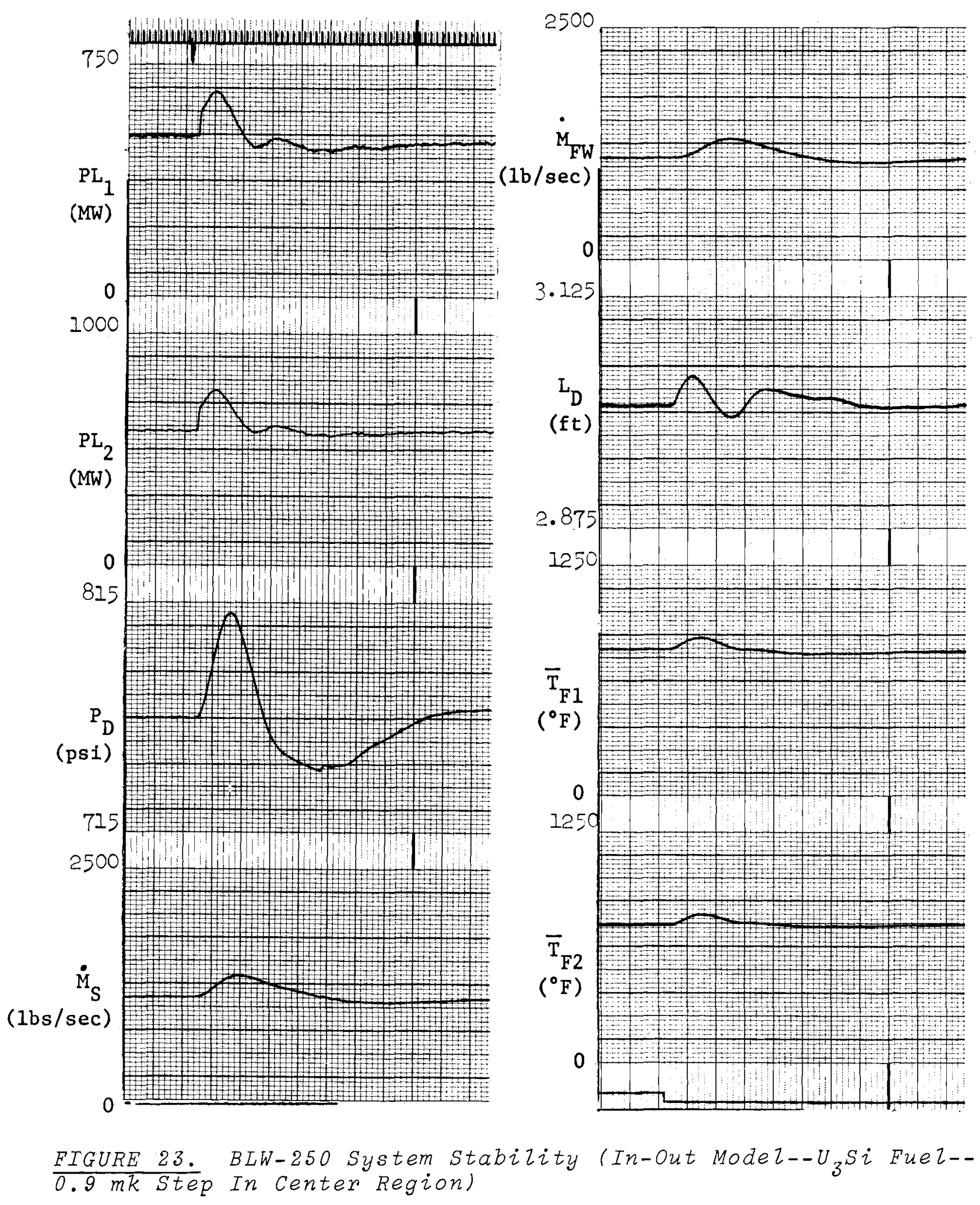



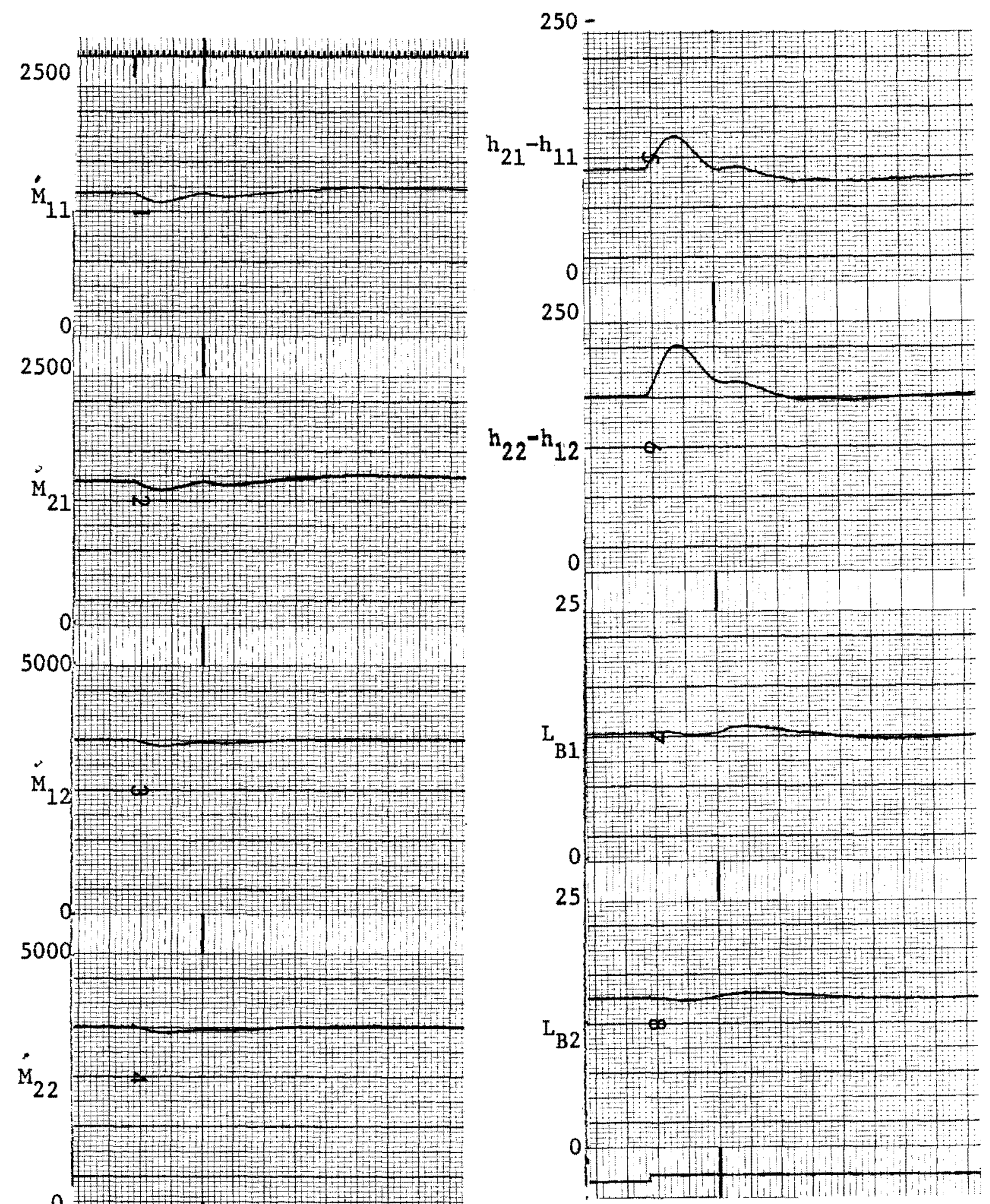

FIGURE 23. (Contd) 
Decoupling between steam drum pressure and coolant density effects was observed to accompany a $4 \%$ step increase in steam demand (Figure 24). The variation in drum pressure was similar to the oxide case, although only a slight variation in reactor power during the transient was noted.

The $\mathrm{U}_{3} \mathrm{Si}$ fueled core was not as sensitive to a reactivity step increase in the center region during a reduced coolant flow (Figure 25) as was the oxide-core.

Results obtained from changing the fuel time constant to simulate uranium metal fuel were indistinguishable from the silicide results (Figures 26 thru 30 ).

It should be noted that a drastic alteration, such as the change from uranium oxide to either uranium silicide or uranium metal fuel would necessitate a reassessment of the regulating system not within the purview of this study. obviously, however, any significant changes to a system requiring a controller for stability may be reflected as changes to the controller.

\section{PHASE 4}

The side-by-side model, as discussed earlier, was developed in order to observe other possible modes of oscillation that could possibly be overlooked with the in-out model. The reactor was divided into halves, and average core nuclear and hydraulic parameters were used to define each half.

No oscillations were observed between halves of the reactor in any of the cases studied. The fact that the model behaved much like two strongly coupled point-kinetics models did provide the opportunity for more directly comparing the present method to the point model than to the in-out model. Referring to the results quoted earlier for the point model, it is seen (Figure 31) that excellent agreement was obtained between the two models. Both the magnitude and duration of the transient were in good agreement. 


\section{CORRIGENDA}

The reactivity coefficients, $\alpha$, appearing in Equation (32) are regional coefficients describing the change in reactivity of the whole reactor due to a perturbation in the mth region. In the present study, the values of these coefficients were determined from calculations of the change in system reactivity associated with a perturbation over the whole reactor. The weighting of these latter coefficients as required to convert them to regional coefficients, however, was not done. The effect is to make the BLW-250 appear less stable than it actually is, since the coolant density coefficient is too $1 \mathrm{arge}$ and this term dominates in Equation (32). Consequent1y, the results presented in the present report are actually conservative with regard to stability of the BLW-250.

\section{ACKNOWLEDGEMENTS}

The authors gratefully acknowledge the technical and administrative assistance of D. B. Primeau (AECL) and J. C. Fox (PNL) during the course of this work. Thanks also are due C. R. Cole who assisted in operation of the computer and preparation of results for the final report; W. L. Purcell of the Analytical Physics Unit (PNL) for modifying the computer code HFN to allow calculation of coupling coefficients; and W. R. Cooper (AECL) for visiting PNL to assist in checking the simulation, and for his review of this report. 
BNWL - 574

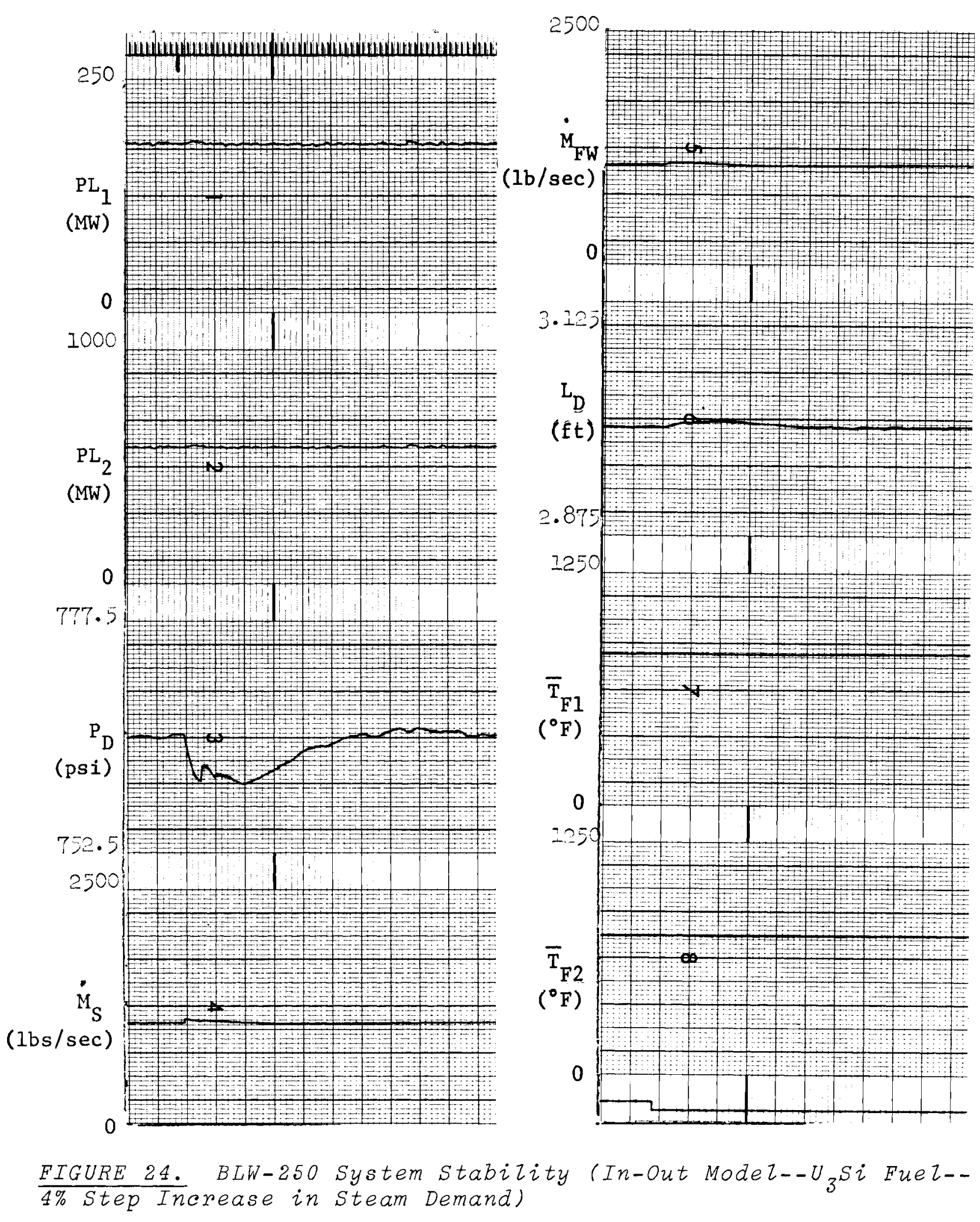



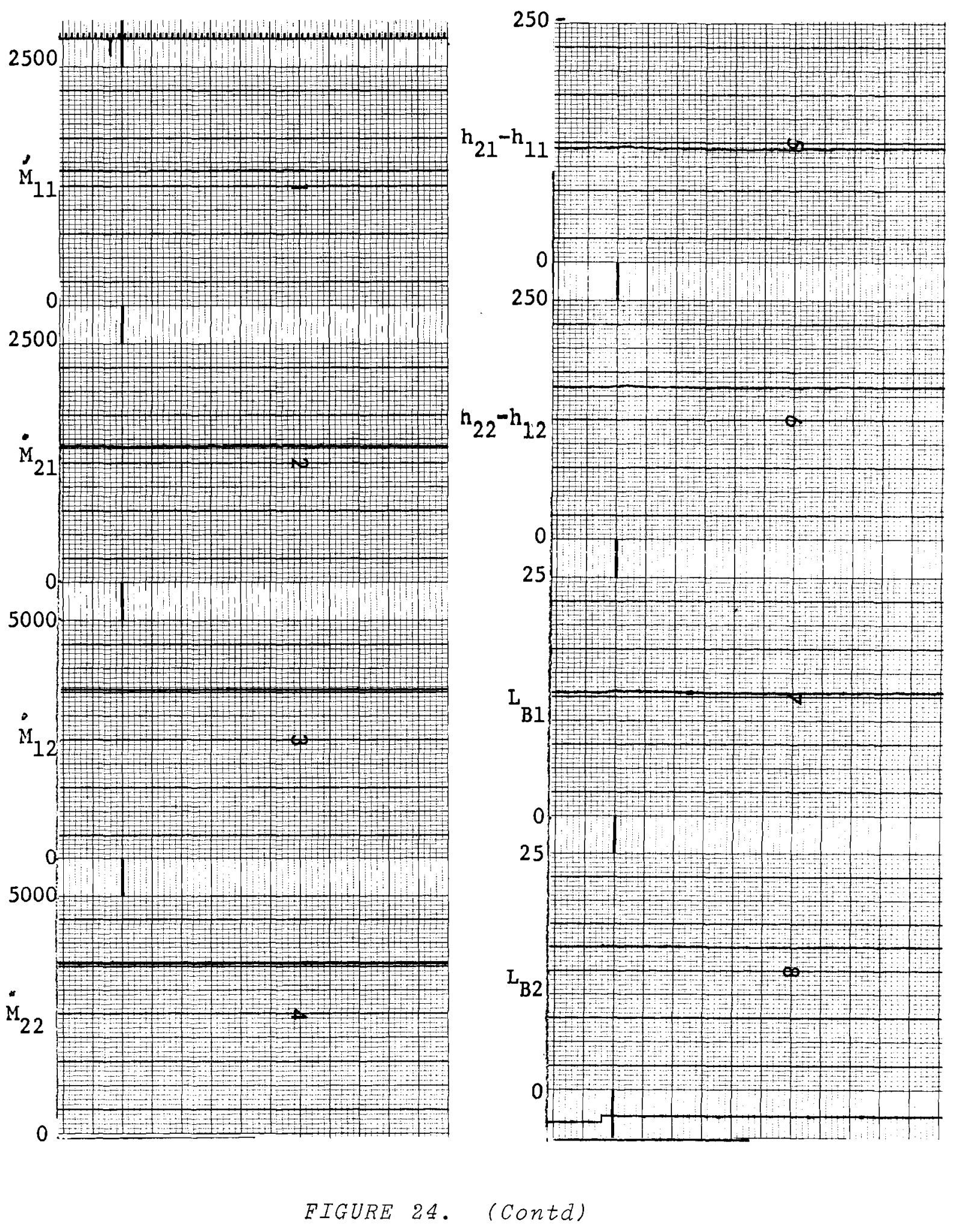

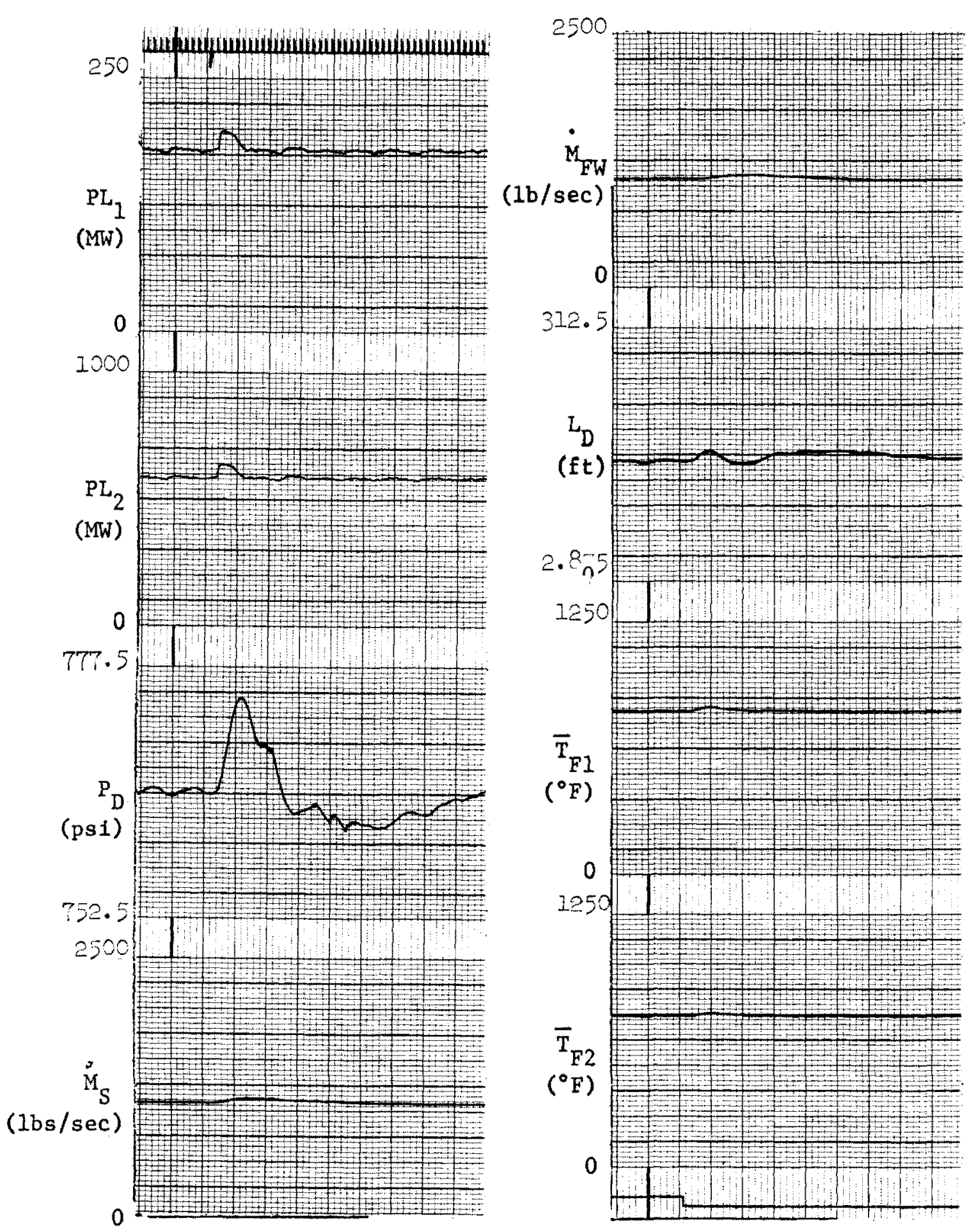

FIGURE 25. BLW-250 system Stabizity (In-Out Model--U Si Fuel-Flow In Core Reduced 10\% $0.5 \mathrm{mk}$ Step In Center Region' 

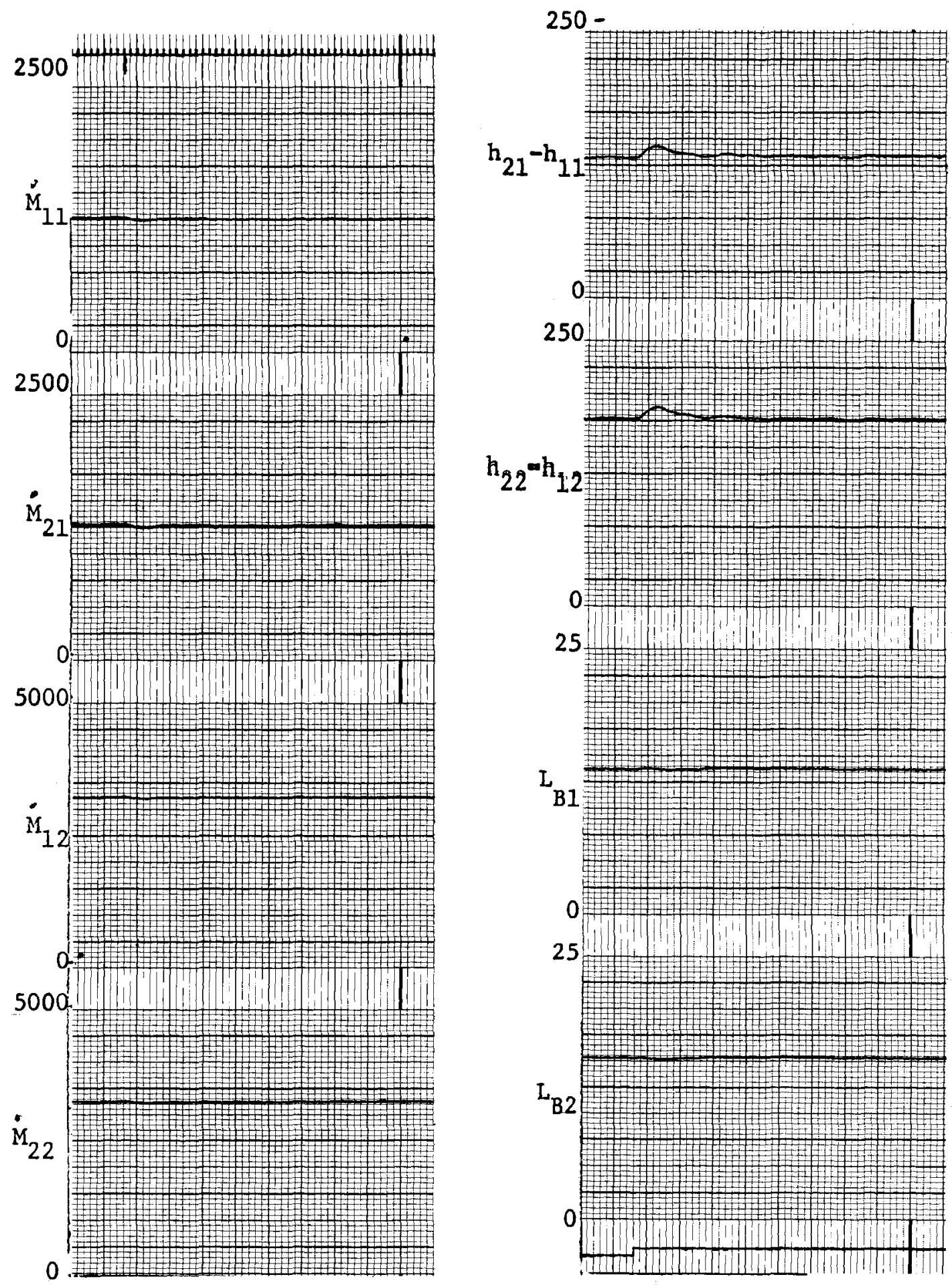

FIGURE 25. (Contd) 

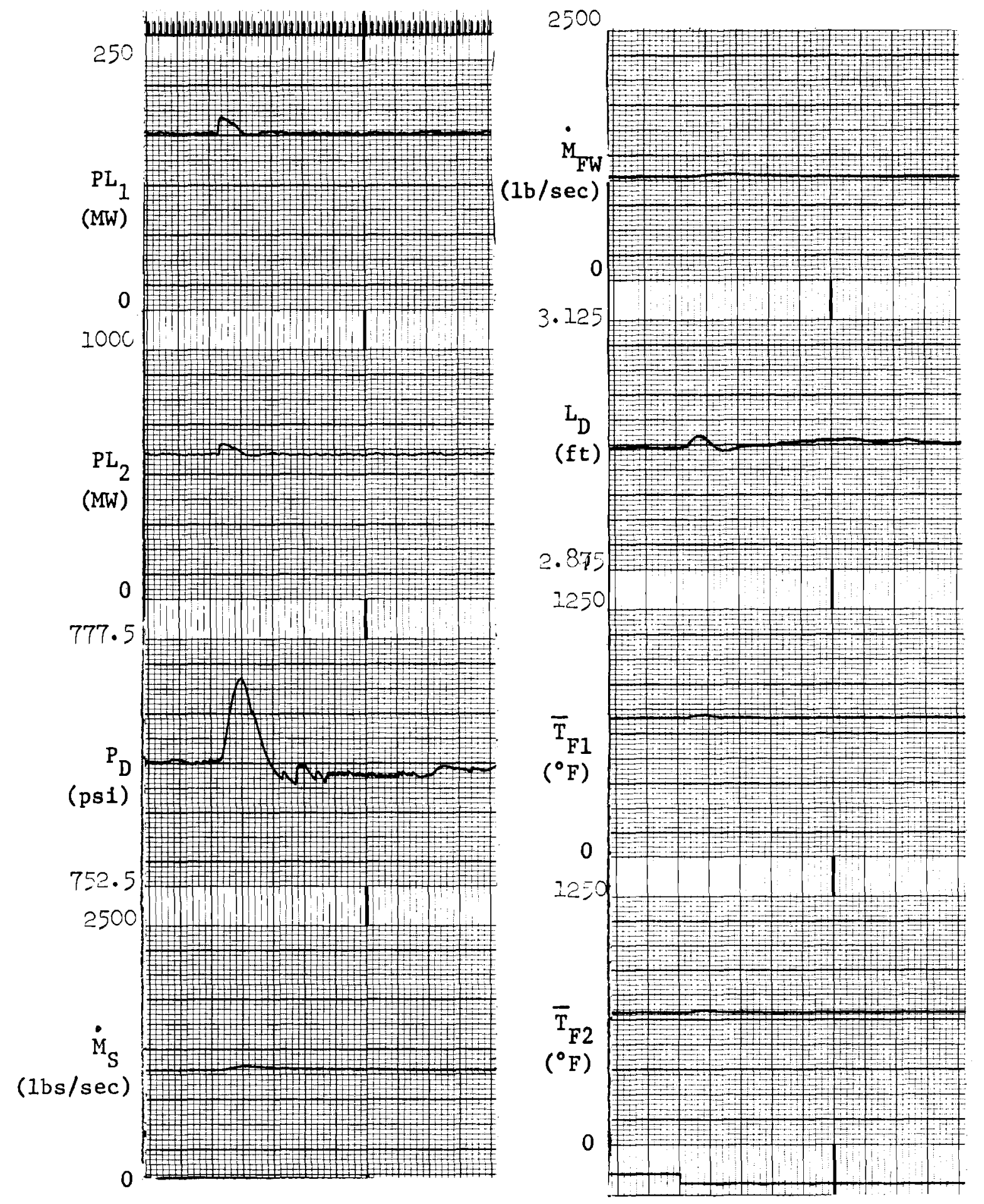

EIGURE 26. BLW-250 System Stability (In-Out Model--Uranium Metal Fuel $0.5 \mathrm{mk}$ Step In Center Region) 

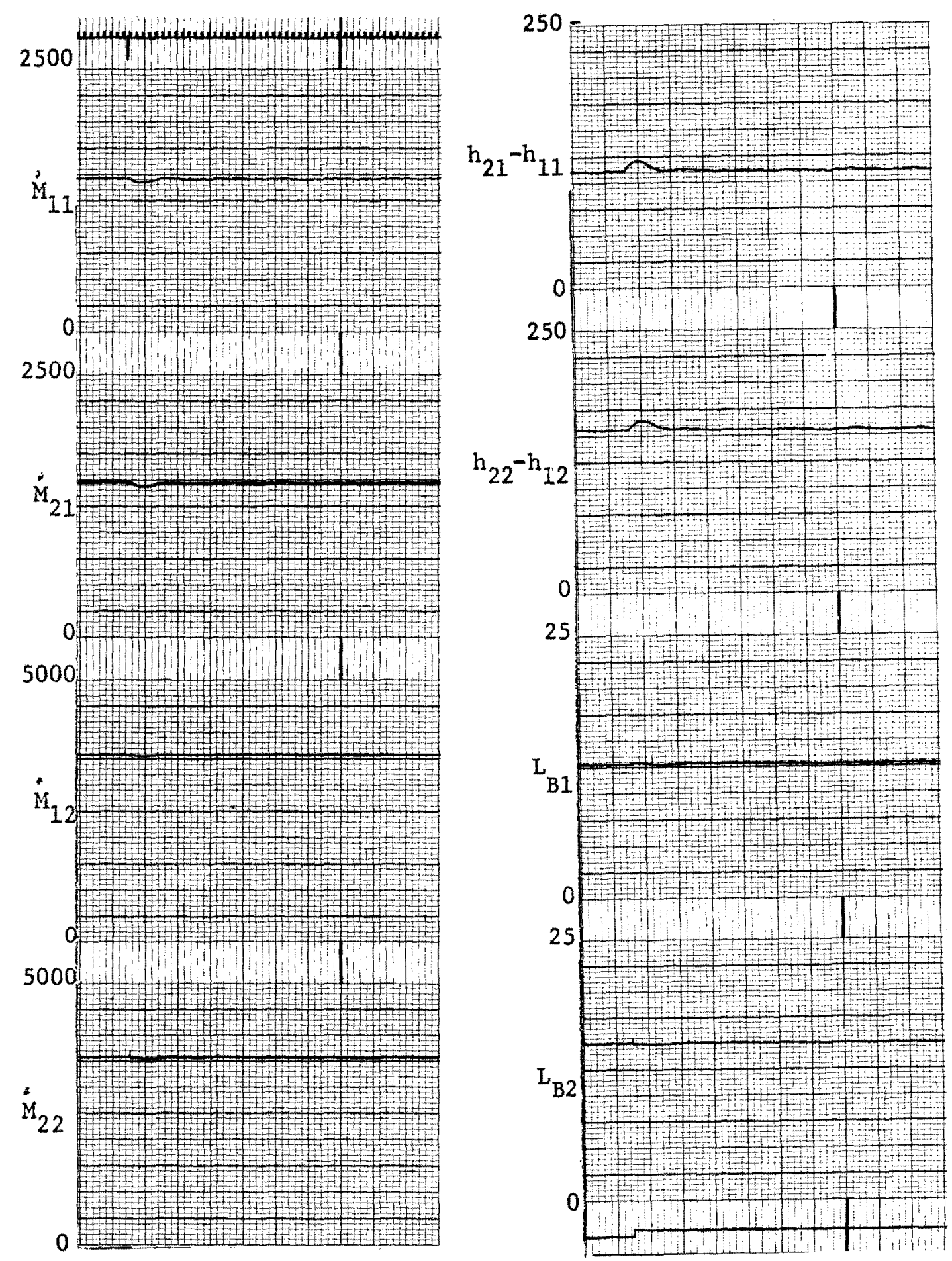

FIGURE 26. (Contd) 

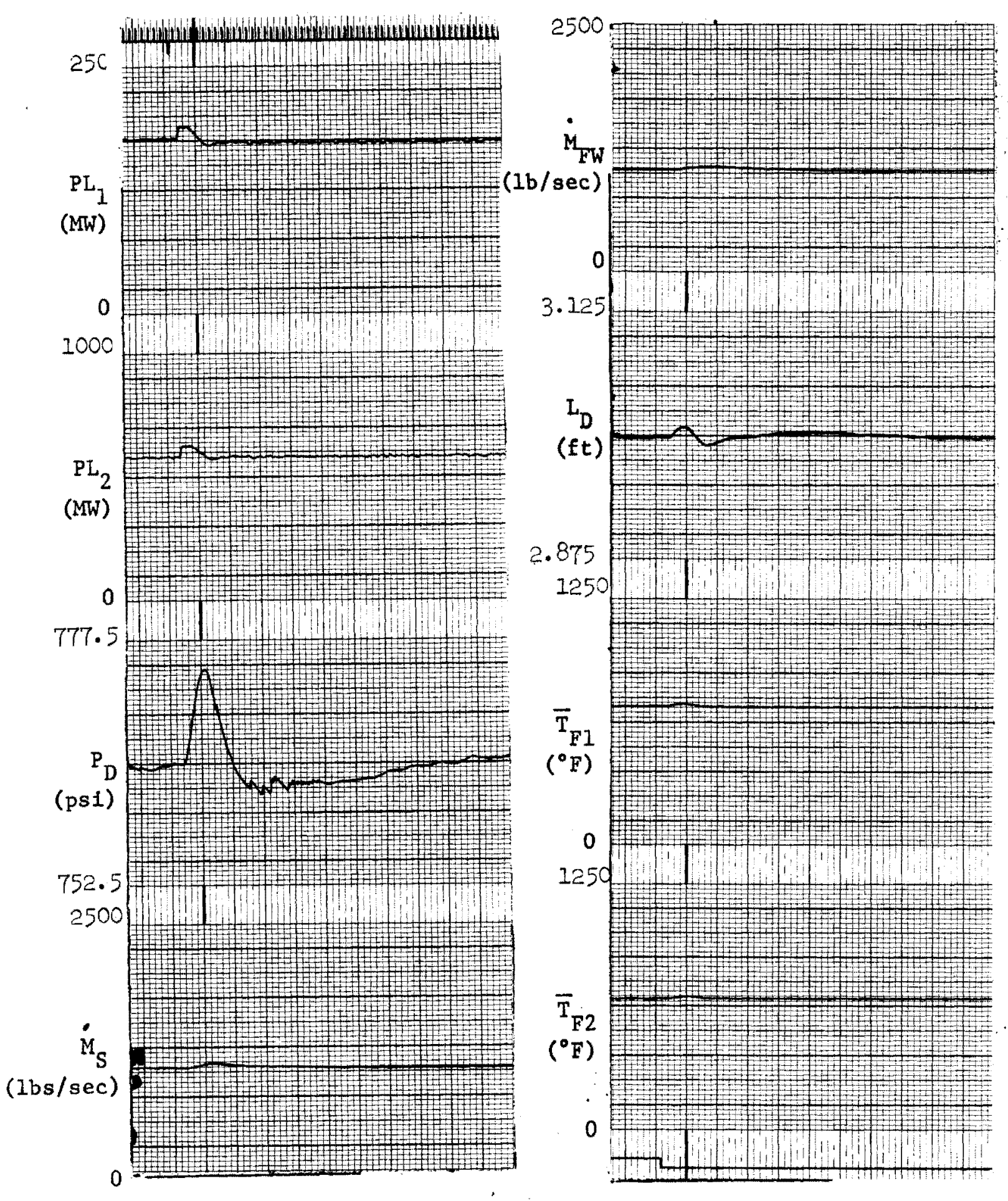

FIGURE 27. BLW-250 System Stability (In-Out Model--Uranium Metal Fuel $0.5 \mathrm{mk}$ Step In Outer Region) 

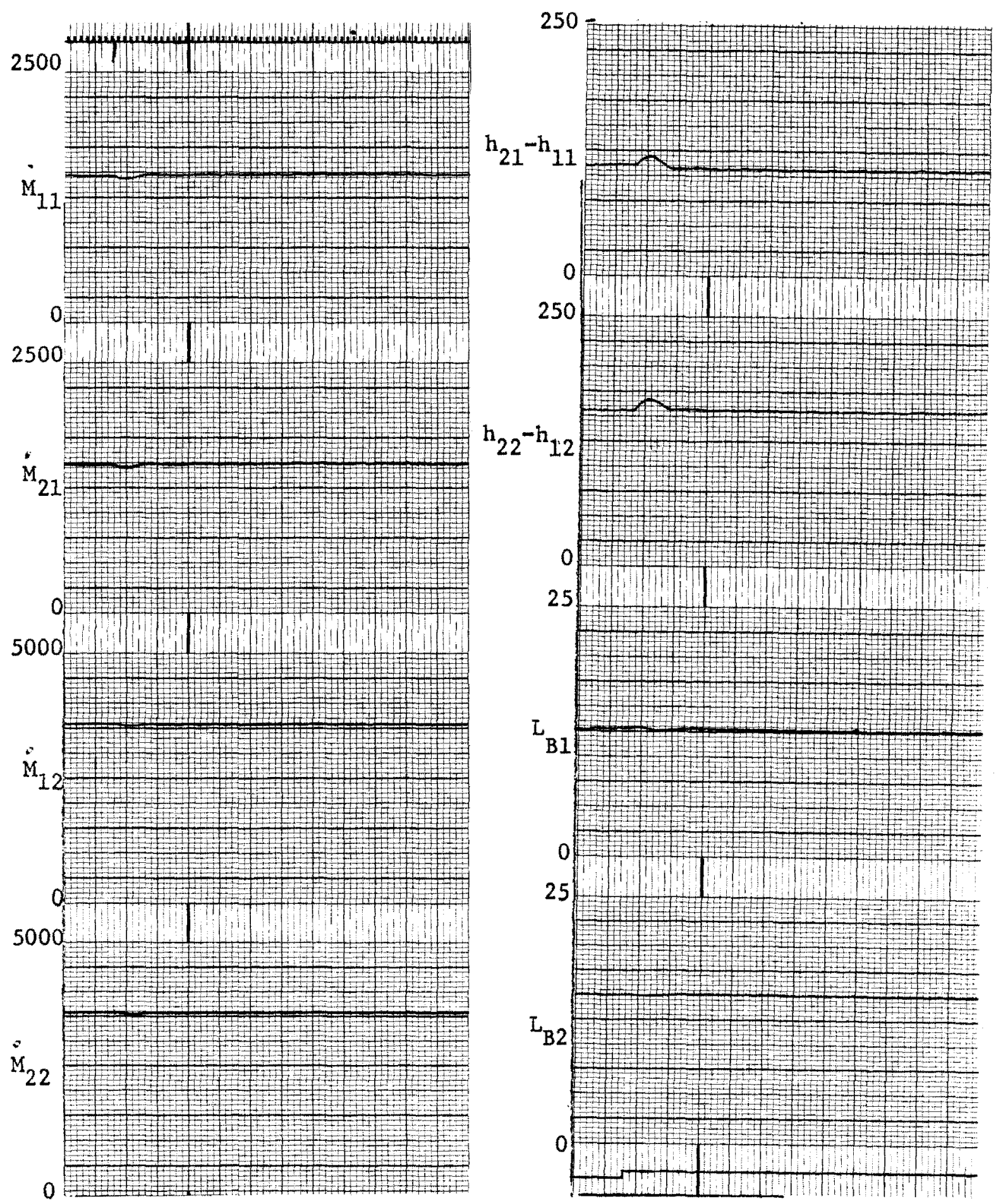

FIGURE 27. (Contd) 


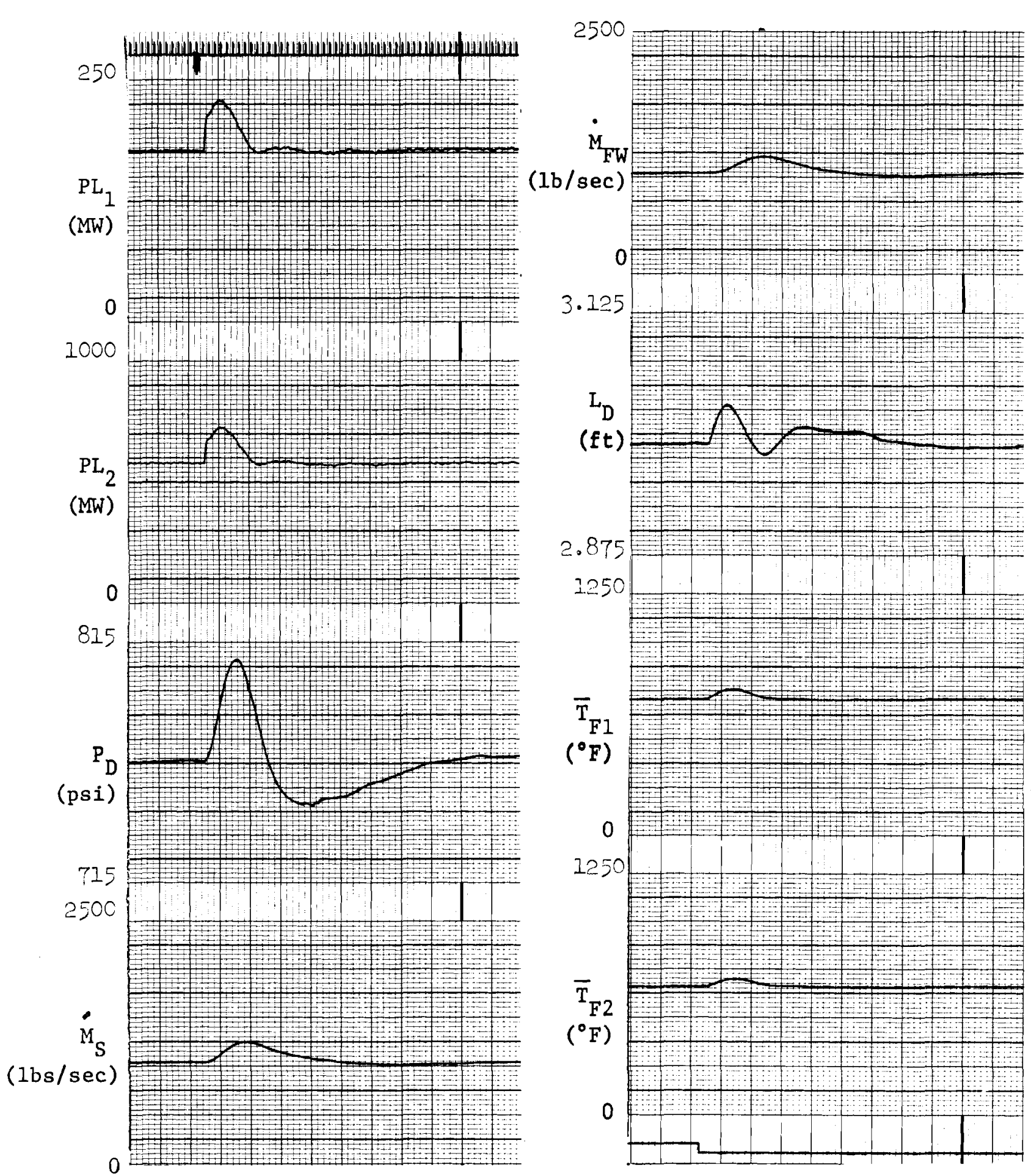

FIGURE 28. BLW-250 system stability (In-Out Model--Uranium Metal Fuel $1.0 \mathrm{mk}$ step In Center Region) 

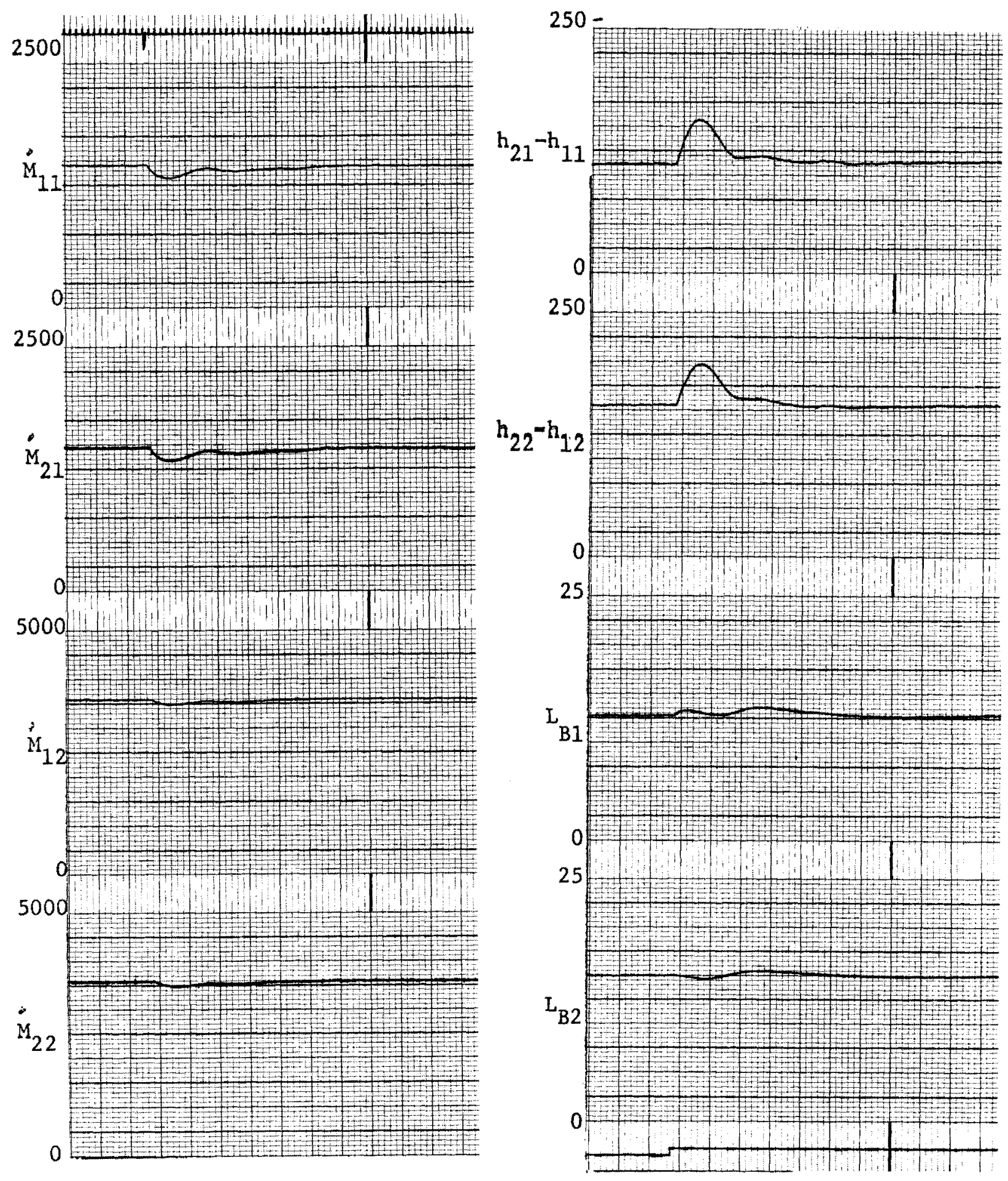

FIGURE 28. (Contd) 


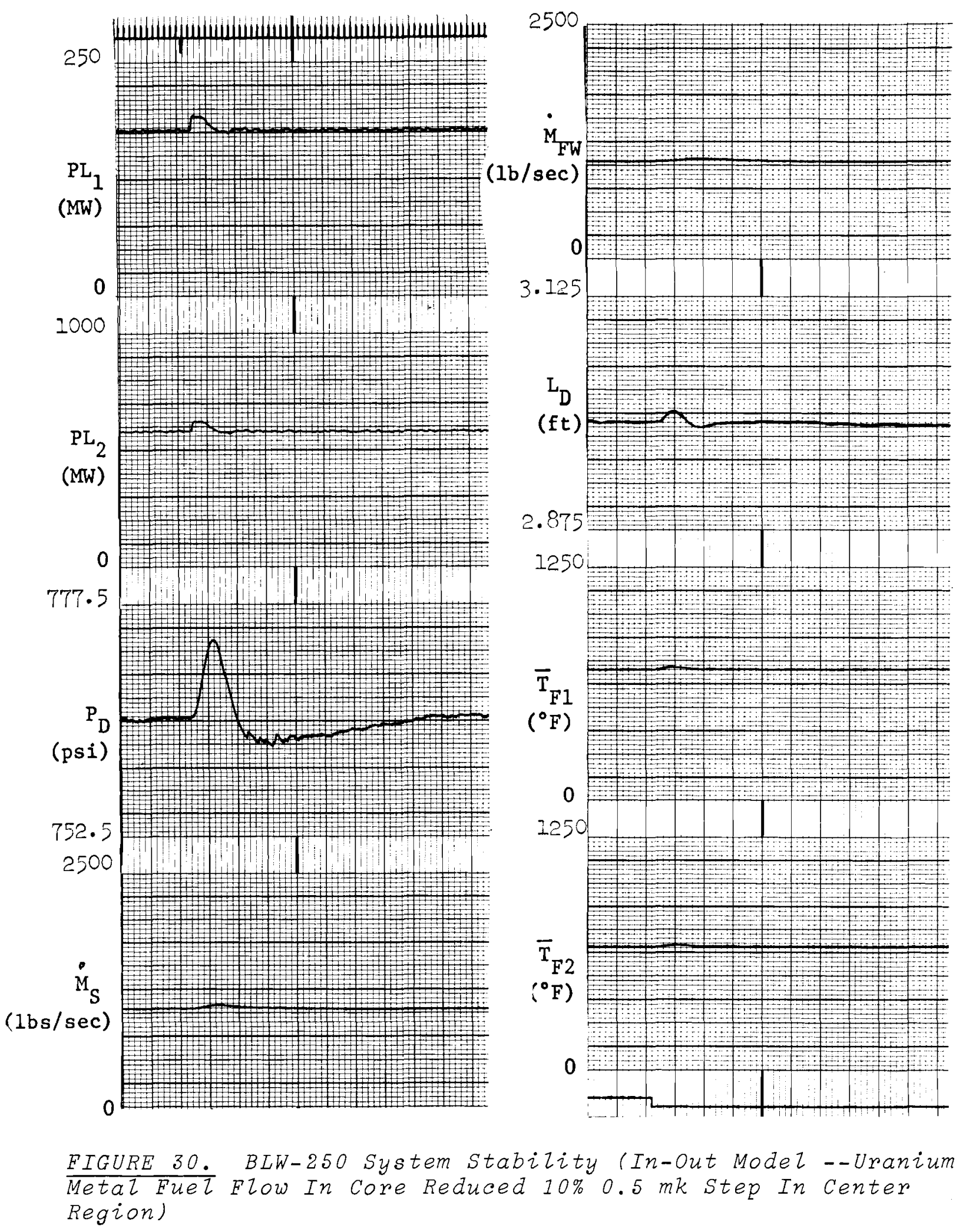




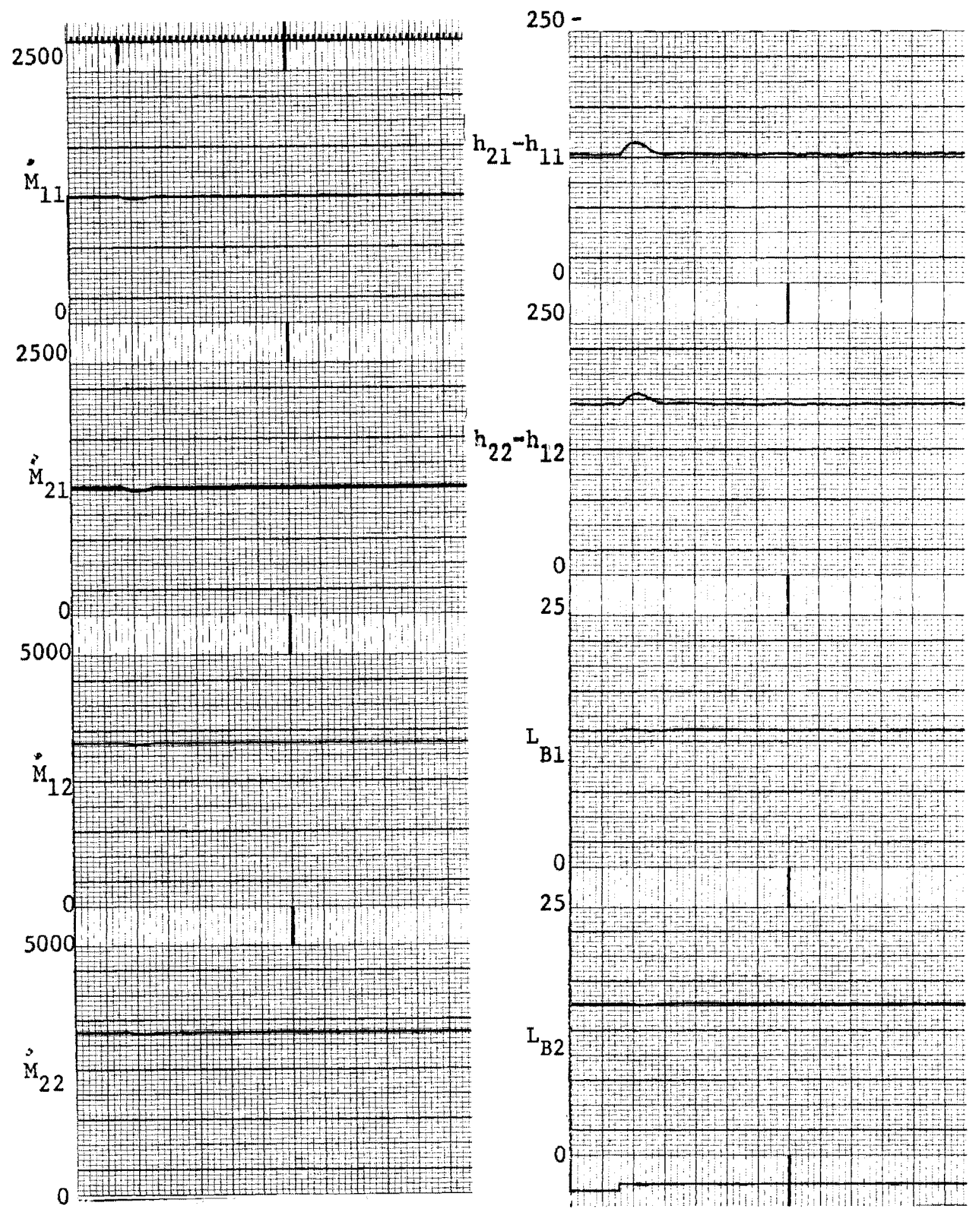

FIGURE 30. (Contd) 


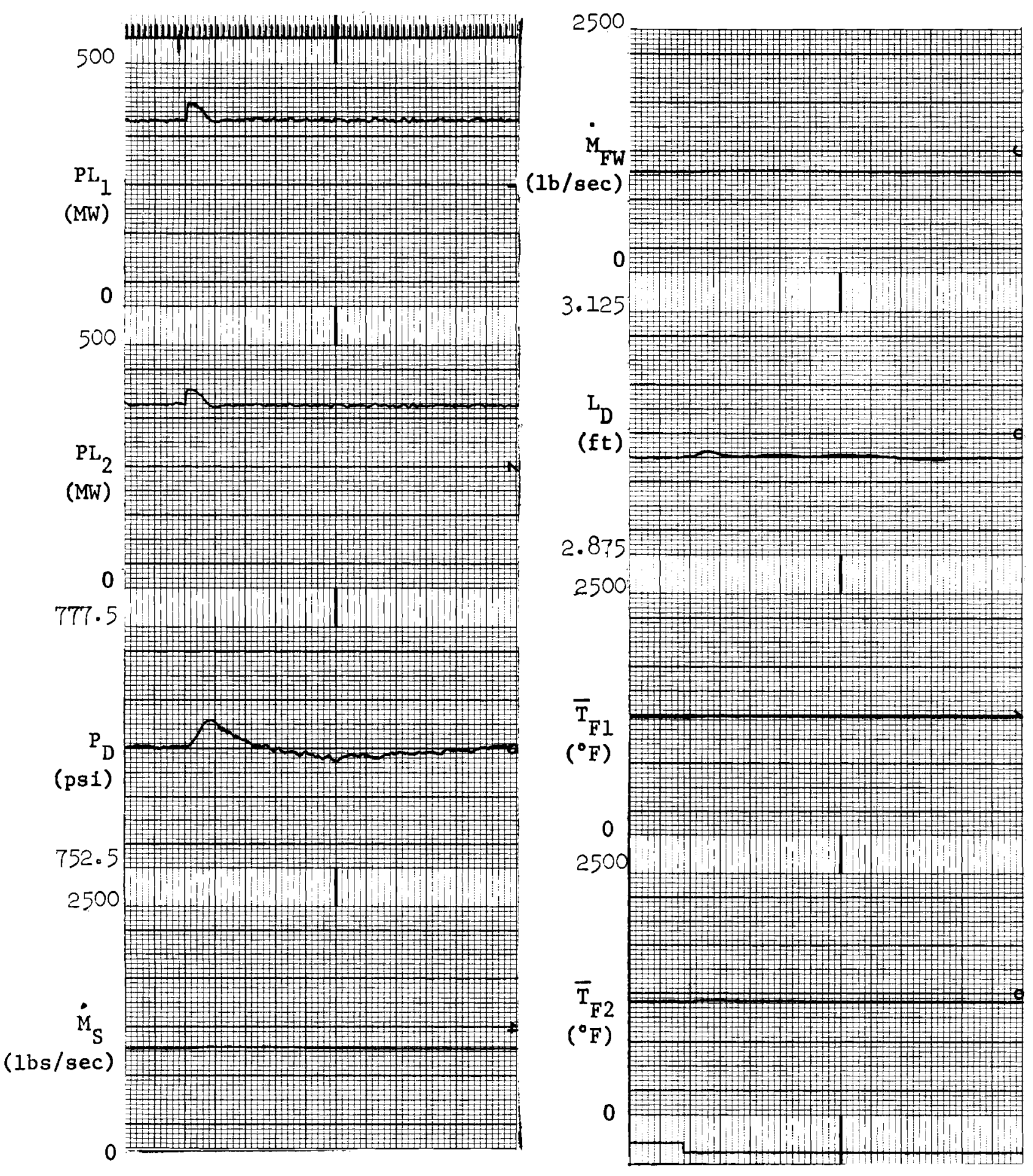

FIGURE 31. BLW-250 System Stability (Side-by-Side Model-$\mathrm{UO}_{2}$ Fuel - $0.5 \mathrm{mk}$ Step In one Region) 

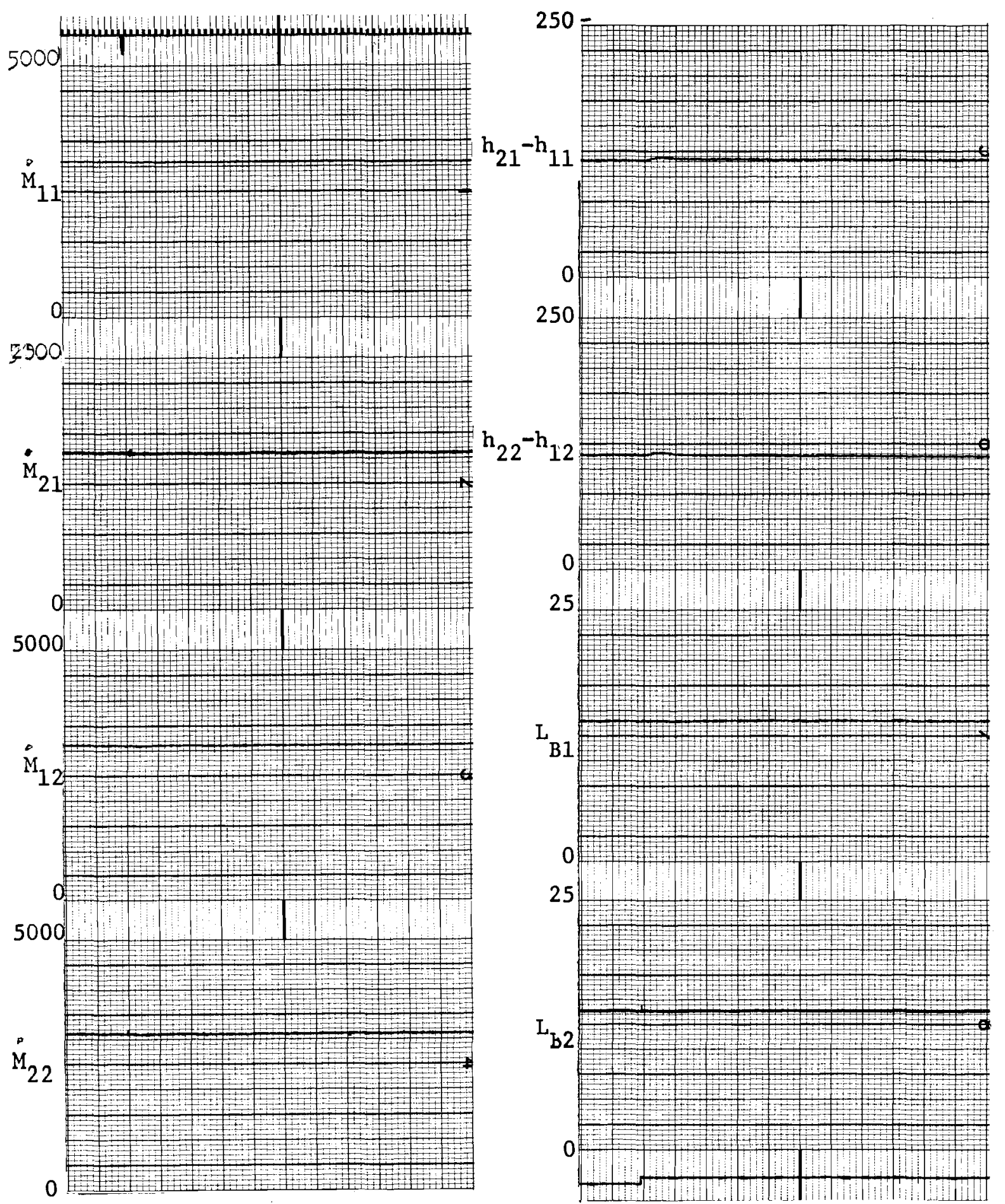

FIGURE 31. (Contd) 


\section{REFERENCES}

1. G. A. Pon, CANDU-BLW-250 Progress Report, 66-CNA-302, May 1966.

2. D. B. Primeau, Unpublished Data, AECL, 1965.

3. A. N. Nahavandi and R. F. Von Halzen, "A Space Dependent Dynamic Analysis of Boiling Water Reactor Systems," Nuclear Science and Engineering, vol. 20, p. 392, 1964.

4. J. E. Meyer, Conservation Laws in One-Dimensional Hydrodynamics, WAPD-BT-20, september 1960 .

5. W. A. Massena, Steam Water Pressure Drop and Critical Discharge Flow - A Digital Computer Program, HW-65706, June 1960 .

6. D. H. Brown, Transient Thermodynamics of Reactors and Process Apparatus, $R 56 \mathrm{GL}$, General Electric Company, December 1956.

7. R. Avery, "Theory of Coupled Reactors," Proceedings of the Second United Nations International Conference on the Peaceful Uses of Atomic Energy, P/1858, vol. 12, p. 182, United Nations, Geneva, 1958 .

8. J. R. Lizzey, Computer Code HFN-Multigroup Multiregion Neutron Diffusion Theory in one space Dimension, $H W-71545$, November 1961 .

9. D. B. Primeau, Unpublished Data, AECL, 1966.

10. R. W. Albrecht and C. Metelmann, "The Use of Reduced Delayed Neutron Group Representations in Nuclear Reactor SimuZation," AEC Research and Development Report, HW-81076, March 1964.

11. L. H. Gerhardstein, "Two Alternate Nuclear Reactor Kinetics Simulations," BNWL-C'C-644, May 1966.

12.W. R. Cooper, Unpublished Data. (Personal communication). 
BNNL - 574

APPENDIX A

ANALOG COMPUTER REPRESENTATION 


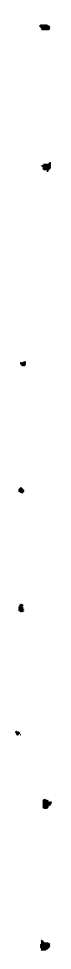

$\checkmark$ 


\section{APPENDIX A \\ ANALOG COMPUTER REPRESENTATION}

The System Block Diagram (Figure A-1) shows the signal flow paths of the major variables for each portion of the simulation. The Fuel Temperature block for each reactor section converts the incoming power level signal (megawatts) for each region into a heat term per unit length $\left(q_{j}-B t u / s e c-f t\right)$. The heat terms are fed into the Hydraulics blocks. The General Nomenclature List, appearing at the end of Appendix A, should be consulted for an explanation of terms used herein.

The circuit used for the Fuel Temperature blocks is simply an RC network, shown in Analog Schematic Diagram No. 2 of Appendix B. Briefly, the fuel rod is divided into four annular fuel regions and one cladding region. The resistor and capacitor values are functions of the size of each section and the material properties. Current in this analogous circuit represents heat flow and voltage represents temperature. The average fuel temperature $\left(\overline{\mathrm{T}}_{F j}\right)$ is fed to the Reactivity block.

The Reactivity block contains all of the reactivity coefficients. The reactivity coefficients convert incoming variables consisting of average fuel temperature $\left(\bar{T}_{F j}\right)$, reactor coolant temperature $\left(\mathrm{T}_{\mathrm{C}_{j}}\right)$, and a sine-squared-weighted coolant density function $\left(\rho^{*}{ }_{2 j}\right)$ into equivalent reactivity (mili-k). The power level controller also sends a signal to the Reactivity blocks. The output of the Reactivity block is the $\Delta K_{j}$ signal (milli-k) which feeds the Power Level blocks.

The Hydraulics compartments are fed by a heat input $\left(q^{-}{ }_{j}\right)$, the saturation enthalpy of the saturated liquid in the Steam Drum $\left(h_{f D}\right)$, the pressure of the Steam Drum $\left(P_{D}\right)$ and the enthalpy of the subcooled liquid in the Steam Drum $\left(h_{D}\right)$. The Hydraulics compartments send two signals to the Reactivity blocks representing the reactor coolant temperature and the 


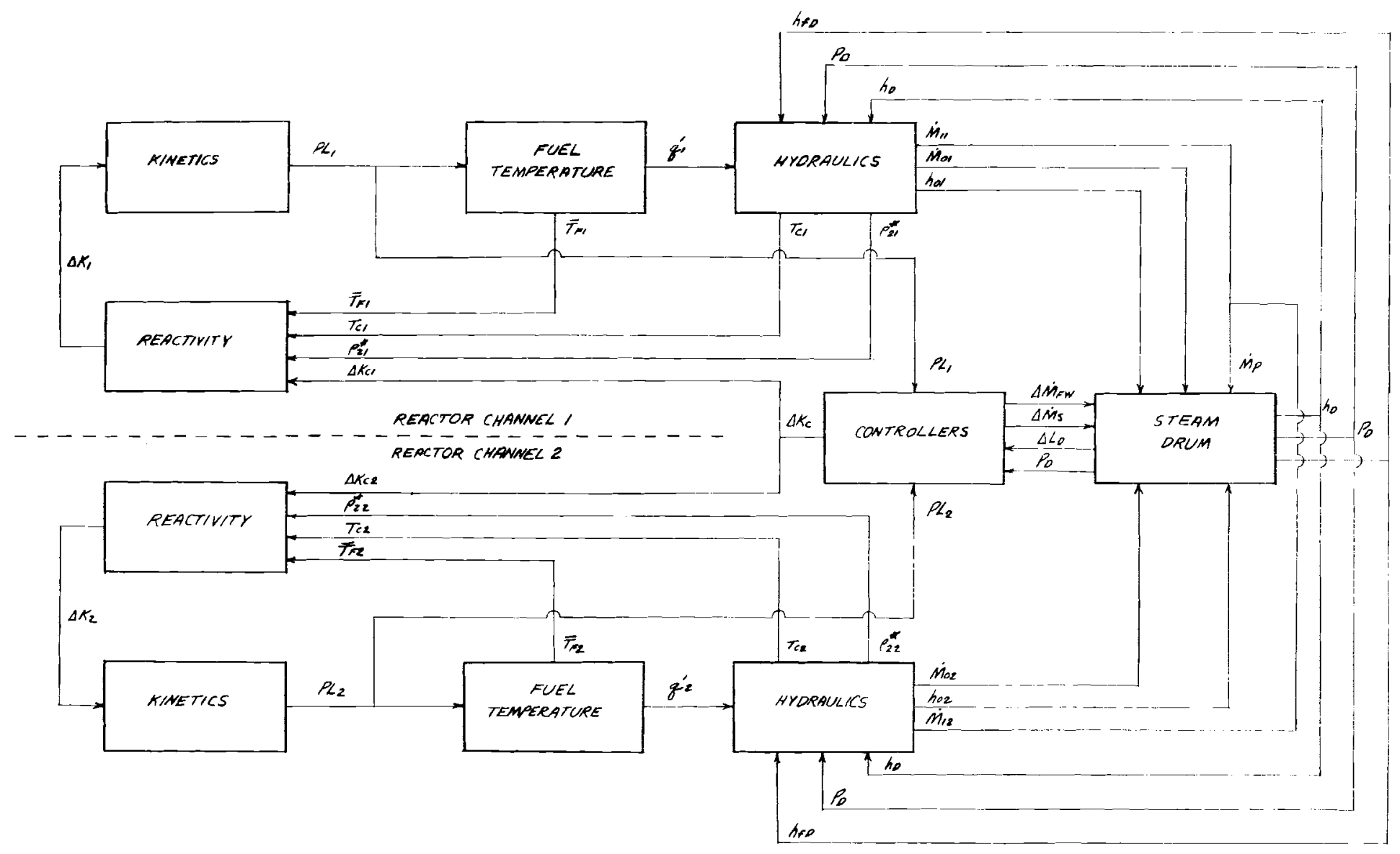

FIGURE A-1. System Block Diagram 
average coolant density. The three signals sent to the Steam Drum from the Hydraulics compartments consist of the flow out of the outret risers $\left(\dot{M}_{o j}\right)$, the enthalpy of the steam water mixture out of the outlet risers $\left(h_{\circ j}\right)$, and the total flow into the reactor $\left(\dot{\mathrm{M}}_{\mathrm{p}}\right)$. The total flow into the reactor is calculated by summing the flow through each of the inlet risers $\left(\dot{M}_{1 j}\right)$.

The Steam Drum receives the flow and enthalpy information from the Hydraulics compartments as well as two signals from the controllers. These last signals are used to calculate the feedwater flow $\left(\dot{M}_{F W}\right)$ and turbine steam demand flow $\left(\dot{M}_{S}\right)$. The pressure $\left(\mathrm{P}_{\mathrm{D}}\right)$, subcooled water enthalpy $\left(\mathrm{h}_{\mathrm{D}}\right)$, and saturated water enthalpy (hfD ${ }_{f}$ values are sent to the Hydraulics compartments.

There are three controllers for the reactor. They control the power level of the reactor, the pressure in the steam drum and the water level of the steam drum. The total power of the reactor is monitored, and any change in the power level from setpoint causes the controllers to send a signal to the Reactivity compartment. This signal brings the power level back to setpoint. The Steam Drum pressure and level controllers adjust the feedwater flow by monitoring the pressure, rate of pressure change, and changes in the steam drum level.

\section{REACTOR HYDRAULICS}

Enthalpy

The enthalpy into the inlet risers $\left(\mathrm{h}_{\mathrm{I}}\right)$ is calculated by assuming it to equal the enthalpy of the subcooled water within the steam drum but delayed to account for the transport time through the downcomers. A first order time delay is used for this calculation and is of the form

$$
\left.h_{I}=\frac{1}{{ }^{D} D} h_{D} e^{-(t / \tau} D\right)
$$

where $\tau_{D}$ is the time delay ( 8.1 sec for this study). 
A similar calculation is also performed to simulate the transport time through the inlet risers. Here the flow changes in the inlet risers are assumed small and allow a constant transport time. Again, a first order time delay is used as follows :

$$
\left.h_{1 j}=\frac{1}{\tau_{i j}} h_{I} e^{-(t / \tau} I j\right) j=1,2
$$

Enthalpy transport through the subcooled portion of the core is lumped with inlet risers.

The boundary between boiling and nonboiling portions of the core is determined by computing the nonboiling length

$$
L_{N B}=\frac{\dot{M}_{1 j}\left(h_{f_{j}}-h_{1 j}\right)}{q_{j}^{\prime}} j=1,2
$$

where $h_{f j}$ is the saturation enthalpy; $q^{\prime} j$ is the average core heat input per unit length; and $\dot{M}_{1 j}$ is the flow rate." The core heat input is computed from the equation

$$
q_{j}^{\prime}=\frac{\left(T_{5 j}-T_{C j}\right)}{R_{56}} \quad j=1,2
$$

where $T_{5 j}$ is the fuel surface temperature and $R_{56}$ represents the surface resistance to heat flow. Coolant temperature, $T_{C j}$, is calculated from a linear approximation of saturation temperature, or

$$
\mathrm{T}_{C j}=403 .+0.144 \mathrm{P}_{\mathrm{Bj}} \quad j=1,2
$$

Similarly, the saturation enthalpy is computed from a linear approximation

$$
h_{f j}=383.5+0.159 \mathrm{P}_{B j} \quad j=1,2
$$

where $P_{B j}$ is the pressure at the boiling boundary.

* The (.) over a variable denotes rate or $d / d t$. 
In the two-phase region of the core, the average enthalpy change rate is from

$$
\left.\left.\dot{\bar{h}}_{2 j}=\left[q_{j}^{\prime}-\stackrel{\dot{M}_{2 j}}{h_{2 j}}-h_{f j}\right)\right\} / L_{B_{j}}\right] / A_{j} R_{2 j} j=1,2
$$

and the average enthalpy of the two-phase region is obtained by integrating Equation (A-7) giving

$$
\bar{h}_{2 j}=\bar{h}_{2 j z}+\int_{0}^{t} \bar{h}_{2 j} d t \quad j=1,2
$$

where $\bar{h}_{2 j z}$ is an initial condition or steady-state value. The enthalpy at the outlet of the two-phase core of the reactor is calculated by

$$
h_{2 j}=2 \bar{h}_{2 j}-h_{f j} \quad j=1,2 .
$$

The term $R_{2 j}$ in Equation $(A-7)$ is an average value of the function given by Equation $(A-10)$ and is

$$
\frac{1}{R_{2 j}}=\int_{L_{N B}}^{L_{c}} \frac{d x}{f\left(h_{2 j}-h_{f j}, P \pi\right)} j=1,2
$$

where $P^{*}$ is a reference pressure.

Assuming a uniform value of $q^{\prime}{ }_{j}$ and steady state enthalpy distribution, this integral is primarily a function of the enthalpy above saturation enthalpy. This is illustrated in Figures $A-2$ and $A-3$ along with the values used in the analog simulation.

The equations used in the enthalpy calculations for the outlet risers are quite similar to those of the two-phase region of the core. The major difference is that there is no heat input to the outlet risers. The equations are: 


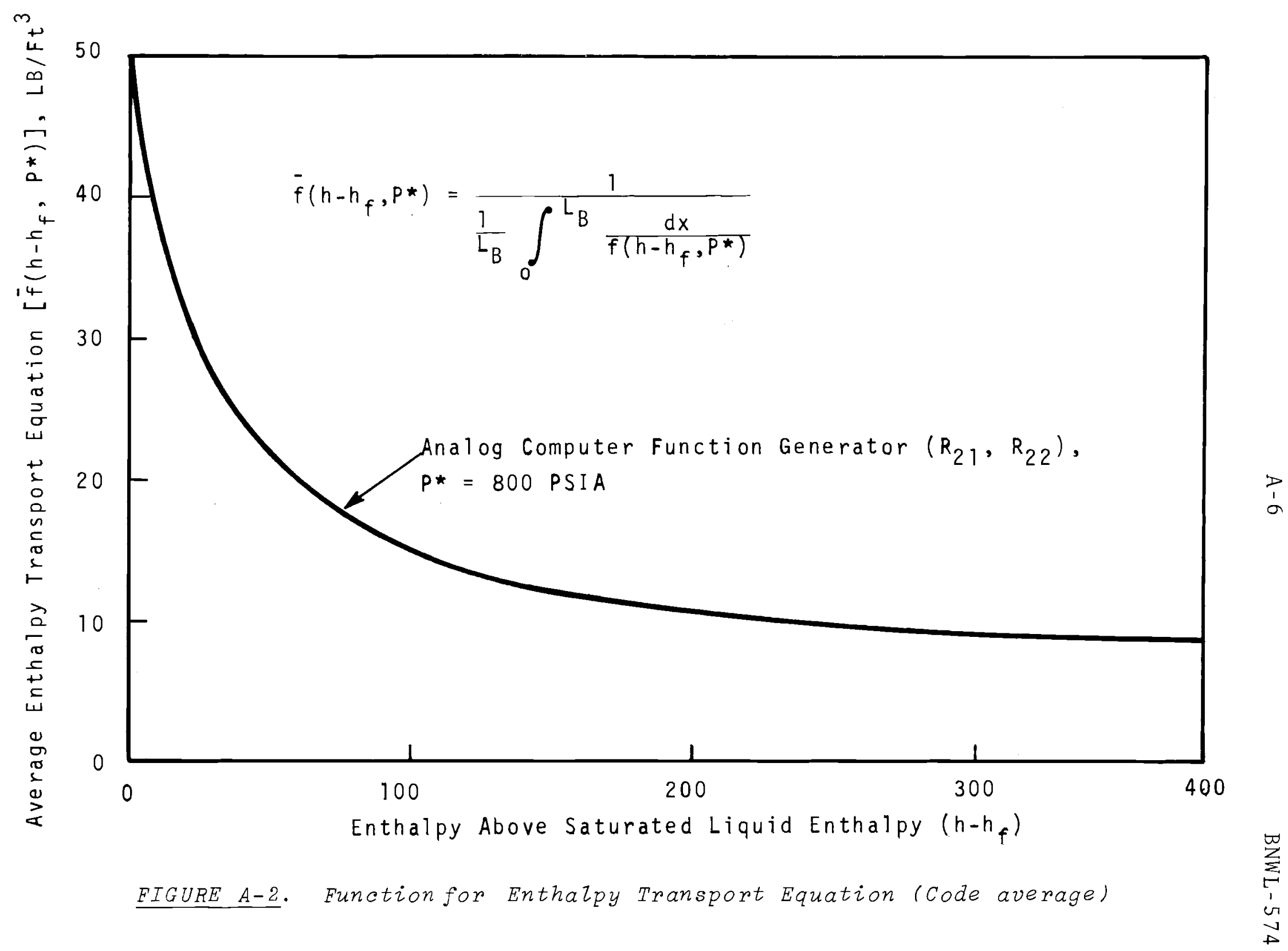




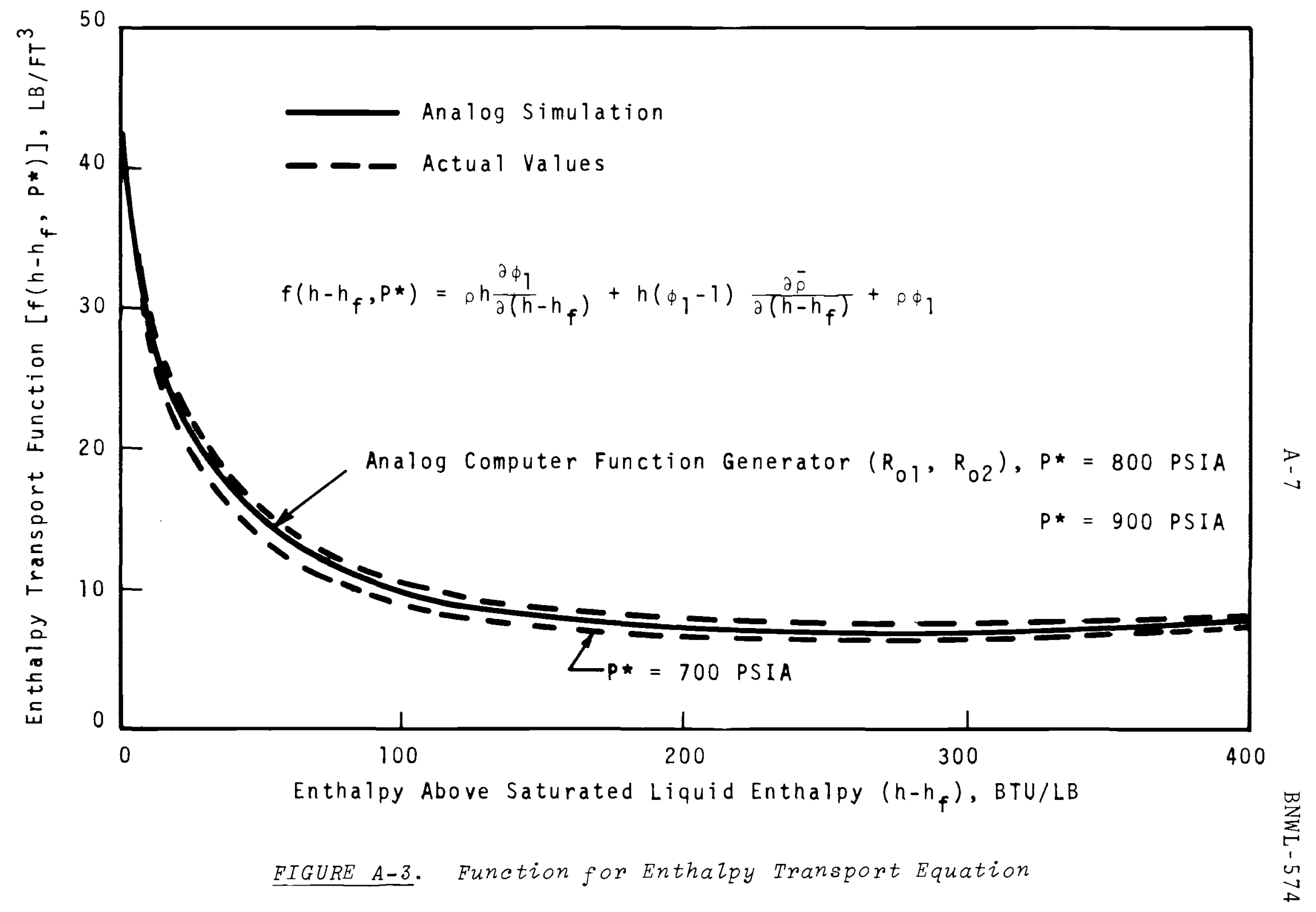




$$
\begin{array}{ll}
\dot{\bar{h}}_{o j}=-\left[\dot{\bar{M}}_{o j}\left(h_{o j}-h_{2 j}\right)\right] / V_{o j} R_{o j} & j=1,2 \\
\dot{h}_{o j}=\bar{h}_{o j z}+\int_{o}^{t} \dot{\bar{h}}_{o j} d t & j=1,2 \\
h_{o j}=2 \bar{h}_{o j}-h_{2 j} & j=1,2
\end{array}
$$

The term $R_{o j}$ is evaluated by Equation (A-10), but since steady state enthalpy is uniform, the value of $R_{0 j}$ is the same as the function $f\left(h-h_{f}, P^{*}\right)$ shown in Figure $A-3$. The values of this function in the analog simulation are also shown in Figure A-3.

\section{Coolant Density}

The density of the coolant $\left(\rho_{D}\right)$ from the steam drum through the downcomers, inlet risers, and subcooled regions of the core itself is assumed to be constant. The density at the outlet of the two-phase region of the core is determined from the function shown in Figure A-4. To determine the average density in the core, the integral

$$
\rho_{2 j}=\frac{1}{L_{B}} \int_{L_{N B}}^{L_{c}} \rho\left(h_{2 j}-h_{f j}, P^{*}\right) d x \quad j=1,2
$$

was evaluated assuming uniform heat input, $q^{\prime} j$, and steady state enthalpy distribution. For purposes of this study, Equation $(A-14)$ can be approximated by

$$
\bar{\rho}_{2 j}=0.37\left(\rho_{2 j}+\rho_{D}\right)
$$

A comparison of Equations $(A-14)$ and $(A-15)$ is shown in Figure A-5.

The error introduced by the only fair approximation of $\rho^{-}$ by Equation $(A-15)$ is not very large because $\bar{\rho}$ is used only to determine the elevation component of measure drop which is rather small term. 


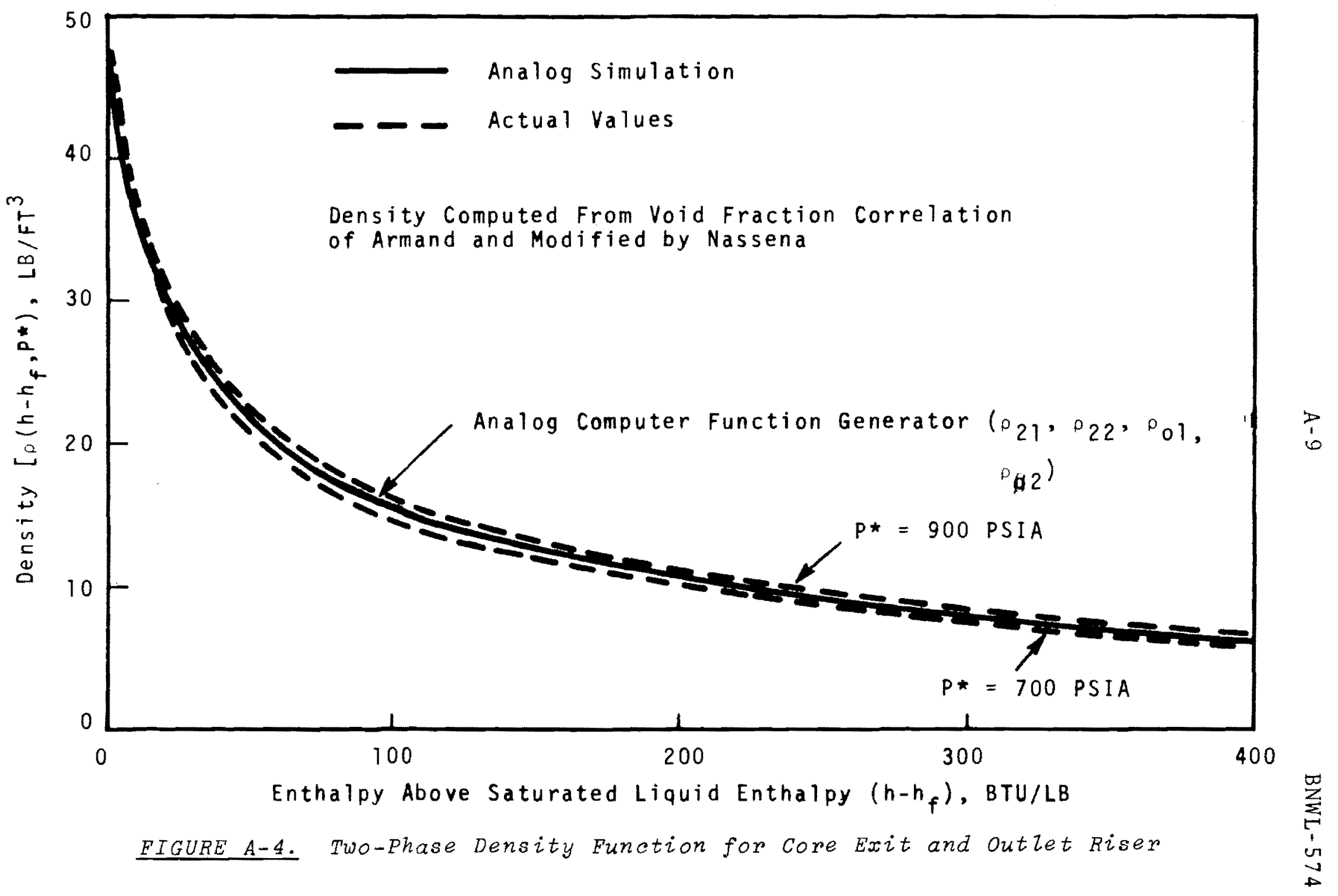




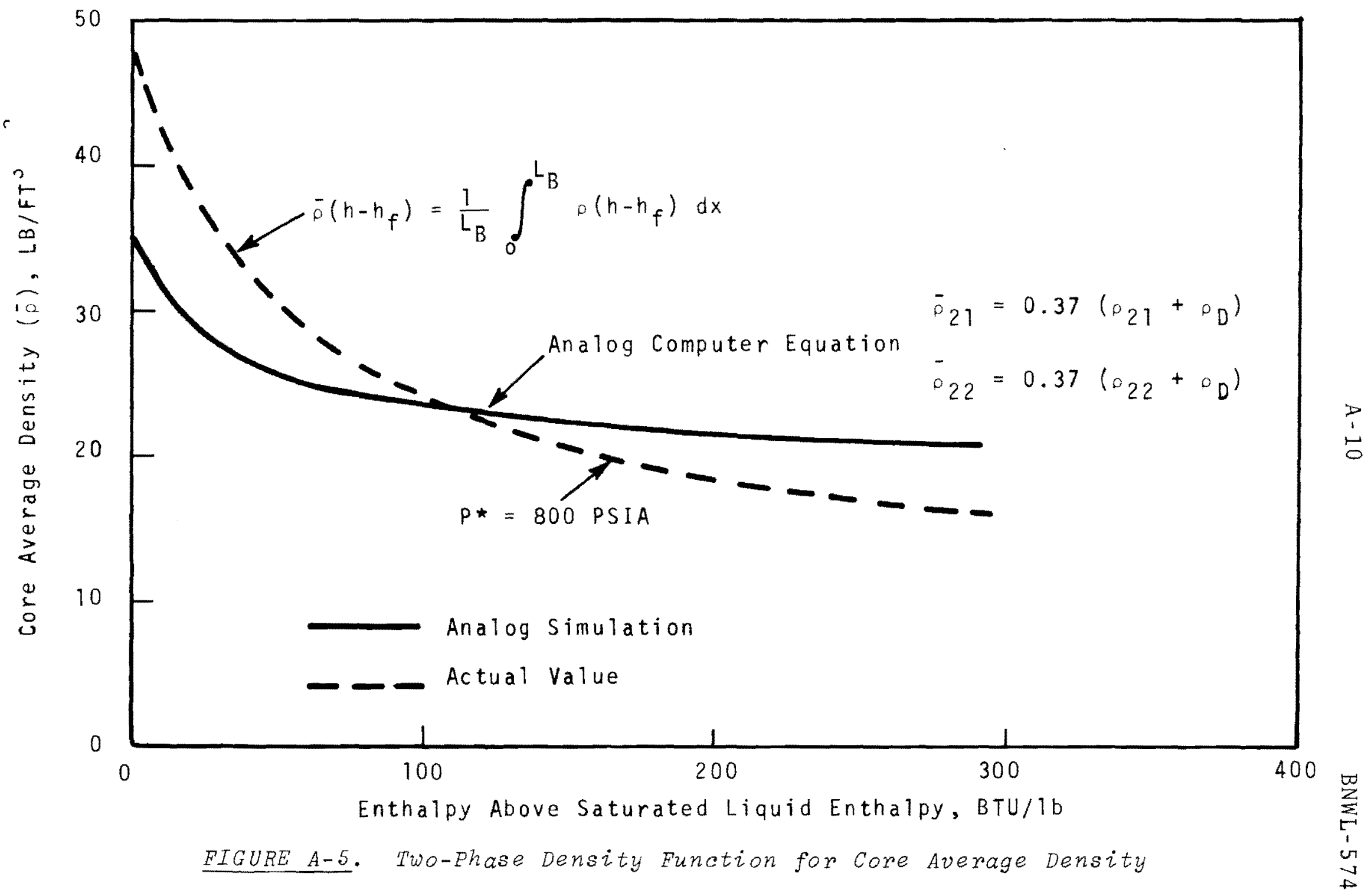


The time rate change of averages density is required for the continuity equation and is computed from

$$
\dot{p}_{2 j}=0.74 \frac{\partial \bar{\rho}_{2 j}}{\partial\left(\mathrm{h}_{2 j}{ }^{\left.-h_{f_{j}}\right)}\right.} \quad \dot{\bar{h}}_{2 j} \quad j=1,2
$$

where the partial derivative is approximated as

$$
\frac{\partial \rho}{\partial\left(h_{2 j}{ }^{-h_{f j}}\right)}=-\frac{5.68}{h_{2 j}{ }^{-h_{f j}}-24.5} \quad j=1,2
$$

and comparison of Equation (A-17) to the actual values is shown in Figure A-6.

For the outlet risers a similar set of equations is obtained:

$$
\begin{array}{rlrl}
\bar{\rho}_{o j} & =0.5\left(\rho_{o j}+\rho_{2 j}\right) & j & =1,2 \\
\dot{\rho}_{o j} & =\frac{\partial \bar{\rho}_{o j}}{\partial\left(h_{o j}-h_{f D}\right)} \dot{\bar{h}}_{o j} & j & =1,2 \\
\frac{\partial \bar{\rho}_{o j}}{\partial\left(h_{o j}-h_{f D}\right)} & =-\frac{5.68}{h_{o j} h_{f D}-24.5} & j & =1,2
\end{array}
$$

Equations (A-18) and (A-20) are compared with actual values in Figures $A-4$ and $A-6$, respectively.

The work coefficient of reactivity uses a sine-square weighted density to determine the reactivity changes from changes in coolant density. This special density, used only for reactivity calculations, is defined as

$$
\rho^{*}=\frac{\int_{0}^{L c} \rho \sin ^{2} \frac{\pi x}{L_{c}} d x}{\int_{0}^{L} \sin ^{2} \frac{\pi x}{L_{c}} d x}
$$




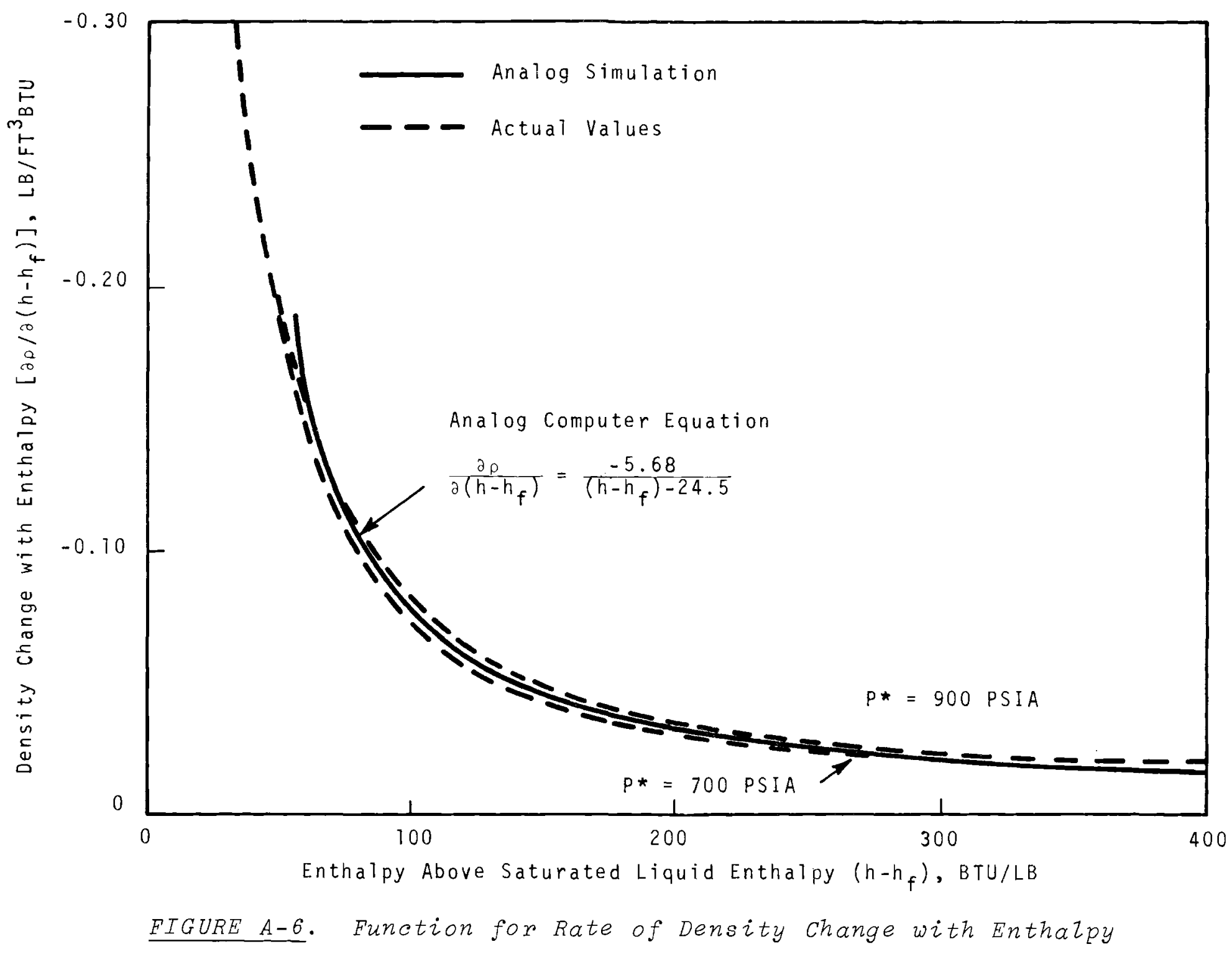


where the density $\rho$ is computed from the local enthalpy given by the integrated axial flux distribution (Figure A-7). Solution of Equation (A-21) is illustrated in Figures A-8 and A-9 as a function of the pressure, inlet enthalpy, and enthalpy rise across the core with the following approximating equation used for analog computations:

$$
\begin{aligned}
\rho_{j}^{*}= & \frac{5000}{h_{2 j}-h_{1 j}+2.5 h_{1 j}-0.267 \mathrm{P}_{\beta j}-929}+0.0267 \mathrm{P}_{B j} \\
& -17.3
\end{aligned}
$$

\section{Flow and Pressure Drop}

The pressure drop and flow for each segment of channel is obtained from the momentum equation. For the inlet risers and the subcooled portion of the core, the momentum equation is:

$$
\begin{aligned}
\ddot{M}_{1 j}= & K_{I I j}\left[P_{I}-P_{B j}-\frac{\dot{M}_{1 j}^{2}}{144 A^{2} j g \rho D}-K_{F I j} \dot{M}_{1 j}^{2}\right. \\
& \left.-\frac{{ }^{\rho} D\left(Z_{R}-Z_{I}+L_{N B j}\right)}{144}\right] \quad j=1,2
\end{aligned}
$$

The inertia factor $K_{I I j}$ is defined as:

$$
\frac{1}{K_{I I j}}=\frac{1}{g} \int \frac{d x}{A_{j}} \quad j-1,2
$$

where the integration starts at the inlet of the riser and ends at the boiling boundary in the core. Since the contribution to the nonboiling part of the core in Equation (A-23) is small, a typical constant length was chosen. The friction constant $K_{F I j}$, evaluated from Equation $(A-23)$, with $\ddot{M}_{1 j}=0$, includes al1 pressure losses from the inlet header to the core boiling boundary. Values of these constants are given in Table A-I. 


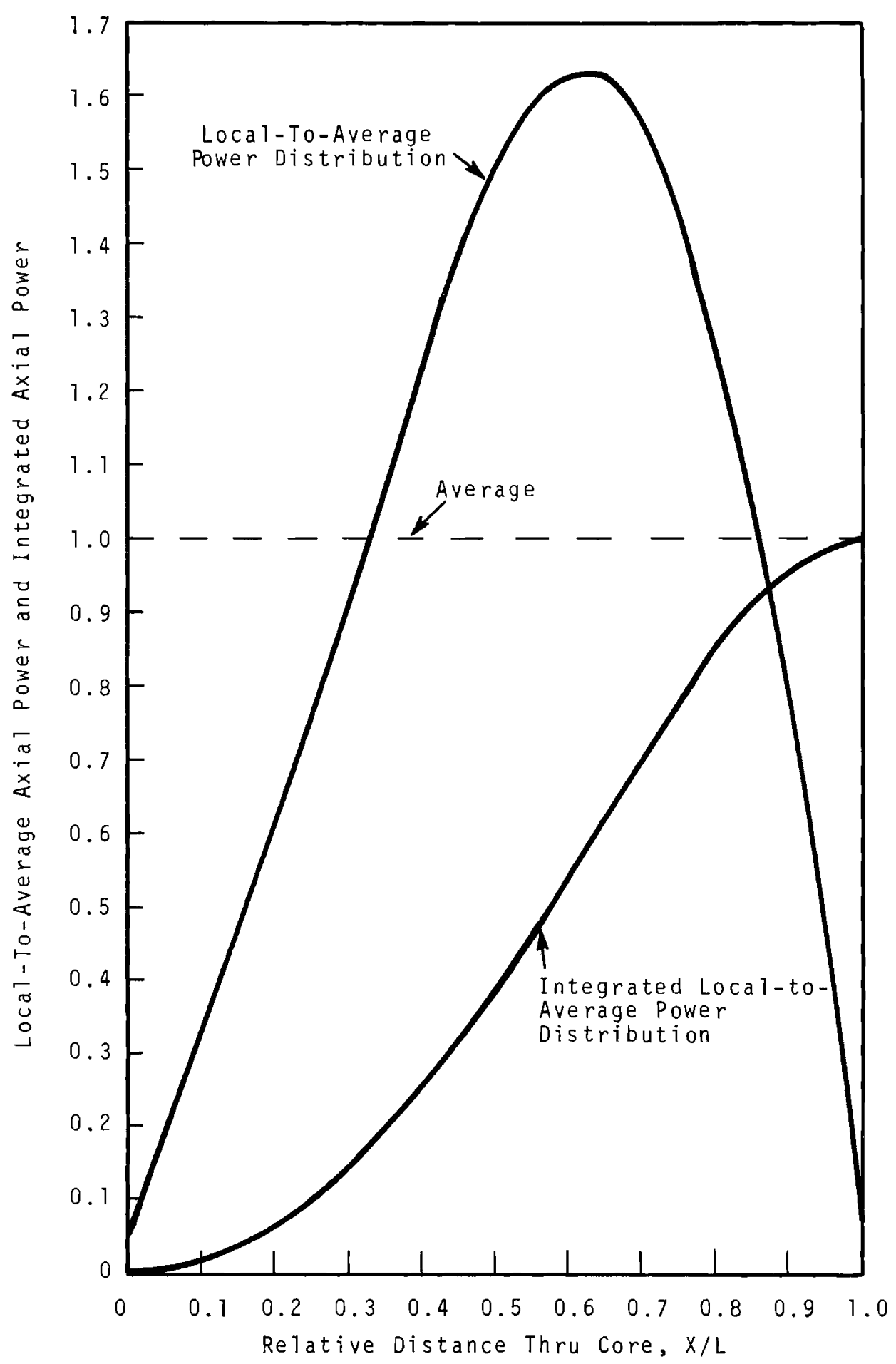

FIGURE A-7. Local Axial Power Distribution and Integrated $A x i a l$ Power Distribution 


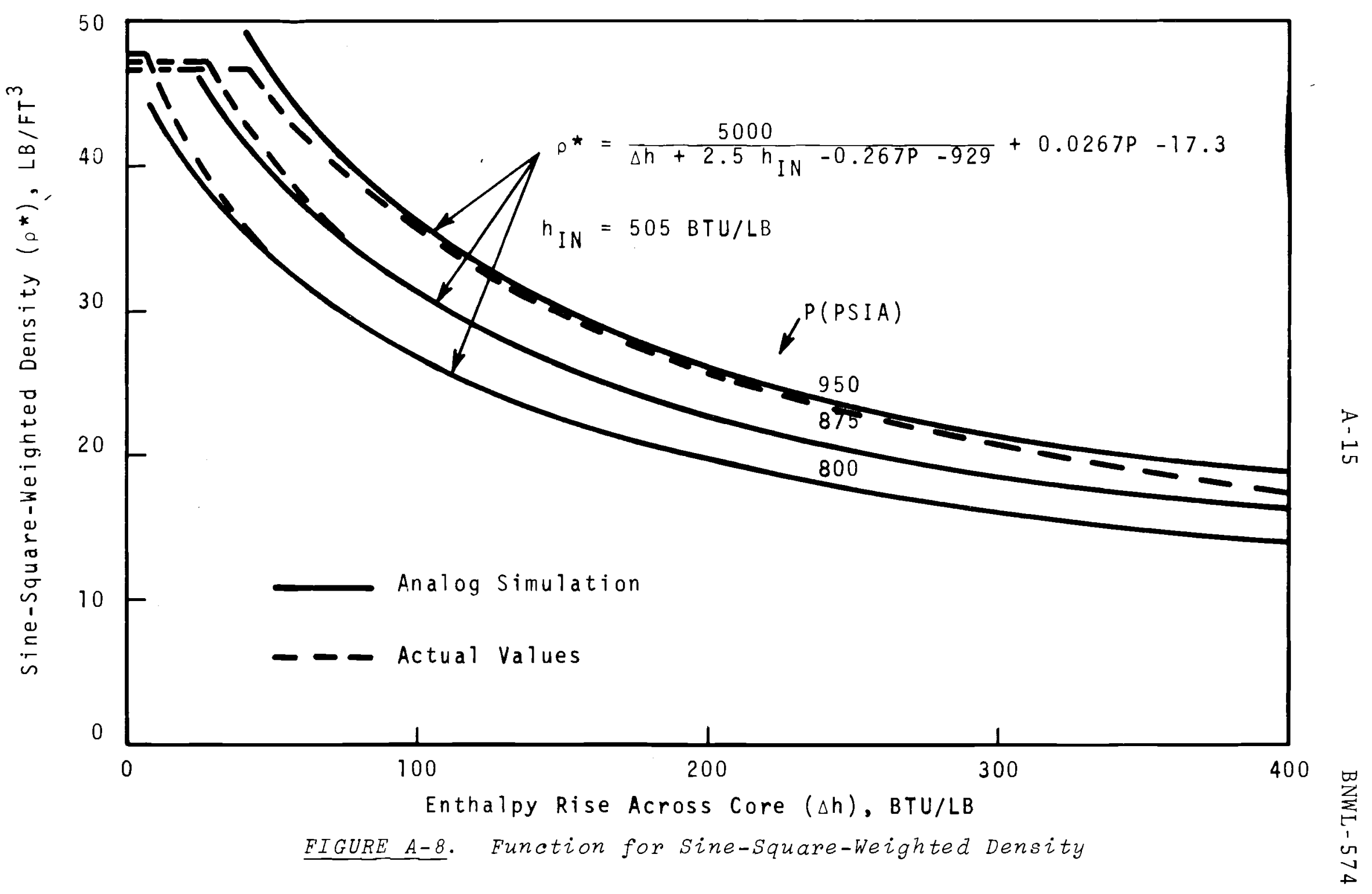




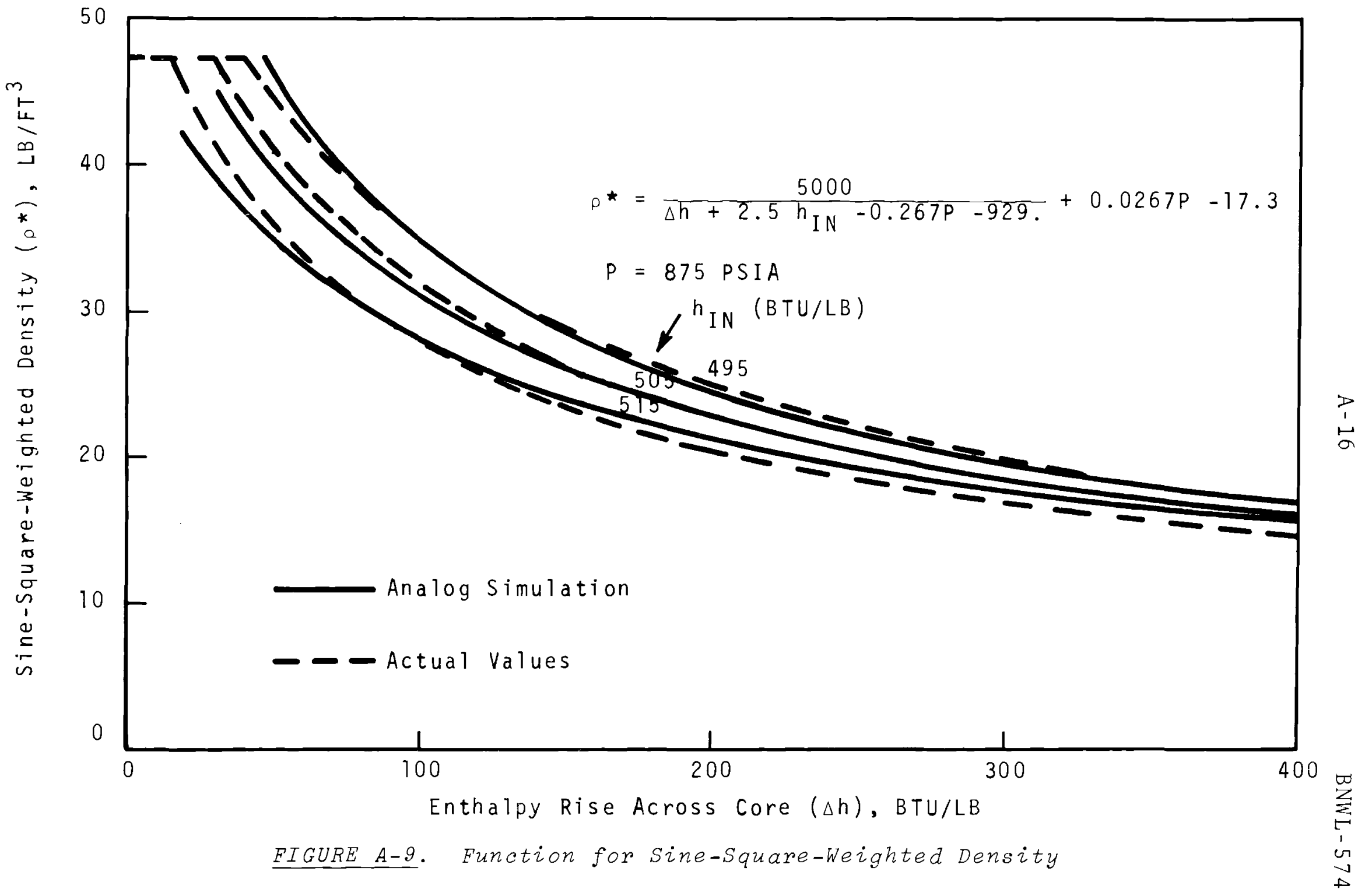


TABLE A-I. Parameters Used for Computing Nominal Hydraulic Constants

\begin{tabular}{|c|c|c|c|c|}
\hline Parameter & Symbol & \multicolumn{2}{|c|}{ In-Out } & $\begin{array}{l}\text { Side-by- } \\
\text { Side } \\
\text { Regions } \\
1 \& 2 \\
\end{array}$ \\
\hline Flow Rate (1b/sec) & $M_{1 j}, M_{2 j}, M_{0 j}$ & 1430 & 4770 & 3100 \\
\hline Inlet Enthalpy (Btu/lb) & $\mathrm{h}_{\mathrm{I}}$ & 503.5 & 503.5 & 503.5 \\
\hline Thermal Power (MW) & $\mathrm{PL}_{j}$ & 167 & 593 & 380 \\
\hline $\begin{array}{l}\text { Outlet Enthalpy } \\
\text { (Btu/1b) }\end{array}$ & $h_{o j}$ & 619.5 & 619.5 & 619.5 \\
\hline Exit Pressure (psia) & $\mathrm{P}_{\mathrm{D}}$ & 765.0 & 765.0 & 765.0 \\
\hline $\begin{array}{l}\text { Inlet Riser Pressure } \\
\text { Drop (psia) }\end{array}$ & $P_{I}-P_{B j}$ & 37.1 & 77.4 & 69.5 \\
\hline $\begin{array}{l}\text { Core Pressure Drop } \\
\text { (psia) }\end{array}$ & $P_{B j}-P_{\circ j}$ & 113.0 & 73.6 & 81.3 \\
\hline $\begin{array}{l}\text { Outlet Riser Pressure } \\
\text { Drop (psia) }\end{array}$ & $P_{\circ j}-P_{D}$ & 28.0 & 27.5 & 27.6 \\
\hline $\begin{array}{l}\text { Elevation of Riser } \\
\text { Inlet }(\mathrm{ft})\end{array}$ & $z_{I}$ & 0 & 0 & 0 \\
\hline $\begin{array}{l}\text { Elevation of Core } \\
\text { Inlet }(f t)\end{array}$ & $z_{R}$ & 14.8 & 14.8 & 14.8 \\
\hline $\begin{array}{l}\text { Elevation of Core } \\
\text { Outlet ( } \mathrm{ft})\end{array}$ & $\mathrm{Z}_{\mathrm{R}}+\mathrm{L}_{\mathrm{C}}$ & 31.2 & 31.2 & 31.2 \\
\hline $\begin{array}{l}\text { Elevation of Riser } \\
\text { Outlet (ft) }\end{array}$ & $\mathrm{Z}_{\mathrm{D}}$ & 50.0 & 50.0 & 50.0 \\
\hline Inlet Riser Length $(f t)$ & - & 21.5 & 17.7 & 18.4 \\
\hline Inlet Riser Area $\left(f t^{2}\right)$ & - & 1.23 & 4.55 & 2.89 \\
\hline $\begin{array}{l}\text { Process Tube Length to } \\
\text { Core Inlet (ft) }\end{array}$ & - & 5.75 & 5.75 & 5.75 \\
\hline $\begin{array}{l}\text { Process Tube Area Before } \\
\text { Entering Fuel }\left(f t^{2}\right)\end{array}$ & - & 4.62 & 19.1 & 11.86 \\
\hline Fuel Flow Area $\left(f t^{2}\right)$ & $A_{j}$ & 1.67 & 6.89 & 4.28 \\
\hline Nonboiling Length $(\mathrm{ft})$ & $\mathrm{L}_{\mathrm{NB} j}$ & 3.41 & 2.46 & 2.62 \\
\hline
\end{tabular}

* Region 1 is the center, comprising 60 tubes of a 308-tube reactor. 
TABLEA-I. (contd)

\begin{tabular}{|c|c|c|c|c|}
\hline \multirow{2}{*}{ Parameter } & \multirow[b]{2}{*}{ Symbo1 } & \multicolumn{2}{|c|}{ In-Out } & $\begin{array}{l}\text { Side -by- } \\
\text { Side }\end{array}$ \\
\hline & & $\begin{array}{l}\operatorname{Reg} \text { ion } \\
1 * \\
\end{array}$ & $\begin{array}{l}\text { Region } \\
\frac{2}{2} \\
\end{array}$ & $\begin{array}{l}\text { Regions } \\
1 \& 2 \\
\end{array}$ \\
\hline Core Length $(f t)$ & $\mathrm{L}_{c}$ & 16.4 & 16.4 & 16.4 \\
\hline $\begin{array}{l}\text { Process Tube Length After } \\
\text { Core Outlet (ft) }\end{array}$ & - & 6.17 & 6.17 & 6.17 \\
\hline $\begin{array}{l}\text { Process Tube Area After } \\
\text { Leaving Fue } 1\left(\mathrm{ft}^{2}\right)\end{array}$ & - & 4.62 & 19.1 & 11.86 \\
\hline Outlet Riser Length ( $f t$ ) & - & 28.2 & 28.4 & 28.4 \\
\hline Outlet Riser Area $\left(f t^{2}\right)$ & - & 3.08 & 9.48 & 6.28 \\
\hline
\end{tabular}

The momentum equation for the boiling portion of the core is

$$
\begin{aligned}
\ddot{M}_{2 j}= & \frac{144 A_{j} g}{L_{B j}}\left[P_{B j}-P_{o j} \frac{1}{144 A_{j}^{2} g}\left(\frac{\dot{M}_{2 j}}{\rho_{2 j}} \Phi_{2 j} \frac{-\dot{M}^{2} 1 j}{\rho_{D}}\right)\right. \\
& \left.\frac{-K_{F 2} j L_{B j}}{L_{C}}-\bar{\psi}_{2 j} \dot{\bar{M}}_{2 j}^{2} \frac{\rho_{2 j} L_{B j}}{144}\right] j=1,2 \quad(A-25)
\end{aligned}
$$

The two-phase friction multiplier $\bar{\psi}_{2 j}$ in Equation (A-25) is a linear approximation of the Armand(5) friction multiplier and is given by

$$
\bar{\psi}_{2 j}=0.5\left(\psi_{2 j}+1.0\right)
$$

where

$$
\psi_{2 j}=1+0.04\left(h_{2 j}-h_{f j}\right)
$$

A comparison of Equation (A-25) and the actual correlation is shown in Figure A-10. The friction constant $K_{F 2} j$ is evaluated from Equation $(A-25)$ by setting $\ddot{\bar{M}}_{2 j}=0$. Values of this constant are given in Table A-I. 


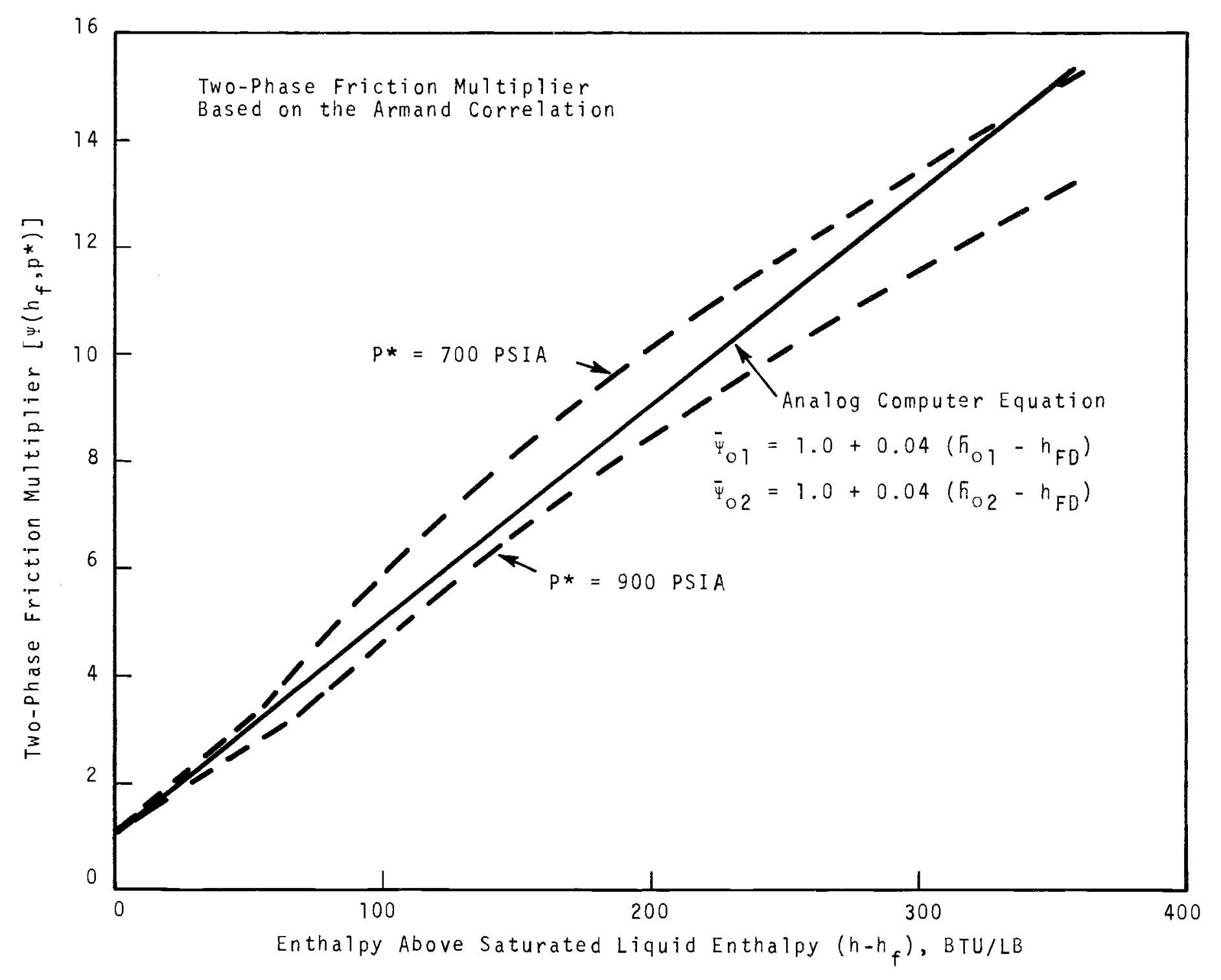

FIGURE A-10. Armand Two-Phase Pressure Drop Friction Multiplier 
The momentum equation for the outlet risers is:

$$
\begin{aligned}
\dot{\bar{M}}_{o j}= & 144 g\left(\frac{\bar{A}_{o j}}{L_{o j}}\right)\left[P_{o j}-P_{D}+144 g \frac{\dot{M}_{2 j}^{2} \frac{\Phi^{\Phi}}{A_{2 j}{ }^{\rho} 2 j}}{-}\right. \\
& \left.-K_{F o j} \bar{\Psi}_{o j} \dot{M}_{o j}^{2}+\left(\frac{Z_{D}-Z_{o j}}{144}\right) \bar{\rho}_{o j}\right] j=1,2(A-28)
\end{aligned}
$$

As for the boiling region of the core, a linear approximation (Figure A-10) of the two-phase friction multiplier is used:

$$
\bar{\psi}_{o j}=1+0.04\left(\bar{h}_{o j}-h_{f D}\right) \quad j=1,2
$$

The friction constant, $\mathrm{K}_{\text {Foj }}$, includes all pressure drops from the core outlet to the steam drum. Since variations in cross-sectional area occur in the chosen outlet riser segment, the ratio $\bar{A}_{o j} / L_{o j}$ is evaluated from the integral

$$
\frac{L_{o j}}{A_{o j}}=\int \frac{d x}{A_{j}} \quad j=1,2 \quad(A-30)
$$

The integration starts at the fuel outlet and continues to the steam drum. Table A-I also contains the parameters used to evaluate the riser constants.

The momentum equation for the downcomer is written as:

$$
\begin{aligned}
\ddot{M}_{P}= & K_{I D}\left[P_{D}-P_{I}+\Delta P_{O}-\left(K_{P}+K_{F D}\right) \dot{M}^{2}\right. \\
& \left.+\frac{{ }_{D}\left(Z_{D}-Z_{I}\right)}{144}\right]
\end{aligned}
$$

where $K_{I D}$ is an inertia factor defined as:

$$
\frac{1}{K_{I D}}=\int \frac{d x}{A}
$$

The integration in Equation (A-32) is taken from the steam drum to the inlet risers. Equation (A-31) also includes the 
pump simulation with the terms $\Delta P_{0}$ and $K_{P}$, denoting the zero flow pump head and internal friction, respectively. The constants used to evaluate $K_{F D}$ are given in Table A-I. Boundary Condition on Pressure Drop

To solve the momentum Equations (A-23, 25, 28) and (A-31), the sum of all pressure drops around a closed loop equaling zero is used for the boundary condition. The two loops chosen for this problem are through the downcomer and one of the reactor channels, and through the downcomer and the other reactor channel. The resulting equations are:

$$
\begin{aligned}
& \frac{\ddot{M}_{p}}{K_{I D}}+\frac{\ddot{M}_{1 j}}{\bar{K}_{I I j}}+\frac{L_{B j} \ddot{M}_{2 j}}{144 A_{j}^{g}}+\left(\frac{L_{o j}}{\bar{A}_{o j}}\right) \frac{M_{o j}}{144 g}
\end{aligned}
$$

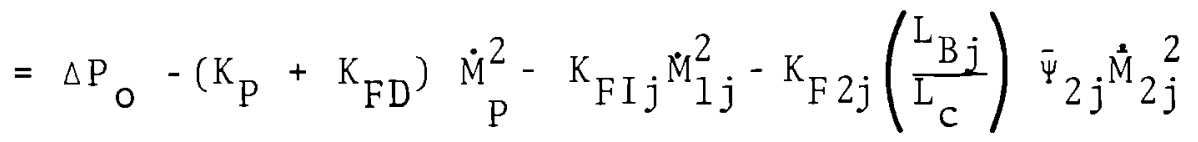

$$
\begin{aligned}
& -K_{F o j} \bar{\psi}_{o j} \dot{\bar{M}}_{o j}^{2}+\frac{\rho_{D}\left(Z_{D}-Z_{R}+L_{N B j}\right)}{144}-\frac{\bar{\rho}_{2 j} L_{B j}}{144} \\
& -\frac{\left(Z_{D}-Z_{o j}\right)}{144} \bar{\rho}_{o j} \quad j=1,2
\end{aligned}
$$

Integration of Equation $(A-23)$ for $j=1$ and $j=2$ gives two equations in flow with seven unknowns. The additional equations are obtained from the continuity equations. To relate the two channels to the downcomer:

$$
\mathrm{M}_{\mathrm{p}}=\dot{\mathrm{M}}_{11}+\dot{\mathrm{M}}_{12}
$$

For each core and riser section we can write

$$
\dot{\mathrm{M}}_{2 j}=\dot{\mathrm{M}}_{1 \mathrm{j}}-\dot{\bar{\rho}}_{2 j} \mathrm{~A}_{\mathrm{j}} \mathrm{L}_{\mathrm{B} j} \quad j=1,2
$$

where

$$
\dot{\bar{M}}_{2 j}=0.5\left(\ddot{M}_{2 j}+\dot{M}_{1 j}\right) \quad j=1,2
$$


and

$$
M_{o j}=M_{2 j}-\dot{\bar{\rho}}_{o j} V_{o j} \quad j=1,2
$$

where

$$
\dot{\bar{M}}_{o j}=0.5\left(\dot{M}_{0 j}+\dot{M}_{2 j}\right) \quad j=1,2
$$

The volume term is used in Equation (A-35) because of nonuniform flow area in the outlet riser section. Simultaneous solution of Equations (A-33) through (A-38) give the flow rates in all sections of the system.

STEAM DRUM MODEL

Mixing Belt

The flow into the steam drum is the sum of the flows from the outlet risers and the feedwater flow, illustrated in Figure A-11, is shown as follows:

$$
M_{I D}=M_{F W}+M_{01}+M_{02}
$$

With perfect mixing assumed in the mixing belt, a mean mixed enthalpy into the drum is given by:

$$
h_{I D}=\frac{M_{F W} h_{F W}+M_{O 1} h_{O 1}+M_{O 2} h_{O 2}}{M_{I D}}
$$

Separator

The stean drum separator physically separates the twophase flow into liquid and vapor. The steam quality, or weight fraction of steam, is computed from

$$
X=\frac{h_{I D^{-h}} f D}{h_{G D^{-h}} f D}
$$

where $h_{f D}$ is the saturated liquid enthalpy given by the linear approximation

$$
h_{f D}=383.5+0.159 P_{D}
$$




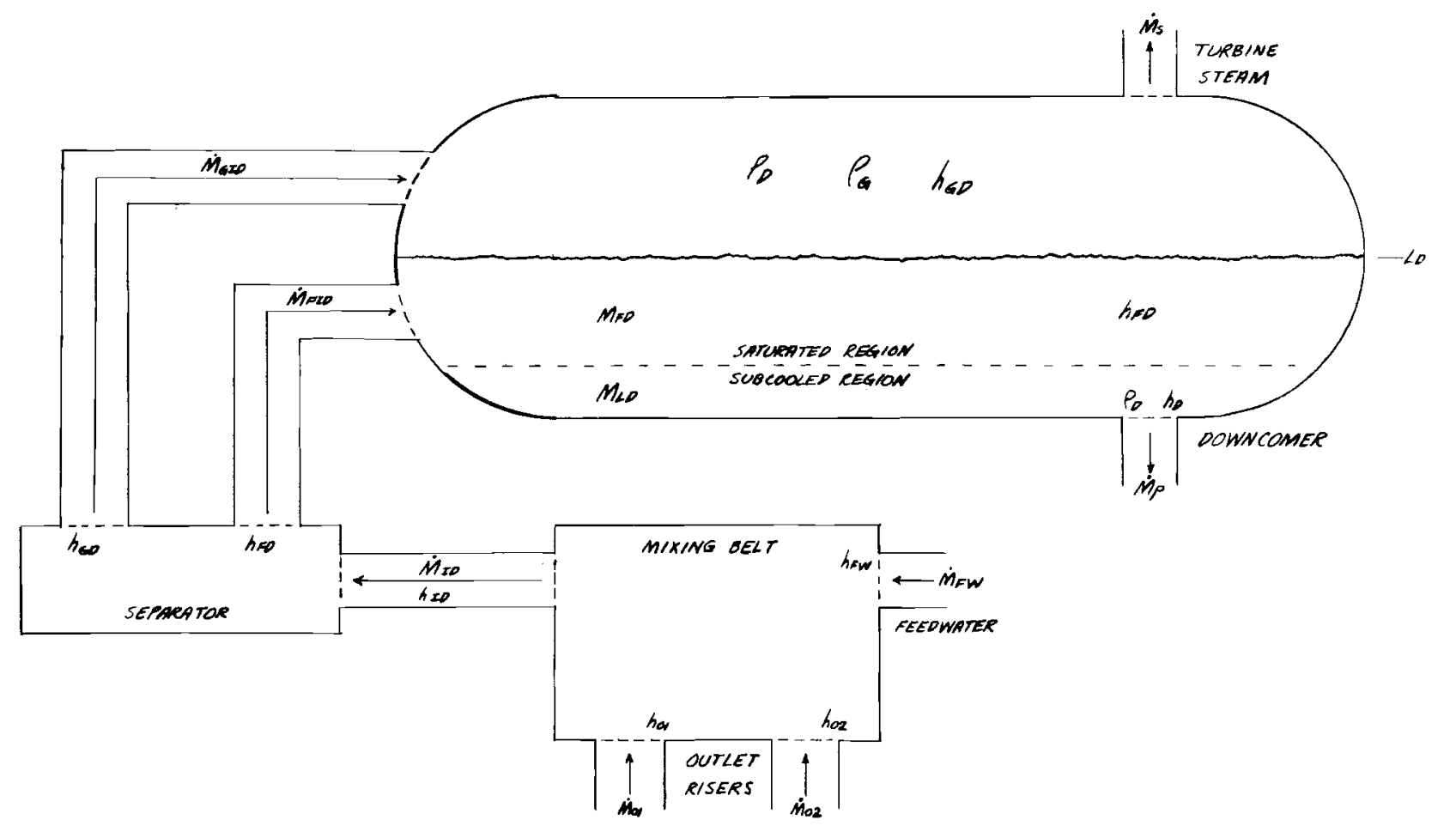

FIGURE A-11. Steam Drum 
and $h_{G D}$ is the saturated vapor enthalpy (assumed constant). From the definition of $X$, the steam flow into the drum is:

$$
\mathrm{M}_{\mathrm{GID}}=\mathrm{X} \dot{\mathrm{M}}_{\mathrm{ID}}
$$

and the saturated flow is:

$$
\dot{\mathrm{M}}_{\mathrm{FID}}=(1-\mathrm{X}) \dot{\mathrm{M}}_{\mathrm{ID}}
$$

\section{Steam Drum Pressure}

From Equation (19), the rate of pressure change in the drum is written as

$$
\dot{\mathrm{P}}_{\mathrm{D}}=\left[\left(\dot{\mathrm{M}}_{\mathrm{GID}}{ }^{-\dot{\mathrm{M}}_{S}}\right) / \rho_{\mathrm{G}}+\left(\dot{\mathrm{M}}_{\mathrm{FID}}{ }^{-\dot{\mathrm{M}}_{\mathrm{P}}}\right) / \rho_{D}\right] f\left(z, \mathrm{P}_{D}\right) \quad(\mathrm{A}-45)
$$

and integration gives the pressure

$$
\mathrm{P}_{\mathrm{D}}=\mathrm{P}_{\mathrm{D} z}+\int_{0}^{t} \dot{\mathrm{P}}_{\mathrm{D}} \mathrm{dt}
$$

where $P_{D z}$ is the initial pressure. Vapor density in Equation (A-43) is calculated from the linear approximation:

$$
\rho_{G}=0.00244 \mathrm{P}_{\mathrm{D}}-0.195 \mathrm{lb} / \mathrm{ft}^{3}
$$

and $\rho_{D}$ is a constant $\left(\rho_{D}=48.11 \mathrm{~b} / \mathrm{ft}^{3}\right)$

The function $f\left(z, P_{D}\right)$ was evaluated by using saturated thermodynamic properties of water. The calculations were based upon two steam drums lumped as one. The equivalent drum was $6 \mathrm{ft}$ ID by $46 \mathrm{ft}$ long, with the liquid level at $3 \mathrm{ft}$. The steam line volume from the drum to the turbine was assumed to equal the volume of the steam drum. This gives an effective steam volume three times that of the water volume within the drum.

The function $f\left(z, P_{D}\right)$, evaluated for several pressures, yielded an approximate equation. For the two cases: 
Case 1

For a decreasing pressure $\left(P_{D}<0\right)$ and the drum 1iquid saturated $\left(h_{D}=h_{f D}\right)$

$$
f\left(1, P_{D}\right)=\frac{1}{23.23-0.0209 P_{D}}
$$

Case 2

For increasing pressure $\left(P_{D}>0\right)$, or, if pressure is decreasing $\left(P_{D}<0\right)$ and the subcooled fraction of water $(1-z)$ has not reached saturation $\left(h_{D}<h_{f D}\right)$ then

$$
\left.f\left(z, P_{D}\right)=\frac{1}{\left(6.23-0.0041 P_{D}\right)+z\left(17.0-0.0168 P_{D}\right.}\right)
$$

The parameter $z$ in the above equation is the assumed constant fraction of the remaining saturated drum water.

The change of water level is a function of the mass of water in the drum. A linear approximation of the deviation in drum level from the nominal value $\left(L_{D}=3 \mathrm{ft}\right)$ is used

$$
\Delta L_{D}=0.000072\left(M_{F D}+M_{L D}\right)-2.308
$$

where the nominal level at the center of the drum is $3 \mathrm{ft}$.

The rate of change of water in the drum equals the difference between inflow and outflow of the water:

$$
\frac{\cdot}{\left(\mathrm{M}_{\mathrm{FD}}+\mathrm{M}_{\mathrm{LD}}\right)}=\dot{\mathrm{M}}_{\mathrm{FID}}-\dot{\mathrm{M}}_{\mathrm{P}} \text {; }
$$

therefore, the amount of water is

$$
M_{F D}+M_{L D}=\int_{0}^{t} \frac{\cdot}{\left(M_{F D}+M_{L D}\right)} d t+\left(M_{F D}+\dot{M}_{L D}\right) z(A-52)
$$


Now substituting Equation (A-56) into Equations (24) and (25) yields:

$$
\begin{aligned}
& (P L)_{1}=\frac{(1-\beta) K_{11}}{\ell_{1}}(P L)_{1}+\frac{(1-\beta) K_{12}}{\ell_{2}}(P L)_{2}-\frac{(P L)_{1}}{\ell_{1}} \\
& +K_{11} \sum_{i=1}^{3} \lambda_{i} D_{i 1}+K_{11} \frac{\beta}{l}{ }_{1}(P L)_{1} \\
& +K_{12} \sum_{i=1}^{3} \lambda_{i} D_{i 2}+K_{12} \frac{\beta}{\ell_{2}}(P L)_{2} \\
& (\dot{\mathrm{PL}})_{2}=\frac{(1-\beta) K_{22}}{\ell_{2}}(\mathrm{PL})_{2}+\frac{(1-\beta) K_{21}}{\ell_{1}}(\mathrm{PL})_{1}-\frac{(\mathrm{PL})_{2}}{\ell_{2}} \\
& +K_{22} \sum_{i=1}^{3} \lambda_{i} D_{i 2}+K_{22} \frac{\beta}{\ell_{2}}(P L)_{2} \\
& +K_{21} \sum_{i=1}^{3} \lambda_{i} D_{i 1}+K_{21} \frac{\beta}{\ell}(P L)_{1}
\end{aligned}
$$

Rearranging,

$$
\begin{aligned}
& (\dot{\mathrm{PL}})_{1}=\frac{1}{\ell}{ }_{1}\left(\mathrm{~K}_{11}-\beta \mathrm{K}_{11}-1+\beta \mathrm{K}_{11}\right)(\mathrm{PL})_{1}+\frac{1}{\ell_{2}}\left(\mathrm{~K}_{12}-\beta \mathrm{K}_{12}\right. \\
& \left.+\beta K_{12}\right)(P L)_{2}-K_{11} \sum_{i=1}^{3} \lambda_{i} D_{i 1}+K_{12} \stackrel{3}{\sum}=1 \\
& \lambda_{i} D_{i 2} \\
& (\dot{P L})_{2}=\frac{1}{\ell_{2}}\left(K_{22}-\beta K_{22}-1+\beta K_{22}\right)(P L)_{2}+\frac{1}{\ell}{ }_{1}\left(K_{21}-\beta K_{21}\right. \\
& \left.+\beta K_{21}\right)(P L)_{1}+K_{22} \sum_{i=1}^{3} \lambda_{i} D_{i 2}+K_{21} \begin{array}{l}
3 \\
\sum
\end{array} \\
& \lambda_{i} \mathrm{D}_{\mathrm{i} 1}
\end{aligned}
$$


or

$$
\begin{aligned}
(P L)_{1}= & -\frac{\left(1-K_{11}\right)}{\ell_{1}}(P L)_{1}+\frac{K_{12}}{l_{2}}(P L)_{2}+K_{11} \sum_{i=1}^{3} \lambda_{i} D_{i 1} \\
& +K_{12} \sum_{i=1}^{3} \lambda_{i} D_{i 2} \\
(P L)_{2}= & -\frac{\left(1-K_{22}\right)}{\ell_{2}}(P L)_{2}+\frac{K_{21}}{\ell}(P L)_{1}+K_{22} \underset{i=1}{3} \lambda_{i} D_{i 2} \\
& +K_{21} \sum_{i=1}^{3} \lambda_{i} D_{i 1}
\end{aligned}
$$

These are the equations actually programmed.

The number of delay groups chosen for the present study was selected as a compromise between accuracy and amount of computing equipment required. The original six delay group parameters supplied by AECL personnel were reduced(12) to the effective three-group set shown in Table A-V.

TABLE A-V. Original 6-Group and Reduced 3-Group
Delay Parameters
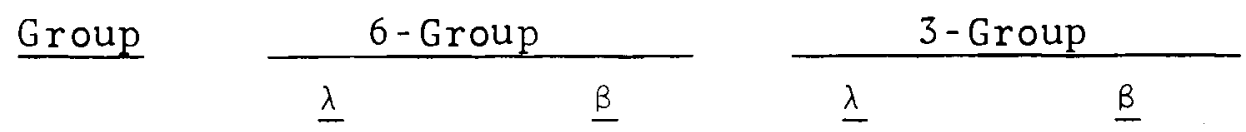

$\begin{array}{lll}1 & 0.0128 & 0.0002 \\ 2 & 0.0315 & 0.0012 \\ 3 & 0.1210 & 0.00099 \\ 4 & 0.3173 & 0.00227 \\ 5 & 1.3555 & 0.00065 \\ 6 & 3.6606 & 0.00014\end{array}$




\section{Controller Equations}

\section{Power Level Controller}

The rate of change of the controller output is a constant times the difference between the calculated power level and the power level setpoint.

$$
\begin{aligned}
\Delta \dot{\mathrm{K}}_{\mathrm{C}}= & \mathrm{G}_{\mathrm{P}}\left[\mathrm{PL}_{\mathrm{S}}-(\mathrm{PL})_{2}\right] \\
& -0.2 \leq \Delta \dot{\mathrm{K}}_{\mathrm{C}} \leq 0.2 \mathrm{mk} / \mathrm{sec}
\end{aligned}
$$

Notice that the power level controller is set up to monitor (PL) 2 or the outer region on $1 y$.

The output of the power level controller is:

$$
\begin{aligned}
\Delta \mathrm{K}_{\mathrm{C}}= & \int_{0}^{\mathrm{t}} \Delta \dot{\mathrm{K}}_{\mathrm{C}} \mathrm{dt} \\
& -3.5 \leq \Delta \mathrm{K}_{\mathrm{C}} \leq 3.5 \mathrm{mk}
\end{aligned}
$$

\section{Steam Drum Pressure}

The rate of change in percent of the control valve lift is a function of changes in the steam drum pressure and changes in the rates of changes of steam drum pressure:

$$
\Delta \dot{\mathrm{L}}=\mathrm{k}_{1} \Delta \mathrm{P}_{\mathrm{D}}+\mathrm{k}_{2} \Delta \dot{\mathrm{P}}_{\mathrm{D}}
$$

and the corresponding percent change in control valve lift is:

$$
\Delta \mathrm{L}=\int_{0}^{\mathrm{t}} \Delta \dot{\mathrm{L}} \mathrm{dt}
$$

Changes in the steam flow to the turbine are represented by:

$$
\Delta \dot{\mathrm{M}}_{\mathrm{S}}=\mathrm{k}_{3} \Delta \mathrm{P}_{\mathrm{D}}+\mathrm{k}_{4} \Delta \mathrm{L}
$$

Changes in steam drum water level are represented by:

$$
\Delta \dot{\mathrm{M}}_{\mathrm{FW}}=\frac{1}{\tau}\left[\Delta \dot{\mathrm{M}}_{S}-\frac{1}{\tau} G_{L} \Delta \mathrm{L}_{D} e^{-t / \tau}\right] e^{-t / \tau}
$$




\section{GENERAL NOMENCLATURE LIST}

$a_{c j}$

$A_{j}$

A oj

$\mathrm{A}_{\mathrm{T} j}$

$\alpha_{p}^{*}$

${ }^{\alpha} \mathrm{TC}$

${ }^{\alpha} \overline{\mathrm{T}}_{\mathrm{F}}$

$\beta_{i}$

$D_{i j}$

e

$f_{i}\left(P_{D}, Z\right)$

g

$\mathrm{G}_{\mathrm{L}}$

${ }^{G} \mathrm{P}$

$\mathrm{h}_{\mathrm{D}}$

$\mathrm{h}_{\mathrm{Dz}}$

$\mathrm{h}_{\mathrm{fD}}$

$h_{f j}$

$\mathrm{h}_{\mathrm{FW}}$

$\mathrm{h}_{\mathrm{GD}}$
Regional power level controller feedback ratio

Regional cross sectional area of reactor $-f t^{2}$

Regional cross sectional area of outlet risers -

Fuel element cross sectional area per region -

Coolant density reactivity coefficient $\mathrm{k} / \mathrm{gm} / \mathrm{cm}^{3}$

Coolant temperature reactivity coefficient $\mathrm{k} /{ }^{\circ} \mathrm{C}$

Fue 1 temperature reactivity coefficient $-\mathrm{k} /{ }^{\circ} \mathrm{C}$

Fraction of fission neutrons which are delayed and appear in group $i$

Regional modified concentration of precursor from which the $i^{\text {th }}$ group of neutrons arise $\mathrm{MW} / \mathrm{sec}$

The base of the natural system of logarithms

Function which accounts for the amount of saturated water and steam in the steam drum $\mathrm{psia} / \mathrm{ft}^{3}$

Gravity constant - $f t / \sec ^{2}$

Drum level to flow conversion constant $\mathrm{lb} / \mathrm{ft}-\mathrm{sec}$

Power level to reactivity conversion constant $\mathrm{mk} / \mathrm{W}-\mathrm{sec}$

Enthalpy of subcooled water in the steam drum Btu/1b

Nominal or initial value of enthalpy of subcooled water in the steam drum - Btu/lb

Saturation enthalpy of saturated water in the steam drum - Btu/lb

Saturation enthalpy of the water in the reactor core - Btu/lb

Enthalpy of feedwater to the steam drum Btu/1b

Enthalpy of the steam in the steam drum - Btu/1b 
$\mathrm{h}_{\mathrm{I}}$

$\mathrm{h}_{\mathrm{I} z}$

$\mathrm{h}_{\text {ID }}$

$\mathrm{h}_{\mathrm{oj}}$

hoj

$\overline{\mathrm{h}}_{\mathrm{ojz}}$

$h_{1 j}$

$h_{1 j z}$

$\mathrm{h}_{2 \mathrm{j}}$

$\bar{h}_{2 j}$

$\bar{h}_{2 j z}$

$k_{1}$

$\mathrm{k}_{2}$

$\mathrm{k}_{3}$

$\mathrm{k}_{4}$

$\mathrm{K}_{\mathrm{F} 1 \mathrm{j}}$

$\mathrm{K}_{\mathrm{Foj}}$

$\mathrm{K}_{\mathrm{F} 2 \mathrm{j}}$

$\mathrm{K}_{\text {FD }}$

$\mathrm{K}_{\mathrm{P}}$
Enthalpy of the subcooled water at the input to the inlet risers - Btu/lb

Nominal or initial value of enthalpy of the subcooled water at the input to the inlet risers $\mathrm{Btu} / \mathrm{Ib}$

Enthalpy of the two phase mixture at the input of the steam drum - Btu/lb

Enthalpy of the two-phase mixture at the output of the outlet risers - Btu/lb

Average enthalpy of the two-phase mixture in the outlet risers - Btu/lb

Nominal or initial value of the average enthalpy of the two-phase mixture in the outlet risers $\mathrm{Btu} / \mathrm{Ib}$

Enthalpy at the inlets of the reactor core Btu/Ib

Nominal or initial value of the enthalpy at the inlets of the reactor core - Btu/lb

Enthalpy at the outlets of the reactor core $\mathrm{Btu} / \mathrm{Ib}$

Average enthalpy of the two-phase mixture in the reactor core - Btu/1b

Nominal or initial value of the average enthalpy of the two-phase mixture in the reactor core $\mathrm{Btu} / 1 \mathrm{~b}$

Pressure controller conversion constant $\% /$ psia-sec

Pressure controller conversion constant $\% /$ psia

Pressure controller conversion constant $1 b / \mathrm{psia-sec}$

Pressure controller conversion constant $1 \mathrm{~b} / \mathrm{sec}-\frac{0}{0}$ opening

Inlet risers friction factor $-\sec ^{2} / 1 b-i n .^{2}$

outlet risers friction factor $-\sec ^{2} / 1 b-i n .^{2}$

Two-phase region of core friction factor sec $^{2} / 1 \mathrm{~b}-$ in. 2

Downcomer friction factor $-\sec ^{2} / 1 b-i n .^{2}$

Downcomer pump friction factor $-\sec ^{2} / 1 b-i n .^{2}$ 


\begin{tabular}{|c|c|}
\hline${ }^{K}$ I D & Downcomer inertia factor $-\sec ^{2} /$ in. ${ }^{2}$ \\
\hline I I j & Inlet risers inertia factor $\sec ^{2} /$ in..$^{2}$ \\
\hline$K_{B j}$ & Reactivity feedback zero bias - milli-k \\
\hline$\Delta \mathrm{K}_{\mathrm{C}}$ & Power level controller output - milli-k \\
\hline$K_{i j}$ & $\begin{array}{l}\text { Time dependent coupling coefficients - } \\
\text { milli-k }\end{array}$ \\
\hline & $\begin{array}{l}\text { Change in time dependent coupling coefficients } \\
\text { milli-k }\end{array}$ \\
\hline & $\begin{array}{l}\text { Nominal or initial value of coupling } \\
\text { coefficients - milli-k }\end{array}$ \\
\hline$\Delta K_{j}$ & $\begin{array}{l}\text { System reactivity change in } j^{\text {th }} \text { region - } \\
\text { milli-k }\end{array}$ \\
\hline e. & Prompt neutron lifetime - sec \\
\hline$\Delta \mathrm{L}$ & Change in control valve lift - : \\
\hline & Boiling length - ft \\
\hline & Core length $-\mathrm{ft}$ \\
\hline & Change in steam drum water level - ft \\
\hline$L_{N B j}$ & Nonboiling length $-\mathrm{ft}$ \\
\hline $\mathrm{L}_{c}$ & Length of outlet risers - ft \\
\hline$\lambda_{i}$ & Decay constant $-\sec ^{-1}$ \\
\hline${ }_{\mathrm{MD}}$ & Mass of saturated water in steam drum - $1 \mathrm{~b}$ \\
\hline & Water flow into steam drum - $1 \mathrm{~b} / \mathrm{sec}$ \\
\hline & Feedwater flow into steam drum $-1 \mathrm{~b} / \mathrm{sec}$ \\
\hline$\dot{\mathrm{M}}_{\mathrm{FW} \mathrm{z}}$ & $\begin{array}{l}\text { Nominal or initial value of feedwater flow } \\
\text { into steam drum - lb/sec }\end{array}$ \\
\hline$\dot{\mathrm{M}}_{\mathrm{GID}}$ & Steam flow into steam drum - $1 \mathrm{~b} / \mathrm{sec}$ \\
\hline$\ddot{M}_{I D}$ & $\begin{array}{l}\text { Total steam-water flow into steam drum - } \\
\text { lb/sec }\end{array}$ \\
\hline $\mathrm{M}_{\mathrm{LD}}$ & Mass of subcooled water in the steam drum - 1 b \\
\hline$\left.{ }^{\left(M_{L D}\right.}+M_{F D}\right)_{z}$ & $\begin{array}{l}\text { Nominal or initial value of mass of water in } \\
\text { the steam drum - 1b }\end{array}$ \\
\hline
\end{tabular}


Two-phase flow out of outlet risers - $1 \mathrm{~b} / \mathrm{sec}$ Average two-phase flow in outlet risers - $1 b / s e c$ Waterflow in downcomers - $1 \mathrm{~b} / \mathrm{sec}$

Steam flow out of steam drum - $1 \mathrm{~b} / \mathrm{sec}$

Nominal or initial value of steam flow out of steam drum - $1 \mathrm{~b} / \mathrm{sec}$

Water flow in inlet risers and subcooled regions of the reactor core - $1 \mathrm{~b} / \mathrm{sec}$

Nominal or initial value of water flow in inlet risers and subcooled regions of the reactor core - $1 \mathrm{~b} / \mathrm{sec}$

Two-phase flow out of two-phase regions of the reactor core - $1 b / \mathrm{sec}$

Average two-phase flow in two-phase regions of the reactor core - $1 \mathrm{~b} / \mathrm{sec}$

Pressure at interface between subcooled and twophase regions of the reactor core - psia

Pressure in the steam drum - psia

Nominal or initial value of pressure in the steam drum - psia

Pressure at the inlet to the inlet risers - psia

Summation of friction and head pressure drops in the two-phase regions of the core - psia

Summation of friction and head pressure drops in the outlet risers - psia

zero flow pressure drop across downcomer pumps psia

Regional power level - MW

Nominal or initial value of regional power levels - MW

Total power level controller setpoint - MW

Outlet risers average two-phase friction multiplier

Core average two-phase friction multiplier

Heat input to reactor regions - Btu/ft-sec 


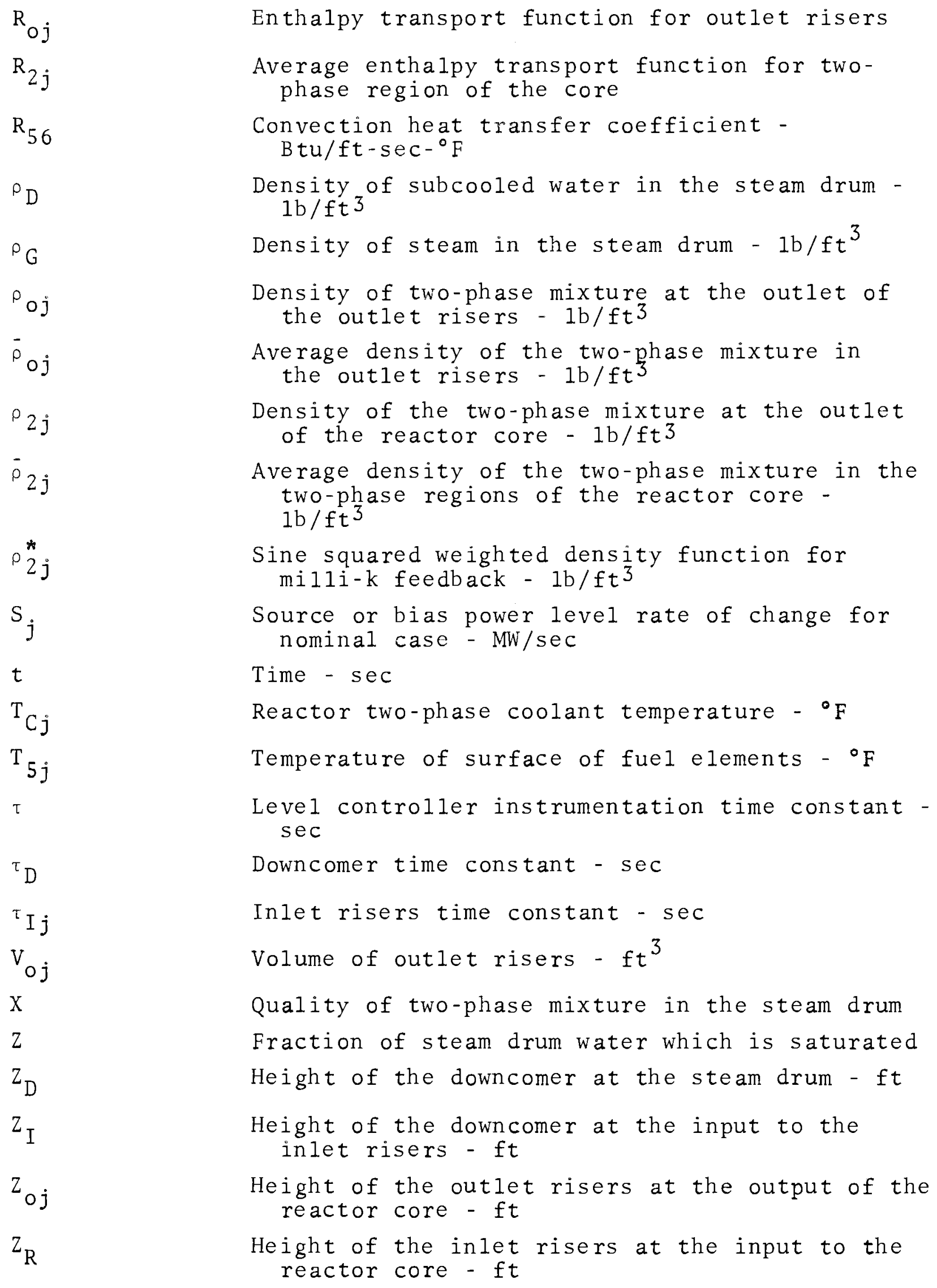

Enthalpy transport function for outlet risers

Average enthalpy transport function for twophase region of the core

Convection heat transfer coefficient $\mathrm{Btu} / \mathrm{ft}-\mathrm{sec}^{\circ} \mathrm{F}$

Density of subcooled water in the steam drum $1 \mathrm{~b} / \mathrm{ft}^{3}$

Density of steam in the steam drum - $1 \mathrm{~b} / \mathrm{ft}^{3}$

Density of two-phase mixture at the outlet of the outlet risers - lb/ft 3

Average density of the two-phase mixture in the outlet risers - $1 \mathrm{~b} / \mathrm{ft}^{3}$

Density of the two-phase mixture at the outlet of the reactor core - $1 \mathrm{~b} / \mathrm{ft} 3$

Average density of the two-phase mixture in the two-phase regions of the reactor core $\mathrm{lb} / \mathrm{ft}^{3}$

Sine squared weighted density function for milli-k feedback - lb/ft 3

Source or bias power level rate of change for nominal case - MW/sec

Time - sec

Reactor two-phase coolant temperature - ${ }^{\circ} \mathrm{F}$

Temperature of surface of fuel elements - ${ }^{\circ} \mathrm{F}$

Level controller instrumentation time constant sec

Downcomer time constant - sec

Inlet risers time constant - sec

Volume of outlet risers - $\mathrm{ft}^{3}$

Quality of two-phase mixture in the steam drum Fraction of steam drum water which is saturated Height of the downcomer at the steam drum - ft

Height of the downcomer at the input to the inlet risers - $f t$

Height of the outlet risers at the output of the reactor core - $f t$

Height of the inlet risers at the input to the reactor core - $f t$ 


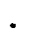

$+$

$\bullet$ 
APPENDIX B

ANALOG SCHEMATICS, POT SET, AND STATIC SET SHEETS 


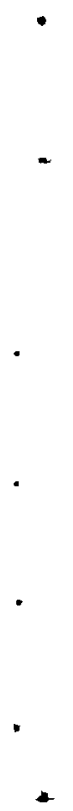

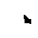

•

‘

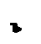




\section{APPENDIX B \\ ANALOG SCHEMATICS, POT SET, AND STATIC SET SHEETS}

\section{ANALOG SCHEMATIC DIAGRAMS}

The following Analog Schematic Diagrams (Figures B-1

thru B-11) depict the schematic arrangements of computer circuits for each phase of the Boiling Stability Study. The large hexagonal symbols are used to denote circuit connections between the pages. The smaller hexagonal symbols represent the trunk 1 ines connecting the three computers together. The oval symbols contain the strip chart recorder graph numbers. POT SET SHEETS

Pots 15 and 20 on the 2133 are only approximate values. They are adjusted at each computing session to balance the heat input to the remainder of the circuit.

Pots 0 and $69,\left(0.001 / \ell_{1}\right)$ and Pots 1 and $19,\left(0.001 / \ell_{2}\right)$ are set at 0.9999 . While normally these pots would not be required, in their presence in the circuits allows for changes in $\ell_{1}$ and $\ell_{2} \cdot$

The setting of Pot 31 to zero means that particular pathway is not needed in the circuit. Again, however, it does allow for changes in $\Delta \mathrm{K}_{21} / \Delta \mathrm{K}_{2}$ as necessary. All of these pots are on the EASE 1132 . 


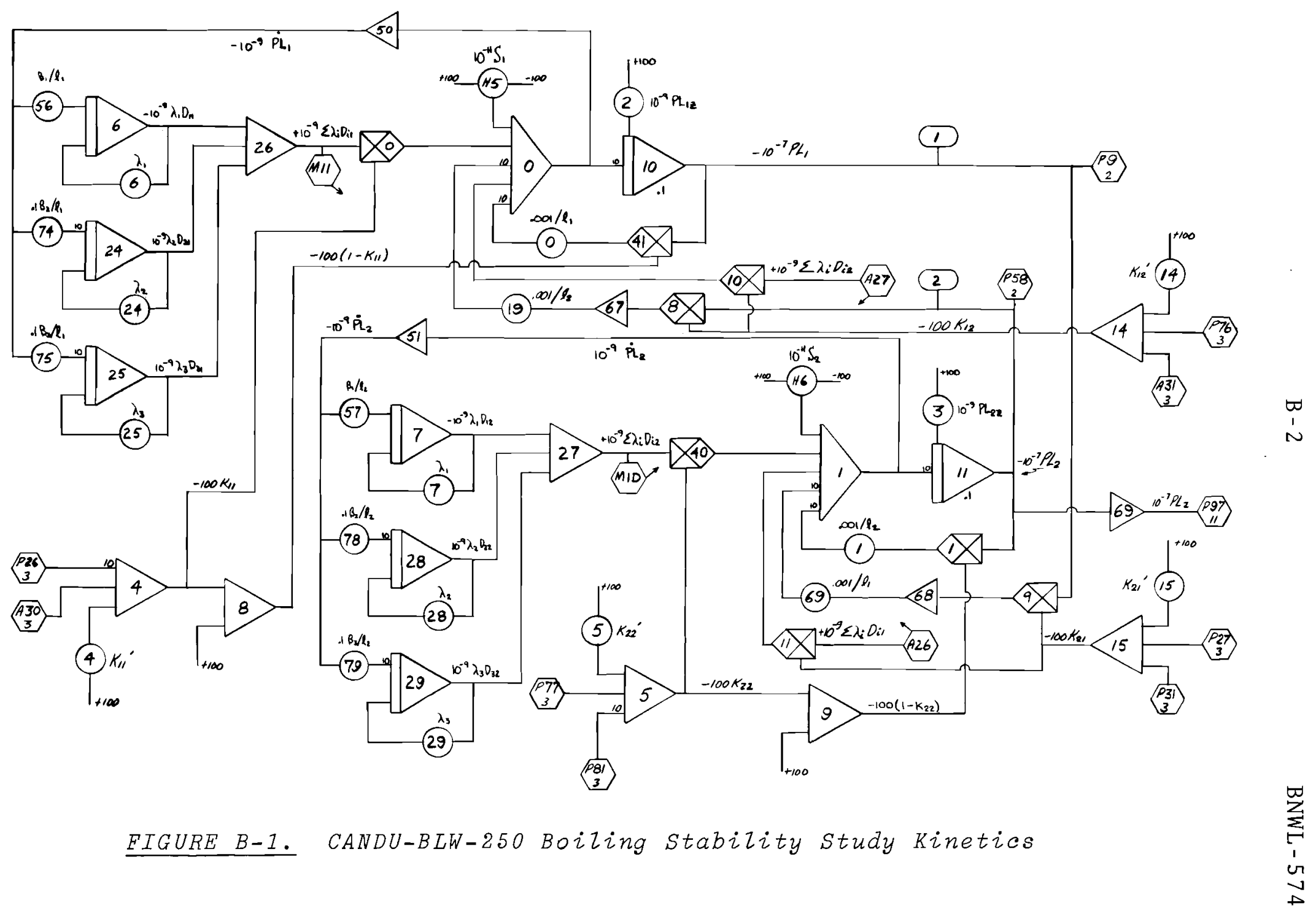




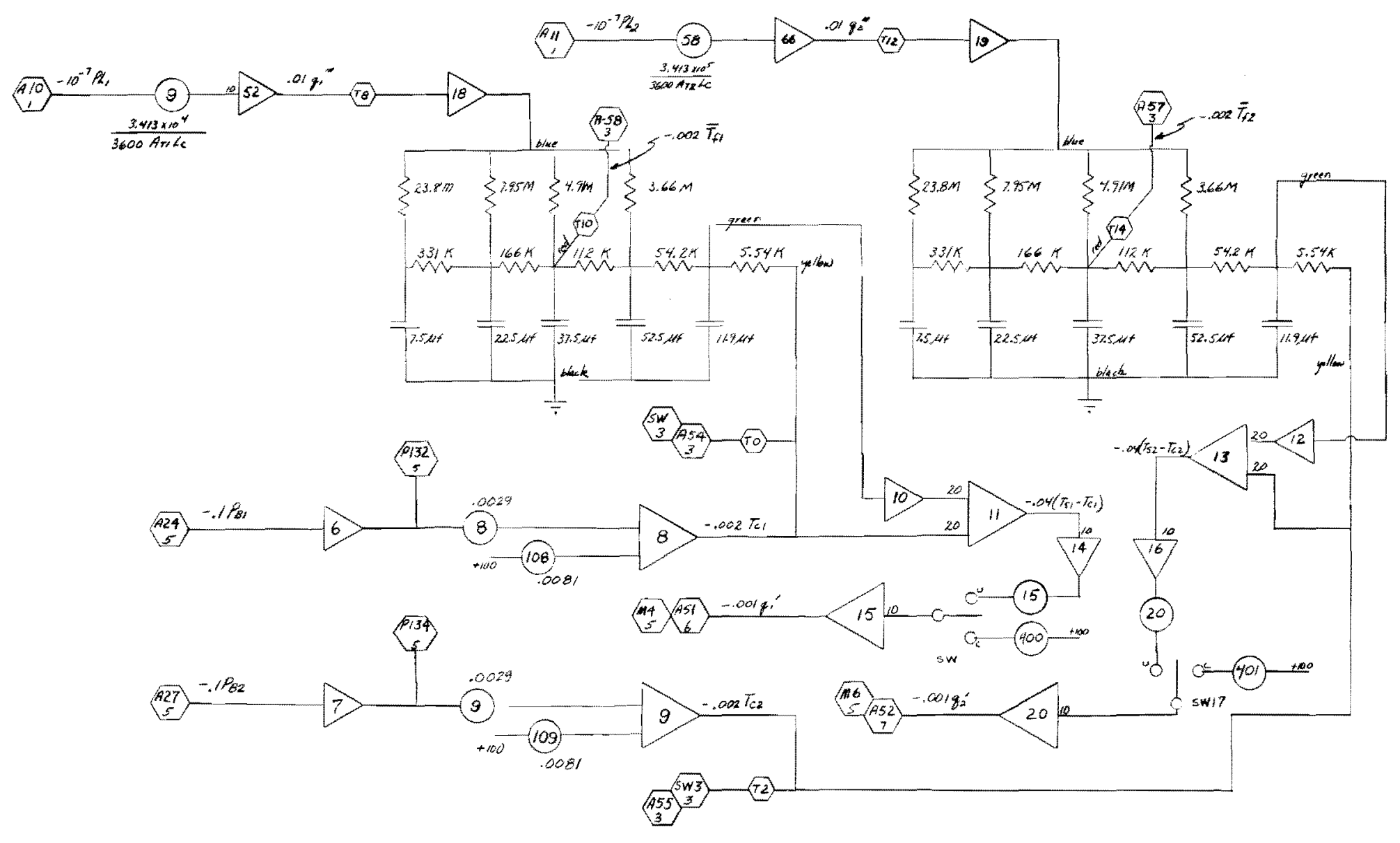

FIGURE B-2. CANDU-BLW-250 Boizing stability Study Temperature Circuit-Fuel Modet 


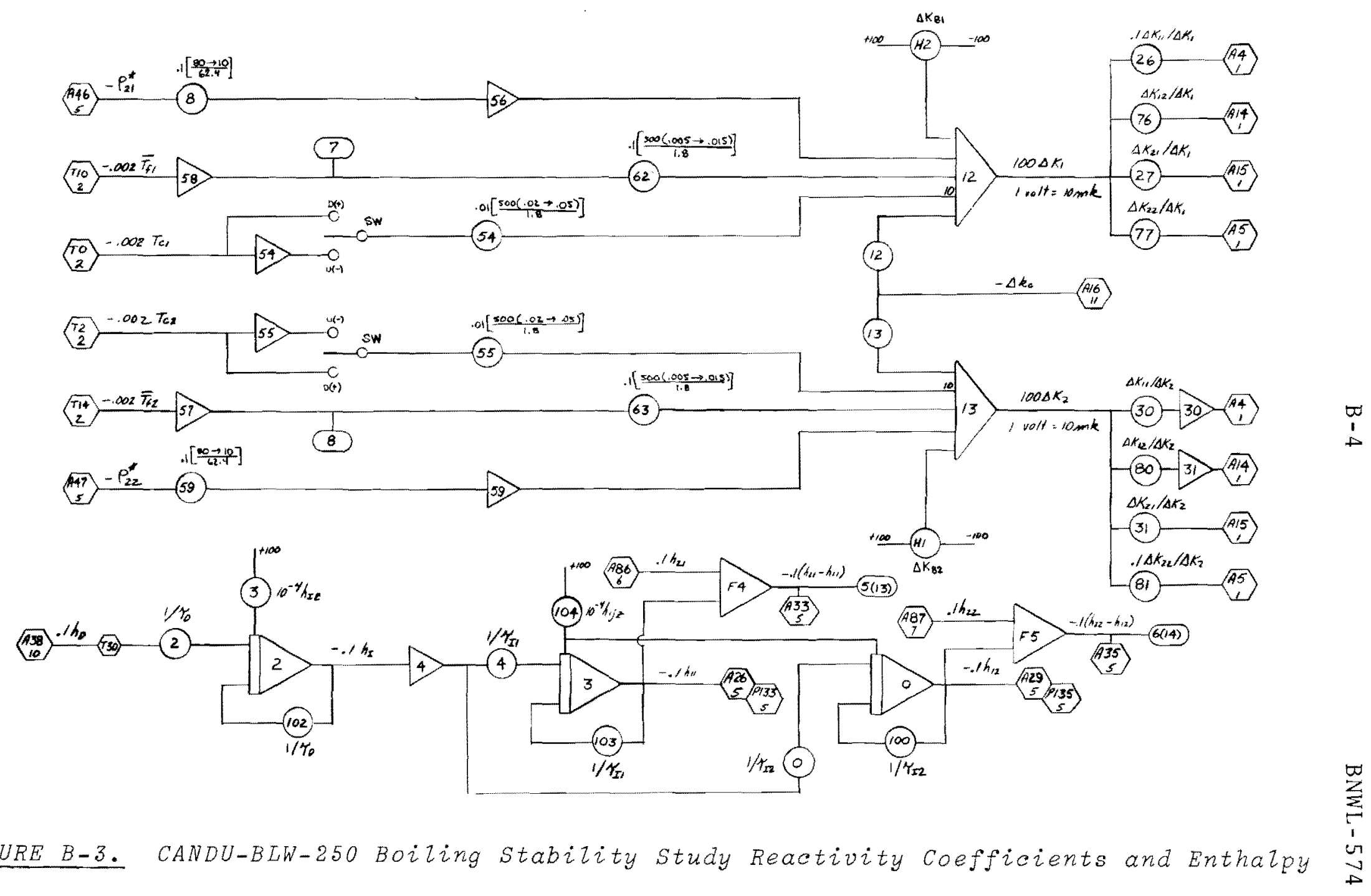

EIGURE B-3. CANDU-BLW-250 Boiling Stability Study Reactivity Coefficients and Enthalpy 


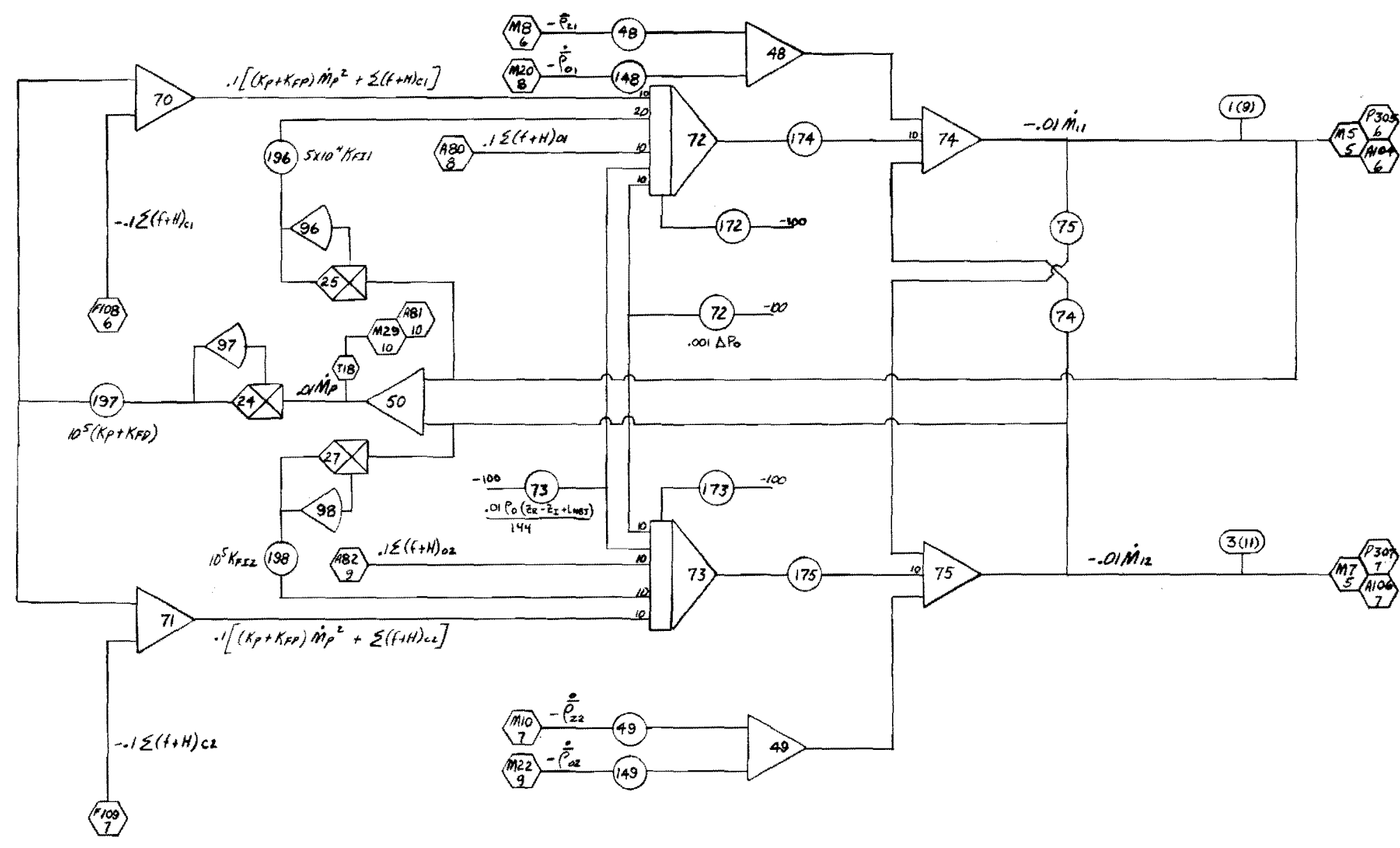

FIGURE B-4. CANDU-BLW-250 Boiling Stability Study Inlet Risers 


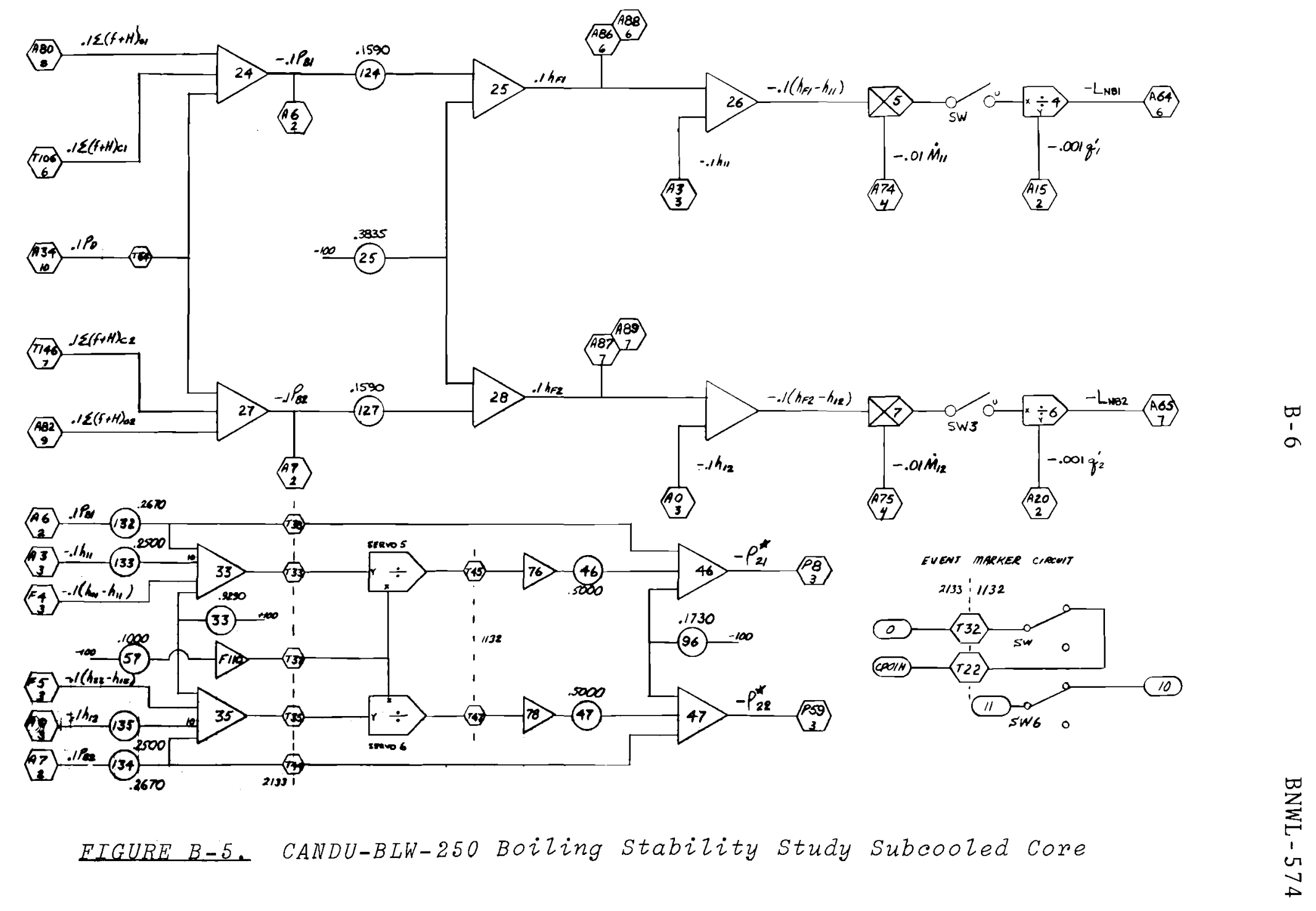




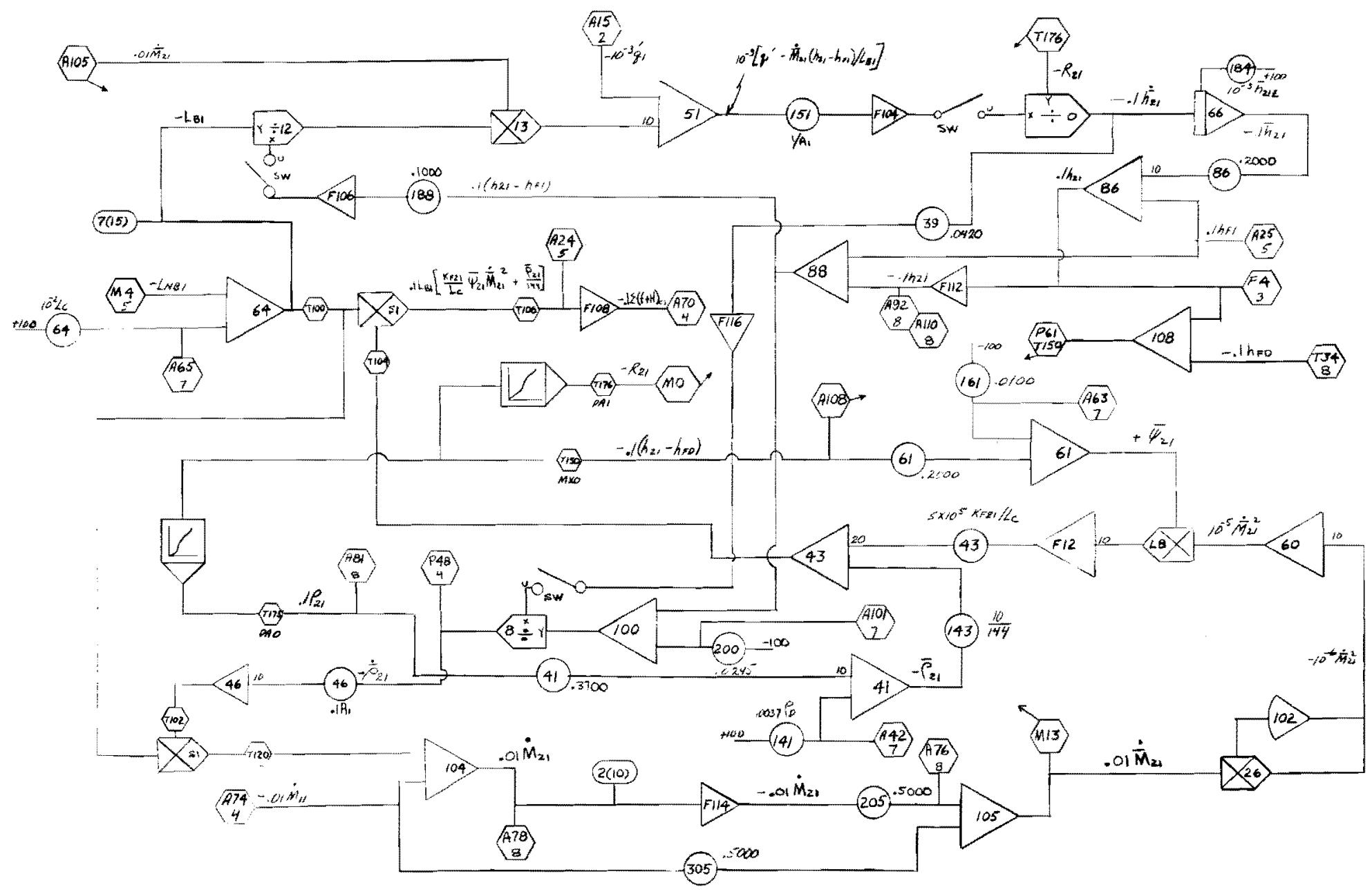

EIGURE B-6. Two-Phase Core Elow Channel 1 


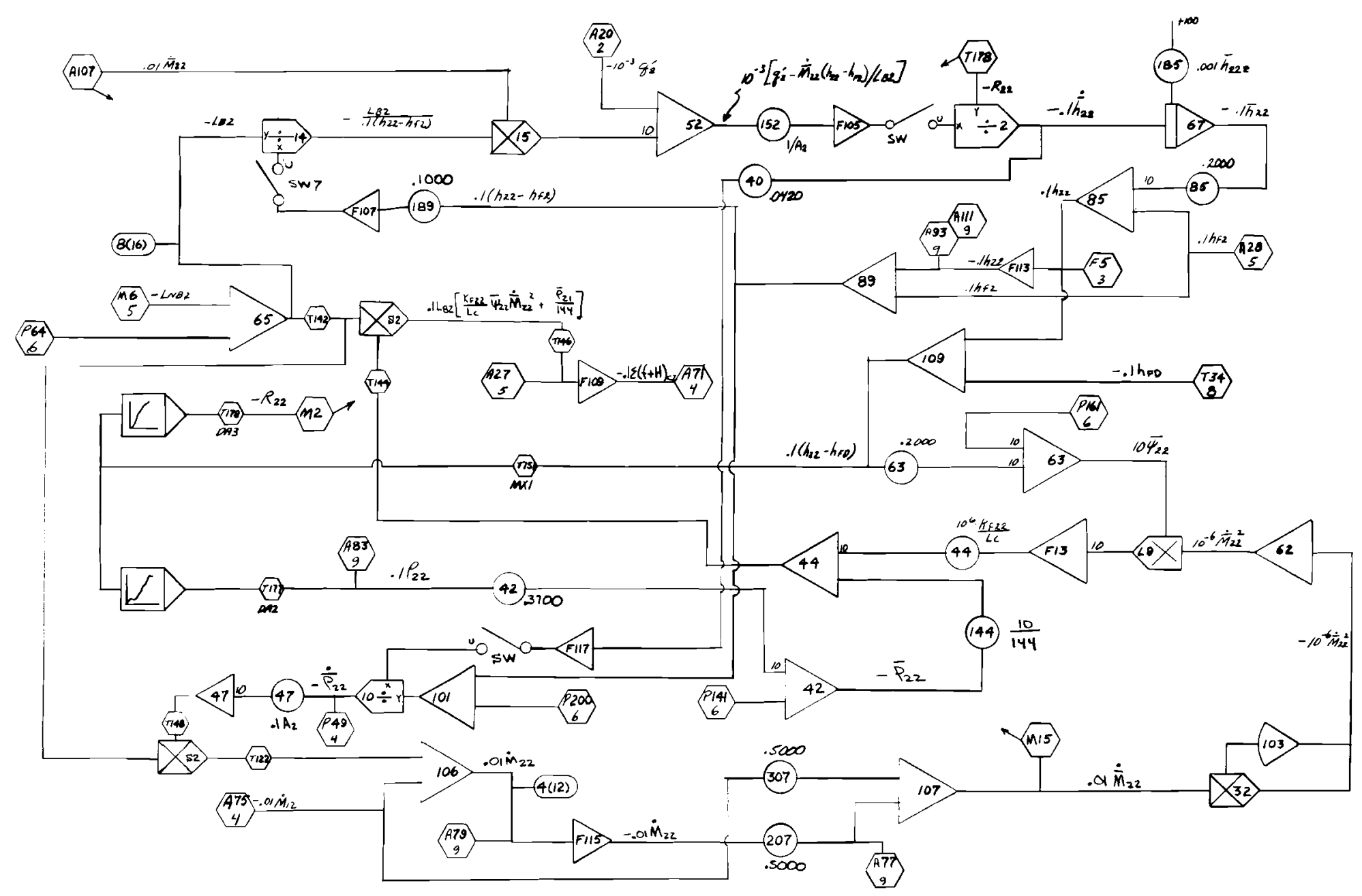

FIGURE B-7. Two-Phase Core Flow Channel 2 


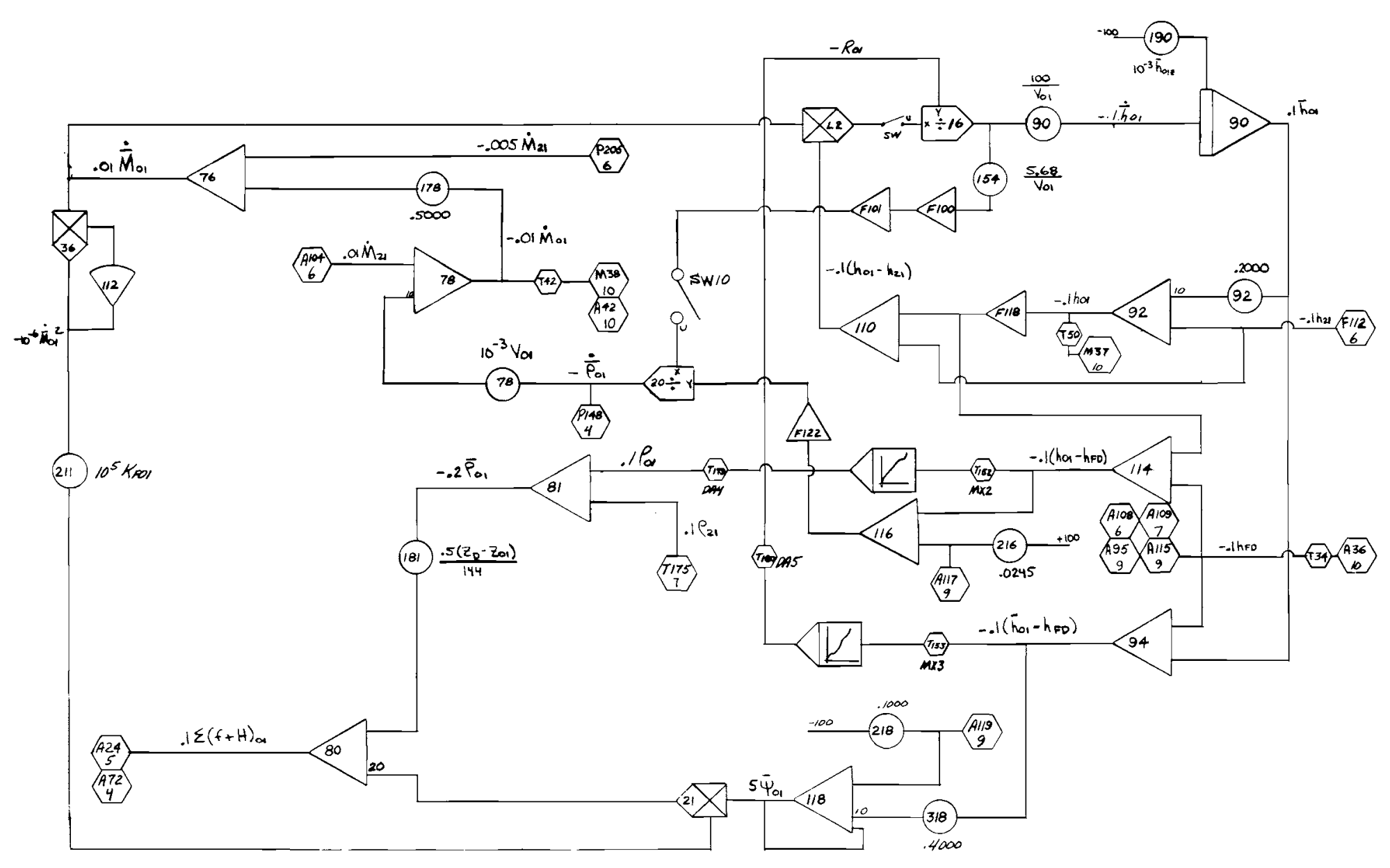

$\varpi$
1
0

FIGURE B-8. CANDU-BLW-250 Boiling Stability Study outzet Riser-Flow Channel 1 


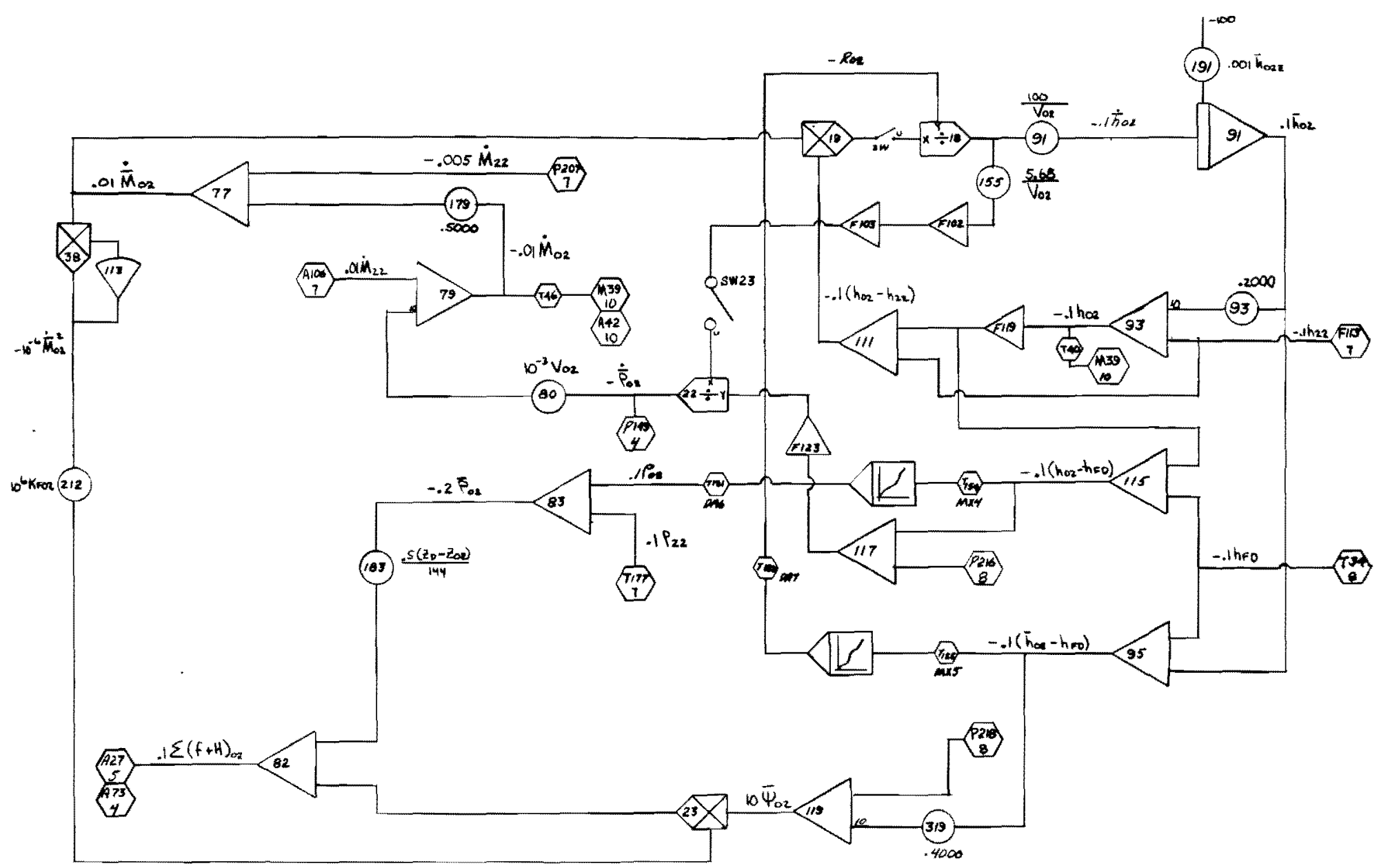

FIGURE B-9. CANDU-BLW-250 Boizing Stabizity Study outzet Riser-Flow Channel 2 


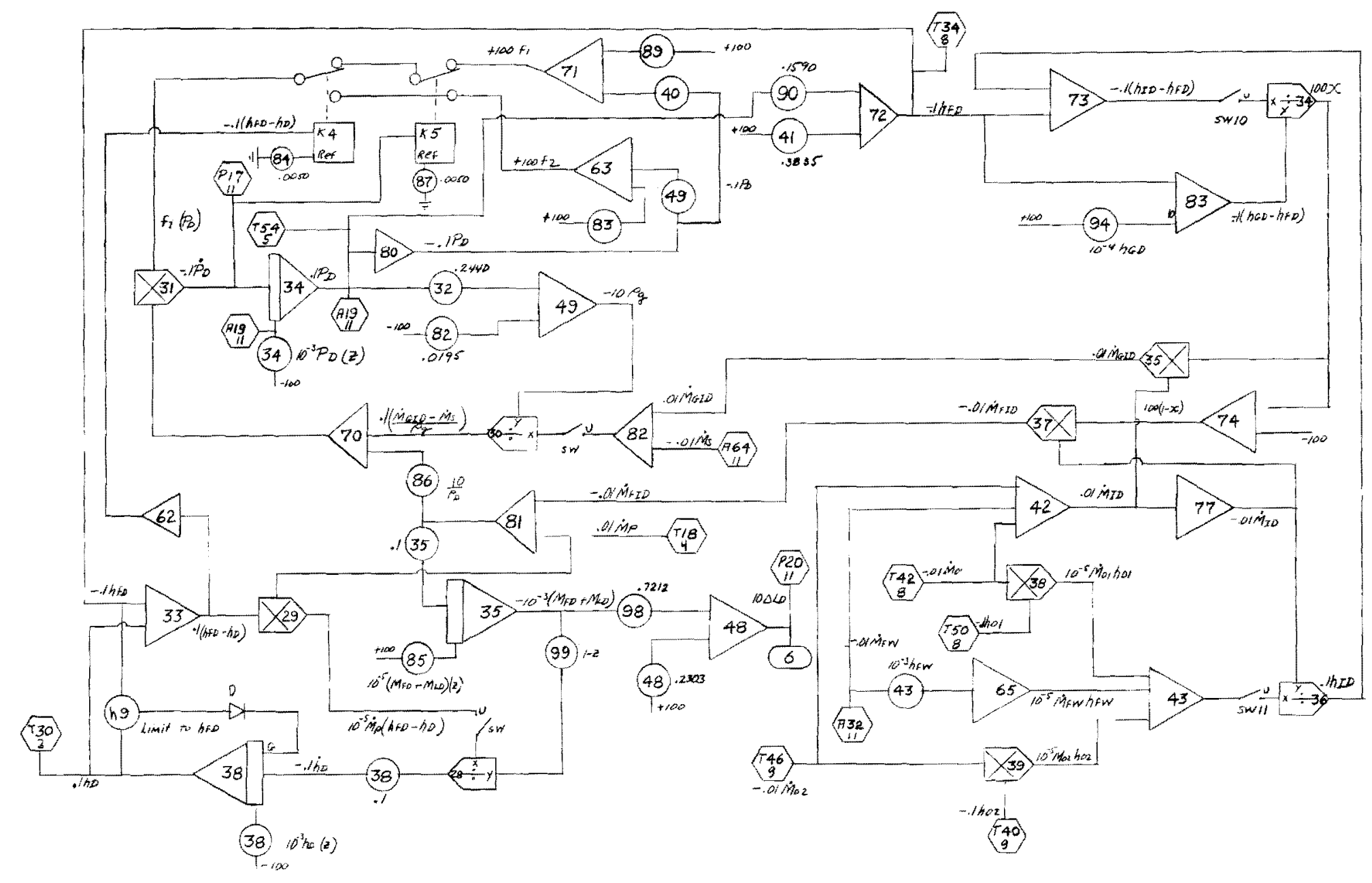




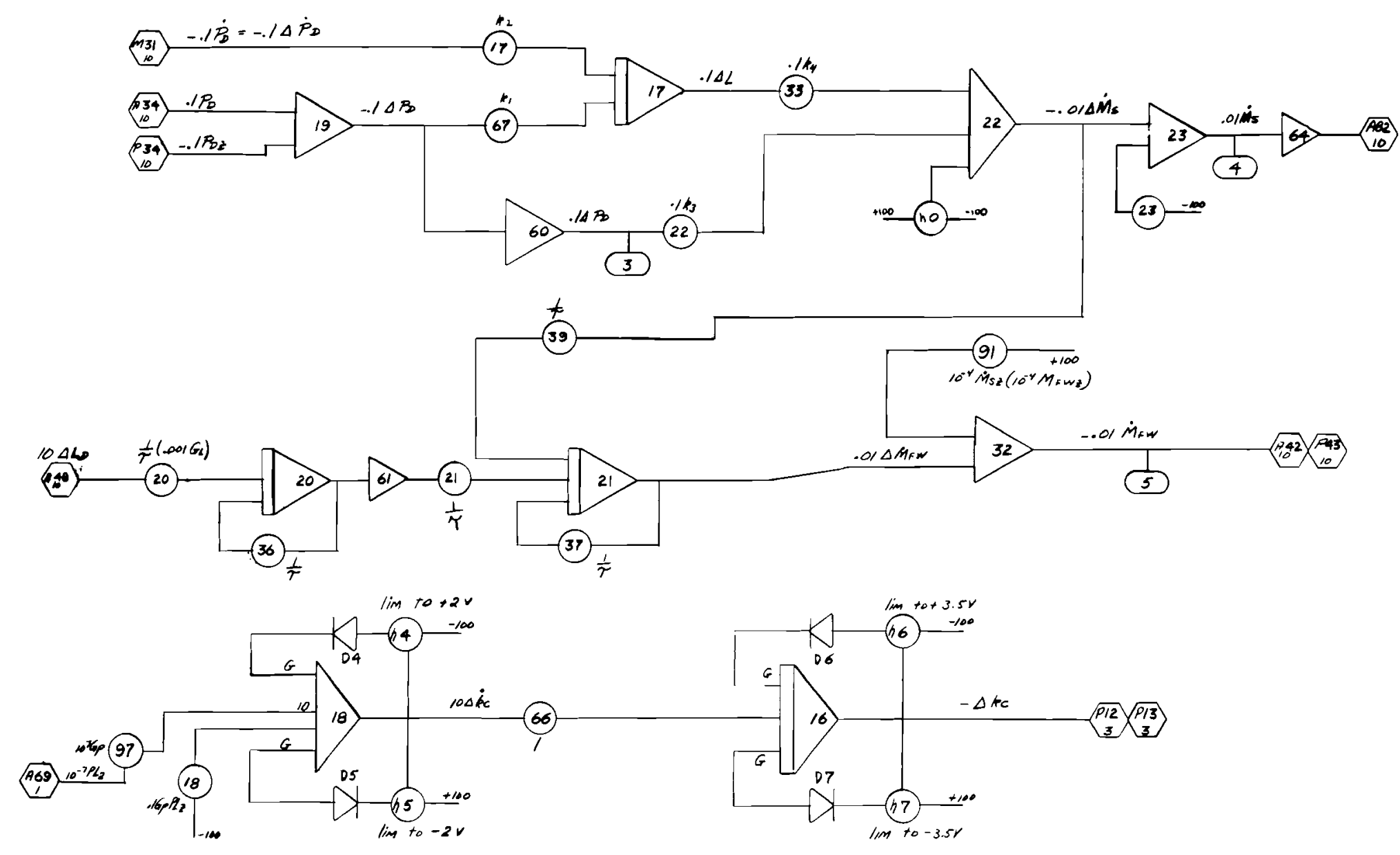

FIGURE B-11. CANDU-BLW-250 Boizing stability study Controlzers 
ANALOG COMPUTER POTSET COEFFICIEINTS - SHEET I

\begin{tabular}{|c|c|c|c|c|}
\hline \multicolumn{2}{|c|}{$\begin{array}{l}\text { CONDITION } \\
\text { EINGIUIERR }\end{array}$} & \multicolumn{3}{|c|}{ Nominal } \\
\hline & SETITING & REMARISS & HO. SETTIVG & REMARKS \\
\hline 000 & .9999 & $.001 / 21$ & 050 & \\
\hline & .9999 & $.001 / 81$ & 051 & \\
\hline 002 & .1750 & $10^{-9}$ PLiz & 052 & \\
\hline 003 & .5850 & $10^{-9} \mathrm{PL}_{22}$ & 053 & \\
\hline & .8413 & $\mathrm{~K}_{77}{ }^{\prime}$ & $054 \lcm{.1388}$ & $\alpha T_{C 2}$ \\
\hline 005 & .9780 & $\mathrm{~K}_{72}{ }^{\prime}$ & $055 \lcm{.1388}$ & $\alpha T<2$ \\
\hline & .1210 & $\lambda 1$ & \begin{tabular}{|l|l|}
056 & .2900 \\
\end{tabular} & $B \sqrt{\ell 1}$ \\
\hline & .1210 & $\lambda 1$ & \begin{tabular}{|l|l|}
057 & .9900 \\
\end{tabular} & $B \sqrt{\ell 2}$ \\
\hline 008 & .0865 & $\alpha \quad 1$ & \begin{tabular}{|l|l|}
058 & .4208 \\
\end{tabular} & $3.413 \times 10^{5} / 3600 \mathrm{AT2LC}$ \\
\hline & .1739 & $3.413 \times 10^{4} / 3600 \mathrm{~A}_{T I} \mathrm{LC}$ & \begin{tabular}{|l|l|}
059 & .0865 \\
\end{tabular} & \\
\hline 010 & & & 060 & $\mathrm{pZ}$ \\
\hline 027 & & & 061 & \\
\hline 012 & & $\operatorname{acc}$ & \begin{tabular}{l|l}
062 & .1111 \\
\end{tabular} & $\alpha T_{\mathrm{F}}$ \\
\hline 013 & .0206 & $a_{02}$ & \begin{tabular}{|l|l|}
063 & .1111 \\
\end{tabular} & $\alpha \mathrm{T}_{\mathrm{F} 2}$ \\
\hline OI4 & .0474 & $K_{72}$ & 064 & \\
\hline 015 & .0737 & $\mathrm{~K}_{27^{\prime}}$ & 065 & \\
\hline 016 & & & \begin{tabular}{|l|l|}
066 & .1000 \\
\end{tabular} & Reactor Controller Scale Fact \\
\hline 027 & .2000 & $\mathrm{~kg}$ & \begin{tabular}{|l|l|}
067 & .0600 \\
\end{tabular} & $\mathrm{k}]$ \\
\hline 018 & .7600 & $.1 \mathrm{G}_{0} \mathrm{PL}_{\mathrm{z}}$ & \begin{tabular}{|l|l|}
068 & .1000 \\
\end{tabular} & $10^{7} \mathrm{G}_{0}$ \\
\hline 019 & .2999 & .001 & \begin{tabular}{|l|l|}
059 & .9999 \\
\end{tabular} & $.001 / \ell_{1}$ \\
\hline 020 & .2000 & $(1 / \tau)\left(.001 G_{I}\right)$ & 070 & \\
\hline & .5000 & I/ $\tau$ & 072 & \\
\hline 022 & .0983 & $.1 \mathrm{k}_{3}$ & 072 & \\
\hline & .1000 & $10^{-4} \mathrm{M}_{S Z}$ & 073 & \\
\hline & .0232 & $\lambda 2$ & \begin{tabular}{|l|l|}
074 & .1316 \\
\end{tabular} & $.1 B_{2} / \ell 1$ \\
\hline 025 & .6755 & $\lambda 3$ & 075.3144 & $.1 \beta_{3} / \ell_{1}$ \\
\hline 026 & .4762 & $.1 \Delta \mathrm{K}_{71} / \Delta \mathrm{K}_{7}$ & \begin{tabular}{|l|l|}
076 & .4080 \\
\end{tabular} & $\Delta K_{12} / \Delta K_{1}$ \\
\hline 027 & .3400 & $\Delta K_{21} / \Delta^{K} 1$ & \begin{tabular}{|l|l|l|}
077 & .0680 \\
\end{tabular} & $\Delta K_{22} / \Delta K_{2}$ \\
\hline 028 & .0232 & $\lambda 2$ & 078.1316 & $.182 / \ell 2$ \\
\hline 029 & .6755 & $\lambda 3$ & $079 \cdot 3144$ & $.1 \beta 3 \sqrt{\ell 2}$ \\
\hline 030 & .7970 & $\Delta \mathrm{K}_{11} / \Delta \mathrm{K}_{2}$ & $080 \quad .1080$ & $\Delta K_{12} / \Delta K_{2}$ \\
\hline 031 & .0000 & $\Delta K_{2 l} / \Delta K_{2}$ & 081.1284 & $.1 \Delta \mathrm{K}_{22} / \Delta \mathrm{K}_{2}$ \\
\hline 032 & .2440 & $\rho$ Slope & $\begin{array}{ll}0.0195 \\
\end{array}$ & $\rho_{0} \quad$ intercept \\
\hline 033 & .9360 & \begin{tabular}{|l|l|}
$\mathrm{g}$ & $.1 \mathrm{~kL}$ \\
\end{tabular} & \begin{tabular}{|l|l|}
083 & .0810 \\
\end{tabular} & $\mathrm{~B}_{\mathrm{f}_{2}}$ intercept $(\mathrm{z}=.1 / 2)$ \\
\hline 034 & .7650 & $.001 \quad \mathrm{PDz}$ & 084.0050 & Relay roise Suppressor \\
\hline 035 & .1000 & & \begin{tabular}{|l|l|}
085 & .3200 \\
\end{tabular} & $10^{-5}\left(N_{D D}+M_{L T}(I) z\right.$ \\
\hline 036 & .5000 & $1 / \tau$ & \begin{tabular}{l|l}
0086 & .2079 \\
\end{tabular} & $10 / 0$ \\
\hline 037 & .5000 & $1 / \tau$ & \begin{tabular}{|l|l|}
087 & .0050 \\
\end{tabular} & Relay loise Suppressor \\
\hline 038 & .1000 & Water Mass in S.D. Scale Fact & \begin{tabular}{l|l}
0888 & .5051 \\
\end{tabular} & $.001 \mathrm{~h}_{\mathrm{DZ}}$ \\
\hline 039 & .5000 & $1 / \tau$ & \begin{tabular}{|l|l|}
089 & .0900 \\
\end{tabular} & $f_{1}$ intercept $(\mathrm{Z}=1)$ \\
\hline 040 & .3000 & f) slope $(\mathrm{Z}=1)$ & \begin{tabular}{|l|l|}
090 & .1590 \\
\end{tabular} & hFD slope \\
\hline 041 & .3835 & $h_{\text {ND }}$ intercept & \begin{tabular}{|l|l|}
092 & .1000 \\
\end{tabular} & $10^{-4} \mathrm{MENZ}$ \\
\hline 042 & & & 092 & \\
\hline 043 & .4892 & $.001 h_{\mathrm{FW}}$ & 093 & \\
\hline 044 & & & 094.1200 & $10^{-4} h_{0 D}$ \\
\hline 045 & & & 095 & \\
\hline 046 & .5000 & $P * 21$ value (scale) & \begin{tabular}{|l|l|}
096 & .1730 \\
\end{tabular} & $P * 2$ j value \\
\hline 047 & .5000 & P*22 value (scale) & \begin{tabular}{|l|l|}
097 & .1000 \\
\end{tabular} & $10 \mathrm{Gp}$ \\
\hline 048 & .2308 & In intercept & \begin{tabular}{|l|l|}
098 & .7212 \\
\end{tabular} & L. slope \\
\hline 049 & .3600 & $f_{2}$ slope $\left(z=\frac{1}{2}\right)$ & \begin{tabular}{|l|l|}
099 & .5000 \\
\end{tabular} & $1-Z \quad Z=\frac{1}{2}$ \\
\hline
\end{tabular}


1. AIOG COIPUIER POTSTT COLTFICIDIS - SINLT I

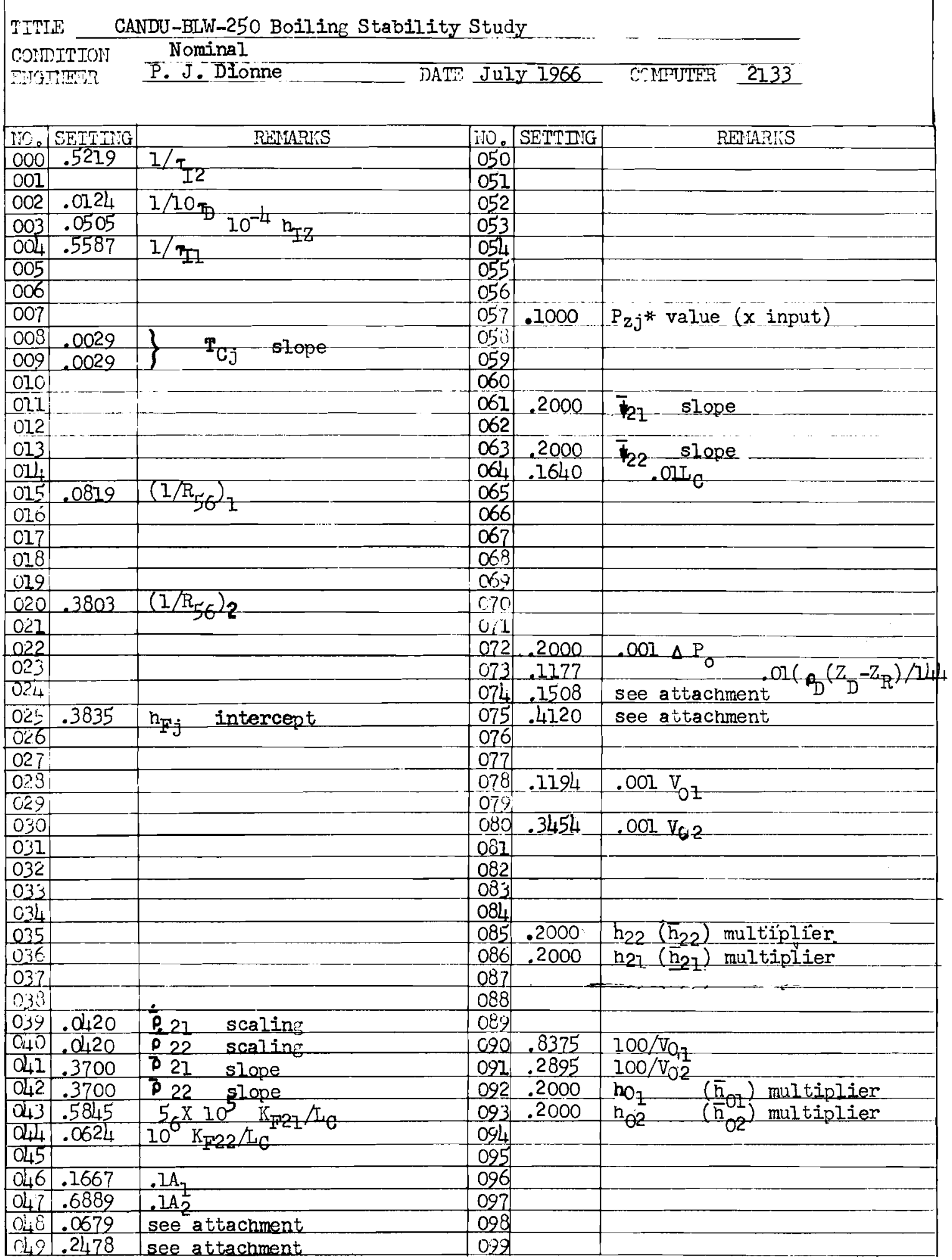

$A R-1800-057.1 \quad(8-65)$ 
ANALOG COMPUTER POTSET COEFFICIENTS - SHEET 2

\begin{tabular}{|c|c|c|c|c|c|}
\hline \multicolumn{2}{|c|}{$\begin{array}{l}\text { TITIE } \\
\text { CONDIMION } \\
\text { ENGINEER }\end{array}$} & \multicolumn{4}{|c|}{$\frac{\text { GANDU - BLW - } 250 \text { Boiling Stability study }}{\text { Nominal }}$} \\
\hline 19. & SETTING & RTMAPKS & NOO. & SEITING & REMARKS \\
\hline 100 & .5219 & $1 / T_{T 2}$ & 150 & & \\
\hline 202 & & & 152 & .6000 & $1 / \mathrm{A}_{0}$ \\
\hline 102 & .1235 & $1 / m$ & 152 & .1452 & $1 / \mathrm{A}_{9}^{1}$ \\
\hline 103 & .5587 & $1 / 47$ & 153 & & \\
\hline $10_{4}$ & .0505 & $10^{-4} b_{l}=7$ & 154 &.$\alpha_{476}$ & $5.68 / \mathrm{V}$ \\
\hline 103 & & & 155 & .0164 & $5.68 / \mathrm{V}$ \\
\hline 106 & & & 156 & & \\
\hline 107 & & & 157 & & \\
\hline 208 & .0081 & & 158 & & \\
\hline 109 & .0081 & Intereept & 159 & & \\
\hline 110 & & & 260 & & \\
\hline 111 & & & 161 & .0100 & intercept \\
\hline 212 & & & 162 & & \\
\hline 113 & & & 163 & & \\
\hline 114 & & & 164 & & \\
\hline 115 & & & 165 & & \\
\hline 116 & & & 166 & & \\
\hline 117 & & & $16 ?$ & & \\
\hline 118 & & & 268 & & \\
\hline 119 & & & 169 & & \\
\hline 120 & & & 170 & & \\
\hline 121 & & & 171 & & \\
\hline 122 & & & 172 & .1997 & see attachment \\
\hline 123 & & & 173 & .1520 & see attachment \\
\hline 124 & .1590 & hy slope & 174 & .1010 & see attachment \\
\hline 125 & & & 275 & .2760 & see attachment \\
\hline 126 & & & 176 & & \\
\hline 127 & .1590 & $b_{T 2}$ slope & 177 & & \\
\hline 128 & & & 278 & .5000 & I $(M \circ)$ multiplier \\
\hline 129 & & & 179 & .5000 & $\mathrm{II}_{\mathrm{O}}(\mathrm{M})$ multiplier \\
\hline 130 & & & 180 & & \\
\hline $13 i$ & & & 181 & .0653 & $.5\left(\mathrm{Z}_{0}-\mathrm{Z}_{01}\right) / \mathrm{IL}_{4}$ \\
\hline 132 & .2670 & $P_{21}$ * value $\left(P_{B 1}\right)$ & 282 & & \\
\hline 133 & .2500 & $\mathrm{P}_{22} *$ value $\left(\mathrm{h}_{71}\right)$ & 283 & .0653 & $.5\left(z_{n}-2_{Q}\right) / 244$ \\
\hline 134 & .2670 & $\mathrm{P}_{22} *$ value $\left(\mathrm{P}_{\mathrm{B} 2}\right)$ & 184 & .5730 & $.001 \quad 1272$ \\
\hline 135 & .2500 & $P_{22} *$ value $\left(h_{12}\right)$ & 185 & .5865 & .001528 \\
\hline 136 & & & 186 & & \\
\hline 137 & & & 187 & & \\
\hline 138 & & & 188 & .1000 & $\left(h_{27}-h_{12}\right)$ scaling \\
\hline 139 & & & 189 & .1000 & $\left(n_{22}-n_{72}\right)$ scaling \\
\hline 140 & & & 190 & .6150 & $.001 \overline{\mathrm{h}} \mathrm{077}$ \\
\hline 241 & .1780 & $.0037 \quad 8$ & 191 & .6550 & $.001 \bar{h}$ \\
\hline 142 & & & 292 & & \\
\hline 143 & .0694 & 10/11/4 & 3.93 & & \\
\hline IVt & .0694 & 10/014 & 194 & & \\
\hline 145 & & & 195 & & \\
\hline 146 & & & 196 & .6825 & $5 \times 10^{4} \mathrm{~K}_{\mathrm{m}}$ \\
\hline 14.7 & & & 197 & .1005 & $10^{5}\left(\mathrm{~K}_{\mathrm{p}}+1 \mathrm{~K}_{\mathrm{n}}\right)$ \\
\hline 148 & .1366 & see attackment & 198 & .8066 & $10^{\circ} K_{\mathrm{F} 2}^{2}$ \\
\hline 149 & .3416 & see attachment & 199 & & \\
\hline
\end{tabular}




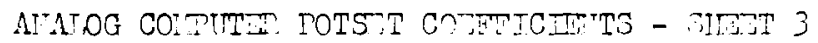

\begin{tabular}{|c|c|c|c|c|c|}
\hline \multicolumn{2}{|c|}{$\begin{array}{l}\text { TITIE } \\
\text { CONDITION } \\
\text { ENG.INEER }\end{array}$} & \multicolumn{4}{|c|}{ 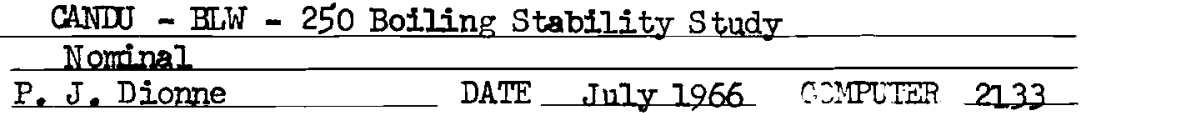 } \\
\hline $\mathrm{NO}_{0}$ & SETTINYG & \multirow{2}{*}{\multicolumn{4}{|c|}{ 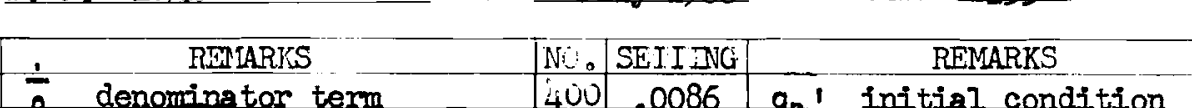 }} \\
\hline 200 & .0245 & & & & \\
\hline 201 & & & 401 & .0338 & \\
\hline 202 & & & 402 & & \\
\hline 203 & & & 403 & & \\
\hline 204 & & & 404 & & \\
\hline 205 & .5000 & $\vec{I}_{z}\left(\mathrm{M}_{2 q}\right)$ multiplier & 405 & & \\
\hline 200 & & & 406 & & \\
\hline 207 & .5000 & $\mathrm{M}_{0}\left(\mathrm{M}_{22}\right)$ multiplier & 407 & & \\
\hline 208 & & & 408 & & \\
\hline 208 & & & 409 & & \\
\hline 210 & & & 410 & & \\
\hline 211 & .3308 & $10^{3}$ K & 411 & & \\
\hline 212 & .2600 & $10^{6} \mathrm{r}$ & 412 & & \\
\hline 213 & & & 413 & & \\
\hline $2 \mathrm{II}_{4}$ & & & 414 & & \\
\hline 215 & & & 415 & & \\
\hline 216 & .0245 & $\bar{T}_{0}$ denominator term & 416 & & \\
\hline 217 & & & 417 & & \\
\hline 218 & .1000 & intercept & 418 & & \\
\hline 212 & & & 419 & & \\
\hline & & & 420 & & \\
\hline & & & 422 & & \\
\hline 300 & & & 422 & & \\
\hline 301 & & & 423 & & \\
\hline 302 & & & & & \\
\hline 303 & & & ho & .5005 & $M$ perturb \\
\hline $30_{4}$ & & & $\mathrm{hl}$ & & \\
\hline 305 & .5000 & $\overline{\mathrm{M}}_{27}\left(\mathrm{M}_{77}\right)$ multiplier & h2 & & \\
\hline 306 & & & h3 & & \\
\hline 307 & .5000 & $\bar{M}_{22}\left(M_{72}\right)$ multiplier & $\mathrm{n} 4$ & .011 & limit to +1.67 volts \\
\hline 308 & & & h5 & .011 & limit to -1.67 volts \\
\hline 309 & & & h6 & .031 & Iimit to +3.5 volts ? Ak \\
\hline 310 & & & h7 & .031 & limit to -3.5 volts ${ }^{\circ} \mathrm{C}$ \\
\hline 311 & & & h8 & & \\
\hline 312 & & & h2 & .5000 & limit to $\mathrm{h}$ \\
\hline 313 & & & h10 & & \\
\hline $3 u_{4}$ & & & bl1 & & \\
\hline 325 & & & HO & .497 & $.01 \Delta K_{\mathrm{pZ}}$ \\
\hline 315 & & & HI & .497 & . O1 $\Delta K_{2}$ \\
\hline 317 & & & $\mathrm{H}^{2}$ & & \\
\hline 318 & .4000 & I slope & $\mathrm{H3}$ & & \\
\hline 319 & .4000 & of slope & $\mathrm{H} 4$ & & \\
\hline & & & H5 & .501 & $10^{-1 \pm} \mathrm{S}_{7}$ \\
\hline & & & $\mathrm{H6}$ & .503 & $10^{-11} s_{2}^{1}$ \\
\hline & & & H7 & & \\
\hline & & & $\mathrm{HB}$ & & \\
\hline & & & H9 & & \\
\hline & & & HIO & & \\
\hline & & & & & \\
\hline & & & & & \\
\hline
\end{tabular}

$A B-1800-057.3 \quad(8-65)$ 


$$
B-17
$$

BNWL -574

POT SET SHEET ATTACHMENT

These sheets contain the pot settings which were too large to put on the regular pot set sheets. These pots are all associated with the calculations of the flows into the reactor. 


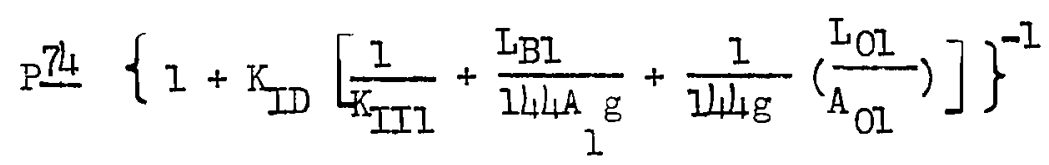

$$
\begin{aligned}
& p^{75}\left\{1+K_{I D}\left[\frac{1}{K_{I I 2}}+\frac{I_{B 2}}{144 \mathrm{Ag}}+\frac{I}{I_{4} g}\left(\frac{I_{02}}{A_{02}}\right)\right]\right\}^{-1}
\end{aligned}
$$

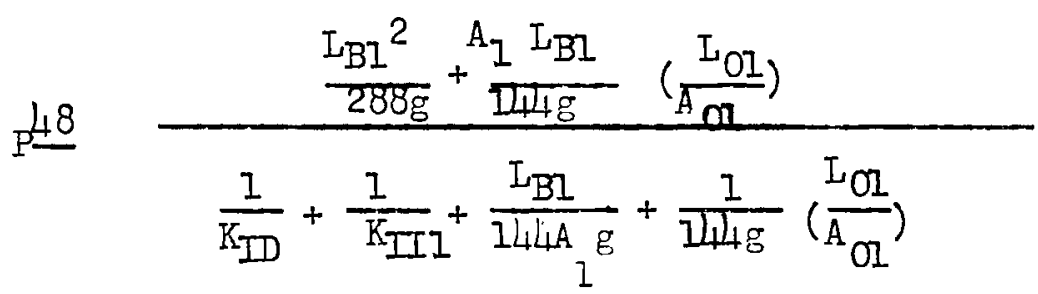

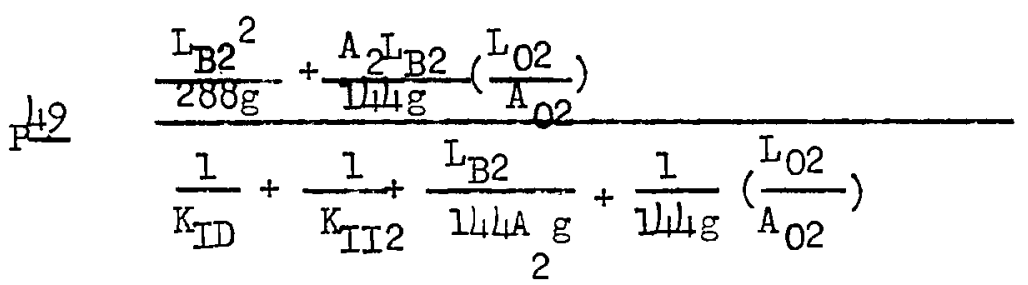

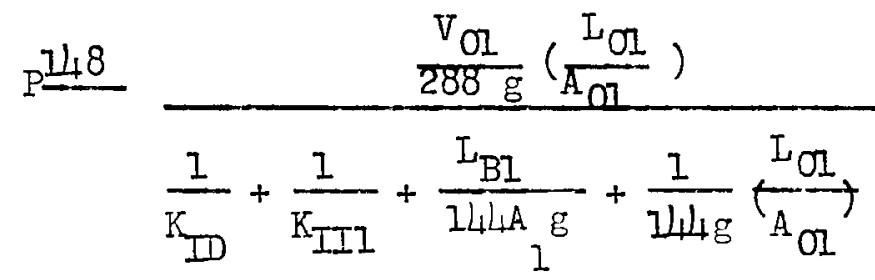

$$
\begin{aligned}
& P=\frac{V_{0 E}}{2885}\left(\frac{I_{02}}{A_{02}}-\right) \\
& \frac{I}{K_{I D}}+\frac{I}{K_{I I 2}}+\frac{I_{B 2}}{I_{4 L A}}+\frac{I}{I_{L 45}}\left(\frac{I_{02}}{A_{02}}\right)
\end{aligned}
$$




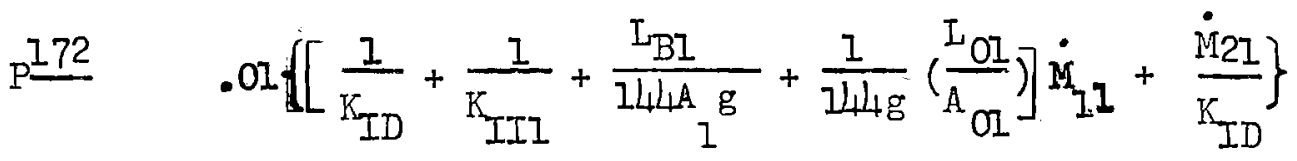

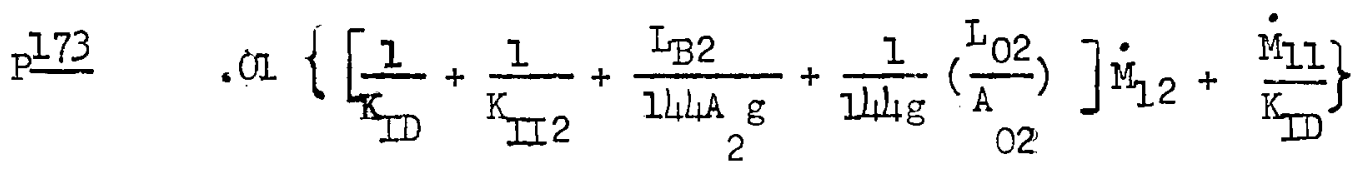

$$
\begin{aligned}
& P=174 \\
& 10^{-4} \dot{M}_{72}+(p 74)\left(10^{-4} \dot{M}_{21}\right) \\
& p^{172} \\
& 175 \\
& 10^{-4} \dot{M}_{21}+(p 75)\left(10^{-4} \dot{M}_{11}\right) \\
& \text { p } 173
\end{aligned}
$$




\section{STATIC CHECK SHEETS}

These sheets with the initial condition voltages of all the amplifiers and multipliers of both computers can be used to check the patching and potentiometers settings any time this model is rerun. 
TITLE CANDU - BLW - 250 Boiling Stability Study

ENGINEFR P. J. Dionne COMPUTERR

\begin{tabular}{|c|c|c|c|c|c|c|c|c|c|c|c|c|c|c|}
\hline \multicolumn{6}{|c|}{ ENGINEFR P. J. Dionne } & \multicolumn{5}{|c|}{ COMPUTER } & \multicolumn{4}{|c|}{ DATE } \\
\hline \multicolumn{15}{|c|}{ STATIC CHECK SHEET - AMPLIFIER OUTPUTS } \\
\hline No. & Voltage & Variable & No. & Voltage & Variable & No. & Voltage & Variable & No. & Voltage & Variable & No. & Voltage & Variable \\
\hline 0 & -50.50 & & 37 & & & 74 & -14.80 & & 111 & & & 27 & & \\
\hline 1 & & & 38 & & & 75 & -35.90 & & 112 & -2.43 & & 28 & & \\
\hline 2 & -50.50 & & 39 & & & 76 & 14.70 & & 113 & -13.00 & & 29 & & \\
\hline 3 & -50.50 & & 40 & & & 77 & 35.83 & & 114 & -10.93 & & 30 & & \\
\hline 4 & 50.50 & & 41 & -24.18 & & $7^{8}$ & & & 115 & -14.99 & & 31 & & \\
\hline 5 & & & 42 & -22.53 & & 79 & -35.79 & & 116 & 8.52 & & 32 & & \\
\hline 6 & 92.01 & & 43 & 92.70 & & 80 & 4.02 & & 117 & 12.54 & & 33 & & \\
\hline 7 & 84.23 & & 44 & 34.00 & & 81 & -3.01 & & 118 & 26.99 & & 34 & & \\
\hline 8 & -1.07 & & 45 & & & 82 & 2.49 & & 119 & 70.13 & & 35 & & \\
\hline 9 & -1.04 & & 46 & & & 83 & -2.37 & & & \multicolumn{2}{|c|}{ F AMPIIFITR } & & & \\
\hline 10 & 1.12 & & 47 & & & 84 & & & 0 & & & 100 & & \\
\hline 11 & -1.03 & & 48 & & & 85 & 65.47 & & 1 & & & 101 & & \\
\hline 12 & 1.08 & & 49 & & & 86 & 61.72 & & 2 & & & 102 & & \\
\hline 13 & $-\quad .80$ & & 50 & 50.61 & & 87 & & & 3 & & & 103 & & \\
\hline 14 & 15.06 & & 52 & & & 88 & 8.59 & & 4 & -11.23 & & 104 & & \\
\hline 15 & -9.11 & & 52 & & & 89 & 13.97 & & 5 & -15.23 & & 105 & & \\
\hline 16 & 9.17 & & 53 & & & 90 & 61.50 & & 6 & & & 106 & -.85 & \\
\hline 17 & & & 54 & & & 91 & 65.50 & & 7 & & & 107 & -1.39 & \\
\hline 18 & -30.43 & & 55 & & & 92 & -61.50 & & 8 & & & 108 & -11.69 & \\
\hline 19 & -24.60 & & 56 & & & 93 & -65.50 & & 9 & & & 109 & -5.10 & \\
\hline 20 & -32.01 & & 57 & & & 94 & -11.03 & & 10 & & & 110 & 10.00 & \\
\hline 21 & & & 58 & & & 95 & -15.03 & & 11 & & & 111 & & \\
\hline 22 & & & 59 & & & 96 & -2.24 & & 12 & -7.70 & & 112 & -61.71 & \\
\hline 23 & & & 60 & 23.61 & & 97 & -25.81 & & 13 & -52.51 & & 113 & -65.75 & \\
\hline 24 & -92.46 & & 61 & 3.24 & & 98 & -13.17 & & 14 & & & 114 & -14.39 & \\
\hline 25 & 53.00 & & 62 & 12.96 & & 99 & & & 15 & & & 115 & -35.19 & \\
\hline 26 & -2.59 & & 63 & 40.51 & & 100 & -6.17 & & 16 & & & 116 & & \\
\hline 27 & -84.24 & & 64 & -12.63 & & 101 & -11.55 & & 17 & & & 117 & & \\
\hline 28 & 51.72 & & 65 & -15.03 & & 102 & -2.34 & & 18 & & & 128 & 61.38 & \\
\hline & -1.24 & & 66 & -57.27 & & 103 & -12.95 & & 19 & & & 119 & 65.44 & \\
\hline 30) & & & 67 & -58.62 & & 104 & 14.40 & & 20 & & & 120 & & \\
\hline 31 & & & 68 & & & 105 & 14.59 & & 21 & & & 121 & & \\
\hline 32 & & & 69 & & & 106 & 35.40 & & 22 & & & 122 & -8.52 & \\
\hline 33 & 19.70 & & 70 & 14.08 & & 107 & 35.67 & & 23 & & & 123 & -12.54 & \\
\hline 34 & & & 71 & 7.76 & & 108 & -11.22 & & 24 & & & & & \\
\hline & 25.90 & & 72 & 19.96 & & 109 & -15.25 & & 25 & & & & & \\
\hline $3 E$ & & & 73 & 15.19 & & 1110 & & & 26 & & & & & \\
\hline
\end{tabular}


TITLE

CANDU = BLW - 250 Boiling Stability Study

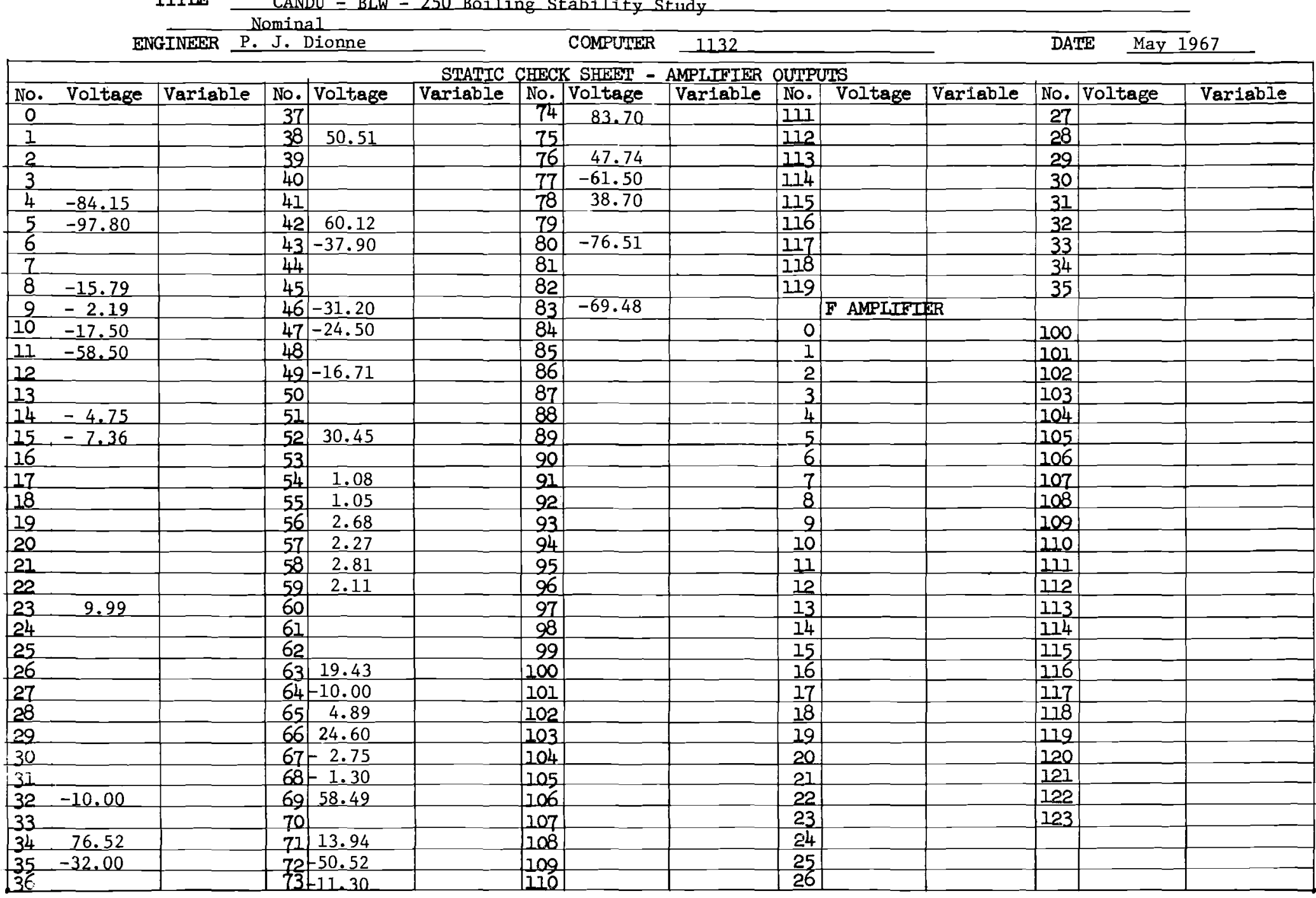


STATIC CHECK SHEET

TITLE: CANDU - BLW - 250 Boiling Stability Study ENGINEER: P. J. Dionne CORTUTER:

$$
2133
$$

DATE: May 1967

\begin{tabular}{|c|c|c|c|c|c|c|c|c|c|c|c|c|c|c|c|c|c|c|}
\hline & & MLLII & LIER & & & & & & & $D T F$ & EERENITIA & REI & CAYS & & & & & \\
\hline $\mathrm{IO}$ & VOITAGE & VARTABLE & ino. & VOLTAGE & VARIABIE & no. & REF. & INPUT & & Fund & ION & No. & RFI & & INP & UT & & FUNSCTION \\
\hline 0 & & & 36 & & & 0 & & & & & & 8 & & & & & & \\
\hline 1 & & & 37 & & & 1 & & & & & & 9 & & & & & & \\
\hline 2 & & & 38 & & & 2 & & & & & & 10 & & & & & & \\
\hline 3 & & & 39 & & & 3 & & & & & & 11 & & & & & & \\
\hline 4. & -3.80 & & 10 & & & 4 & & & & & & 12 & & & & & & \\
\hline 5 & .35 & & 41 & & & 5 & & & & & & 13 & & & & & & \\
\hline 6 & -1.36 & & & & & 6 & & & & & & 4 & & & & & & \\
\hline 7 & .42 & & & & & 7 & & & & & & 15 & & & & & & \\
\hline 8 & & & $\mathrm{I} \mathrm{O}$ & & & & & & & & & & & & & & & \\
\hline 9 & & & II & & & & & & & & & & & & & & & \\
\hline 10 & & & $I 2$ & & & & UUNCTIO & SWITCH & & & & PT TF & ITR & OII & TPIIT - & TMITI & TERS & \\
\hline 11 & & & $I 3$ & & & No. & FUS & ION & 110. & AMP & $+I M T T$ & +5 & SET & & LTMTT & $-\mathrm{SE}$ & & VARIABIE \\
\hline 12 & 6.75 & & I4 & & & 0 & & & 0 & & & & & & & & & \\
\hline 13 & .94 & & I5 & & & 1 & & & 1 & & & & & & & & & \\
\hline$\Psi_{4}$ & 9.35 & & I6 & & & 2 & & & 2 & & & & & & & & & \\
\hline 15 & 3.34 & & I7 & & & 3 & & & 3 & & & & & & & & & \\
\hline 16 & & & $\mathrm{~L} 8$ & .77 & & 4 & & & 4 & & & & & & & & & \\
\hline 17 & & & I9 & 5.26 & & 5 & & & 5 & & & & & & & & & \\
\hline 18 & & & L10 & & & 6 & & & 6 & & & & & & & & & \\
\hline 19 & & & LII & & & 7 & & & 7 & & & & & & & & & \\
\hline$\frac{20}{27}$ & & & & & & 8 & & & 8 & & & & & & & & & \\
\hline 21 & -.43 & & & & & 9 & & & 9 & & & & & & & & & \\
\hline 22 & & & & & & 10 & & & 70 & & & & & & & & & \\
\hline 23 & -2.36 & & & & & 11 & & & 11 & & & & & & & & & \\
\hline 24 & & & & & & 12 & & & 12 & & & & & & & & & \\
\hline 25 & & & & & & 13 & & & 13 & & & & & & & & & \\
\hline 26 & & & & & & 14 & & & $\mathrm{II}_{4}$ & & & & & & & & & \\
\hline 27 & & & & & & 15 & & & 15 & & & & & & & & & \\
\hline 28 & & & & & & 16 & & & 16 & & & & & & & & & \\
\hline 29 & & & & & & 17 & & & 17 & & & & & & & & & \\
\hline 30 & & & & & & 18 & & & 18 & & & & & & & & & \\
\hline 32 & & & & & & 19 & & & 19 & & & & & & & & & \\
\hline 32 & & & & & & 20 & & & 20 & & & & & & & & & \\
\hline 33 & & & & & & 21 & & & 21 & & & & & & & & & \\
\hline 34 & & & & & & 22 & & & 22 & & & & & & & & & \\
\hline 35 & & & & & & 23 & & & 23 & & & & & & & & & \\
\hline . & & & & & & & & & & & & & & & & & & \\
\hline
\end{tabular}


STATTC CHECK SHEET

THITE CANDU - BLW - 250 Boiling Stability Study

Nominal

\begin{tabular}{|c|c|c|c|c|c|c|c|c|c|c|c|c|c|c|}
\hline & ENGT & $\mathrm{E} U \mathrm{P} \cdot \mathrm{J}$ & Dior & & 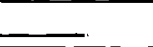 & $\operatorname{COM}$ & PTIER & 2133 & & - & $\overline{D A}$ & & $2 y \quad 1967$ & \\
\hline & & & & & & & rFilNT L & MNS & & & & & & \\
\hline 30. & Toltage & Tariable & IINo." & Joltage & Tariable & ITa & Toltage & Tariable & To. & Toltage & Variable & Xo.1 & Toltage & Variable \\
\hline 80 & & & 117 & & & 154 & -15.05 & & 191 & & & $\mathrm{EO}$ & & \\
\hline 81 & & & 118 & & & 255 & -14.97 & & 192 & & & E2 & & \\
\hline 82 & & & 112 & & & 156 & & & 193 & & & 52 & & \\
\hline 83 & & & 120 & & & 157 & & & 134 & & & 73 & & \\
\hline 84 & & & 121 & & & 258 & & & 195 & & & EL & & \\
\hline 85 & & & 122 & & & 159 & & & 196 & & & E5 & & \\
\hline 86 & & & 123 & & & 160 & & & 197 & & & 56 & & \\
\hline 87 & & & 124 & & & 161 & & & 198 & & & $E^{7}$ & & \\
\hline 33 & & & 125 & & & 162 & & & 199 & & & 28 & & \\
\hline 89 & & & 126 & & & 163 & & & & & & $\mathrm{E} ?$ & & \\
\hline 90 & & & $127 \mid$ & & & 164 & & & & & & E20! & & \\
\hline 27 & & & 128 & & & 165 & & & & & & EII. & & \\
\hline 92 & & & 229 & & & 166 & & & & & & 512 & & \\
\hline 93 & & & 730 & & & 167 & & & & & & E13 & & \\
\hline 94 & & & 131 & & & 168 & & & & & & 524 & & \\
\hline 95 & & & 132 & & & 169 & & & & & & E15! & & \\
\hline 96 & & & 133 & & & 170 & & & & & & $=16$ & & \\
\hline 97 & & & $13 \frac{1}{4}$ & & & 172 & & & & & & F17 & & \\
\hline 99 & & & 235 & & & 172 & & 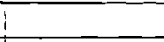 & & & & ت78 & & \\
\hline 99 & & & 136 & -100.00 & & 173 & & & & & & P19 & & \\
\hline 100 & -12.40 & & 137 & & & 174 & & & & & & 820 & & \\
\hline 101 & & & 138 & & & 175 & +01.72 & & & & & E21 & & \\
\hline 102 & & & 139 & & & $1 \div 6$ & -17.14 & & & & & 722 & & \\
\hline 103 & & & Jio & & & 277 & +01.27 & & & & & $833 i$ & & \\
\hline 104 & +93.12 & & 21 & & & 178 & -12.38 & & & & & $22_{4}^{4}$ & & \\
\hline 105 & & & 142 & -15.03 & & 179 & +01.29 & & & & & 725 & & \\
\hline 106 & +11.59 & & $\nu_{4} 3$ & & & 180 & -09.38 & & & & & ₹26 & & \\
\hline 207 & & & 24 & +33.96 & & 182] & +01.23 & & & & & 527 & & \\
\hline 108 & & & 245 & 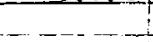 & & 182 & -08.00 & & & & & 328 & & \\
\hline 109 & & & 146 & $\begin{array}{r}05.08 \\
\end{array}$ & & 283 & & & & & & $\overline{329}$ & & \\
\hline 120 & & & II] & & & 184 & & & & & & $E 30$ & & \\
\hline 112 & & & 248 & & & 285 & & & & & & E31 & & \\
\hline 112 & & & 149 & & & 186 & & & & & & & & \\
\hline 113 & & & 150 & -11.02 & & 187 & & & & & & & & \\
\hline 1114 & & & 151 & -14.90 & & 188 & & & & & & & & \\
\hline 115 & & & 152 & $=11.00$ & & 189 & & & & & & & & \\
\hline 126 & & & 153 & -10.98 & & 190 & & & & & & & & \\
\hline
\end{tabular}


APPENDIX C

FUNCTION GENERATORS AND LINEAR APPROXIMATIONS 


\section{APPENDIX C \\ FUNCTION GENERATORS AND LINEAR APPROXIMATIONS}

FUNCTION GENERATORS

The layout of this reaction shows the original curves followed by the approximation function generator curve. The ordinate and abscissa of the function generator curves (Figures $\mathrm{C}-2$ through $\mathrm{C}-7$ ) are 1 abeled with the scaled output and input parameters. The units are volts, and the polarities are those necessary for the model on the computer.

The function generators were programmed on a Digital Equipment Corporation PDP-7 computer connected to the EASE 2133 analog computer. The following block diagram (Figure C-1) shows how the calculations were made. 

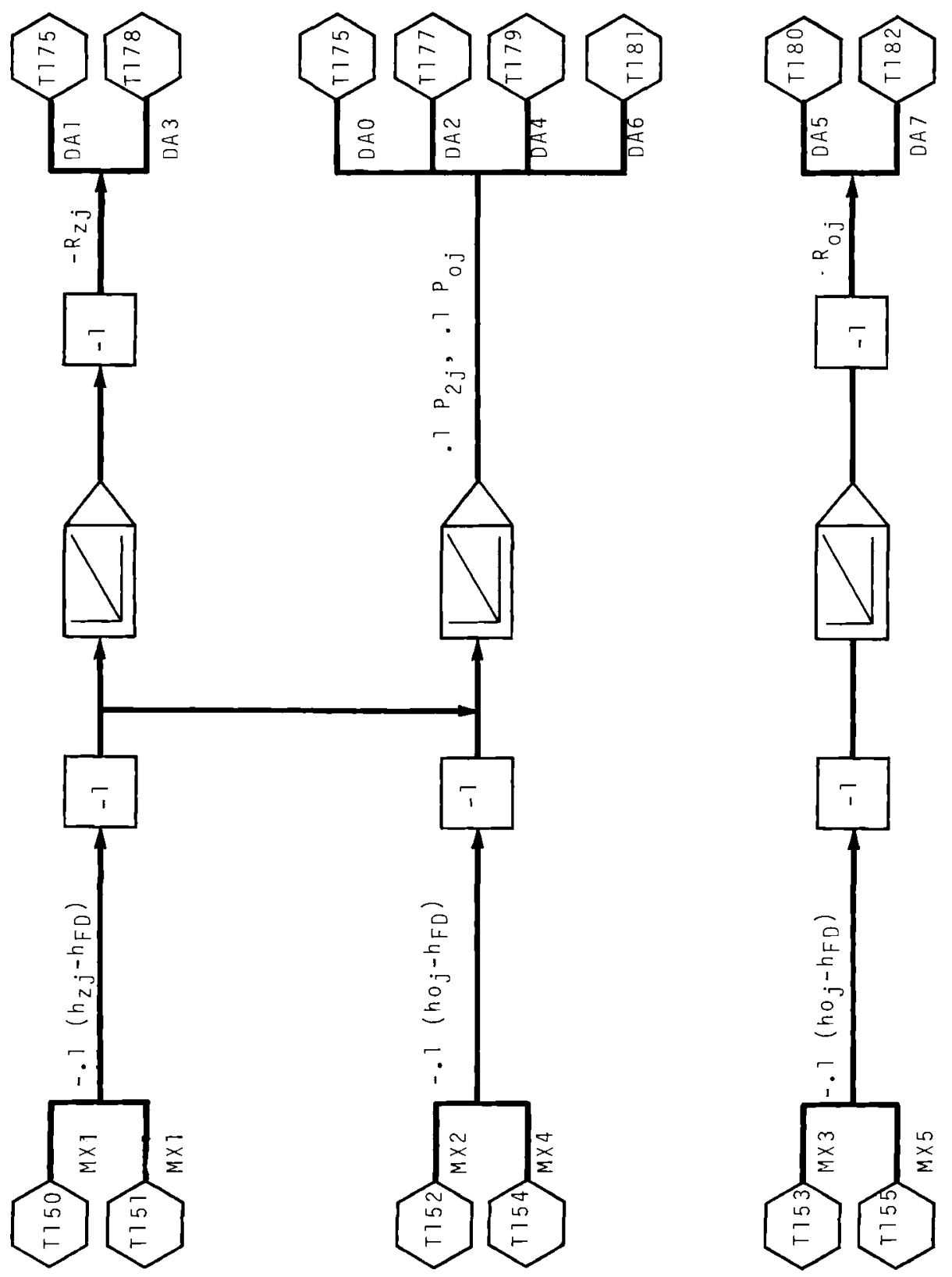

EIGURE C-1. Schematic of Digital Computer Function Generator 


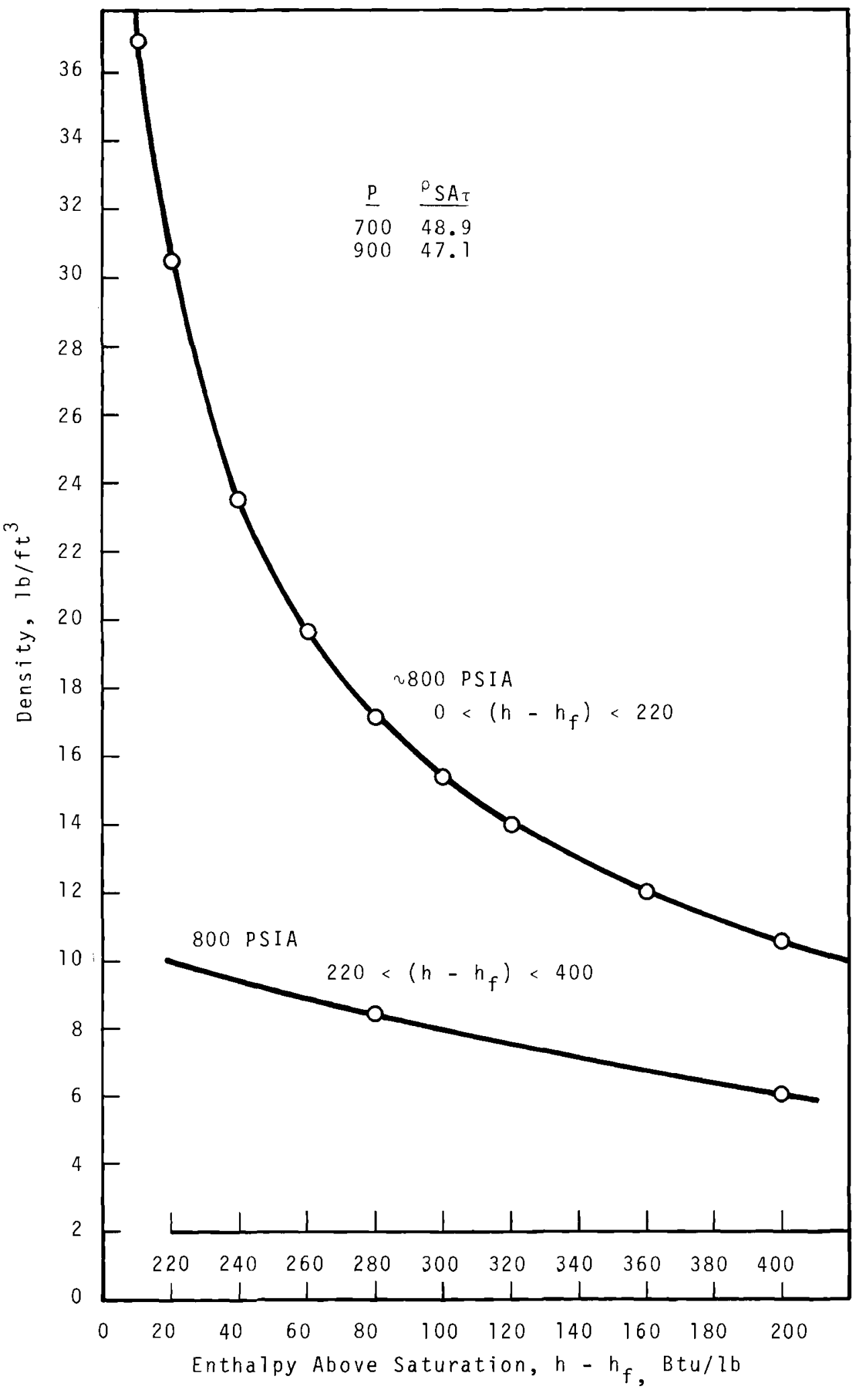

FIGURE C-2. Steam Density Versus Enthalpy Above Saturation (Modified Armand Correzation) 


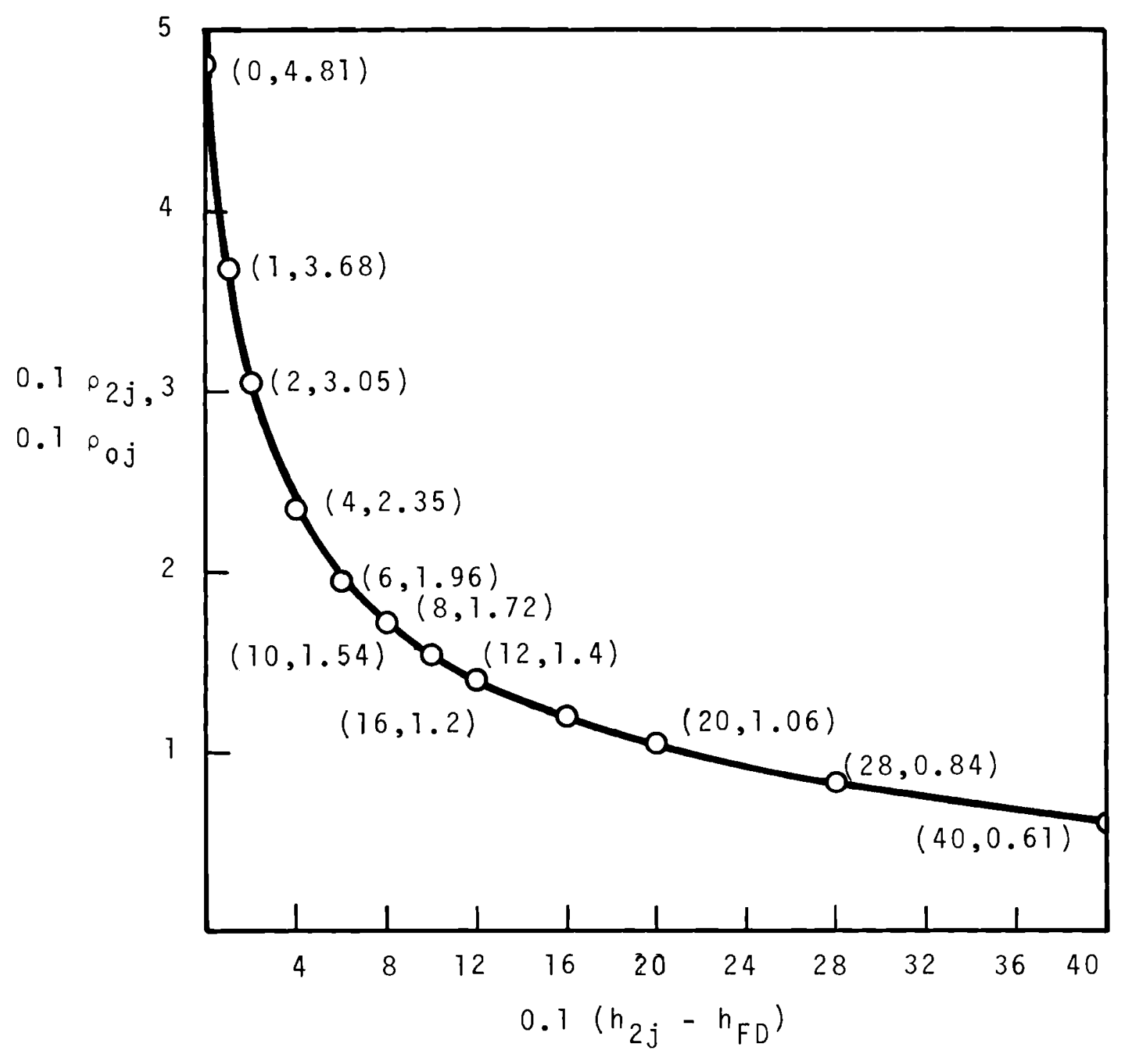

FIGURE C-3. Function Generator Curve. Core Two-Phase Regions, outlet Risers (Modified Armand Correlation) 


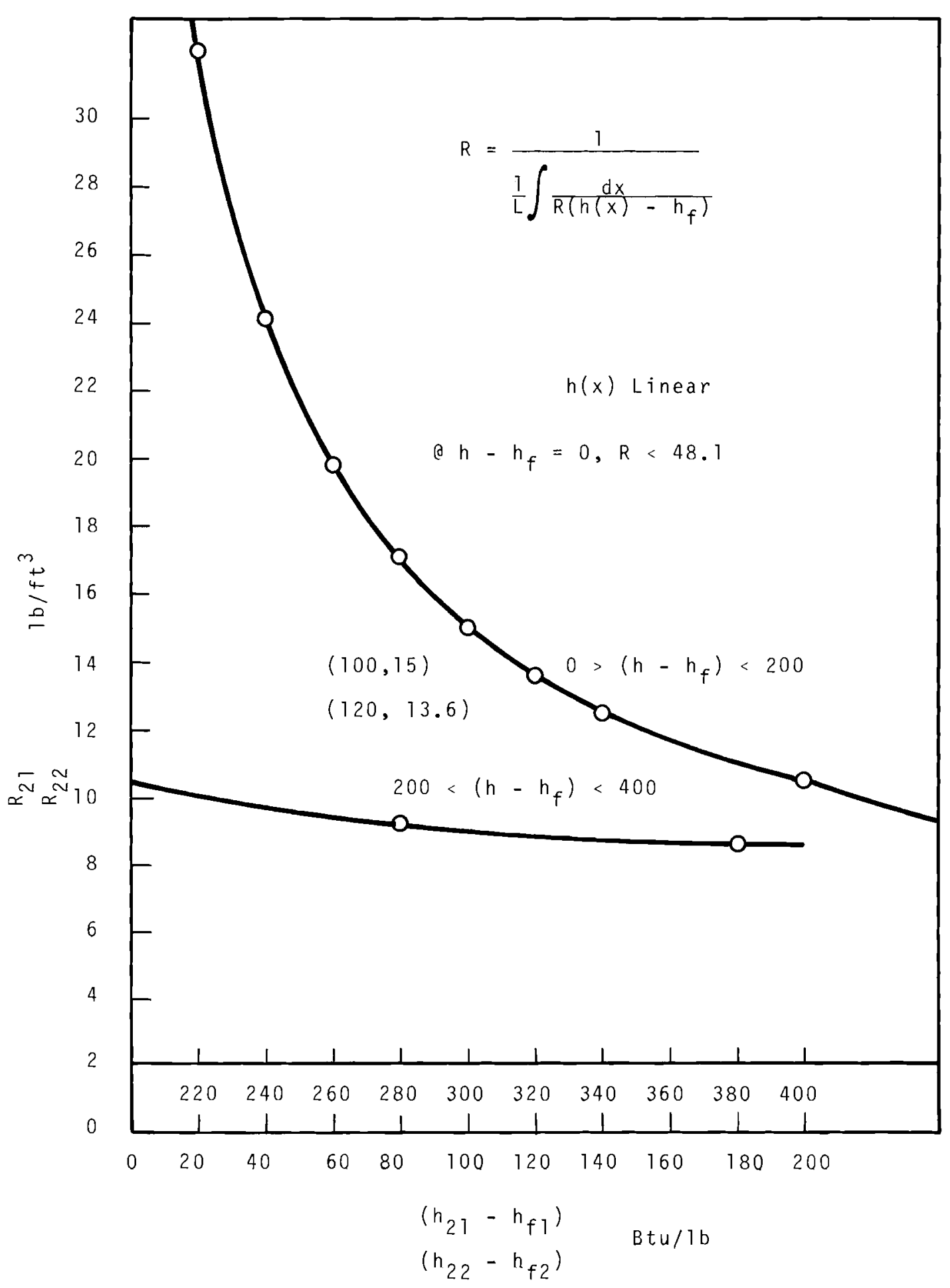

FIGURE C-4. Core Average Value of $R$ at Approximately 800 psia 


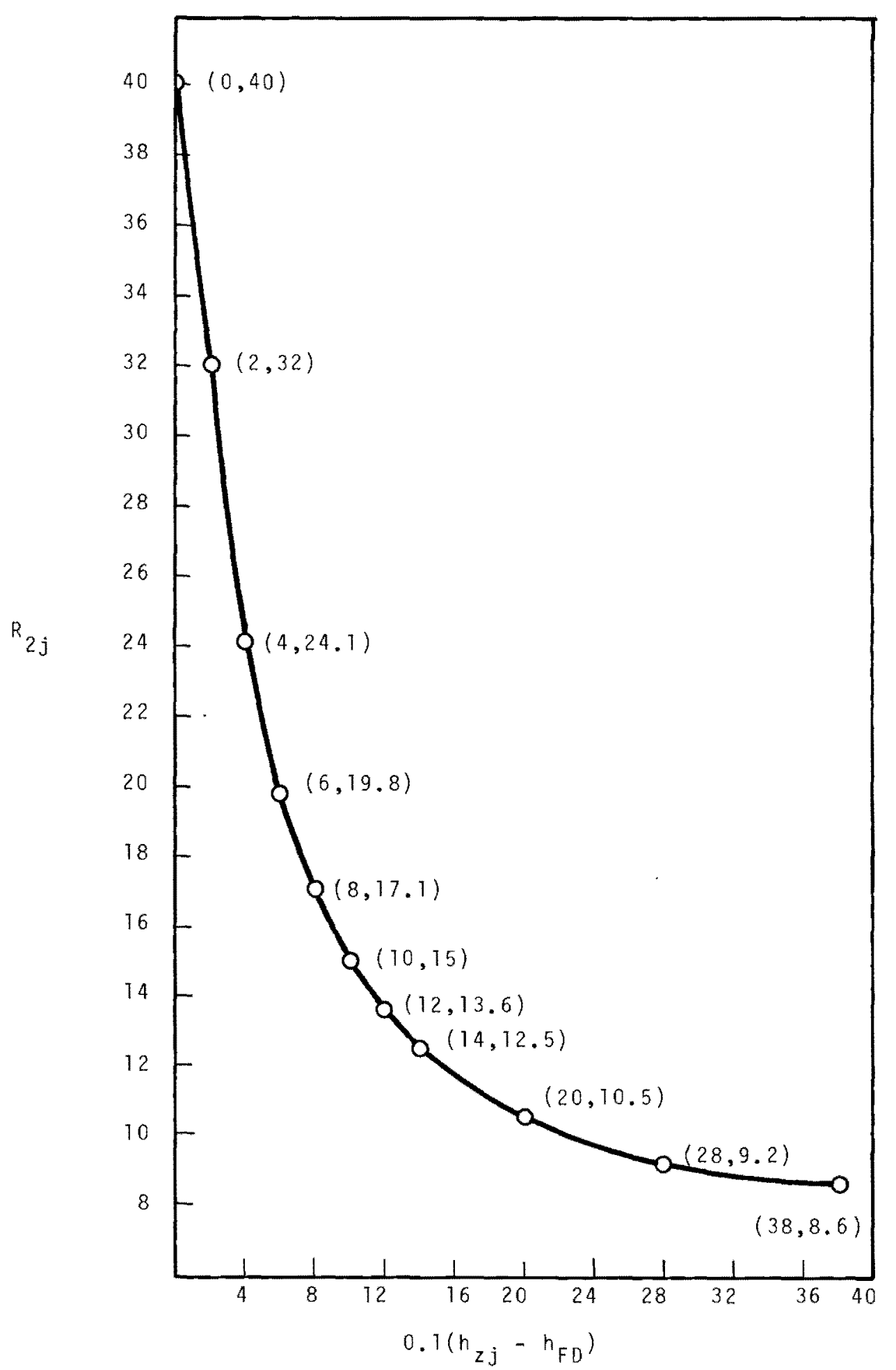

FIGURE C-5. Function Generator Curve. Core Two-Phase Regions, Average Value of $R$ 


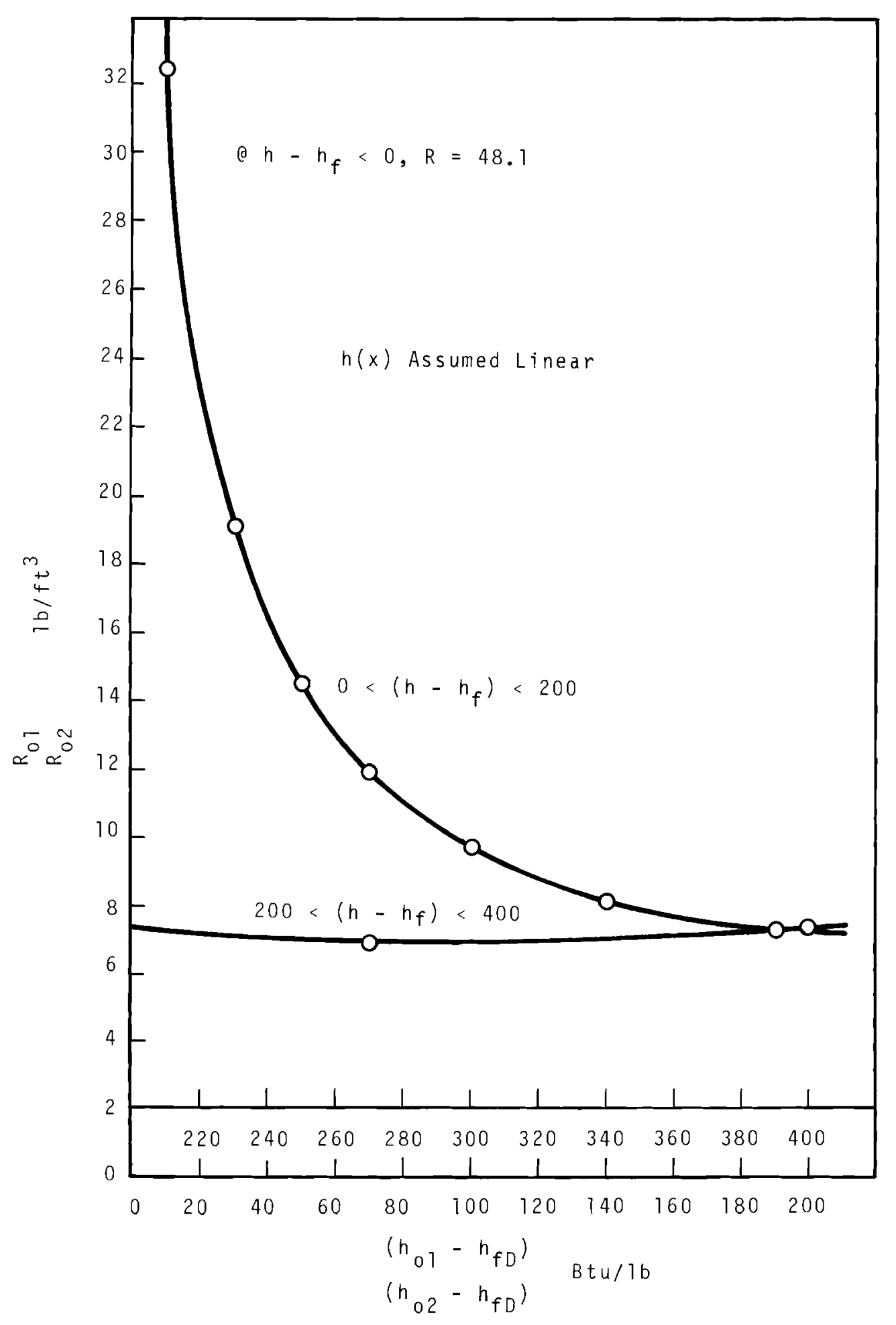

FIGURE C-6. Riser, Value of $R$ at Approximately 800 psia. 


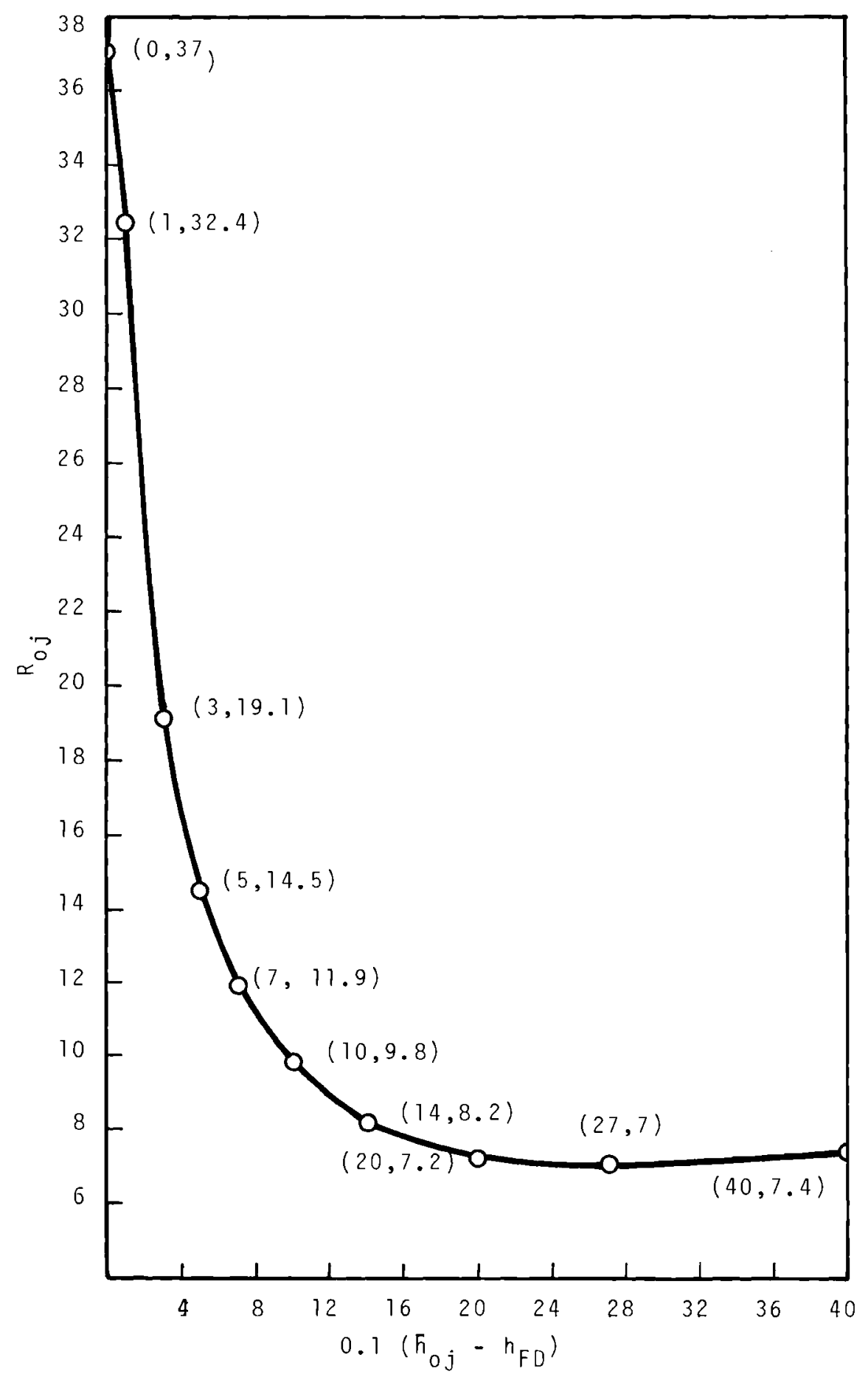

FIGURE C-?. Function Generator Curve, outlet Risers (Average value of $R$ ) 


\section{LINEAR APPROXIMATIONS}

Because of equipment limitations, some of the functions that normally would be put on function generators were approximated by the general linear equation

$$
y=m x+b
$$

where $m$ is the slope and $b$ is the intercept on the $y$-axis at $x=0$. Care was taken in choosing the functions to be linearized so that they would not introduce any appreciable error.

1. Two-Phase Friction Multiplier $-\bar{\psi}_{2 j}, \bar{\psi}_{0 j}$

$$
\bar{\Psi}_{2 j}=m\left(h_{2 j}-h_{F D}\right)+b
$$

From the curve

$$
\begin{aligned}
& m=\frac{5-1}{100}=0.04 \\
& b=1
\end{aligned}
$$

so

$$
\bar{\psi}_{2 j}=1+0.04\left(h_{2 j}-h_{F D}\right)
$$

Since we are putting in a $\Delta h$, than $\Delta h$

$$
\bar{\Psi}_{2 j}=1+0.02\left(h_{2 j}-h_{F D}\right)
$$




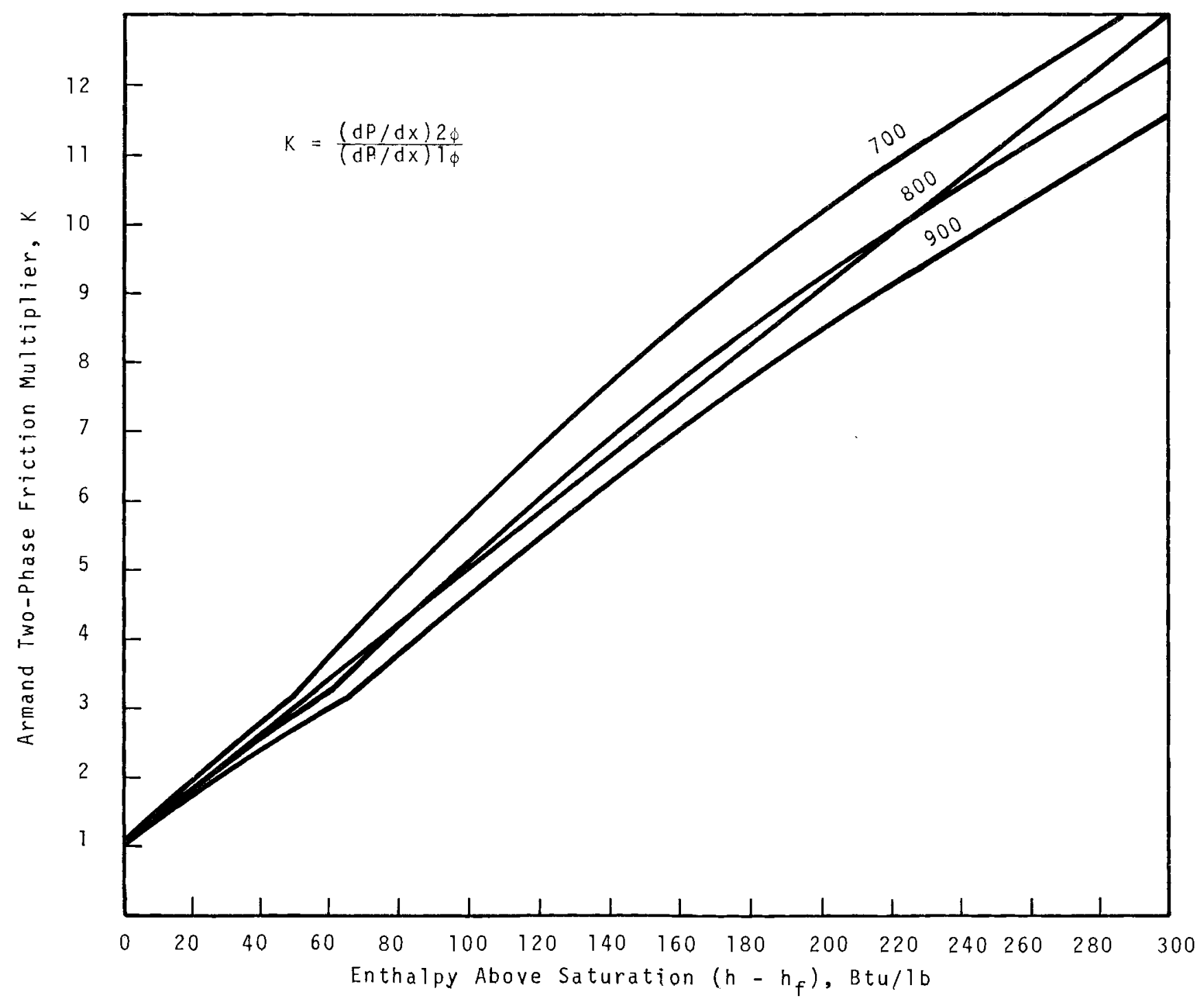

EIGURE C-8. Two-Phase Friction Multiplier (Armand Correlation) 


\section{STEAM DRUM LEVEL}

$$
\begin{aligned}
& M_{F D}+M_{L D}=320001 b s @ L_{D}=3, \\
& L_{D}=\text { slope }\left(M_{F D}+M_{L D}\right)+\text { intercept }
\end{aligned}
$$

From the curve

$$
\begin{aligned}
& \text { slope }=\frac{(6)(0.2)}{(64000)(0.26)}=\frac{1.2}{1.664 \times 10^{4}}=7212 \times 10^{-4} \\
& \text { For } M_{F D}+M_{L D}=32,0001 b s \text { e } L_{D}=3 \text { ' } \\
& \text { intercept }=3-\left(0.7212 \times 10^{-4}\right)\left(3.2 \times 10^{4}\right) \\
& =3-2.308=0.692
\end{aligned}
$$

Therefore

$$
L_{D}=0.7212 \times 10^{-4}\left(M_{F D}+M_{L D}\right)+0.692
$$

Since we work with $\Delta L_{D}$ it is a simple job to convert the above equation to

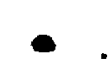

$$
\begin{aligned}
& \Delta \mathrm{L}_{\mathrm{D}}=0.7212 \times 10^{-4}\left(\mathrm{M}_{\mathrm{FD}}+\mathrm{M}_{\mathrm{LD}}\right)+2.308 \\
& \Delta \mathrm{L}_{\mathrm{D}}=0.7212\left[10^{-3}\left(\mathrm{M}_{\mathrm{FD}}+\mathrm{M}_{\mathrm{LD}}\right)\right]+23.08
\end{aligned}
$$




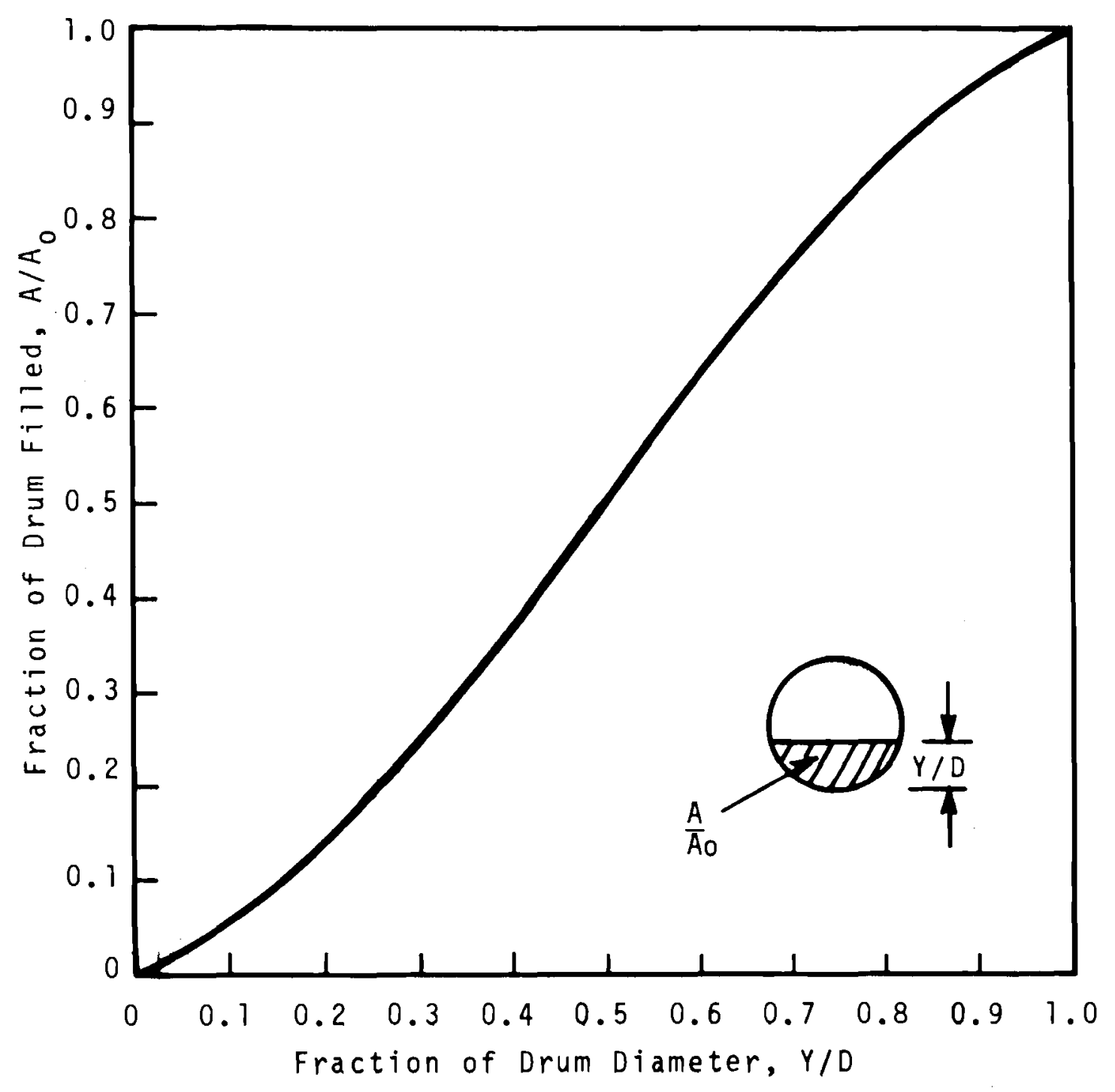

EIGURE C-9. Steam Drum Water Level as Function of Diameter 


\section{FLASHING FUNCTION}

$$
\begin{aligned}
& f_{\left(P_{D}, Z\right)}=1 /\left[6.23-0.0041 P_{D}+Z\left(17-0.162 P_{D}\right)\right] \\
& f_{1}\left(P_{D}, 1\right)=1 /\left[23.23-0.0209 P_{D}\right] \\
& f_{1}(600,1)=0.0935 \\
& f_{1}(700,1)=0.1163 \\
& f_{1}(800,1)=0.1536 \\
& f_{2}\left(P_{D}, 0.5\right)=1 /\left[14.73-0.0125 P_{D}\right] \\
& f_{2}(600,0.5)=0.1383 \\
& f_{2}(700,0.5)=0.1672 \\
& f_{2}(800,0.5)=0.2114 \\
& f_{i}=M_{i} P_{D}+b_{i} \\
& M_{2}=\frac{0.207-0.135}{200}=\frac{0.072}{200}=0.00036 \quad b_{2}=-0.081 \\
& f_{2}=0.00036 P_{D}-0.081 \\
& 100 f_{2}=0.3600\left(0.1 P_{D}\right)-8.1 \\
& M_{1}=\frac{0.15-0.09}{200}=\frac{0.06}{200}=0.003 \\
& f_{1}=0.003 P_{D}-0.09 \\
& 100 f_{1}=0.3000\left(0.1 P_{D}\right)-9 \\
& p 49=3600 ; p 83=0.0810
\end{aligned}
$$




$$
\begin{aligned}
& f\left(P_{D}, Z\right)=1 /\left[6.23-0.0041 P_{D}+Z\left(17-0.0160 P_{D}\right)\right] \\
& \mathrm{f}_{2}\left(\mathrm{P}_{\mathrm{D}}\right)=1 /\left(6.23-0.0041 \mathrm{P}_{\mathrm{D}}\right) \\
& f_{2}(600)=1 /(6.23-2.46)=1 / 3.77 \\
& \mathrm{f}_{2}(600)=0.265 \\
& f_{2}(700)=1 /(6.23-2.87)-1 / 3.36 \\
& \mathrm{f}_{2}(800)=1 /(6.23-3.28)=1 / 2.95 \\
& \mathrm{f}_{2}(800)=0.339 \\
& f_{i}=m_{k} P_{D}+b_{i} \\
& \mathrm{~m}_{i}=\frac{0.335-0.2625}{200}=\frac{0.0725}{200}=3.625 \times 10^{-4} \\
& \mathrm{f}_{2}(0)=3.625 \times 10^{-4} \mathrm{P}_{\mathrm{D}}+\mathrm{b}_{\mathrm{i}} \\
& \text { a } 800 \\
& 0.335=\left(3.625 \times 10^{-4}\right)\left(8 \times 10^{2}\right)+b_{1} \\
& b_{1}=0.335-0.29=0.045 \\
& f_{2}(0)=3.625 \times 10^{-4} P_{D}+0.045 \\
& 100 \mathrm{f}_{2}(0)=0.3625\left(0.1 \mathrm{P}_{\mathrm{D}}\right)+4.5
\end{aligned}
$$




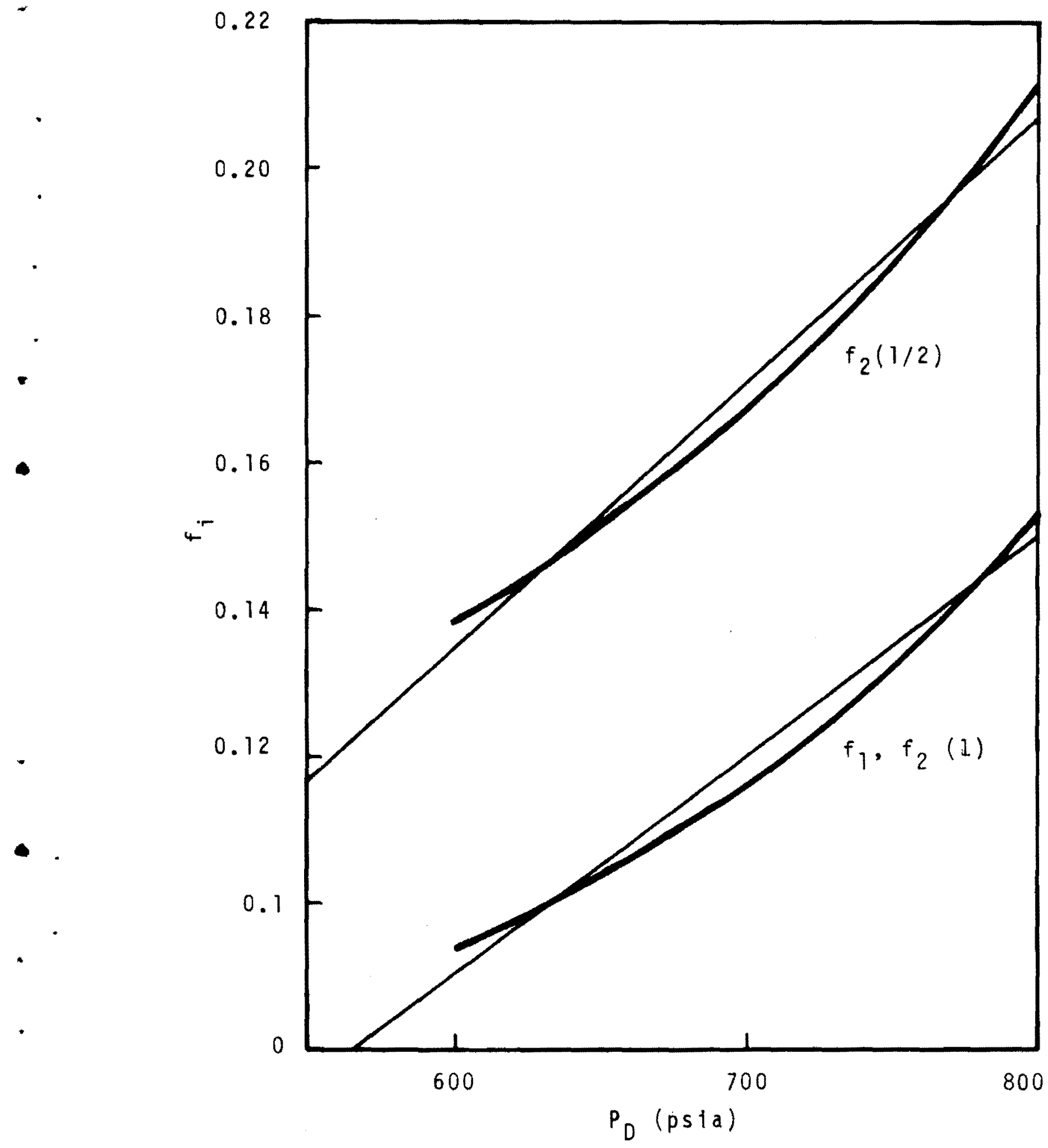

FIGURE C-10. Flashing Functions 
C -16

BNWL - 574

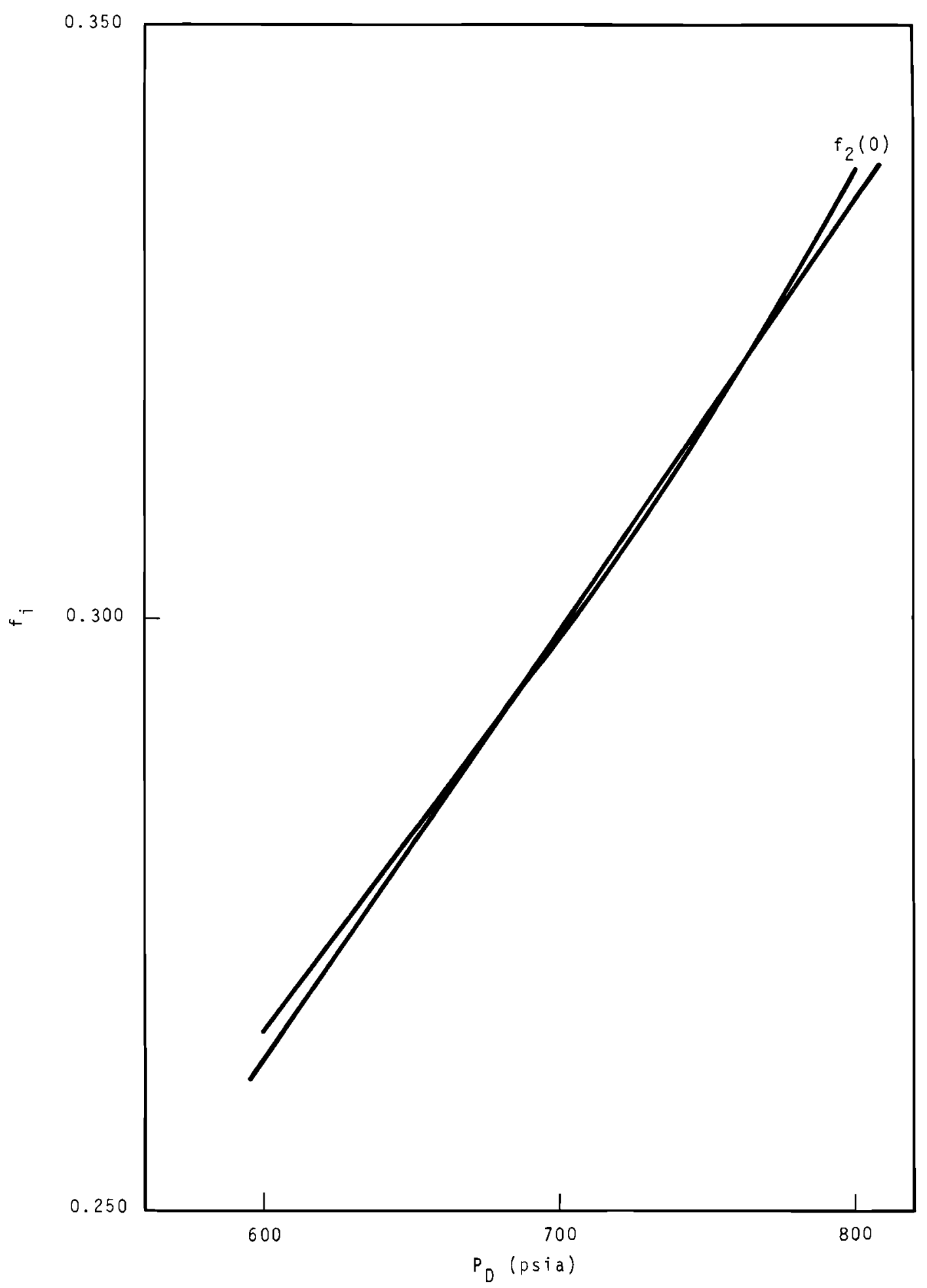

FIGURE C-11. Flashing Functions

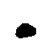




\section{CENTRAL PATCH BAY}

The simulation has been programmed so that the common trunk lines and the servo multiplier are patched on the left hand (facing the panel) or even board. The right hand (odd board) is used for the servo dividers that are required in the $0^{*}{ }_{2 j}$ calculations. The servo multiplier is normally connected to the odd board so that shifting of the connector to the even board is required. This is accomplished from the rear of the central patch bay cabinet. Following is a layout of the odd and even board, and a list of the patching required for this simulation. 


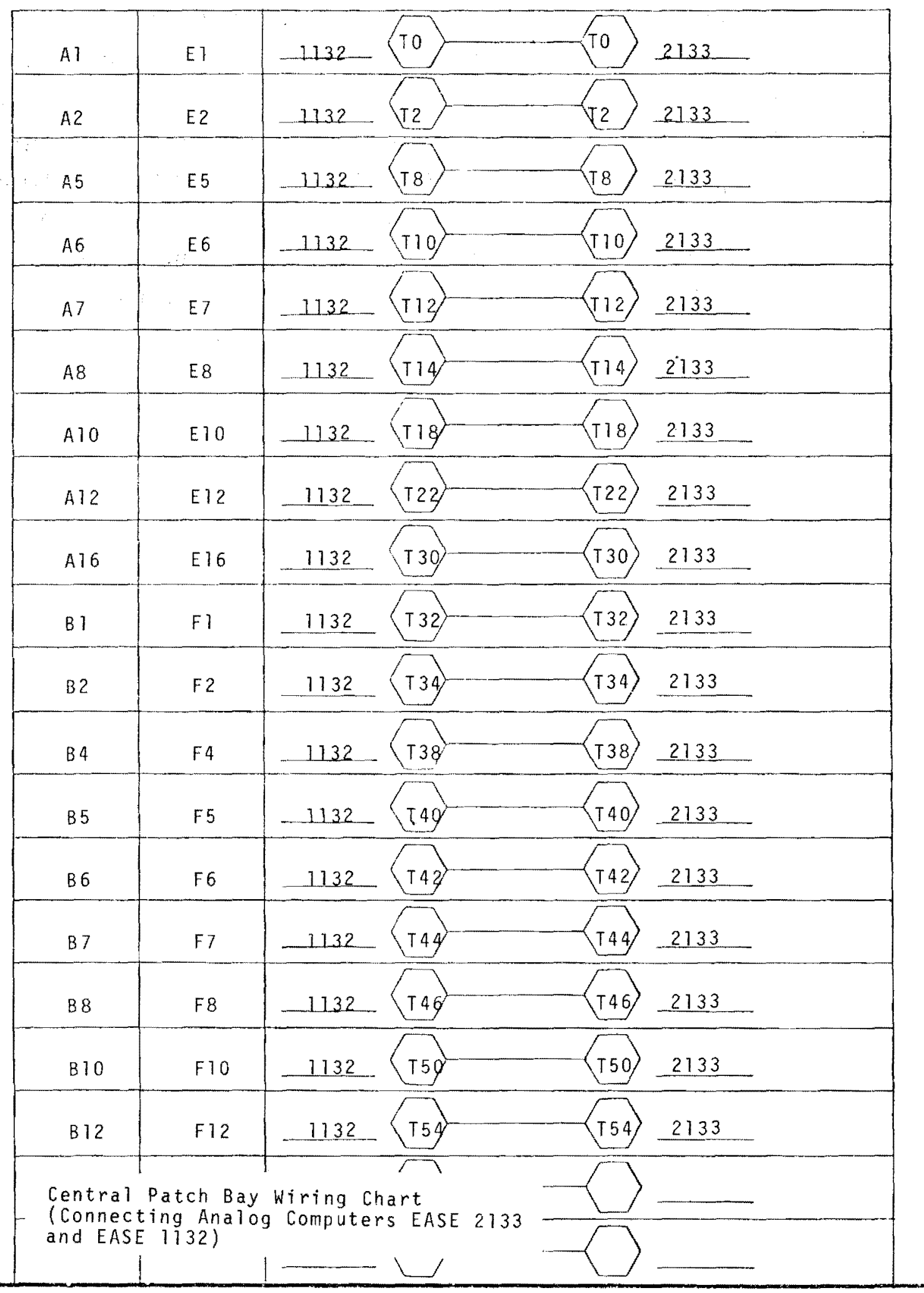




\begin{tabular}{|c|c|c|c|}
\hline H3 & T1 & $2133-\langle 1700$ & SERVO 1 \\
\hline $\mathrm{H} 4$ & U3 & $2133 \quad$ T102 & SERVO 1 \\
\hline H5 & U2 & $2133 \quad T 104$ & SERVO 1 \\
\hline H6 & $\mathrm{T} 2$ & 2133 & SERVO I \\
\hline I5 & $v_{1}$ & $2133 \quad(1136$ & SERVO I \\
\hline I 5 & U8 & 2133 & SERVO 2 \\
\hline I 8 & T 8 & 2133 & RVQ 2 \\
\hline I 9 & U9 & 2133 & SERVO 2 \\
\hline I 10 & T9 & 2133 & SERVO 2 \\
\hline I 11 & บ10 & 2133 & SERVO 2 \\
\hline H13 & T3 & 2133 & SERVO 1 \\
\hline H14 & $\mathrm{T} 10$ & 2133 & SERVO 2 \\
\hline S 1 & w 1 & GND & \\
\hline S2 & w2 & GND & \\
\hline S 3 & w3 & GND & \\
\hline 58 & w8 & GND & \\
\hline S9 & w9 & GND & \\
\hline S10 & พา0 & GND & \\
\hline
\end{tabular}




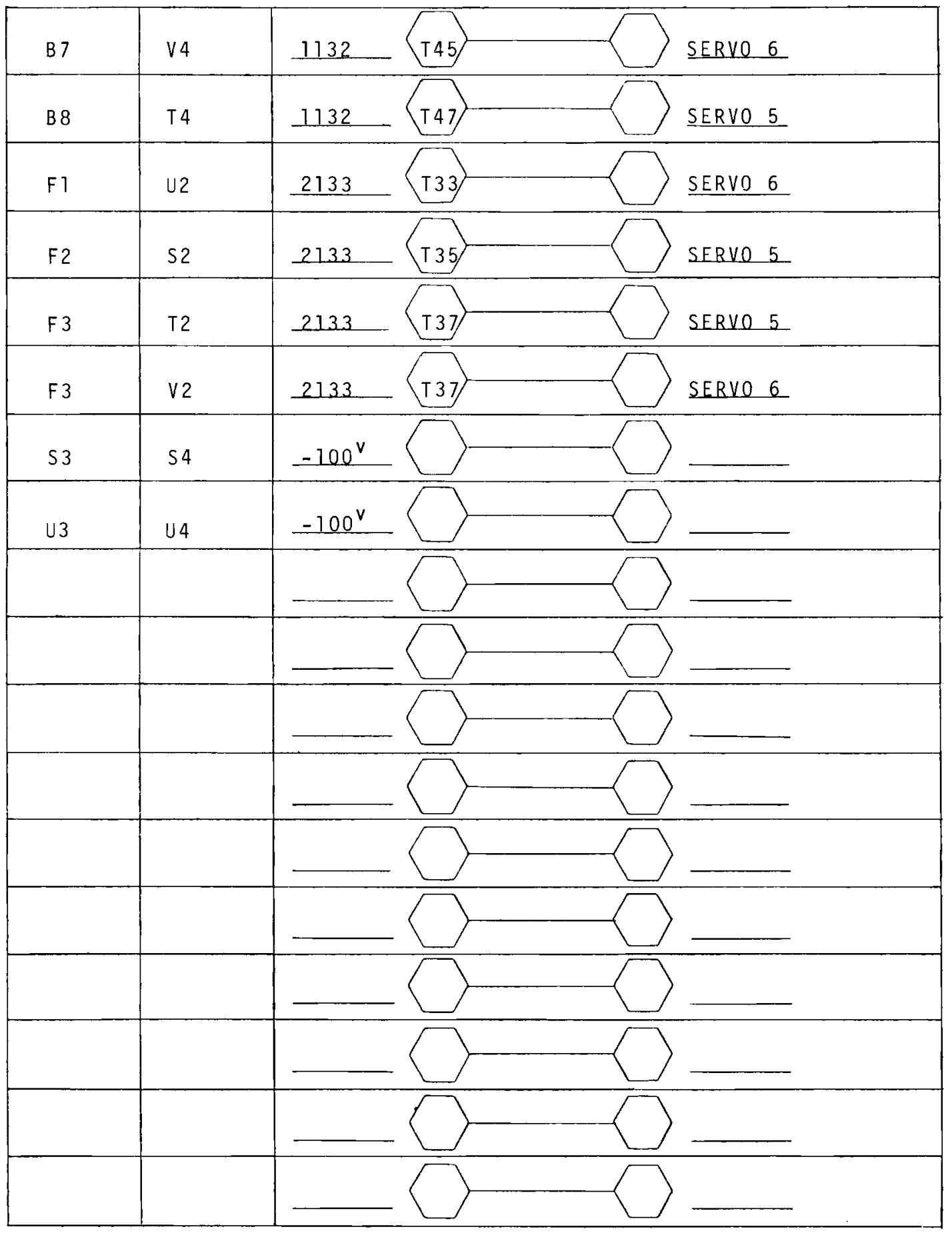




\section{DISTRIBUTION}

No. of

Copies

2

265

2

3

14

3

3

AEC Chicago Patent Group

G. H. Lee

R. K. Sharp, Richland

AEC Division of Technical Information Extension

AEC Richland Operations Office

C. L. Robinson

Technical Information Office

AEC, RDT Site Representative - PNL

P. G. Holsted (2)

A. G. Waterhouse

Atomic Energy Commission, Washington, D.C. Division of Reactor Development and Technology

M. A. Rosen

R. A. Anderson

A. N. Tardiff

E. A. Kintner

R. W. Bean

E. E. Sinclair

J. M. Simmons

N. Grossman

N. E. Todreas

R. Feit

R. M. Scroggins

S. Strauch

A. Van Echo

\section{A. Van Echo}

Atomic Energy of Canada, Limited

Chalk River, Ontario, Canada

A. Pearson

L. Pease

M. N. Huds on

Atomic Energy of Canada, Limited Sheridan Park, Ontario, Canada

D. B. Primeau

G. A. Pon

H. J. Reynolds 
No. of

Copies

1

2

3

1

3

1

2

1
Columbia University (NYO-187)

Engineering Research Laboratory

J. E. Casterline

Combustion Engineering, Inc.

A. J. Alexander

F. Bevilacqua

Douglas United Nuclear

DUN File

Duke Power Company

P. O. Box 2178

Charlotte, North Carolina

E. C. Fiss

duPont Company, Aiken

E. F. Babcock

G. Dessauar

S. W. O'Rear

Massachusetts Institute of Technology

E. P. Gyftopoulos

Oak Ridge National Laboratory

H. O'Brien

A. M. Perry

Phillips Atomic Energy Division (NRTS)

O. R. Beyer

Battelle-Northwest

F. W. Albaugh

J. M. Batch

A. L. Bement

R. D. Benham

J. J. Cadwe11

N. C. Carter

D. L. Condotta

F. G. Daws on

R. L. Dillon

P. J. Dionne 


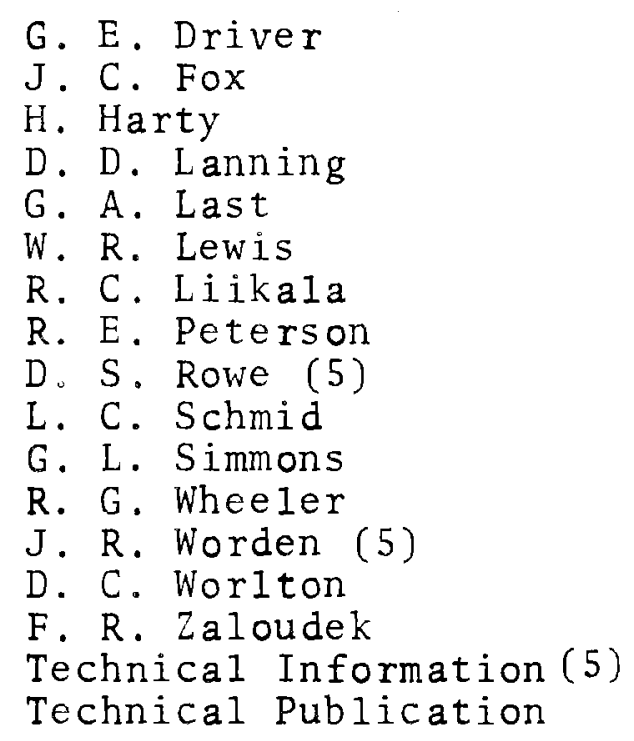


4

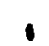

